\title{
Aggregate Fluctuations and Development
}

Citation for published version (APA):

Kaba, I. S. (2019). Aggregate Fluctuations and Development: Essays on macroeconomic volatility and economic growth. [Doctoral Thesis, Maastricht University]. Datawyse / Universitaire Pers Maastricht. https://doi.org/10.26481/dis.20190327ik

Document status and date:

Published: 01/01/2019

DOI:

10.26481/dis.20190327ik

Document Version:

Publisher's PDF, also known as Version of record

\section{Please check the document version of this publication:}

- A submitted manuscript is the version of the article upon submission and before peer-review. There can be important differences between the submitted version and the official published version of record.

People interested in the research are advised to contact the author for the final version of the publication, or visit the DOI to the publisher's website.

- The final author version and the galley proof are versions of the publication after peer review.

- The final published version features the final layout of the paper including the volume, issue and page numbers.

Link to publication

\footnotetext{
General rights rights.

- You may freely distribute the URL identifying the publication in the public portal. please follow below link for the End User Agreement:

www.umlib.nl/taverne-license

Take down policy

If you believe that this document breaches copyright please contact us at:

repository@maastrichtuniversity.nl

providing details and we will investigate your claim.
}

Copyright and moral rights for the publications made accessible in the public portal are retained by the authors and/or other copyright owners and it is a condition of accessing publications that users recognise and abide by the legal requirements associated with these

- Users may download and print one copy of any publication from the public portal for the purpose of private study or research.

- You may not further distribute the material or use it for any profit-making activity or commercial gain

If the publication is distributed under the terms of Article $25 \mathrm{fa}$ of the Dutch Copyright Act, indicated by the "Taverne" license above, 
Aggregate Fluctuations and Development

\section{Essays on Macroeconomic Volatility and Economic Growth}

Ibrahima Sory Kaba 
(C) Copyright: Ibrahima S. Kaba (kaba@merit.unu.edu), Maastricht 2019.

All rights reserved. No part of this publication may be reproduced, stored in a retrieval system, or transmitted in any form, or by any means, electronic, mechanical, photocopying, recording or otherwise, without the prior permission of the author.

Cover: West African Adinkra symbols from Ashanti and Baoulé nations and tribes of Côte d'Ivoire and Ghana; by artist Yulianas. Image license purchased from www . shutterstock. com. Cover designed by artist and friend Nasser Majlesi Rad of Tehran.

Printing: Datawyse | Universitaire Pers Maastricht. 


\section{Aggregate Fluctuations and Development Essays on Macroeconomic Volatility and Economic Growth}

\section{DISSERTATION}

to obtain the degree of Doctor at Maastricht University, on the authority of the Rector Magnificus, Prof. Dr. Rianne M. Letschert in accordance with the decision of the Board of Deans, to be defended in public on Wednesday 27 March, 2019, at 12:00 hours by

Ibrahima Sory Kaba 


\section{Supervisors:}

Prof. Dr. Théophile Azomahou, CNRS, IRD, CERDI, University Clermont

Auvergne, France

Prof. Dr. Bart Verspagen

\section{Assessment Committee:}

Prof. Dr. Pierre Mohnen, (Chair)

Prof. Alban Ahoure, University Félix Houphouët-Boigny, Côte d’Ivoire

Prof. Phu Nguyen-Van, CNRS, Université de Strasbourg, France

Dr. Thomas Ziesemer 


\section{Synopsis}

This dissertation is about the empirical analyses of macroeconomic fluctuations and economic growth. It contributes to fragments of the larger questions implicitly raised by the title. It addresses different aspects of the development puzzle in two parts: understanding how aggregate volatility affects development from the consumption perspective, and how it affects development from the output perspective. Part I is a collection of two essays focusing on the empirics of business cycles inherent to consumption series. Part II consists of two essays on the empirics of growth volatility and the theoretical aspects of stochastic shocks on growth and the speed of convergence.

Chapter 1 provides a general introduction to the thesis.

Chapter 2 takes stock of the recent developments in the Optimum Currency Area (OCA) debate and draws on different parametric and nonparametric models, to posit that the welfare cost of business cycles - defined as the compensatory factor or the percentage increase in consumption across all dates and states that would be necessary to make a representative consumer indifferent between a smooth consumption path and one that is subject to aggregate fluctuations - is between 11 and 48 percent higher for sub-Saharan countries outside the CFA Franc Zone (11 in our sample) than those inside the union (25 in our sample). ${ }^{1}$ However, through a parametric two-sample $t$-test, the chapter shows that these results are not sufficiently robust to means difference comparisons, suggesting an additional implication for the decades-long fixed exchange rate regime policy of the CFA Franc. Among the ways forward for the union, the chapter proposes a semi-flexible exchange rate regime and advocates for the anchoring of the CFA Franc on a basket of international currencies instead of the Euro alone.

Chapter 3 combines a robust recursive framework à la Epstein and Zin (1989) and a strong structural break algorithm congruent with that of Bai (1997), Bai and Perron (1998), and Bluhm et al. (2016), to infer on both the welfare gains from entirely eliminating aggregate consumption fluctuations and the welfare gains from an additional percentage point increase of consumption growth forever. Annual data for 37 Low-Income

\footnotetext{
${ }^{1}$ The CFA Franc Zone is a more than seven-decade old sub-Saharan common currency union, currently spanning most of the former French colonies of West and Central Africa - Benin, Burkina Faso, Cameroon, Central African Republic, Côte d'Ivoire, Chad, Gabon, Mali, Niger, Republic of Congo and Togo - with the noticeable exception of Equatorial Guinea and Guinea-Bissau.
} 
and Lower-Middle-Income countries - of which 24 are located in sub-Saharan Africa - are gathered for the purpose of the chapter, and consistently indicate that the gains from boosting consumption growth transcend the gains from consumption stabilisation. This result backs up the decades-long growth-enhancing policies in developing countries. Furthermore, and central to the quests of Chapter 3, we show that structural breaks do not matter for the welfare gains from eliminating consumption fluctuations while they consistently do when the welfare gains from an additional percentage point of consumption growth are concerned.

Chapter 4 examines the multiplex relationships between structural characteristics of economic development and macroeconomic volatility, using both a linear panel model and a threshold panel approach. The analysis is based on a novel macro-panel dataset of sectoral shares in the GDP and the volatility of growth rates for 108 countries from 1960 to 2010. The dependent variable - the growth volatility - is measured as the standard deviations of consecutive five-year per capita GDP growth rates. Structural characteristics include the degree of sectoral specialisation, the share of manufacturing and the share of modern sector in the GDP. The chapter shows that higher shares of manufacturing, high and increasing shares of the modern sector and a more diversified structure of production all contribute to a reduced volatility of the growth patterns. Furthermore, while using the threshold model to investigate potential non-linearities, we found that the impact of economic structure on growth volatility crucially depends on a certain specific threshold of the production structure of the economy, the initial per capita income level in 1960, the countries' population in 1960 and to a lesser extent on a threshold of exports share in the GDP. ${ }^{2}$

Chapter 5 proposes a new stochastic model of rare disasters - defined as a collection of low-probability events with a massive negative effect on economic variables, mostly consumption - and investigates their overarching implications for both the steady-state economic growth and the speed of convergence. It follows a growing trend in the macroeconomics and finance literature. Taking stock of Barro (2006), Gourio (2012), FernándezVillaverde and Levintal (2017) and others, it shows in an exclusively theoretical setting that a rare disaster affects the steady-state economic growth - derived from a standard Euler equation - through the expected value of the equilibrium interest rate. It also shows that a rare disaster disrupts the the balanced growth path's speed of convergence through the elasticity of output with respect to steady-state intensive-form physical capital, and that the direction and amplitude of this disruption depend on how the new value of this elasticity compares to the share of physical capital in total output when there is no shock.

Chapter 6 concludes the dissertation with some policy recommendations and suggested areas for future research.

\footnotetext{
${ }^{2}$ This chapter is based on a joint paper with Neil Foster-McGregor of UNU-MERIT, which itself extends Foster-McGregor et al. (2015), a background paper for the 2016 United Nations Industrial Development Organization (UNIDO)'s Industrial Development Report.
} 


\section{Acknowledgements}

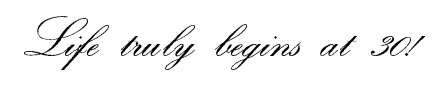

A $\mathrm{PhD}$ dissertation is never a journey entirely made in a vacuum. Rather, it is a voyage kept on track and seen through completion with the unwavering support and encouragement of an incredible string of people: family, supervisors, friends, colleagues, and various well-wishers. Here stands my modest sand castle, built with sweat and words, now ready to be smashed at last. To all those family members, supervisors, friends, colleagues, well-wishers - so many that a mere memory cannot name them all here -, who constantly and tirelessly pushed, pulled, spurred or urged me while in the sandbox, I would like to express my everlasting gratitude.

Economics is an abstruse and esoteric subject, simple at first glance but multiplex after a closer look, rigorously elegant from the surface but steadfastly subjective from beneath. Walking through this incredibly fascinating and dynamic minefield requires the guidance of mentors, of people with the necessary authority to teach meaningful knowledge and dispense lucid advice, even at times when wisdom and subtlety seem desperately in short supply. I have been lucky enough through this journey to esteem my supervisors Professor Théophile Azomahou and Professor Bart Verspagen as both my esoteric mentors as well as my academic paragons. To them I will be eternally grateful for arousing my curiosity and for teaching me many elements and symbols of our arcane subject.

Thanks to Professor Pierre Mohnen, Professor Alban Ahoure, Professor Phu NguyenVan, and Doctor Thomas Ziesemer, who generously and genuinely accepted to partake in my assessment committee. I value the timely input, invaluable attention and energy that they gave away in the course of this responsibility. They took the task at heart and provided me with pertinent and helpful comments. Needless hence to say, that although I did my utmost to implement each suggestion for improvement, they cannot by any shape or form be held responsible for what I made of it.

My heartfelt thanks to Doctor Tania Treibich of The Maastricht University's School of Business and Economics (SBE) and to Doctor Neil Foster-McGregor of UNU-MERIT, whose patience I've tested more than once at various stages of my PhD journey. All two gave me the most invaluable gift there is for any rookie PhD student: seemingly infinite 
amounts of their time. Working with Tania on different courses at the SBE this year seemed like bringing full circle a process that started many years ago.

This thesis has greatly benefited from challenging and insightful comments at various audiences, in Atlanta, Barcelona, Maastricht, Malabo, Oxford, and Strasbourg. At these occasions I have had the chance to engage in often productive intellectual exchanges with many distinguished people. Among them, I would like to particularly praise Professor Shyama Ramani and Professor Adam Szirmai (Eddy) of UNU-MERIT.

Moreover, I would like to mention the outstanding four cohorts of UNU-MERIT PhD students (2015-2019), today my colleagues, whom I had the guilty pleasure to make endure my compulsive knack for mathematics, during the two intensive weeks of Introductory Quantitative Methods and Microeconomics they each had to go through. Alongside their incredible patience, for what were their very first weeks in Maastricht, they constantly forced me to clarify my own thoughts and gave me an every-day renewed sense of purpose. Your company, I will certainly miss the most! Special thanks to Bart Kleine Deters.

Someone before me said that undertaking a $\mathrm{PhD}$ is like marrying. ${ }^{3}$ At first you desperately want it, and you swear the seven skies about your fidelity. After the speedy honeymoon, you're brought down to earth and suddenly realise that it's in fact not so simple after all. One day - usually a lonely Sunday in office -, with no one watching, a bloom springs. Whether the ripe fruit is equally sweet I hope to find out soon. In this rockstrewn relationship, I feel blessed to have had the most wonderful cohort of UNU-MERIT $\mathrm{PhD}$ fellows to share the many joys, challenges, celebrations, lessons, and special moments with: Alison, Ayla, Charlotte, Elisa, Elise (Mama Africa), Elvis (little naughty boy), Hassen (Il Professore), Iulia, Jenny, Mary, Mira, Mueid (The Sultan), Rashmi, Tamer, Valéria and Youssef. Together, we've been through thick and thin; but we learned to power through, shoulder to shoulder, hand in hand, with a beautiful trust in one another. Wherever the odds bring us next, I wholeheartedly hope we remain bound for as long as the sun rises in the Levant. A special thanks to Elisa for our not-so-much Tour de France like rides through the hills and valleys of Limburg: Valkenburg, Kerkrade, Valls, Margraten and other Drielandenpunts. Elvis, your Friday nights parties had almost become an integral institution in the cultural landscape of Maastricht. They are thoroughly missed, although not so much your stubbornly unconvincing dancing moves. Thank you Mueid and Gintare, for being the most kind and warm-hearted friends that one could ever dream of, and for being en passant two of my favourite humans in Maastricht. Shukraan - Ačiū!

Life chooses for us our first siblings, but our journeys uncover many more from various parts of the world. Iman Rajabzadeh, Nasser Davarzani and Maka Badle have been those siblings from different countries to me. With Nasser, I've discovered a whole new meaning to brotherhood and found out about my hidden 'talent' for Persian folk traditional music, perhaps the greatest in the world together with my own Mandingo heritage. Thank you so much Iman and Ortrun for your generosity and for your unlimited readiness to

\footnotetext{
${ }^{3}$ If you were to ask my humble opinion, I would rather see it as a rocky, on-again off-again relationship.
} 
always lend a helping hand, every hour of every day. Maka has been the best younger sister I never had: incredibly witty, keen and prolific at connecting people, culturally hyperactive, jovial, and thoroughly Pan-Africanist, with a hint of Pan-Somalism. Thank you Davina Osei (Ngozi) for your magnanimity and for opening my eyes to the wonders of the Ghanaian cuisine. Many thanks to my first-rate officemates Lika and Wondi.

My time at UNU-MERIT would not have been smooth and fulfilling without the presence of many wonderful people: Ad, Danny, Diego, Ingeborg, Julieta, Herman, Howard, Lisbeth, Maty, Mitie, Monique, Serdar and Zina. My foremost gratitude goes to Sueli Kyomi Brodin (my first paranymph), who first trusted me with a microphone, and to Herman Pijpers for his constant availability in diligently answering my many questions and for always having the eye for the perfect shoot. By ricochet, I would also like to thank all my friends at ACMUS, Amnesty International Maastricht Students, UM-Ambassador Lecture Series, Cries for Justice, Vigil for Palestine, ClimateKeys, Green Office Maastricht, Fossil Free Maastricht, PechaKucha, TEDx Maastricht, Universities Allied for Essential Medicines (UAEM), InciSion-NL and Studium Generale. My experiences with each one of you have, at various degrees, shaped the convictions that I hold today.

Every place needs its soul, its beating heart, a person who glues things together and helps mend fences and build bridges anywhere the fords seem insurmountably deep. Eveline in de Braek (my second paranymph) is such a person. At times when the roads where quite dumpy and when the winds hellishly heavy for me, she's been a solid anchor, a genuine presence and a reliable support. I've been incredibly lucky to call her mon amie, throughout all these bygone years. Of the many reasons that make you feel at home at UNU-MERIT, Eveline is by a million miles the most important. And if the old proverbial adage that 'all roads lead to Rome' is to be taken for face value, then one could safely infer that all hallways at MERIT lead to Eveline's door. Merci beaucoup ma sour!

Since I would hardly find the right words and the correct tone to thank my family, I decided to dedicate this book to them. To my parents Djibril Kaba and Sayon Bangoura, who have been present every step of the way ever since I landed on this skewed ship of ours. To my siblings Aïcha, Mohamed, Papus, Laye and Sidiki, whose patience I have been testing, I am afraid, in more ways than one. To my uncle Yamoussa Bangoura, whose many visits in Maastricht have been such a comfort to me. And by and large, to my whole extended family, from my hyperactive grandmother to my bubbly little niece.

Last but definitely not least, to you Francesca. See, our journey together has been more a stormy sea than a plain sailing, for reasons that none of us could neither fully comprehend nor entirely control. But I would like you to know that no matter what occurs next, I will forever cherish every minute of every hour of the last four years we spent together. To meet you has been one of the most august moment of my life. Thank you so much, chère Francesca, for bearing my indomitable whims and for staying staunch all these years. I can only wish you the best that there is, for you are the most genuine and charitable person that I know. I wish you time and I wish you joy. Grazie di tutto! 
To the United States of West. Africa, today a distant dream, tomorrow a steadfast reatity't 


\section{Contents}

$\begin{array}{ll}\text { Synopsis } & \text { iii }\end{array}$

Acknowledgements $\quad$ iv

1 Introduction 1

I Volatility from Consumption Perspective 11

2 The Welfare Cost of Business Cycles in Developing Countries: Do Currency Unions Matter? 13

2.1 Introduction . . . . . . . . . . . . . . . . . . . . . . . . . 14

2.2 The CFA Franc Zone and the OCA Debate . . . . . . . . . . . . 16

2.3 The Welfare Cost of Business Cycles . . . . . . . . . . . . . . . . . . 19

2.4 Theoretical Frameworks . . . . . . . . . . . . . . . . . 23

2.4.1 The CRRA Approach . . . . . . . . . . . . . . . . . 23

2.4.2 The Recursive Preference Approach . . . . . . . . . . . . . . . . 24

2.5 Empirical Analysis . . . . . . . . . . . . . . . . . . . . 28

2.5.1 Data and Calibration . . . . . . . . . . . . . . . 28

2.5.2 Main Results . . . . . . . . . . . . . . . . . . 28

2.6 Robustness Checks . . . . . . . . . . . . . . . . . . . 37

2.6.1 Higher Risk-Aversion and Higher IES . . . . . . . . . . . . . . . 37

2.6.2 Sub-Period Analysis . . . . . . . . . . . . . . . . . 37

2.6.3 The Asset Pricing Approach . . . . . . . . . . . . . . . . . 38

2.7 Concluding Remarks . . . . . . . . . . . . . . . . . . . . 41

3 Structural Breaks, Growth and the Welfare Cost of Business Cycles 55

3.1 Introduction . . . . . . . . . . . . . . . . . . 56

3.2 Theoretical Framework . . . . . . . . . . . . . . . . . . 60

3.2 .1 Model Economy . . . . . . . . . . . . . . . . 60

3.2.2 Welfare Effects and Gains from Growth . . . . . . . . . . . . . . . . 62

3.2.3 Structural Breaks . . . . . . . . . . . . . . . . . . . 63

3.3 Empirical Analysis . . . . . . . . . . . . . . . . . 68 
3.3.1 Data and Calibration . . . . . . . . . . . . . . . 68

3.3 .2 Main Results . . . . . . . . . . . . . . . . . . . 68

3.4 Mean-Comparison Tests . . . . . . . . . . . . . . . . . . . 78

3.5 Robustness Checks . . . . . . . . . . . . . . . . . . . . 81

3.5.1 Alternative Values for the Parameters . . . . . . . . . . . . . . . 81

3.5.2 Additional Structural Break Tests . . . . . . . . . . . . . . . 81

3.5.3 Analysis of Variance-ANOVA . . . . . . . . . . . . . . . . 82

3.6 Concluding Remarks . . . . . . . . . . . . . . . . . . . . . 82

\section{Volatility from the Output Perspective 93}

4 Structural Change and Macroeconomic Volatility: A Linear and Threshold Panel Analysis $\quad 95$

4.1 Introduction . . . . . . . . . . . . . . . . . . 96

4.2 Related Literature . . . . . . . . . . . . . . . . . . . . . . . . . . . . . 99

4.2.1 Structural Diversification and Growth . . . . . . . . . . . . . . 99

4.2.2 Which Sectors Act as the Engines of Growth? . . . . . . . . . . . . 100

4.2.3 What is the Role of Thresholds? . . . . . . . . . . . . . . . . . . . . 102

4.3 Linear Panel Analysis . . . . . . . . . . . . . . . . . . . . . . . 103

4.4 Data, Variables and Descriptive Statistics . . . . . . . . . . . . . . . . . 104

4.5 Empirical Results . . . . . . . . . . . . . . . . . . . . . . . . 110

4.6 Threshold Panel Analysis . . . . . . . . . . . . . . . . . . . . 117

4.7 Alternative Specialisation Indicators . . . . . . . . . . . . . . . 121

4.7 .1 The Gini Coefficient . . . . . . . . . . . . . . . . . . . . 121

4.7.2 The Normalised Herfindahl Index . . . . . . . . . . . . . . . . . . . 122

4.7 .3 The Hirschman Index . . . . . . . . . . . . . . . . . . . . . . . . 122

4.8 Concluding Remarks . . . . . . . . . . . . . . . . . . . . . . . . . 124

5 A Stochastic Model of Rare Disasters and Economic Growth 129

5.1 Introduction . . . . . . . . . . . . . . . . . . . 130

5.2 The Model . . . . . . . . . . . . . . . . . . . . . . . . . . . . . 133

5.2.1 Modelling Rare Disasters . . . . . . . . . . . . . . . . . . . 133

5.2 .2 The Firms . . . . . . . . . . . . . . . . . . . . . . . . . 135

5.2 .3 The Households . . . . . . . . . . . . . . . . . . . . . . 137

5.2.4 Stripping Down the Full Model . . . . . . . . . . . . . . . . . . . . 139

5.3 Possible Extensions . . . . . . . . . . . . . . . . . . . . . . . 141

5.3 .1 The AK Model . . . . . . . . . . . . . . . . . . . . . 141

5.3.2 Learning-by-Doing Technology . . . . . . . . . . . . . . . . . . . . . 142

5.4 Implications for Convergence . . . . . . . . . . . . . . . . . . . . 143

5.5 Concluding Remarks . . . . . . . . . . . . . . . . . . . . . . . . 147 
6 Synthesis

153

Societal Relevance

171

Samenvatting in het Nederlands

174

About the Author

179

xiii 


\section{Chapter 1}

\section{Introduction}

Economic development, by its very definition, represents the process by which nations improve the economic, political, and social well-being of their people. If anything, this process has shown to be inherently non-linear and often subject to abrupt interruptions and in some cases to dramatic reversals. These frequent interruptions, are both a source and a reflection of economic underdevelopment, and represent a fundamental concern for developing countries (Pallage and Robe, 2003). The high and beyond-average aggregate instability of these countries' economies mostly results from a combination of large external shocks, volatile macroeconomic policies, microeconomic rigidities, and weak economic and political institutions (Loayza et al., 2007). Economic volatility entails a direct welfare cost for risk-averse individuals, as well as an indirect one through its adverse effect on income growth and development (Lucas, 1987).

Deciphering the causes and different features of aggregate fluctuations, though important, is only one aspect of understanding the bigger process that is economic development (Romer, 2011). Unraveling why some countries are poor - or remain so - while others are rich, how this gap can be closed, and how to spur economic growth, remains the single most fundamental question in development economics, macroeconomics and economic history. The enormous differences in standards of living across parts of the globe have continued to widen on average over the whole of the modern era. Average real incomes in countries such as the United States, Germany, and Japan appear to exceed those in countries such as Bangladesh and Kenya by a factor of 20 (Romer, 2011). As with worldwide growth, cross-country income differences are not immutable. Growth in individual countries often differs considerably from average worldwide growth; that is, there are often large changes in countries' relative incomes.

The most remarkable examples of large changes in relative incomes are growth miracles and growth disasters. Growth miracles are episodes where growth in a country far exceeds the world average over an extended period, with the result that the country moves rapidly up the world income distribution. Some prominent growth miracles are Japan from the end of World War II to around 1990 and the newly industrialised countries (NICs) of East Asia - South Korea, Taiwan, Singapore, and Hong Kong - starting 
around 1960. Average incomes in the NICs, for example, have grown at an average annual rate of over 5 percent since 1960. As a result, their average incomes relative to that of the United States have more than tripled.

Growth disasters are episodes where a country's growth falls far short of the world average. Two very different examples of growth disasters are Argentina and many of the countries of sub-Saharan Africa. In 1990, Argentina's average income was only slightly behind those of the world's leaders, and it appeared poised to become a major industrialised country. But its growth performance over most of the twentieth century was dismal, and it is now near the middle of the world income distribution. Sub-Saharan African countries such as Chad, Madagascar, and Niger have been extremely poor throughout their histories and have been unable to obtain any sustained growth in average incomes. As a result, their average incomes have remained close to subsistence levels while average world income has been rising steadily.

Other countries exhibit more complicated growth patterns. Côte d'Ivoire was held up as the growth model for Africa through the 1970s. From 1960 to 1978, real income per person grew at an average annual rate of 3.5 percent. But in the next decade, average income fell by a third, before nearing a double digits during the last decade. To take another example, average growth in Mexico was extremely high in the 1960s and 1970s, negative in most of the 1980s, and again very high - with a brief but severe interruption in the mid-1990s. The 2000s have been a lost decade for the country, due to political conflicts that at some point led to the country being split in two. Since the return to 'normalcy' in 2010, the country has consistently be growing in double digits terms.

Finding answers to these puzzles has been at the heart of the economic profession over the past decades and can be structured by a progression from proximate to ultimate causality of development (Maddison, 1988). Regarding the proximate sources of growth, the early neoclassical growth theory has highlighted the fundamental role played by physical capital accumulation, labour and total factor productivity in determining the level of income per capita (Solow, 1956). To these factors, the endogenous growth theory has added increasing returns to scale by incorporating human capital and innovation capacity. The main conclusion of the Solow (1956) model is that the accumulation of physical capital cannot account for either the vast growth over time in output per capita or the vast cross-country differences in output per capita. The model treats other potential sources of differences in real incomes as either exogenous and thus not explained by the model - in the case of technological progress, for instance - or absent altogether - in the case of positive spillovers from capital, for example. Although the model posits about the fundamental role of technological progress in increasing the output level, it still does not provide the "ultimate" sources of economic growth to try explain the onset of the industrial revolution, the cross-country income divergence, and to a lesser extent the instability of economic growth (Pritchett, 1997; Pomeranz, 2009).

The instability of growth itself received new attention as the developed world expe- 
rienced the 'great moderation' from the mid-1980s until the early 2000s, while economic volatility remained high in the developing world and it was noted that there is little persistence of growth across decades (Easterly et al., 1993). Such stylised facts spurred a body of research that questioned the established practice of analysing growth determinants by looking at levels or average growth rates of GDP per capita. Instead, it highlighted the uneven nature of growth in the developing world which can be much more easily characterised by sequences of qualitatively different episodes, such as accelerations, collapses, stagnation and recovery (Pritchett, 2000; Jones and Olken, 2008). While this uncertainty expanded our understanding of the dynamics of growth, most of the literature did not explore the theoretical underpinnings of unstable growth. Interestingly, because output fluctuations are all but regular, modern macroeconomics has also turned away from attempts to interpret fluctuations as combinations of deterministic cycles of different lengths; efforts to discern regular Kitchin (3-year), Juglar (10-year), Kuznets (20-year), and Kondratiev (50-year) cycles have for example been largely abandoned as mostly unproductive. Instead, the prevailing view is that the economy is perturbed by disturbances of various types and sizes at more or less random intervals, and that those disturbances then propagate somehow through the economy. Where the major macroeconomic schools of thought differ is rather in their hypotheses concerning these shocks and propagation mechanisms.

Dissecting the welfare implications of short-term fluctuations and describing some long-term empirical and theoretical features of volatile economic growth are the central goals of this dissertation. It contributes to various fragments of the larger development macroeconomic instability question in two parts: understanding how currency unions and structural breaks affect the welfare cost of business cycles on the one hand, and understanding the role of structural change for growth stability and the links between stochastic rare disasters and economic growth on the other. Part I is a collection of two essays focusing on the theory and empirics of the welfare cost of business cycles, in line with Lucas (1987). The first essay examines the role of currency unions in smoothing down the welfare cost of business cycles, using the CFA Franc Zone in sub-Saharan Africa as an example. The second essay focuses on the econometric identification of structural breaks in consumption series and the role of those structural breaks in amplifying or reducing both the welfare costs and the growth gains from business cycles fluctuations. Part II of the dissertation consists of two empirical essays on growth, its volatility, structural change and rare disasters. The third essay is an empirical contribution to the growth volatility literature. It is an applied econometrics paper that builds on and extends Foster-McGregor et al. (2015), by considering the linear and non-linear relationships between economic structure and the volatility of per capita GDP growth. Finally, the last and fourth essay proposes a new stochastic model of rare disasters and steady-state economic growth as well as the implications of those disasters for the speed of convergence.

The remainder of this introduction outlines in more details the arguments made in 
the following chapters, focusing on the main research questions, the contributions to the respective literature and the common themes.

\section{Part I: Volatility from Consumption Perspective}

In the spirit of Lucas (1987) we define business cycles as recurrent fluctuations of output around the trend and the co-movements among other aggregate time series. These fluctuations are typically represented as expansions and recessions in economic activity. And from Imrohoroglu (1989), we understand the welfare cost of business cycles as the measures of the benefits in terms of additional consumption that would be obtained by individuals from eliminating all the macroeconomic instability in a given economy. One of the prevailing views in macroeconomics is that business cycles are welfare reducing and that governments should try to stabilise the economy by using counter-cyclical fiscal or monetary policies (Imrohoroglu, 2008).

In his path-breaking exercise, Lucas (1987) endeavoured to quantify the welfare cost of business cycles in the United States. The original idea was to approximate as much as possible an upper-bound for this cost, by simulating a simple economy where consumption is generated by a stochastic process, with independently and identically distributed (i.i.d) shocks, that matches the variance and the mean of the observed consumption series. In his now influential 1987 monograph Models of Business Cycles, later complemented in 2003 by Macroeconomic Priorities, Robert Lucas, assuming individual preferences that many economists view as a reasonable benchmark, calculated that individuals would sacrifice at most 0.1 percent of their lifetime consumption, prompting him to conclude that there would be little benefit to "devising ever more subtle policies to remove the residual amount of business cycle risk."

Section 2.3 of Chapter 2 of the dissertation provides a detailed discussion of all the recent extensions of the Lucas (1987)' framework and calculations: from the Epstein and Zin (1989) modelisations of Obstfeld (1994) and Dolmas (1998), to the Real Business Cycles' framework à la Tallarini (2000), and the endogenous growth modelings of Epaulard and Pommeret (2003) and Barlevy (2004). The common feature of all these extensions is that most of their inherent estimates were for the postwar U.S. economy. Overall, one can reasonably argue over the true welfare cost of macroeconomic fluctuations in the United States to be relatively modest, if not negligible, as initially claimed by Lucas (1987). The low cost estimates obtained in most of the post-Lucas (1987) literature stems mainly from the fact that the U.S. economy since the 1950s has been relatively stable. What is less debatable however is the sheer magnitude of aggregate fluctuations in developing countries compared to the industrialised world. In particular, the volatility of output in developing countries ranges from two to six times that in the United States (Mendoza, 1995; Carmichael et al., 1999; Agenor et al., 2000). What about the welfare cost of macroeconomic fluctuations in developing countries? Few studies have really explored 
that question, with the noticeable exceptions of Pallage and Robe (2003) and Houssa (2013). Using a three-model economy, encompassing a CRRA and an Epstein and Zin (1989) preferences, a stationary auto-regressive and a finite-state Markov chain processes for per capita consumption, Pallage and Robe (2003) showed that the median welfare cost of business cycles in Africa is 10 to 30 times larger than that of the United States. Additionally, they argue that the welfare gain from eliminating aggregate fluctuations in Africa may be so large as to exceed that of receiving an additional 1 percent of growth forever, which suggests the crucial importance of macroeconomic stabilisation policies in developing countries. Houssa (2013) reaches almost the same conclusion by conducting a Bayesian inference over the consumption series of a mixed set of 82 countries.

\section{Do Currency Unions Matter?}

There is currently an enormous variety of currency arrangements and monetary institutions across the developing world. In the case of sub-Saharan Africa, this comes down as the consequence of the different trajectories that the countries of the continent have taken ever since gaining their independence from their former colonial rulers (Belgium, Britain, France, Portugal and Spain) in the 1950s, 1960s and 1970s. The most remarkable monetary institution in sub-Saharan Africa is the CFA Franc Zone, a common currency union currently spanning most of the former French colonies of West and Central Africa, with the exception of Guinea-Bissau and Equatorial Guinea, who were ruled by Portugal and Spain respectively. The CFA Franc (CFAF) is convertible with the French Franc/Euro at a fixed rate and is currently pegged against the Euro. At first glance, it might appear that a currency union of developing countries anchored to a global and stable currency such as the Euro provides a nominal anchor, thus preventing runaway inflation, as often seen in the developing world. However, a more cautious scrutiny shows that such arrangement implies the inability to use monetary policy to deal with a real and financial crisis affecting the union members as well as with external shocks that have the power to change the exchange rates between global currencies (Aizenman, 2016). As such, Chapter 2 of this thesis asks the following question: how important is the welfare cost of macroeconomic fluctuations in a developing-country currency union such as the CFA Franc Zone, compared to that in the non-CFA African member states?

To answer this question, we build on two parametric and one nonparametric models, including the original Lucas (1987) endowment economy, and compute the estimates of the welfare cost of aggregate fluctuations for a sample of 36 sub-Saharan African countries. We then contrast the costs estimates for the two groups: the $11 \mathrm{CFA}$ member states and the 25 non-CFA member states. For each country included in the analysis, we calibrate the models using consumption and population figures derived from the latest Penn World Tables (PWT 9.0), and carry out a string of robustness checks. And across all model specifications, we find that the sample average cost of economic fluctuations in the nonCFA countries is consistently between 11 and 48 percent higher than that in the CFA Franc 
Zone. However, a parametric two-sample $t$-test applied to the welfare cost estimates, shows that these results are not sufficiently robust to means difference comparisons. We also find that the welfare cost of macroeconomic fluctuations for sub-Saharan Africa is still many times what it is in the United States, the country often taken as the benchmark. This latest result is congruent with the findings of Pallage and Robe (2003).

\section{What about the Role of Structural Breaks?}

Chapter 3 combines the structural break approach inspired from Andrews (1993), and the recursive preference specifications developed by Epstein and Zin (1989) to argue that the welfare gains for developing countries from increasing consumption growth forever consistently and robustly exceed the welfare gains from stabilising consumption fluctuations entirely. This suggests that what appears to be at first glance a developing-country conundrum between simultaneously controlling adverse fluctuations and improving growth is not exactly as such. To make this case, we use an optimisation model in which consumers are subject to aggregate shocks and ask what happens when consumption series feature trend-changing unknown structural breaks. The framework of the model builds on Obstfeld (1994), Dolmas (1998), Pallage and Robe (2003), and to some extent Bluhm et al. (2016). To get the discrete versions of the national per capita consumption series, we apply the finite state Markov-chain approximations to univariate and multivariate auto-regressions developed by Tauchen (1986).

Most importantly, we find that the null hypothesis of the equality between the sample averages of the welfare cost of business cycles for the general and the restricted models of recursive preference specifications is not rejected. This implies that in the context of an Epstein and Zin (1989) preference specification, unique structural breaks do not matter when it comes to the interpretation of the sample average welfare cost of business cycles, especially when such sample exhibits a high degree of homogeneity. Conversely, the twotail probability of the test equating the sample averages of the welfare gains from growth between the general and the restricted models is significant and is robustly skewed to the left. The overarching and cardinal implication of this result is that structural breaks do matter for growth, exactly as posited by Pritchett (2000)'s seminal works with his identification and classification of various growth regimes. And in the specific context of this analysis, the average welfare gain from an additional one percent of yearly consumption becomes higher when structural breaks for each individual country are taken into account.

\section{Part II: Volatility from the Output Perspective}

Notwithstanding its short and medium-term welfare implications, macroeconomic stability is also an important factor for the long-run growth of output and the overall economic performance, and developing countries exhibit an economic volatility far above the world 
average (Ramey and Ramey, 1995; Azeinman and Pinto, 2005; Imbs, 2007). The numerous global economic crises of the last decade alone have made macroeconomic volatility a key issue in analysing the determinants of economic growth. The multiplicity of ways in which it affects the long-term growth potential of economies, its diverse causes and the array of methods by which it is measured, make economic volatility a multiplex and multidimensional phenomenon (Cariolle, 2012). Countries' vulnerability to macroeconomic volatility is often driven by a number of handicaps, which are either structural or congruent on the level of economic development: the exposition to bigger external shocks (capital flows, terms of trade, world interest rate), the frequency of domestic shocks, often generated by intrinsic self-inflicted policy mistakes, and finally the absence of strong "shock stabilisers" in the forms of diversified financial markets and macroeconomic stabilisation policies (Loayza et al., 2007). According to estimates produced by Hnatkovska and Loayza (2005), based on a sample of 79 countries, increasing the average value of volatility by the value of its standard deviation would have resulted in an average loss of 1.3 points for growth in GDP over the period 1960-2000, and a 2.2 points for the decade 1990-2000.

\section{Could the Structure of the Economy Reduce Output Volatility?}

Chapter 4 investigates the relationships between structural change and the ability of economies to sustain a stable economic growth over longer periods of time, using both a linear panel model and a threshold panel analysis. It borrows heavily and extends on Foster-McGregor et al. (2015), which was initially written as a background paper for the United Nations Industrial Development Organisation (UNIDO)'s 2016 Industrial Development Report (IDR) on Sustainable and Inclusive Industrial Development. This paper - just like its original longer version - focuses on the first dimension of sustainability and specifically asks what types of economic structure and what patterns of structural change contribute to developing countries' and to emerging economies' ability to sustain a stable economic growth over longer periods of time.

To answer this question we consider one specific dimension of economic performance. In particular, we consider the relationship between economic structure and the volatility of per capita GDP growth. Our main argument put forward in this chapter is that for Low and Middle-Income countries, diversification of the structure of economic activities is important for the ability to sustain stable growth over longer periods of time and thus achieve sustained growth and catch up. To capture this relationship, we relate the volatility of economic growth to a wide range of variables measuring different structural characteristics of modern economies. These include measures of the share of manufacturing - and other modern sectors - in the GDP and indicators of the degree of specialisation and diversification. We consider both the levels (structure) and changes over time (structural change) in these variables. The empirical analysis is primarily based on a newly created database of sectoral shares in value added for the 1960-2010 period, which includes data 
for 108 developing and advanced economies. This macro-panel dataset is used to construct the indicators of economic structure and specialisation, which are combined with data on economic growth from the Maddison Project database to address our questions of interest.

The chapter provides indications that, other things being equal, a larger share of manufacturing in the economy - i.e., greater industrialisation - contributes to a lower volatility of economic growth. In contrast, the share of the modern sector taken as a whole does not have significant effects on volatility, though the share of manufacturing within the modern sector has a substantial and significant impact on the ability to sustain stable growth. These latter effects are even more marked than those of manufacturing shares in the total economy. In our analysis we account for the possibility of non-linear effects related to a country's level of economic development. At lower levels of per capita GDP, growth generally tends to be more erratic and more vulnerable to sudden interruptions, especially if the production structure is highly undiversified and the manufacturing sector is underdeveloped. Some countries achieve structural transformations, which go hand in hand with longer and more stable growth experiences. Advanced economies tend to have fewer interruptions in their growth process and longer lasting growth episodes (Pritchett, 2000). But at high levels of per capita income, further diversification may no longer be so important. We therefore account for the potentially differing impacts of specialisation and structure on performance at different levels of economic development in our analysis.

\section{Modelling Rare Disasters, Economic Growth and Convergence}

In Chapter 5 of this dissertation, we investigate theoretically the relationship between the steady-state economic growth and rare disasters on the one hand and the implications for the speed of convergence of rare disasters on the other, taking stock from Barro (2006), Gourio (2012), and Fernández-Villaverde and Levintal (2017) among others. The steadystate economic growth is derived from a standard Euler equation, which itself results from the joint optimisations of a social planner with an infinitely-lived household and a rational representative firm. In our model, a rare disaster affects economic growth through its adverse effects on the three proximate factors of production: physical capital, labour and total factor productivity. It affects the speed of convergence through the elasticity of output with respect to the balanced growth path's intensive-form physical capital, which incidentally happens to be also the share of physical capital in total output.

In Section 5.2 of this chapter we set up the fundamentals of the model, its underlying assumptions, and we present the optimisation problems of the representative firm and household. Using all these information, we strip down the full model, using the Euler equation and some results from probability theory. The representative firm of the benchmark economy uses a Harrod-neutral Cobb-Douglas technology and is subject to constant returns to scale. The market of goods is competitive, i.e., factors are paid at their marginal products. The households in our model are dynastic families whose size 
grows at an exponential and exogenous rate. This household maximises its lifetime utility subject to a specific budget constraint, taking into account the overall wealth of the household at each point in time. To ensure that our economy converges to a balanced growth path, we choose a standard CRRA as our preferred instantaneous utility function.

In Section 5.3 we extend the model by using alternative production specifications, in the spirit of Rebelo (1991) and Arrow (1962). When the production function espouses an $A K$ form or when the TFP follows a learning-by-doing shape, we show that the features of the expected growth is not that much different from that in the baseline model.

In Section 5.4 we investigate the implications of a rare and violent shock on the speed at which an economy converges toward its steady-state. We derive the speed of convergence following the same iteration as Romer (2011). We find that a rare disaster affects convergence through the expected elasticity of output with respect to the intensiveform physical capital. We also show, through a back-of-the-envelop calibration, that the direction of this effect depends on how this expected elasticity compares to the share of capital in output when there is no shock. 


\section{Part I}

\section{Volatility from Consumption Perspective}




\title{
Chapter 2
}

\section{The Welfare Cost of Business Cycles in Developing Countries: Do Currency Unions Matter?}

\begin{abstract}
Adverse macroeconomic shocks have long been acknowledged to be larger and more costly in developing countries, compared to the rest of the world. Yet, while most of the literature continues to hold a monolithic approach to development macroeconomics, it still remains an open question of how differently the fluctuations are absorbed by developing countries with different monetary institutional arrangements. Taking stock of the recent developments in the Optimum Currency Area debate and using different parametric and nonparametric models, we show that the welfare cost of business cycles is between 11 and 48 percent higher for the sub-Saharan African countries outside the CFA Franc Zone than for those inside the union. However, a parametric two-sample $t$-test shows that these results are not sufficiently robust to means difference comparisons, suggesting another implication of the fixed exchange rate regime policy of the CFA Franc. As ways forward for the union, we propose a semi-flexible exchange rate regime and the anchoring of the CFA Franc on a basket on international currencies instead of the Euro alone. This is a particularly important reform agenda, at a time when the political temptations for some member states to leave the union might trump its economic benefits.
\end{abstract}

Keywords: Business Cycles, Optimum Currency Area, Welfare, Growth.

JEL Classification: C14, C22, E32, E42.

\footnotetext{
${ }^{0}$ This chapter was submitted for the forthcoming African Integration and Development Review and was successively presented at the Augustin Cournot Doctoral Days, at the $5^{\text {th }}$ Congress of African Economists and at the Oxford University CSAE Conference. We are grateful to Stéphane Pallage for providing some of the codes used for the calibration of the recursive model included in this article.
} 


\subsection{Introduction}

The decades long Optimum Currency Area (OCA) debate has often neglected the developing world. This debate, first pioneered by Mundell (1961), McKinnon (1963), and Kenen (1969) - later enriched by Corden (1972), Ishiyama (1975) and Tower and Willet (1976) - explores two key questions: the criteria as well as the benefits of entering or forming a common currency area. The four often mentioned criteria for a successful union since Mundell (1961) are: labour mobility across the area, openness with capital mobility and price and wage flexibility, an advanced risk sharing mechanism, and similar business cycles for all the countries within the area. In addition to those conservative and more consensual criteria, Kenen (1969) proposes production diversification, homogeneous preferences and commonality of destiny. As for the advantages of forming or joining a currency area, they seem obvious, if hard at all to quantify: reduced transaction costs, elimination of currency risk, greater transparency, and possible greater competition due to easier comparability of prices (Krugman, 2012). ${ }^{1}$

The OCA debate was initially ignited by Mundell (1961) and others as a purely academic abstract discussion in the early 1960s. But this discussion morphed throughout the 1990s into a very passionate debate about the desirability and the viability of the European Monetary Union (EMU) as an OCA. From this frantic discussion, what emerged as a consensus among the economists therefore was that the main conditions favouring keeping the national currency and exchange rate flexibility include a low labour mobility across borders, the absence of super national tax-cum-transfer mechanisms, a high degree of nominal rigidity in domestic prices, a low degree of openness to trade, and dissimilarities in national economic structures (Aizenman, 2016). Therefore, the perfect currency areas should be those composed of countries where most of these conditions do not hold. The same considerations could also apply to the choice of pegging the exchange rate to another currency, as it is the case for the CFA Franc of West and Central Africa.

There is currently an enormous variety of currency arrangements and monetary institutions across the developing world. In the case of sub-Saharan Africa, this comes down as the consequence of the different trajectories that the countries of the continent have taken ever since gaining their independence from their former colonial rulers (Belgium, Britain, France, Portugal and Spain) in the 1950s, 1960s and 1970s. The most remarkable monetary institution in sub-Saharan Africa is the CFA Franc Zone, a common currency union covering a set of heterogeneous countries, and currently spanning most of the former French colonies of West and Central Africa, with the exception of Guinea-Bissau and Equatorial Guinea, who were ruled by Portugal and Spain respectively. ${ }^{2}$ The CFA Franc

\footnotetext{
${ }^{1}$ There are also some costs attached to the membership of a single currency area. Prominent among those is the potential loss of flexibility. A common currency area is often limited to a one-size-fits-all monetary policy, and also induces a loss of potential adjustment mechanisms (Krugman, 2012).

${ }^{2}$ The 14 Members States of the CFA Franc Zone in 2019 are: Benin, Burkina Faso, Cameroon, Central African Republic, Côte d'Ivoire, Chad, Equatorial Guinea, Gabon, Guinea-Bissau, Mali, Niger, Republic
} 
(CFAF) is convertible with the French Franc/Euro at a fixed rate and is currently pegged against the Euro. At first glance, it might appear that a currency union of developing countries anchored to a global and stable currency such as the Euro provides a nominal anchor, thus preventing runaway inflation, as often seen in the developing world (see Figure 2.1 below). However, a more cautious scrutiny shows that such arrangement implies the inability to use monetary policy to deal with a real and financial crisis affecting the union members as well as with external shocks that have the power to change the exchange rates between global currencies (Aizenman, 2016). As such, one is entitled to ask the following question: how important is the welfare cost of macroeconomic fluctuations in a developing-country currency union such as the CFA Franc Zone, compared to that in the non-CFA African member states?

To answer this question, we build on two parametric and one nonparametric models, including the original Lucas (1987) endowment economy, and compute the estimates of the welfare cost of aggregate fluctuations for a sample of 36 sub-Saharan African countries. We then contrast the costs estimates for the two groups: the 11 CFA member states and the 25 non-CFA member states. For each country included in the analysis, we calibrate the models using consumption and population figures derived from the latest Penn World Tables (PWT 9.0), and carry out a string of robustness checks. And across all model specifications, we find that the sample average cost of economic fluctuations in the nonCFA countries is consistently between 11 and 48 percent higher than that in the CFA Franc Zone. However, a parametric two-sample $t$-test applied to the welfare cost estimates, shows that these results are not sufficiently robust to means difference comparisons. We also find that the welfare cost of macroeconomic fluctuations for sub-Saharan Africa is still many times what it is in the United States, the country often taken as the benchmark. This latest result is congruent with the findings of Pallage and Robe (2003).

This paper investigates another implication of the fixed exchange rate regime that characterises the CFA Franc Zone. It adds to the growing and renewed debates about the necessary reforms of the union, in light of some of its clear limitations. Predating civil societies, economists and academics have long criticised the functioning of the union, notably its perceived lack of transparency, lack of inclusiveness and its inability to carry out major structural reforms. Although the membership to the union has brought about greater monetary stability over the years to countries like Benin, Mali, Senegal and others, the pegged currency to the Euro and the fixed exchange rate policy regime of the CFA Franc have substantially curtailed the monetary sovereignty of the member states and their ability to carry out effective counter-cyclical policies.

The remainder of the article is organised as follows: Sections (2.2) and (2.3) discuss the literature on macroeconomic policy in the CFA Franc Zone and the estimation of the welfare cost of business cycles respectively; Section (2.4) outlines the two baseline theoretical frameworks of the paper; Section (2.5) presents the empirical results of the 
estimations and calibrations; Section (2.6) provides the sensitivity and robustness checks; Section (2.7) concludes.

\subsection{The CFA Franc Zone and the OCA Debate}

The CFA Franc Zone was officially created by France on the 26th of December 1945 and has ever since changed names and composition, depending on the realities of the day: from 1945 to 1958 it was referred to as the Colonies Françaises d'Afrique (or African French Colonies), from 1958 to the early days of the independence (1960s) its name changed to Communautés Françaises d'Afrique (African French Communities), and ever since the CFA means Communauté Financière Africaine (African Financial Community) in West Africa and Coopération Financière en Afrique Centrale in Central Africa. These recurrent changes in names give a very interesting insight into attitudes towards political correctness in the francophone world. While some countries have left the union for good (Mauritania and Guinea for example), others like Equatorial Guinea and Guinea-Bissau joined it "recently", in 1985 and 1993 respectively. The cornerstone of the Franc Zone is the use of currencies that the French Treasury guarantees to exchange for French Francs (now Euros) at a fixed rate, and in Africa, member states are grouped into two regions, each of which has one central bank issuing a single currency - to add to the confusion, both currencies are called the CFA Franc, CFAF - that is convertible with the French Franc/Euro at a fixed rate. The Bank of Central African States (Banque des Etats de l'Afrique Centrale, BEAC) is the institution charged of issuing currency for the Central African Economic and Monetary Union (CAEMC) while the Central Bank of West African States (Banque Centrale des Etats de l'Afrique de l'Ouest, BCEAO) deals with the West African Monetary Union (WAEMU). ${ }^{3}$

The two unions that constitute the CFA Franc Zone in Africa are in reality two completely separate and independent monetary entities with two different currencies, although both unions share many common features. They form a complex array of contractual obligations on the part of the African states and France. These obligations fall into two categories. First, there are the constitutional principles designed to achieve the objective of complete financial integration between member states. Under this heading fall the guarantees of convertibility between the CFA and French Francs (Euros), and the fixed exchange rate. Maintenance of the principles implies a heavy obligation on the part of France, with some obligations on the part of the Franc Zone. Second, there are the administrative structures to which member states bind themselves, and which prevent

\footnotetext{
${ }^{3}$ In addition to WAEMU and CAEMC, the Franc Zone also includes the Comoros. In 1979, the government of the Comoros signed a monetary cooperation agreement with France, making the Comoros part of the Franc Zone but not really part of the CFA Franc Zone. The exchange rate of the Comoran Franc to the French Franc (now Euro) has also since 1994 differed from that for the CFA Franc. The Comoros will therefore not be part of the discussions in this paper.
} 
(or, at least, which are designed to prevent) African States from free riding on French guarantees, as well as on each other. These in fact entail considerable loss of economic sovereignty on the part of the African states. As for the Franc Zone constitutions, they are designed to describe and safeguard the principles and institutional structures of the union. The revised Franc Zone constitution of 1972-73, which devolved policy-making authority from the French Treasury to the two central banks, insists for the member states to ensure the four following economic conditions: guaranteed convertibility (from Article 2 of the BEAC constitution and Article 1 of the WAEMU convention), a fixed exchange rate (Article 9 of the BEAC constitution and Article 2 of the WAEMU convention), free transferability (Article 10 of the BEAC constitution and Article 6 of the WAEMU convention), and harmonisation of the rules governing currency exchange (Article 14 of the BEAC constitution and Article 6 of the WAEMU convention). See Bathia (1986) and Vizy (1989) for a more detailed explanation of the principles and institutional structures of the union.

The recent literature on the CFA Franc Zone has focused on four main areas: assessing the (potential) costs and the benefits of monetary union, analysing the convergence in the Franc Zone and the OCA theory, exploring the positive and normative analysis of monetary and exchange rate policy, and finally investigating the issue of poverty within the Franc Zone. Using the statistical framework developed by Blanchard and Quah (1989), albeit with differing assumptions about the underlying economic structure of the countries in question, several papers have explored the extent to which macroeconomic shocks differ between the CFA Franc Zone and their neighbours, and among the Franc Zone countries themselves. Hoffmaister et al. (1998) compare the nature and sources of shocks in the Franc Zone countries - considered as a single whole - and fifteen neighbouring countries and conclude that the Franc Zone countries are relatively less susceptible to shocks that originate within the domestic economy, and relatively more susceptible to shocks impacting on the price of imports and exports. Fielding and Shields (2001) use a similar (but not identical) approach to Hoffmaister et al. (1998) and find some results consistent with them: for example, in terms of the relative importance of domestic shocks in countries outside the union. Bleaney and Fielding (2002) address directly the issue of real output volatility within the Franc Zone and find that the standard deviation of real GDP growth is significantly higher in Franc Zone countries than elsewhere. On average, the standard deviation is 1.4 percentage points higher. Bénassy-Quéré and Coupet (2003) look at the West African macroeconomic convergence from a more general perspective. Their results are mixed, with differing degrees of homogeneity within and beyond the Franc Zone and suggest therefore that there is an economic rationale for an alternative partitioning of the Franc Zone on economic grounds. ${ }^{4}$ Among the early studies trying

\footnotetext{
${ }^{4}$ Taking the current economic structure, their suggested grouping of the countries they study is: Benin, Burkina Faso, Mali, Togo; Côte d'Ivoire, Senegal, plus The Gambia; Cameroon, Central African Republic, Chad; Congo, Gabon, plus Nigeria; and Guinea-Bissau, Niger, plus Ghana, Sierra Leone.
} 
Figure 2.1: Annual CPI Inflation Rate in SSA

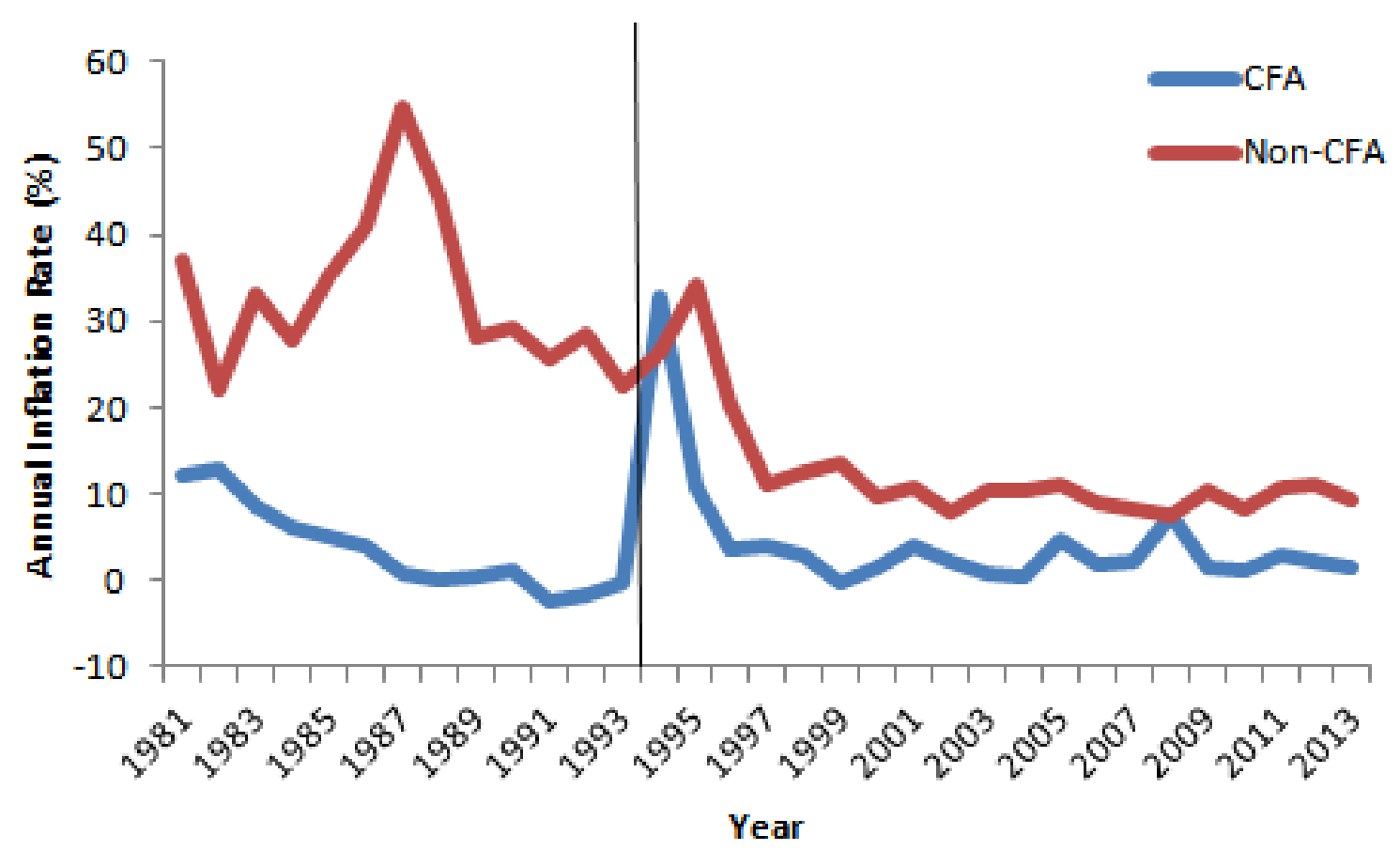

Note: The Consumer Price Indexes (CPI) displayed in this figure are the sample average of those of two groups of randomly selected countries: 7 CFA member states (Burkina Faso, Côte d'Ivoire, Cameroon, Gabon, Niger, Senegal and Togo) and 14 other non-member states (Burundi, Botswana, Ethiopia, Ghana, The Gambia, Kenya, Madagascar, Mauritania, Malawi, Nigeria, Sierra Leone, Tanzania, Uganda, and South Africa). The figure shows that for almost all the 1981-2013 period, the average inflation rate in the CFA Franc Zone was far below that of the rest of the continent. The only exception is probably 1994, when France in an unprecedented move decided to devaluate the CFA Franc by 50 percent. Although this devaluation helped the member states to regain part of their international competitiveness, it came at a very heavy cost. The immediate side effect of this was a one-time surge in prices, which immediately led to higher inflation. The figure further shows that the gap between the two regions was somehow higher before the devaluation than after it. This has more to do with better inflation-targeting policies from the rest of the continent rather than a prolonged steady inflation rate from the CFA Franc Zone.

to determine whether the Franc Zone membership promotes economic growth, we could mention Devarajan and de Melo (1987) and Plane (1988). Devarajan and de Melo (1987) find that when CFA members are compared with just the rest of sub-Saharan Africa, a statistically significantly better performance appears for the high-income countries and for the high and low-income countries pooled, whilst there is no statistically significant difference for low-income countries alone. Using a more general model of economic growth, Plane (1989) finds that the cross-country residual is not significantly dependent on Franc Zone membership. However, a large number of studies have consistently found the Franc Zone membership to be associated with lower average rates of inflation (Plane, 1989; Elbadawi and Majd, 1996; Bleaney and Fielding, 2002), as shown by Figure (2.1) above.

On the convergence of the Franc Zone, Bamba (2004) shows that between 1980 and 2001, the convergence as defined by the UEMOA pact, has not reduced the countries' 
instability vis-à-vis most of the UEMOA convergence criteria, with the sole exception of inflation. Fielding et al. (1995) fit a Vector Error Correction Model (VECM), on output and prices in ten Franc Zone countries, and show that there is less heterogeneity in the macroeconomic dynamics (in terms of inflation and output growth) of the UEMOA countries than there is among the CEMAC members, and so the costs of adhering to a single currency are likely to be lower, ceteris paribus. Using the Blanchard and Quah (1989) decomposition, Coleman (2004) identifies and decomposes structural shocks into three important variables (real exchange rate appreciation, real output growth, and the growth in real money balances) between 12 Franc Zone countries and 4 non-Franc Zone countries, and argues that there might be some heterogeneity in the policy-coordination and restrictions on individual adjustment strategies within a monetary union.

Regarding the positive and normative analysis of monetary and exchange rate policy, Shortland and Stasavage (2003) argue that despite all the policy instruments at its disposal, the BCEAO did not take a particular active role in steering private sector credit in the Franc Zone member countries. They also estimated an interest rate reaction function for the BCEAO and argue that there is a nuanced picture regarding monetary policy in the WAEMU. Finally, regarding the issue of poverty, Azam and Wane (2001) analysed the effects of the 1994 devaluation of the CFAF on growth and poverty in the WAEMU, with a medium-run horizon. Bleaney and Nishiyama (2002) show that the Franc Zone dummy is insignificant when added to the regression of the growth of the income of the poorest 20 percent of the population. Fielding (2004) ultimately shows that the price volatility that occurs in the wake of a change in the value of the monetary policy instruments, affects particularly the poor households.

\subsection{The Welfare Cost of Business Cycles}

The welfare cost of business cycles, defined by Imrohoroglu (1989) as the percentage increase in consumption across all dates and states that would be necessary to make a representative consumer indifferent between a smooth consumption stream and one that is subject to fluctuations, was first pioneered by Lucas (1987). In his path-breaking exercise, Lucas (1987) endeavoured to quantify the welfare cost of business cycles in the United States. The original idea was to approximate as much as possible an upper-bound for this cost, by simulating a simple economy where consumption is generated by a stochastic process with independently and identically distributed (i.i.d) shocks, that matches the variance and the mean of the observed consumption series. In his now influential 1987 monograph Models of Business Cycles, later complemented in 2003 by Macroeconomic Priorities, Robert Lucas, assuming individual preferences that many economists view as a reasonable benchmark, calculated that individuals would sacrifice at most 0.1 percent of their lifetime consumption, prompting him to conclude that there would be little benefit to "devising ever more subtle policies to remove the residual amount of business cycle 
risk." 5

A fantastic mounting body of research has since challenged Lucas (1987)'s early estimations of the welfare cost of business cycles by altering his modeling framework. Most of these challenges concern the building assumptions of Lucas (1987)'s original model, of which the perfect homogeneity of the economic agents with complete access to fully developed capital markets represents the main building block. It is easy to imagine that, while the costs of fluctuations may be low for some consumers, such as those endowed with generous savings, they may in contrast be devastating for those incapable of insuring themselves against the adverse effects of aggregate shocks (Krusell and Smith, 1999). In general, the many alternative implementations of the Lucas (1987)'s calculations could be grouped in four broad categories: the category emphasising the heterogeneous nature of the economic agents with a limited access to capital markets, the one proposing alternative specifications of the consumer's preferences away from the Constant Relative Risk Aversion (CRRA) utility function of the Lucas (1987)'s model, the stream of literature investigating the cost of fluctuations in the context of the Real Business Cycle (RBC) theory, and finally the one exploring the question within the framework of endogenous growth.

Imrohoroglu (1989) was the first to challenge Lucas (1987)'s findings, on the ground of agents homogeneity with access to fully developed capital markets. She considers a general equilibrium model with idiosyncratic shocks and liquidity constraints in order to assess the impact of imperfect insurance on the magnitude of the cost of fluctuations. Her argument builds on the observation that unemployment spells are typically short in booms but long in recessions, whereas in a more stable environment unemployment durations would presumably be of average length. When Imrohoroglu (1989) computes the cost of business cycles assuming agents cannot borrow and earn zero real interest on their savings, she finds a cost of business cycles of 0.3 percent. When she also allows agents to borrow at a real rate of 8 percent (while saving at a zero rate), the cost falls to a mere 0.05 percent. Atkeson and Phelan (1994) present a model in which the effect of counter-cyclical policy is simply to eliminate the correlation across individuals in the unemployment risk they face. Specifically, their model is based on the notion that the unemployment risk faced by individuals is determined in equilibrium by their choices of search strategy in the labour market. When they ask how much individuals would need to receive as a compensation for the fluctuations in their consumption, they get only 0.2 percent of lifetime consumption. Krusell and Smith (1999) examine an economy with

\footnotetext{
${ }^{5}$ This strong conclusion of Lucas, to readjust the priorities of macroeconomic stabilisation policies, comes in stark contrast with the conventional wisdom, at least in the United States, that macroeconomic policies should consistently aim at charting a stable course for economic growth. The importance given to this goal is reflected in the flurry of legislation passed by the United States Congress in the post-WWII (postwar) period: the 1946 Employment Act and the 1978 Full Employment and Balanced Growth Act (also known as the Humphrey-Hawkins Act after its two co-authors) are some prominent illustrations of that evidence.
} 
substantial heterogeneity where individuals face idiosyncratic and aggregate risks and can smooth down their consumption only through private savings. Their model encompasses a variety of heterogeneity, including employment status, wealth and preferences. They found that the poor and unemployed individuals facing liquidity constraints together with the wealthy ones would all benefit from stabilisation while the middle-income class would end up losing from it. Gomez et al. (2001) construct a search-theoretic model of equilibrium unemployment, built to be consistent with the key stylised facts of the labour market and business cycles, where job opportunities are subject to both aggregate and idiosyncratic productivity shocks. Krebs (2003) argues that if the effects of a bad shock are to be permanent, then the welfare costs of business cycles could be as high as 7.5 percent of consumption. Storesletten et al. (2001) showed that, in an environment where small aggregate shocks can have a long-lasting impact on individuals' earnings, the welfare cost of business cycles could be much higher than Lucas (1987)'s estimates. Equally, Beaudry and Pages (2001) consider idiosyncratic wage risks that worsen in recessions, and hence obtain higher estimates. More recently, Krebs (2007) investigated the welfare costs of business cycles with individuals facing a risk of job displacement, with the probability of job displacement and the consumption losses on displacement assumed to be static over the business cycles. Adopting this particular feature, Krebs (2007) showed that the welfare cost of business cycles become quite substantial.

The second category of the Lucas (1987)'s extensions, focuses broadly on alternative specifications of the consumers' preferences. While Lucas (1987)' calculations were based on a Constant Relative Risk Aversion (CRRA) utility function, Obstfeld (1994), and later on Dolmas (1998), Houssa (2013), and Ellison and Sargent (2015) adopted a martingale consumption process and recursive lifetime preferences à la Epstein and Zin (1989). Assuming this new setting, Obstfeld (1994) considers that when shocks are permanent, then a fall in consumption today is expected to persist ad vitam aeternam, and he found that the cost of business cycles can be as much as 1.8 percent of lifetime consumption. Dolmas (1998) shows that the cost of fluctuations could be even larger - over 20 percent of lifetime consumption - when shocks are permanent and when individual preferences exhibit first-order risk aversion. Using Bayesian estimates for welfare effects of consumption fluctuations and economic growth, Houssa (2013) argues that a great deal of caution is needed when drawing conclusions from point estimates of welfare costs of business cycles. More recently, Ellison and Sargent (2015) combine the insights of de Santis (2007) on the double aggregate and idiosyncratic nature of shocks and the intuition of Barillas et al. (2009) about the agents' fear of model misspecification, and conclude that the welfare costs of business cycles are important and larger than previously thought by Lucas (1987). A specific mention has to be given to Alvarez and Jermann (2005) who took a completely different route to evaluate the welfare cost of business cycles. They used a nonparametric approach to evaluate the potential gains from stabilisation policy, relating the marginal cost of business cycle risk to observed market prices without ever 
committing to a utility function, and found much higher estimates than Lucas (1987).

Another set of papers have explored the question within the RBC framework. Tallarini (2000) for example, using an RBC model combined with Epstein and Zin (1989) preferences, calibrated to reflect the salient features of the U.S. economy, found a much larger welfare cost of fluctuations than the Lucas (1987)' calculations. The main factor underlying this finding is the use of higher values of the relative risk-aversion coefficient, to be consistent with asset price determination. Otrok (2001) also develops and analyses a complete RBC model, with temporally dependent preference specifications, first proposed by Heaton (1995), and equally found larger estimates for the welfare cost of business cycles.

The fourth and perhaps final category of Lucas (1987)'s extensions concerns the papers investigating the welfare cost of business cycles within the framework of endogenous growth. It draws from the observation that the short term fluctuations negatively affect the long term economic growth, as shown by Ramey and Ramey (1991). In an endogenous growth framework, substitution against risky technologies can affect the rates of growth as well as the output levels (Lucas, 2003). Epaulard and Pommeret (2003) explore some of these possibilities, though their study does not explicitly attribute the large welfare gains to volatility-induced reductions in growth rates. Barlevy (2004) proposes a framework with diminishing returns on investment implying that eliminating fluctuations reallocates investment from periods of high investment to periods of low investment. This mechanism results in achieving higher growth rates without necessarily requiring higher investment levels. He also found higher estimates for the cost of fluctuations than in the original Lucas exercise. François and Lloyd-Ellis (2006) challenge the findings of Barlevy (2004), using a model where aggregate fluctuations and economic growth are endogenously determined. Ultimately, their model generates a positive relationship between fluctuations and growth.

It is important to stress that most of the estimates that have been discussed so far have been for the postwar U.S. economy. Overall, one can reasonably argue over the true welfare cost of macroeconomic fluctuations in the United States to be relatively modest, if not negligible, as initially claimed by Lucas (1987). ${ }^{6}$ The low cost estimates obtained in most of the post-Lucas (1987) literature stems mainly from the fact that the U.S. economy since the 1950s has been relatively stable. What is less debatable however is the sheer magnitude of aggregate fluctuations in developing countries compared to the industrialised world. In particular, the volatility of output in developing countries ranges from two to six times that in the United States (Mendoza, 1995; Carmichael et al., 1999; Agenor et al., 2000). What about the welfare cost of macroeconomic fluctuations in developing countries? Few studies have really explored that question, with the noticeable exceptions of Pallage and Robe (2003) and Houssa (2013). Using a three-model economy,

\footnotetext{
${ }^{6}$ Congruent with that conclusion, the literature on international risk-sharing shows that computational estimates of the welfare gains from better international insurance rely heavily on the underlying economy (Van Wincoop, 1994).
} 
encompassing a CRRA and an Epstein and Zin (1989) preferences, a stationary autoregressive and a finite-state Markov chain processes for per capita consumption, Pallage and Robe (2003) showed that the median welfare cost of business cycles in Africa is 10 to 30 times larger than that of the United States. Additionally, they argue that the welfare gain from eliminating aggregate fluctuations in Africa may be so large as to exceed that of receiving an additional 1 percent of growth forever, which suggests the crucial importance of macroeconomic stabilisation policies in developing countries. Houssa (2013) reaches almost the same conclusion by conducting a Bayesian inference over the consumption series of a mixed set of 82 countries, developed and developing alike. ${ }^{7}$

\subsection{Theoretical Frameworks}

\subsubsection{The CRRA Approach}

The following baseline model is a replica of the seminal work of Lucas (1987). It is an infinitely lived representative agent model where the aggregate lifetime utility $U$ is given by the present discounted value (with $\beta$ representing the discount factor of the optimisation) of all per period utilities $(u(\cdot))$. The per period utility in turn depends on the consumption level $\left(C_{t}\right)$.

$$
U=\sum_{t=o}^{\infty} \beta^{t} u\left(C_{t}\right)
$$

A noticeable feature of Lucas' model is to distinguish between two streams of consumption: a smooth, non-fluctuating, and systematically growing consumption trend $\left(\mathfrak{C}_{t}\right)$ and one that fluctuates over time with prevailing conditions $\left(C_{t}\right)$. This distinction stems from the assumption that business cycles represent random shocks around a trend growth path. In the case of certain consumption path, the per period consumption is then given by:

$$
\mathfrak{C}_{t}=\mathfrak{C}_{0} e^{g t}
$$

where $\mathfrak{C}_{0}$ is the initial risk-free consumption and $g$ the growth rate of consumption. We will see that none of these two parameters really matter in the evaluation of the welfare cost of business cycles. This means that they can be normalised to 1 and 0 respectively.

When the consumption stream follows an uncertain and random path, its per period value becomes:

$$
C_{t}=(1+\mu) \mathfrak{C}_{0} e^{g t} e^{-\frac{1}{2} \sigma_{\eta}^{2}} \eta_{t}
$$

where $\sigma_{\eta}^{2}$ represents the standard deviation of the natural logarithm of per capita consumption and $\eta_{t}$ a random shock which Lucas assumed to be log-normally distributed according to the following process: $\ln \left(\eta_{t}\right) \sim N\left(0, \sigma_{\eta}^{2}\right)$. This distribution implies that the expected value of $e^{-\frac{1}{2} \sigma_{\eta}^{2}} \eta_{t}$ is equal to 1 and that the mean value of consumption at time $t$

\footnotetext{
${ }^{7}$ For that purpose, he uses the World Development Indicators (2010)' classification of developed and developing countries.
} 
is equal to $\mathfrak{C}_{0} e^{g t}$, which, put together suggest that on average volatile consumption is not that different from certain consumption. ${ }^{8}$ Building up on these settings, $\mu$ stands as the compensation factor mentioned earlier, which measures the percentage by which average consumption has to be increased for the consumer to be indifferent between the certain and the fluctuating paths of consumption. $\mu$ is therefore the welfare cost of macroeconomic fluctuations.

Finding $\mu$ requires equating the stochastic and the risk-free lifetime utilities of the consumer. And in the case of an isoelastic per period utility function of the CRRA form, this is equivalent of writing: ${ }^{9}$

$$
\mathbf{E}\left(\frac{C_{t}^{1-\gamma}-1}{1-\gamma}\right)=\frac{\left(\mathfrak{C}_{0} e^{g t}\right)^{1-\gamma}-1}{1-\gamma}
$$

If this condition is true period $t$ by period $t$ and event $s^{t}$ by event $s^{t}$, it should also be true when summed up. Moreover, the converse is also true: $\mu$ represents the smallest possible number that could make aggregate utilities equivalent over time. That is because of the CRRA nature of the preferences and the independently and identically distributed (i.i.d.) structure of the random variable $\eta_{t}$.

The compensating condition is equivalent to the following equality:

$$
\mathbf{E}\left\{\sum_{t=0}^{\infty} \beta^{t} \frac{\left((1+\mu) C_{t}\right)^{1-\gamma}-1}{1-\gamma}\right\}=\sum_{t=0}^{\infty} \beta^{t} \frac{\left(\mathfrak{C}_{0} e^{g t}\right)^{1-\gamma}-1}{1-\gamma}
$$

where $C_{t}$ is given by the same process as in (2.3). Doing some arithmetic by canceling, taking logarithms and collecting terms finally gives: ${ }^{10}$

$$
\mu \cong \frac{1}{2} \gamma \sigma_{\eta}^{2}
$$

This compensation parameter $\mu$ - the welfare gain from eliminating consumption risk depends, naturally enough, on the amount of risk that is present, $\sigma_{\eta}^{2}$, and the degree of aversion people have towards risk, $\gamma$.

\subsubsection{The Recursive Preference Approach}

The model is set in discrete time; that is, all the variables of the model are defined at specific dates (i.e., $t=0,1,2, \ldots) .{ }^{11}$ The real per capita consumption $\left\{C_{t}\right\}$ grows at a

\footnotetext{
${ }^{8}$ The moment generating function of a log-normal distribution implies that: $\mathbf{E}\left(\eta_{t}^{m}\right)=e^{\frac{m^{2} \sigma_{\eta}^{2}}{2}}$ and $\mathbf{E}\left(e^{-\frac{1}{2} \sigma_{\eta}^{2}} \eta_{t}\right)=1$, which in turns implies that: $\mathbf{E}\left(\eta_{t}^{1-\gamma}\right)=e^{\frac{1}{2}(1-\gamma)^{2} \sigma_{\eta}^{2}}$.

${ }^{9}$ The Constant Relative Risk Aversion or CRRA utility function has the general following form: $u\left(C_{t}\right)=\frac{C_{t}^{1-\gamma}-1}{1-\gamma}$ for whenever the coefficient of relative risk aversion $\gamma$ is different from 1 and gets down to $u\left(C_{t}\right)=\ln C_{t}$ in case $\gamma=1$.

${ }^{10}$ Appendix 2.A gives the details of this operation.

${ }^{11}$ The choice between discrete and continuous time is usually based on convenience. In most macroeconomic models, continuous time is privileged, because such approach makes the analysis easier and the computations more tractable.
} 
rate $g_{t}$ (equivalent to $g_{t}=\frac{C_{t}}{C_{t-1}}-1$ ), and the growth factor $\Psi_{t}=\frac{C_{t}}{C_{t-1}}$, which in turn follows an auto-regressive stationary process of order $p$ (equivalently $A R(p)$ ) of the form:

$$
\Psi_{t}=\varphi_{0}+\sum_{i=1}^{p} \varphi_{i} \Psi_{t-i}+\epsilon_{t}
$$

where $\varphi_{0}$ represents the constant term of the stochastic process, $\left(\varphi_{1}, \varphi_{2}, \ldots, \varphi_{p}\right)$ its parameters and $\epsilon_{t}$ the error term. $\epsilon_{t}$ is assumed to be an i.i.d. normally distributed white noise such as:

$$
\epsilon_{t} \sim \mathcal{N}\left(0, \sigma_{\epsilon}^{2}\right)
$$

The long-term growth rate of consumption is defined as the unconditional expectation of its instantaneous value. In addition, this long-term growth rate is assumed to be time-invariant and corresponds to:

$$
g=\mathbf{E} g_{t}=\frac{\varphi_{0}}{1-\sum_{i=1}^{p} \varphi_{i}}
$$

For the sake of simplicity and in order to facilitate the discretisation of the random growth process, we will consider that the growth factor $\Psi_{t}$ specifically follows an auto-regressive process of order $1(A R(1))$. Pallage and Robe (2003) used the same approach while estimating the welfare cost of business cycles in Africa. The process in equation (2.7) then becomes:

$$
\Psi_{t}=\varphi_{0}+\varphi_{1} \Psi_{t-1}+\epsilon_{t},
$$

where $\varphi_{0}=\left(1-\varphi_{1}\right)(1+g)$. This process is also the same as considered in Dolmas (1998) and when the persistence parameter of the process $\varphi_{1}=0$ it becomes similar to the model proposed by Obstfeld (1994). The common denominator of all these specifications is to build on the random walk hypothesis for the consumption process, which is equivalent of saying that the natural logarithm of per capita consumption $\left\{\ln C_{t}\right\}$ follows a random walk process. $^{12}$

The original calculations of the welfare cost of business cycles by Lucas (1987) and Imrohoroglu (1989) heavily rely on the role of the consumers' degree of risk aversion embedded in their preferences. Obstfeld (1994) argues that in a context of intertemporal optimisation, the weights consumers use to cumulate the per-period costs of risks with persistent effects, depend both on the intertemporal subsitutability as well as on risk aversion. As such, in dynamic stochastic welfare comparisons, the intertemporal elasticity of substitution (IES) should clearly be distinguished from the risk aversion parameter, if one wants to avoid misleading assessments of the impact of risk aversion on the welfare cost of consumption-risk changes. Additionally, Obstfeld (1994) considers that when shocks are persistent over future periods, the discount rate of their static welfare costs

\footnotetext{
${ }^{12}$ The random walk hypothesis for consumption was first hypothesised by Hall (1988), as an answer to the Lucas critique. It later got confirmed by further empirical studies (see, for example, Nelson and Plosser (1982), Ogaki (1992), and Cooley and Ogaki (1996)).
} 
increases with the degree of intertemporal substitutability. ${ }^{13}$ As such, a higher IES would imply a larger welfare cost of fluctuations for reasons that are not necessarily inherent to the risk aversion parameter. This is the main reason why the recursive formulation of consumers' preferences does a better job in assessing the welfare cost of business cycles than the standard Constant Relative Risk Aversion (CRRA) function.

The perfect example of recursive utility corresponds to the preferences à la Epstein and Zin (1989) of the form:

$$
U_{t}=\left(C_{t}^{1-\theta}+\beta\left[\mathbf{E}\left(U_{t+1}^{1-\gamma}\right)\right]^{\frac{1-\theta}{1-\gamma}}\right)^{\frac{1}{1-\theta}}
$$

which is an increasing, concave, and homogeneous function of degree one in per capita consumption $C_{t}$. The scalar $\beta \in(0,1)$ is a constant discount factor, $\gamma(0<\gamma \neq 1)$ the coefficient of relative risk aversion, and $1 / \theta(0<\theta \neq 1)$ the IES for the deterministic consumption paths. ${ }^{14}$

$\lambda \equiv \lambda\left(\varphi, \sigma_{\epsilon}^{2}, g\right)$ denotes the welfare effect of consumption fluctuations or the compensatory factor, which depends on the parameters of the auto-regressive process (2.7), the variance of the white noise error term, and the time-invariant long-term growth rate. As in Lucas (1987), $\lambda$ is defined as the percentage increase in consumption, across all states and dates, required to leave the representative consumer indifferent between the risk-free and smooth trend of consumption and the consumption path subject to fluctuations. It could also be defined as the representative consumer's willingness to pay in order to eliminate all volatility in consumption or as the welfare gain that would be obtained if consumption were to be completely stabilised.

The calculation of $\lambda$ follows the value function iteration method employed in Dolmas (1998). The recursive utility function could be rewritten as:

$$
v\left(\Psi_{t}\right)=\left(1+\beta\left[\mathbf{E}\left(\Psi_{t+1} v\left(\Psi_{t+1}\right) \mid \Psi_{t}\right)^{1-\gamma}\right]^{\frac{1-\theta}{1-\gamma}}\right)^{\frac{1}{1-\theta}},
$$

where $\Psi_{t}=\frac{C_{t}}{C t-1}$, and $v\left(\Psi_{t}\right)$ is a normalised value function defined as $C_{t} v\left(\Psi_{t}\right)=V\left(C_{t}, \Psi_{t}\right)$ with $V\left(C_{t}, \Psi_{t}\right) \equiv U_{t}$. The stochastic consumption process in equation (2.10) is approximated by a finite state Markov chain process with the methodology proposed by Tauchen (1986). As such, the normalised value functions can be expressed in terms of discrete values of consumption growth $\left\{\tilde{\Psi}^{1}, \tilde{\Psi}^{2}, \ldots, \tilde{\Psi}^{n}\right\}$ across $n$ states. Subsequently, the discrete normalised value functions are solved in an iterative way until successive values differ by no more than $10^{-8} \cdot{ }^{15}$

\footnotetext{
${ }^{13}$ For all positive values of the positive mean adjusted growth rates that result holds. However, when the mean adjusted growth rate is negative, the opposite relationship could be true (Obstfeld, 1994).

${ }^{14}$ When the coefficient of relative risk aversion and the intertemporal elasticity of substitution are identical (i.e., $\gamma=\theta$ ) then the recursive function $U_{t}$ takes the form of a CRRA function: $U_{t}=$ $\mathbf{E} \sum_{s=0}^{\infty} \beta^{s} \frac{1}{1-\gamma} C_{t+s}^{1-\gamma}$.

${ }^{15}$ In dynamic programming, and under Blackwell (1965)' sufficient conditions, it could be shown that the value function iteration method ultimately leads to a unique solution, as argued by Stokey et al. (1989) and Ljungqvist and Sargent (2000) among others.
} 
After solving the normalised value functions, the welfare cost of consumption fluctuations gives: ${ }^{16}$

$$
\lambda=\frac{v_{\text {det }}}{v_{\text {sto }}}-1
$$

where $v_{d e t}=\left[\frac{1}{1-\beta(1+g)^{1-\theta}}\right]^{\frac{1}{1-\theta}}$ is the normalised value function for the deterministic consumption path obtained by plugging the deterministic consumption growth factor $\Psi$ in $v\left(\Psi_{t}\right)$, and $v_{\text {sto }}$ is the corresponding value function for the stochastic consumption process. In particular, $v_{\text {sto }}$ is estimated as the weighted average of the normalised value functions across the $n$ states where the weights are the invariant probabilities $\pi_{j}$ (for $j=1, \ldots, n$ ). Formally:

$$
v_{\text {sto }}=\sum_{j=1}^{n} \pi_{j} v\left(\tilde{\Psi}^{j}\right) .
$$

To define the finite state Markov chain, which stands as an approximation of the stochastic consumption process, two problems need first to be solved: finding the appropriate length $p$ of the auto-regressive process and determining the right number of discrete states $n$. With respect to the lag length, we choose an $A R(1)$, and calibrate the model for each country, to match the moments of the real per capita consumption growth series. The mean growth rate of $g$, the persistence parameter $\varphi_{1}$, and the residual variance $\sigma_{\epsilon}^{2}$ are all obtained from a standard $A R(1)$ fit. When the persistence parameter $\varphi_{1}$, is not statistically significant, the other parameters are re-estimated by regressing the consumption growth rate on a constant. All countries with a negative growth mean growth rate $(g<0)$ are also removed from the sample, given that their consumption streams converge almost surely to zero. Tables (2.1) and (2.2) summarise the regression results for the remaining 31 countries. The new sample is smaller than the original one, but still provides a cross-section of countries between the two groups of CFA and non-CFA countries. This approach borrows from Pallage and Robe (2003). The discretisation of the auto-regressive process in equation (2.10) is done following the methodology proposed by Tauchen (1986). He shows that a continuous auto-regressive process can be approximated by a finite-state Markov chain. The approximation becomes arbitrarily close to the original process, the finer the grid of state variables is defined. ${ }^{17}$ This therefore requires identifying a certain space of state variables together with a transition probability matrix congruent with the features of the auto-regressive process. As for the number of discrete states, $n$ is chosen such that the new discretised variables mimic as much as possible the behaviour of the original process. ${ }^{18}$

\footnotetext{
${ }^{16}$ The value of $\lambda$ is obtained by assuming the homogeneity of the utility consumption.

${ }^{17}$ For highly persistent processes, with $\left(\varphi_{1}>0.9\right)$, Rouwenhorst (1995) proposes a different discretisation method, which will not be used in this analysis.

${ }^{18}$ In general, a good approximation is found when the number of discrete states is set to be $n=19$ for the $A R(1)$ processes and $n=5^{p}$ for the $V A R(1)$ processes. I choose $n=50$, just like Pallage and Robe (2003).
} 


\subsection{Empirical Analysis}

\subsubsection{Data and Calibration}

In order to quantify the cost brought about by macroeconomic fluctuations in sub-Saharan Africa, we parameterise each of the two models, solve it numerically, calibrate it, and carry out four consecutive robustness checks. The data used for that purpose is the natural logarithm of the real per capita consumption at constant 2011 national prices. The aggregate consumption and the population data are all taken from the Penn World Table, version 9.0 (PWT 9.0), which also informs on the levels of relative income, output, inputs, and productivity for 182 countries between 1950 and 2014. ${ }^{19}$ Like Pallage and Robe (2003) this paper focuses on Africa, and more specifically on sub-Saharan Africa, for two reasons mainly. First, African economies throughout the last four decades have experienced fewer foreign exchange and monetary crises than their Latin American and Asian counterparts. Second, and perhaps most importantly, African countries are among the poorest in the world. Hence, concerns that volatility may be truly enormous should be most relevant to those nations (Agenor et al., 2000).

The sample of sub-Saharan African countries is divided between two groups: the ones that belong to the CFA Franc Zone and the ones that do not. A country is considered as a member of the CFA currency union if it has been member of the union since its independence and we drop from the sample all countries that have either joined the union many years after their independence (Equatorial Guinea and Guinea-Bissau) or left the union temporarily (Mali). A country is considered a non-member of the CFA Franc Zone if it left the union in the early years of its independence (Madagascar, Guinea, ... ) or if the country in question has never been part of the union in the first place (Angola, Kenya, South Africa, ... ). For all the countries covered, the data run from 1960 to 2014, with the only exception of Sierra Leone, for which the series begin in 1961. A country is further excluded from the sample if fewer than 22 consecutive years of data are available for that country. These criteria leave 36 countries in the sample, of which 11 belong to the CFA Franc Zone while 25 do not. Table (2.C.8) in the Appendix provides the summary statistics of the growth factors for each of the 36 countries included in the sample. Finally, the inflation data used to plot the figures included in the paper are collected from the Word Bank's World Development Indicators (WDI) on Consumer Price Indexes (CPI).

\subsubsection{Main Results}

The whole empirical analysis assumes that the subjective discount rate $\beta=0.96$, which corresponds to the value often used for the annual data. Regarding the relative risk

\footnotetext{
${ }^{19}$ The inflation data used to compute the figures included in this paper are taken from the annual CPI series of the World Bank' World Development Indicators (WDI). The Penn World Table comes from Feenstra et al. (2015)
} 
aversion parameter $(\gamma)$ and the Intertemporal Elasticity of Substitution $(1 / \theta)$, the results presented in this section are based on $\gamma=5$ and $\theta=2.5$, which equally correspond to the values commonly used in empirical development macroeconomics. However, there is no general consensus about the "true" value of $\gamma$ in the finance literature. To account for this uncertainty, Section (2.5) presents the results of the analysis for higher values of $\gamma$ and $\theta$.

Tables (2.1) and (2.2) present the estimates of the standard $A R(1)$ fit from equation (2.10), for the CFA and the non-CFA countries respectively and for 1960-2014 period. In the two tables, $\varphi_{0}$ is the constant term of the auto-regressive process, $\varphi_{1}$ its persistence parameter, $g$ the mean growth rate of per capita consumption, and $\sigma_{\epsilon}$ is the standard deviation of the residuals of the regressions. As stated previously, the regressions for which $\varphi_{1}$ is not significant (at least at a 10 percent level) are then re-estimated directly on the constant term of the random process. The cost of fluctuations is subsequently estimated for the countries with a strictly positive mean growth rate. This criterion excludes five countries from the original sample (Central African Republic, Niger, Senegal, Democratic Republic of Congo, and Madagascar).

Tables (2.3) and (2.4) present the estimates of the welfare costs of macroeconomic fluctuations in 11 CFA countries and in 25 non-CFA countries respectively. The second column of each table displays the cross-country estimates of $\mu$ from equation (2.6) (derived from a CRRA preference) when the standard deviation $\sigma_{\eta}$ of consumption is approximated by the standard error (s.e.) of the predicted values of the natural logarithms of per capita consumption. The third column of each table shows the estimates of $\mu$ when $\sigma_{\eta}$ is approximated by the standard deviation of the cyclical components of the HodrickPrescott (h.p.) filtered series of the logarithms of real per capita consumption. We chose a smoothing parameter of 100 , which is the conventional value for annual data. Finally, the fourth and last column of each of the two tables shows the welfare cost of business cycles ( $\lambda$ from equation 3.4) when the representative consumer's preference is an Epstein and Zin (1989) function.

The main results displayed in this section are threefold. First, the absolute value of the welfare cost of business cycles depends primarily on the methodology pursued. As an illustration, Gabon has 21.26 percent of lifetime consumption for the value of $\mu$ when the standard deviation of consumption is approximated by the standard error of the predicted values of consumption. This number drops to 0.81 percent when $\sigma_{\epsilon}$ is set to be equal to the standard deviation of the Hodrick-Prescott filtered series. Furthermore, the welfare cost of business cycles for Gabon equals 0.22 percent of lifetime consumption when the recursive preference approach à la Epstein and Zin (1989) is used. This inconsistency in the estimation of the welfare cost of business cycles has long been acknowledged by the literature. ${ }^{20}$ Because of this significant variation in the results, we do not think that the estimates reported here should be taken as reflection of the absolute measures of the

\footnotetext{
${ }^{20}$ See Barlevy (2005) for a forensic assessment.
} 
welfare cost of economic fluctuations in each of the 36 sub-Saharan African countries in the sample.

The second observation stemming from this analysis is that, taken in relative terms, the welfare cost of business cycles in sub-Saharan Africa is way higher than that of the United States, chosen here as the benchmark. ${ }^{21}$ Regardless of the methodology or the country considered, the welfare cost of economic fluctuations is at least three times higher higher than that of the United States. This result is consistent with the findings of Pallage and Robe (2003). This does not come as a surprise, given the weak insurance mechanisms available to these countries. This, combined with the not-so-efficient macroeconomic stabilisation tools, contribute to aggravate the effects of adverse shocks on consumers' welfare as well as on the countries' aggregate performance.

Finally, the perhaps most important conclusion stemming from this paper is that the average welfare cost of economic fluctuations is consistently higher for the group of countries outside the CFA Franc Zone. On average, the cost of fluctuations is between 11 and 48 percent higher for the non-CFA member states compared to their CFA counterparts. The sample means (averages) for the CFA countries read 5.59, 0.91 and 0.24 percent of lifetime consumption respectively, while these numbers rise to 6.29, 1.21 and 0.47 for the non-CFA countries. For all the methodologies used, this pattern is consistent and shows that in addition to helping prevent runaway inflation, belonging to a currency such as the CFA Franc Zone seems to further help keep under control the cost of aggregate fluctuations. ${ }^{22}$ Whether this is a direct result of the more sophisticated stabilisation policies conducted by the BCEAO and the BEAC or whether it is an indirect consequence of the CFA Franc being anchored to an international currency such as the Euro, needs further inquiry. However, for all the high variance of the estimates, when compared to the rest of the world and to the United States in particular, one could safely say that volatility truly matters for sub-Saharan countries, whether they are members of the CFA Franc Zone or not.

How statistically significant are the previous results? There are many available methods to answer that question, most of which fall under the analysis of variance (ANOVA) umbrella. In its simplest form, ANOVA provides a statistical test of whether the average means of various groups are equal, and hence is a generalisation of the $t$-test to more than two groups. In addition of comparing means, ANOVA is also useful for testing three or more groups of variables for statistical significance. However, the rank-based nonparametric tests, including sign, Mann-Whitney and Kruskal-Wallis, take a rather different route to comparing distributions across samples. These tests make weaker assumptions

\footnotetext{
${ }^{21}$ The results for the United Sates are not reported in the tables, but were computed as a control while conducting the calibrations.

${ }^{22}$ When $\sigma$ from equation (2.6) is approximated by the standard error of the predicted values of per capita consumption, the standard deviation of the results become too large - higher than 4.5. This makes comparisons across the two samples almost impossible; hence we choose the second and third specifications to carry out the main interpretations.
} 
about the measurement, the distribution, the shape and spread of the objects to be compared. Consequently, they remain completely valid under a wider range of conditions than ANOVA and its inherent parametric relatives. However, both parametric and nonparametric tests are sometimes used together, mostly to see whether the two point toward similar conclusions. We apply the two-sample $t$-test to our results - to both CRRA specifications with the standard error and Hodrick-Prescott's approximation of the standard deviation and the Epstein and Zin (1989) recursive preference specification - and we find that they are not robust to means comparison between samples. The null hypotheses of the tests equate two by two the estimates of the welfare cost of business cycles between the CFA countries and the non-CFA countries. Across the board, the null hypotheses are not rejected, with the left, two and right-tail probabilities of the $t$-distribution values not significant - i.e., that the welfare cost of business cycles is not significantly lower within the CFA Franc Zone than outside it. ${ }^{23}$

Tables (2.5), (2.6) and (2.7) below provide the details about the three two-sample $t$-tests mentioned earlier. Each table provides the means, standard errors, standard deviations, 95\% confidence intervals, Student statistics, degrees of freedom and probabilities associated to the samples and to the procedure. The parametric two-sample $t$-tests with equal variances consistently show that the null hypothesis of the equivalence between the average welfare cost of business cycles between the CFA Franc Zone and the countries outside the union cannot be rejected.

\footnotetext{
${ }^{23}$ Adjusting the $t$-tests for unequal variances between the two samples and alternative distributions do not alter our conclusions. Also, to further control for the validity of our means comparisons test, we used the nonparametric Kruskal-Wallis test as a means for robustness.
} 
Table 2.1: Estimates of the AR Process in CFA Countries

\begin{tabular}{|c|c|c|c|c|c|c|c|}
\hline & \multicolumn{2}{|c|}{$\varphi_{0}$} & \multicolumn{2}{|c|}{$\varphi_{1}$} & \multirow{2}{*}{$\begin{array}{c}g \\
0.00463\end{array}$} & \multirow{2}{*}{$\begin{array}{c}\sigma_{\epsilon} \\
0.0399813\end{array}$} & \multirow{2}{*}{$\frac{F \text {-stat }}{\ldots}$} \\
\hline Benin & $1.00463^{* * *}$ & $(0.0054408)$ & 0 & $\cdots$ & & & \\
\hline Burkina Faso & $1.299984^{* * *}$ & $(0.1356263)$ & $-0.2805973^{* *}$ & $(0.1334356)$ & 0.0151387 & 0.066718 & 4.42 \\
\hline Cameroon & $0.7724663^{* * *}$ & $(0.1376411)$ & $0.2332085^{*}$ & $(0.1366002)$ & 0.0074007 & 0.044121 & 2.91 \\
\hline Central A. Republic & $0.9913379^{* * *}$ & $(0.0088769)$ & 0 & . & -0.0086621 & 0.0652319 & $\ldots$ \\
\hline Chad & $1.009766^{* * *}$ & $(0.0159895)$ & 0 & .. & 0.009766 & 0.1174985 & $\ldots$ \\
\hline Congo & $0.7210207^{* * *}$ & $(0.1347997)$ & $0.2914929^{* *}$ & $(0.1323876)$ & 0.0176619 & 0.0620041 & 4.85 \\
\hline Côte d'Ivoire & $1.007662^{* * *}$ & $(0.0092907)$ & 0 & . & 0.007662 & 0.0682727 & $\ldots$ \\
\hline Gabon & $1.027258^{* * *}$ & $(0.0119778)$ & 0 & $\ldots$ & 0.027258 & 0.0880181 & $\ldots$ \\
\hline Niger & $1.415827^{* * *}$ & $(0.1271496)$ & $-0.421286^{* * *}$ & $(0.1269975)$ & -0.0038408 & 0.0918772 & 11.00 \\
\hline Senegal & $0.9985827^{* * *}$ & $(0.0046445)$ & 0 & $\ldots$ & -0.0014173 & 0.0341297 & $\ldots$ \\
\hline Togo & $1.010119^{* * *}$ & $(0.0098602)$ & 0 & .. & 0.010119 & 0.0724572 & $\ldots$ \\
\hline
\end{tabular}

Note: This table provides the parameter estimates of equation (2.10) for the sample of 11 CFA member states, as obtained from the regression of a standard $A R(1)$. When the persistence parameter $\varphi_{1}$ is not statistically significant at the 10 percent level, then all the other parameters are re-estimated by regressing the consumption growth factor on a constant. The standard errors of the regressions are in parentheses. ${ }^{* * *},{ }^{* *}$ and ${ }^{*}$ denote significance at 1,5 and 10 percent levels, respectively. 
Table 2.2: Estimates of the AR Process in Non-CFA Countries

\begin{tabular}{|c|c|c|c|c|c|c|c|}
\hline & & & & & $g$ & $\sigma_{\epsilon}$ & $F$-stat \\
\hline Botswana & $0.7929962^{* * *}$ & $(0.1438734)$ & $0.2458094^{*}$ & $(0.1364374)$ & 0.0514533 & 0.0644986 & 3.25 \\
\hline Burundi & $1.017323^{* * *}$ & $(0.0107213)$ & 0 & $\ldots$ & 0.017323 & 0.0787851 & $\ldots$ \\
\hline Cabo Verde & $1.031349^{* * *}$ & $(0.0090517)$ & 0 & $\ldots$ & 0.031349 & 0.0665165 & $\ldots$ \\
\hline Comoros & $1.254552^{* * *}$ & $(0.1379917)$ & $-0.2385355^{*}$ & $(0.1359509)$ & 0.0129318 & 0.062772 & 3.08 \\
\hline Democratic R. of Congo & $0.9995417^{* * *}$ & $(0.0153151)$ & 0 & $\ldots$ & -0.0004583 & 0.1125425 & $\ldots$ \\
\hline Ethiopia & $1.030977^{* * *}$ & $(0.0106793)$ & 0 & $\ldots$ & 0.030977 & 0.0784764 & $\ldots$ \\
\hline The Gambia & $1.004744^{* * *}$ & $(0.0126421)$ & 0 & $\ldots$ & 0.004744 & 0.0928998 & $\ldots$ \\
\hline Ghana & $1.009596^{* * *}$ & $(0.0099465)$ & 0 & $\ldots$ & 0.009596 & 0.0730914 & $\ldots$ \\
\hline Guinea & $1.010741^{* * *}$ & $(0.0068184)$ & 0 & $\ldots$ & 0.010741 & 0.050105 & $\ldots$ \\
\hline Kenya & $1.008767^{* * *}$ & $(0.0073411)$ & 0 & $\ldots$ & 0.008767 & 0.0539459 & $\ldots$ \\
\hline Lesotho & $0.7727522^{* * *}$ & $(0.138479)$ & $0.2491918^{*}$ & $(0.1341498)$ & 0.0292272 & 0.0562424 & 3.45 \\
\hline Madagascar & $0.9877796^{* * *}$ & $(0.0049808)$ & 0 & & -0.0122204 & 0.0366009 & $\ldots$ \\
\hline Malawi & $1.31322^{* * *}$ & $(0.1346211)$ & $-0.3010352^{* *}$ & $(0.1332295)$ & 0.00936546 & 0.0694526 & 5.11 \\
\hline Mauritania & $0.75733256^{* * *}$ & $(0.12380807)$ & $0.2753032^{* *}$ & $(0.1185394)$ & 0.04503367 & 0.1337729 & 5.39 \\
\hline Mauritius & $1.034065^{* * *}$ & $(0.0112543)$ & 0 & $\ldots$ & 0.034065 & 0.0827021 & $\ldots$ \\
\hline Mozambique & $1.018588^{* * *}$ & $(0.0077086)$ & 0 & $\ldots$ & 0.018588 & 0.0566461 & $\ldots$ \\
\hline Namibia & $1.019426^{* * *}$ & $(0.009359)$ & 0 & $\ldots$ & 0.019426 & 0.009359 & $\ldots$ \\
\hline Nigeria & $1.302343^{* * *}$ & $(0.1387341)$ & $-0.2714186^{* *}$ & $(0.1342966)$ & 0.02432275 & 0.1360931 & 4.08 \\
\hline Rwanda & $1.011809^{* * *}$ & $(0.0111339)$ & 0 & $\ldots$ & 0.011809 & 0.0818174 & $\ldots$ \\
\hline Sierra Leone & $0.6449945^{* * *}$ & $(0.1444891)$ & $0.356042^{* *}$ & $(0.1423411)$ & 0.0016096 & 0.0862155 & 6.26 \\
\hline South Africa & $0.5205602^{* * *}$ & $(0.1239096)$ & $0.4876553^{* * *}$ & $(0.1219413)$ & 0.0160351 & 0.0198079 & 15.99 \\
\hline Tanzania & $1.023359^{* * *}$ & $(0.0078047)$ & 0 & $\ldots$ & 0.023359 & 0.0573527 & $\ldots$ \\
\hline Uganda & $0.6870145^{* * *}$ & $(0.1351479)$ & $0.3211845^{* *}$ & $(0.1336203)$ & 0.0120784 & 0.0483587 & 5.78 \\
\hline Zambia & $1.000783^{* * *}$ & $(0.0120835)$ & 0 & $\ldots$ & 0.000783 & 0.0887954 & $\ldots$ \\
\hline Zimbabwe & $1.033907^{* * *}$ & $(0.0280905)$ & 0 & $\ldots$ & 0.033907 & 0.2064218 & $\ldots$ \\
\hline
\end{tabular}

Note: This table provides the parameter estimates of equation (2.10) for the sample of 25 non-CFA countries. Further, see Table (2.1). 
Table 2.3: Estimates of Welfare Costs in CFA Countries

\begin{tabular}{|c|c|c|c|}
\hline & \multicolumn{2}{|c|}{$\mu(\%)$} & \multirow[t]{2}{*}{$\bar{~} \lambda(\%)$} \\
\hline & s.e. & h.p. & \\
\hline Benin & 1.14 & 0.28 & 0.054 \\
\hline Burkina Faso & 2.16 & 0.62 & 0.0872 \\
\hline Cameroon & 5.10 & 0.41 & 0.119 \\
\hline Central A. Republic & 1.95 & 0.79 & $\ldots$ \\
\hline Chad & 7.98 & 2.34 & 0.9655 \\
\hline Congo & 7.37 & 1.02 & 0.1782 \\
\hline Côte d'Ivoire & 6.19 & 1.01 & 0.1620 \\
\hline Gabon & 21.26 & 0.81 & 0.2195 \\
\hline Niger & 4.03 & 1.65 & $\ldots$ \\
\hline Senegal & 1.86 & 0.25 & $\ldots$ \\
\hline Togo & 2.51 & 0.85 & 0.1784 \\
\hline Median & 4.03 & 0.81 & 0.1701 \\
\hline Mean & 5.59 & 0.91 & 0.2455 \\
\hline Standard Deviation & 5.71 & 0.62 & 0.2958 \\
\hline
\end{tabular}

Note: $\mu$ represents the compensation factor, when the representative consumer's preference is embodied by a $C R R A$ function. The second column of the table displays the cross-country estimates $\mu$ when the standard deviation $\sigma_{\eta}$ of consumption is approximated by the standard error (s.e.) of the predicted values of the natural logarithm of per capita consumption. The third column shows the estimates of $\mu$ when $\sigma_{\eta}$ is approximated by the standard deviation of the cyclical component of the Hodrick-Prescott (h.p.) filtered consumption series. $\lambda$ is the welfare cost of business cycles when the consumer's preference is an Epstein and Zin (1989). 
Table 2.4: Estimates of Welfare Costs in Non-CFA Countries

\begin{tabular}{|c|c|c|c|}
\hline & \multicolumn{2}{|c|}{$\mu(\%)$} & \multirow[t]{2}{*}{$\lambda(\%)$} \\
\hline & s.e. & h.p. & \\
\hline Botswana & 4.54 & 1.12 & 0.0890 \\
\hline Burundi & 7.72 & 0.95 & 0.1901 \\
\hline Cabo Verde & 2.64 & 0.83 & 0.0848 \\
\hline Comoros & 2.59 & 0.55 & 0.0807 \\
\hline Democratic R. of Congo & 11.71 & 1.51 & $\ldots$ \\
\hline Ethiopia & 5.61 & 1.10 & 0.1391 \\
\hline The Gambia & 4.26 & 1.45 & 0.4783 \\
\hline Ghana & 5.95 & 0.94 & 0.1859 \\
\hline Guinea & 1.24 & 0.48 & 0.0707 \\
\hline Kenya & 1.47 & 0.49 & 0.0878 \\
\hline Lesotho & 5.12 & 0.94 & 0.0997 \\
\hline Madagascar & 1.60 & 0.25 & $\ldots$ \\
\hline Malawi & 1.59 & 0.87 & 0.1133 \\
\hline Mauritania & 20.00 & 4.25 & 1.2264 \\
\hline Mauritius & 3.89 & 1.31 & 0.1555 \\
\hline Mozambique & 7.33 & 0.46 & 0.0751 \\
\hline Namibia & 4.38 & 0.61 & 0.0019 \\
\hline Nigeria & 10.10 & 2.47 & 0.8509 \\
\hline Rwanda & 6.38 & 1.12 & 0.2487 \\
\hline Sierra Leone & 9.95 & 2.28 & 0.8925 \\
\hline South Africa & 1.34 & 0.11 & 0.0764 \\
\hline Tanzania & 1.68 & 0.55 & 0.0692 \\
\hline Uganda & 11.52 & 0.39 & 0.1465 \\
\hline Zambia & 11.35 & 1.54 & 0.4713 \\
\hline Zimbabwe & 13.31 & 3.60 & 5.0637 \\
\hline Median & 5.12 & 0.94 & 0.1391 \\
\hline Mean & 6.29 & 1.21 & 0.4738 \\
\hline Standard Deviation & 4.72 & 1.00 & 1.0493 \\
\hline
\end{tabular}

Note: $\mu$ represents the compensation factor, when the representative consumer's preference is embodied by a CRRA function. The second column of the table displays the cross-country estimates $\mu$ when the standard deviation $\sigma_{\eta}$ of consumption is approximated by the standard error (s.e.) of the predicted values of the natural logarithm of per capita consumption. The third column shows the estimates of $\mu$ when $\sigma_{\eta}$ is approximated by the standard deviation of the cyclical component of the Hodrick-Prescott (h.p.) filtered consumption series. $\lambda$ is the welfare cost of business cycles when the consumer's preference is an Epstein and Zin (1989). 
Table 2.5: Two-Sample $t$-test for First CRRA Specification

\begin{tabular}{ccccccc}
\hline \hline Variable & Obs & Mean & Std. Err. & Std. Dev. & [95\% Conf. Interval] \\
\hline CFA & 11 & 5.595455 & 1.720674 & 5.70683 & 1.761554 & 9.429355 \\
Non-CFA & 25 & 6.2908 & 0.9440606 & 4.720303 & 4.342355 & 8.239245 \\
& & & & & & \\
Combined & 36 & 6.078333 & 0.8281375 & 4.968825 & 4.397125 & 7.759542 \\
$\quad$ Diff & & -0.6953455 & 1.820133 & & -4.3943 & 3.003609 \\
\hline \hline
\end{tabular}

Note: Student statistic: $t=-0.3820$; degrees of freedom: $\mathrm{df}=34$; left-tail probability $\operatorname{Pr}(T<t)=$ 0.3524; two-tail probability: $\operatorname{Pr}(|T|<|t|)=0.7048$ and right-tail probability: $\operatorname{Pr}(T>t)=0.6476$.

Table 2.6: Two-Sample $t$-test for Second CRRA Specification

\begin{tabular}{ccccccc}
\hline \hline Variable & Obs & Mean & Std. Err. & Std. Dev. & {$[95 \%$ Conf. Interval] } \\
\hline CFA & 11 & 0.9118182 & 0.186088 & 0.6171842 & 0.4971882 & 1.326448 \\
Non-CFA & 25 & 1.2068 & 0.2004293 & 1.002147 & 0.7931342 & 1.620466 \\
& & & & & & \\
Combined & 36 & 1.116667 & 0.1505993 & 0.903596 & 0.8109338 & 1.4224 \\
Diff & & -0.2949818 & 0.3278259 & & -0.9612043 & 0.3712406 \\
\hline \hline
\end{tabular}

Note: Student statistic: $t=-0.8998$; degrees of freedom: $d f=34$; left-tail probability: $\operatorname{Pr}(T<t)=$ 0.1873; two-tail probability: $\operatorname{Pr}(|T|<|t|)=0.3745$ and right-tail probability: $\operatorname{Pr}(T>t)=0.8127$.

Table 2.7: Two-Sample $t$-test for Epstein-Zin Specification

\begin{tabular}{ccccccc}
\hline \hline Variable & Obs & Mean & Std. Err. & Std. Dev. & [95\% Conf. Interval] \\
\hline CFA & 8 & 0.245475 & 0.1046092 & 0.2958796 & -0.0018866 & 0.4928366 \\
Non-CFA & 23 & 0.4738044 & 0.2188012 & 1.049334 & 0.0200384 & 0.9275703 \\
& & & & & & \\
Combined & 31 & 0.4148807 & 0.1644361 & 0.9155415 & 0.0790573 & 0.750704 \\
Diff & & -0.2283294 & 0.3798594 & & -1.005229 & 0.5485704 \\
\hline \hline
\end{tabular}

Note: Student statistic: $t=-0.6011$; degrees of freedom: df $=29$; left-tail probability: $\operatorname{Pr}(T<t)=$ 0.2762; two-tail probability: $\operatorname{Pr}(|T|<|t|)=0.5525$ and right-tail probability: $\operatorname{Pr}(T>t)=0.7238$. 


\subsection{Robustness Checks}

\subsubsection{Higher Risk-Aversion and Higher IES}

There is not a real agreement about the exact magnitude of the relative risk aversion $(\gamma)$ and the intertemporal elasticity of substitution $(1 / \theta)$. The changes in the values of these parameters affect the estimates of the welfare cost of business cycles. For example, for a given value of $\theta$, the cost of fluctuations increases with the relative risk aversion parameter. This is a reflection of the risk-averse consumers' preference for a smooth consumption stream. Consequently, the more risk averse a consumer is, the more welfare compensation he would request to offset the effects of volatility in consumption. Alternatively, when the degree of risk aversion $\gamma$ is held constant, the cost of fluctuations decreases with $\theta$. This captures the positive effect of the IES on the welfare cost of fluctuations when the shocks are persistent. In the presence of persistence shocks, the discount factor of static welfare costs of consumption fluctuations over time increases with the IES. ${ }^{24}$

Because of the lack of general agreement regarding the true empirical values of $\gamma$ and $\theta$, we will double the values of these parameters (from 5 to 10 for $\gamma$ and from 2.5 to 5 for $\theta$ ). ${ }^{25}$ The results obtained from doubling the value of $\gamma$ (as shown by Tables 2.D.9 and 2.D.10 in the Appendix) ceteris paribus, or those computed from doubling the value of $\theta$ (as displayed by Tables 2.E.11 and 2.E.12 in the Appendix) show that the conclusions reached from the benchmark analysis remain robust to parameters shifting. Applying the two-sample $t$-test to those estimates yields the same conclusion, i.e., that the mean averages between the CFA and the non-CFA zones are not statistically different from each other.

\subsubsection{Sub-Period Analysis}

In addition of varying the values of the parameters of the model, it is also possible to divide the consumption series in two or more sub-periods. Here we will divide them in two (from 1960 to 1985 and from 1986 to 2014). This is to account for the potential structural breaks in the time series. For instance, the mid-1980s have been identified by many authors in the macroeconomic literature as the breaking point for a sensible decline in aggregate fluctuations for many countries, developed and developing alike. In order to investigate the effects of this structural break in the data, we will carry out the same estimations for the two groups of countries in each one of the two sub-periods.

Tables (2.F.13) and (2.F.14) in the Appendix summarise the results for the first subperiod (1960-1985) while Tables (2.G.15) and (2.G.16) show the outcomes for the second

\footnotetext{
${ }^{24}$ The result holds true providing that the mean adjusted growth rate of consumption $\left(g-\frac{1}{2} \gamma \sigma^{2}\right)$ is positive. Otherwise, the opposite relationship is true (see Obstfeld (1994) for further discussions).

${ }^{25}$ These are reasonable values, and Ogaki et al. (1996) find for example estimated values of $\theta$ ranging from 2.26 to 2.96 for developing countries, from 1.35 to 2.51 for lower-middle-income countries, from 1.26 to 2.38 for upper-middle-income countries, and from 1.21 to 2.29 for high income countries.
} 
sub-period (1986-2014). However, only $\mu$ (from the Lucas (1987)' CRRA approach) is estimated for each individual country. Again, as far as the sample mean of welfare cost is concerned, the results show the stability of the estimates of $\mu$ to structural break decomposition. The welfare cost of business cycles remains seemingly higher for countries outside the CFA Franc Zone. But the two-sample $t$-test to those estimates yields the same conclusion, i.e., that the mean averages between the CFA and the non-CFA zones are not statistically different from each other, both before and after 1985 .

\subsubsection{The Asset Pricing Approach}

Despite the differences in their formulation, the CRRA approach of Lucas (1987) and the Epstein and Zin (1989) approach of Obstfeld (1994), Dolmas (1998) and others, all belong to the same preference-based estimation of the welfare cost of business cycles. Most of the papers that propose alternative utility formulations continue to find small costs of macroeconomic fluctuations, although a few argue those costs to be significantly larger. The initial question therefore remains, about which of these alternative specifications best captures individual preferences. As mentioned before, Alvarez and Jermann (2005) propose a framework to quantify the welfare cost of business cycles, using asset prices, without a full specification of the representative consumer's preference. Their approach, just like in the seminal contribution of Lucas (1987), is based on the same notion of marginal cost of consumption fluctuations, the per unit benefit of a marginal reduction in consumption fluctuations, expressed as a percentage of the risk-free consumption. By indirectly inferring a utility function from a variety of asset prices, including the return on equity, Alvarez and Jermann (2005) argue that asset prices reveal that individuals strongly dislike fluctuations in trend consumption growth. ${ }^{26}$

The model is cast in discrete time and carried out under the assumptions of a representative agent economy, as in the preference-based approach. $\{x\}$ denotes a stream of random payoffs for all dates $t \geq 0$, and the value function $V_{0}(\{x\})$. In each period $t$, the economy experiences one of the finitely many events $z_{t} \in Z_{t}$, and $z^{t}=\left(z_{0}, z_{1}, \ldots, z_{t}\right)$ denotes the history up through and including period $t$. Consumption is indexed by histories, such that: $C: \mathbf{Z} \longrightarrow \mathbb{R}_{+}$, where $\mathbf{Z} \equiv \Pi_{t \geq 1} Z^{t}$, or simply $\{C\}=\left\{C_{t}\left(z^{t}\right): \forall t \geq 1, z^{t} \in Z^{t}\right\}$. In the model, consumption has two different versions: the stochastic process $\{C\}$, which represents the scheme of consumption subject to fluctuations, and $\{\mathfrak{C}\}$ the stable or risk-free consumption (also referred to as the trend).

In this asset pricing approach, the welfare cost of consumption is also defined with respect

\footnotetext{
${ }^{26}$ Wolfers (2003) proposes using survey on how happy people feel as an alternative way of estimating the cost of business cycles without imposing a specific utility function. He regresses well-being data on the mean and variance of unemployment to arrive at a trade-off between the two. One could do the same with the mean and variance of consumption; however, while consumption grows over time, average reported well-being does not. This incongruity suggests either individuals do not strongly prefer more consumption to less or, more likely, that well-being measures are not directly comparable over time.
} 
to an unspecified lifetime utility function $U_{t}(\cdot)$, mapping the consumption process into $\mathbb{R}$. $U_{t}($.$) is assumed to be differentiable with respect to each C\left(z^{t}\right)$ for all $t$ and $z^{t}$. Therefore the total cost of consumption fluctuations $\Omega(\alpha)$, is the solution of:

$$
U([1+\Omega(\alpha)]\{C\})=U((1-\alpha)\{C\}+\alpha\{\mathfrak{C}\})
$$

where $\alpha \in[0,1]$ measures the fraction of the consumption process $C: \mathbf{Z} \longrightarrow \mathbb{R}_{+}$that has been replaced by the less risky trend $\mathfrak{C}: \mathbf{Z} \longrightarrow \mathbb{R}_{+}$. The total cost function gives the total benefit from reducing consumption fluctuations as a function of the fraction of the reduction in fluctuations. It is straightforward to see that $\Omega(0)=0$, so that no reduction in fluctuations generates no benefit.

In order to find the marginal cost of fluctuations, we first need to recall that the lifetime utility $U_{t}$ is differentiable with respect to each $C\left(z^{t}\right)$ for all $t$ and $z^{t}$. The partial derivatives are therefore $U_{z^{t}}(\{C\}) \equiv \partial U(\{C\}) / \partial C_{t}\left(z^{t}\right)$, which denote the marginal utility from consumption $C\left(z^{t}\right)$ at date $t$. The marginal cost of consumption fluctuations $\omega_{0}$ is defined as the derivative of the total cost function $\Omega(\alpha)$ evaluated at $\alpha=0$, that is:

$$
\omega_{0} \equiv \Omega^{\prime}(0)=\frac{\sum_{t=1}^{\infty} \sum_{z^{t} \in Z^{t}} U_{z^{t}}(\{C\}) \cdot\left[\mathfrak{C}_{t}\left(z^{t}\right)-C_{t}\left(z^{t}\right)\right]}{\sum_{t=1}^{\infty} \sum_{z^{t} \in Z^{t}} U_{z^{t}}(\{C\}) \cdot C_{t}\left(z^{t}\right)} .
$$

Thus, $\omega_{0}$ measures the per-unit benefit of a marginal reduction in consumption fluctuations expressed as a percentage of consumption. This measure is considered by Alvarez and Jermann (2005) as the market price of consumption fluctuations. For any process $x: \mathbf{Z} \longrightarrow \mathbb{R}$, the shadow price for a representative consumer of an asset with payouts given by $\{x\}$ is given by its value function $V_{0}(\{x\})$. This shadow price's explicit formulation is:

$$
V_{0}(\{x\})=\sum_{t=1}^{\infty} \sum_{z^{t} \in Z^{t}} U_{z^{t}}(\{C\}) \cdot x_{t}\left(z^{t}\right) .
$$

Under this shadow price convention, the marginal cost of business cycles becomes:

$$
\omega_{0}=\frac{V_{0}(\{\mathfrak{C}\})}{V_{0}(\{C\})}-1 .
$$

Hence, the marginal cost of consumption fluctuations as a ratio of the values of two securities: a claim to the consumption trend, $V_{0}(\{\mathfrak{C}\})$, and a claim to consumption, $V_{0}(\{C\})$, or equivalently, a consumption-equity claim. These generalisations of Lucas (1987)'s cost of business cycles by Alvarez and Jermann (2005) have some attractive features. First, by focusing on the marginal cost, the approach allows to measure this cost by using information on the representative consumer's marginal evaluation contained in the security prices. Second, it helps rethink the benefits of the partial reduction in consumption fluctuations. Moreover, this measure of the marginal cost of business cycles can be used to bound the standard total cost of the fluctuations for a large class of preferences specifications, without the need to fully parameterise these preferences. 
In order to find an analytic solution to equation (2.18), the value functions $V_{0}(\{\mathfrak{C}\})$, and $V_{0}(\{C\})$ need to be decomposed and an additional assumption is necessary. For a consumption process $\{C\}$ that is abstractly defined as implying a complete elimination of uncertainty in consumption, this suggests that the stochastic consumption is the expected value of its deterministic value, i.e., $C_{t}=\mathbf{E}_{\mathbf{0}}\left\{\mathfrak{C}_{t}\right\}$ for all time $t$ and states $z^{t}$, with $\mathfrak{C}_{0}=C_{0}$. The unconditional expectation of consumption growth is assumed to be time-invariant and corresponds to $g$. Thus $\mathbf{E}\left\{\mathfrak{C}_{t}\right\}=C_{t}=\mathfrak{C}_{0}(1+g)^{t}$. Additionally, using the definition of the yield to maturity $(\mathrm{YTM})$, the value functions become $V_{0}(\{\mathfrak{C}\}) / C_{0}=(1+g) /\left(y_{0}-g\right)$ and $V_{0}(\{C\}) / C_{0}=(1+g) /\left(r_{0}-g\right)$, where $y_{0}$ and $r_{0}$ are the yield to maturity associated to the value functions $V_{0}(\{\mathfrak{C}\})$ and $V_{0}(\{C\})$ respectively. ${ }^{27}$ Thus, the marginal cost of all uncertainty can be written as:

$$
\omega_{0}=\frac{r_{0}-g}{y_{0}-g}-1
$$

The previous expression, as shown by Alvarez and Jermann (2005) provides an upper bound for the total benefit from eliminating all consumption uncertainty. As a first approximation, one could interpret the per capita consumption growth rate as $g$, the average yield on long-term government bond as the yield to maturity associated to the deterministic consumption $\{\mathfrak{C}\}, y_{0}$, and the consumption risk-premium as the difference $r_{0}-y_{0}$.

The data on government bonds in Africa is particularly scarce. In 2006, Seychelles was the first sub-Saharan African country - with the exception of South Africa -, to make its foray into the international financial markets with the issuing of its $\$ 200$ million Eurobond. Ever since, many other sub-Saharan African countries have issued Eurobonds with values generally ranging from $\$ 200$ million to $\$ 1$ billion. The bulk of these countries being in West Africa (Côte d'Ivoire, Ghana, Nigeria and Senegal). We will restrict the calibration here with respect to Senegal and Ghana, the former being a CFA member state while the latter is not. ${ }^{28}$ These two countries are chosen for their relative similarity. In 2014, Senegal issued a 10 -year $\$ 500$ million bonds with 6.25 percent interest rate while Ghana's yield to maturity for the same year equates 8.25 percent. According to the data, the growth rates of per capita consumption in Senegal and Ghana in 2014 were 0.34 and 3.18 percent respectively. For the risk premium, we chose 2 percent (which corresponds to 10 times the benchmark postwar mean consumption risk premium for the United States). Taking stock of these information, we find that $\omega_{0}$ is equal to 33.84 and 39.44 percent of lifetime consumption in Senegal and Ghana respectively. Putting aside the fact that these are huge numbers (congruent with the findings of Alvarez and Jermann (2005)), it appears that the welfare cost of economic fluctuations is seemingly lower for the representative

\footnotetext{
${ }^{27} \mathrm{~A}$ yield to maturity $\xi$ corresponding to the price of asset that entitles to the stream of dividends $\{x\}$ is implicitly defined by

$$
\frac{V_{0}(\{x\})}{X_{0}}=\sum_{t=1}^{\infty}\left[\frac{\mathbf{E}\left(x_{t} / x_{t-1}\right)}{1+\xi}\right]^{t}
$$

${ }^{28}$ Senegal issued its first Eurobond in 2009, two years after Ghana.
} 
country of the CFA Franc Zone, though the difference appears somewhat limited. In addition, the gap between these two non-parametric welfare costs of business cycles $(\approx$ $15 \%$ ) falls within the $11-48 \%$ interval previously found through parametric means.

\subsection{Concluding Remarks}

Macroeconomic fluctuations, both a source and a reflection of underdevelopment, is a fundamental concern for developing countries in general and for sub-Saharan Africa in particular. Their high and beyond-usual aggregate instability results from a combination of large external shocks, volatile macroeconomic policies, microeconomic rigidities, and weak economic and political institutions. Volatility entails a direct welfare cost for riskaverse individuals, as well as an indirect one through its adverse effect on income growth and development. Policy makers, international organisations, and researchers are adamant to kick-starting growth and strengthening institutions, almost forgetting the aggregate fluctuations. This paper is a modest contribution in the study of those fluctuations.

In this article, we computed the welfare cost of macroeconomic fluctuations in 36 subSaharan African countries, of which eleven are members of the CFA Franc Zone, a seven and plus decades currency union. This is carried out using various techniques that have been proposed in the macroeconomic literature. Depending on the calibration model used, we find that the sample mean cost of business cycles for the group of non-CFA member states is between 11 and 48 percent higher than that of the members of the union. However, a parametric two-sample $t$-test shows that these results are not sufficiently robust to means difference comparisons.

Because of the high variance of some estimates - which is a direct consequence of the different estimation techniques used -, it is important not to adopt these numbers as the absolute costs of macroeconomic fluctuations in each individual country. However, the results serve well the purpose of cross-country comparison and hold consistent through a wide range of robustness checks. Two important constants of this analysis are: first, that the welfare cost of economic fluctuations for all the countries in the sample is higher than that of the United States, taken as the benchmark; second, that despite the change in methodology, in the preferred values of key parameters and despite the structural breaks, the CFA Franc Zone countries seemingly absorb better the adverse macroeconomic shocks than the rest of their African counterparts, albeit not significantly. This lack of significance might be a result of the fixed exchange rate regime in the CFA Franc Zone, a policy that has been remarkably consistent for more than seven decades. The immediate implication of such monetary arrangement is the inability to use monetary policy to effectively deal with real and financial crises affecting the union members as well as with external shocks that have the power to change the exchange rates between global currencies (Aizenman, 2016). This goes against the backdrop of a growing ideological and political calls from 
some member states to leave the union altogether. ${ }^{29}$ Potential ways forward could be moving towards a semi-flexible exchange rate regime and the anchoring of the CFA Franc on a basket on international currencies instead of the Euro alone.

While we believe this article to be an important contribution in the renewed developingcountry Optimum Currency Area debate, many questions still remain unanswered and could benefit from further research. What role could structural change and economic modernisation play in taming the welfare effects of aggregate fluctuations? Are currency unions with pegged exchange rates such as the CFA Franc potentially vulnerable to the fluctuations of the Euros? How much the development of robust domestic debt markets could contribute to reducing the exposure of developing countries to the interest rates volatility? Those questions have not been answered by this article but promise to be fruitful avenues for future inquiry.

\footnotetext{
${ }^{29}$ On August 2015, the President Idriss Déby of Chad, during the ceremony celebrating the 55th anniversary of his nation's independence, called all his fellow 13 African Heads of States to pull their countries out of the CFA Franc Zone. This is perhaps the most prominent example of discordant voices from within the union, and it is just one of many.
} 


\section{Appendix 2.A: The Compensation Factor $\mu$}

Here we outline the arithmetic in the computation of the compensation factor $\mu$, defined as the percentage consumption increase at all dates and in all states, that would render the representative consumer indifferent between a world of uncertainty and one of certainty. The compensation condition was equivalent to:

$$
\mathbf{E}\left\{\sum_{t=0}^{\infty} \beta^{t} \frac{\left((1+\mu) C_{t}\right)^{1-\gamma}-1}{1-\gamma}\right\}=\sum_{t=0}^{\infty} \beta^{t} \frac{\left(\mathfrak{C}_{0} e^{g t}\right)^{1-\gamma}-1}{1-\gamma}
$$

and when the consumption stream follows an uncertain and random path, its per period value becomes:

$$
C_{t}=(1+\mu) \mathfrak{C}_{0} e^{g t} e^{-\frac{1}{2} \sigma_{\eta}^{2}} \eta_{t}
$$

when we replace the risky consumption $\left(C_{t}\right)$ by this expression in the compensation equation, and by dropping the triplet of constants $\left\{\beta, \mathfrak{C}_{0}, g\right\}$ we get the following:

$$
\begin{gathered}
\mathbf{E}\left((1+\mu)\left(e^{-\frac{1}{2} \sigma_{\eta}^{2}} \eta_{t}\right)\right)^{1-\gamma}=1 \\
\left\{(1+\mu) e^{-\frac{1}{2} \sigma_{\eta}^{2}}\left(\mathbf{E} \eta_{t}^{1-\gamma}\right)^{\frac{1}{1-\gamma}}\right\}^{1-\gamma}=1
\end{gathered}
$$

The moment generating function of a log-normal distribution implies that:

$$
\mathbf{E}\left(\eta_{t}^{m}\right)=e^{\frac{m^{2} \sigma_{\eta}^{2}}{2}}
$$

then:

$$
\begin{gathered}
\mathbf{E}\left(e^{-\frac{1}{2} \sigma_{\eta}^{2}} \eta_{t}\right)=1 \\
\mathbf{E}\left(\eta_{t}^{1-\gamma}\right)=e^{\frac{1}{2}(1-\gamma)^{2} \sigma_{\eta}^{2}}
\end{gathered}
$$

Applying this to our problem and proceeding to few simplifications, we will obtain the following non-linear equation:

$$
(1+\mu) e^{-\frac{1}{2} \sigma_{\eta}^{2}+\frac{1}{2}(1-\gamma) \sigma_{\eta}^{2}}=1
$$

equivalent to:

$$
(1+\mu) e^{-\frac{1}{2} \gamma \sigma_{\eta}^{2}}=1
$$

To finally obtain a reduced-form solution of $\mu$, we need to log-linearise the previous expression and remembering that for small values of $x$ then $\ln (1+x) \simeq x$, which is self-evident in the case of the compensation factor. Therefore:

$$
\ln (1+\mu) \simeq \mu=\frac{1}{2} \gamma \sigma_{\eta}^{2}
$$




\section{Appendix 2.B: Additional Inflation Figures}

Figure 2.B.2: Cyclical and Trend Components of Annual CPI Inflation in SSA
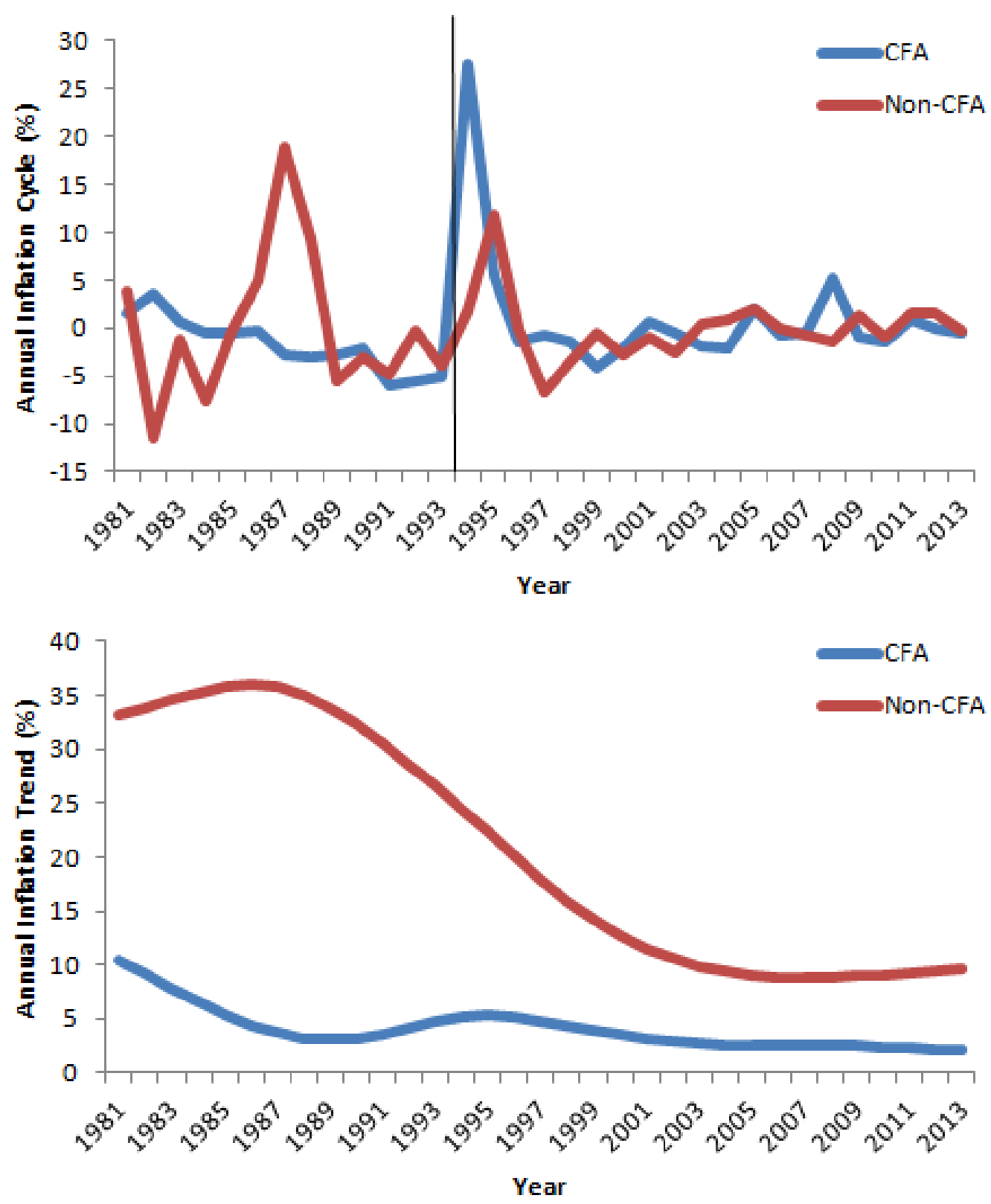

Note: The cyclical and trend components of annual inflation displayed in these figures are derived from the sample average of the Consumer Price Indexes (CPI) of two groups of randomly selected countries: 7 CFA member states (Burkina Faso, Côte d'Ivoire, Cameroon, Gabon, Niger, Senegal and Togo) and 14 other non-member states (Burundi, Botswana, Ethiopia, Ghana, The Gambia, Kenya, Madagascar, Mauritania, Malawi, Nigeria, Sierra Leone, Tanzania, Uganda, and South Africa). The methodology employed to divide the rates of inflation between these two entities is the Hodrick-Prescott filter, with a smoothing parameter of 100. These two figures show that for most part of the last three and half decades, inflation has been quite stable in the CFA Franc Zone, compared to the rest of the continent, with the exception of the immediate aftermath of the 1994 devaluation. The trend of inflation has however been on a decreasing trend for all the non-CFA members of the continent. 


\section{Appendix 2.C: Descriptive Statistics}

Table 2.C.8: Descriptive Statistics of Consumption Growth Factors in SSA 1960-2014

\begin{tabular}{|c|c|c|c|c|c|}
\hline Country & Obs. & Mean & Std. Dev. & Min & Max \\
\hline Benin & 54 & 1.00463 & 0.0399813 & 0.8393903 & 1.085028 \\
\hline Botswana & 54 & 1.051567 & 0.0658962 & 0.9246719 & 1.255013 \\
\hline Burkina Faso & 54 & 1.014325 & 0.0693802 & 0.8589628 & 1.287234 \\
\hline Burundi & 54 & 1.017323 & 0.0787851 & 0.8422803 & 1.278561 \\
\hline Cabo Verde & 54 & 1.031349 & 0.0665165 & 0.8307623 & 1.305812 \\
\hline Cameroon & 54 & 1.007109 & 0.0449415 & 0.874505 & 1.106108 \\
\hline Central A. Republic & 54 & 0.9913379 & 0.0652319 & 0.6783336 & 1.078698 \\
\hline Chad & 54 & 1.009766 & 0.1174986 & 0.777664 & 1.689235 \\
\hline Comoros & 54 & 1.013213 & 0.0640628 & 0.8513388 & 1.318808 \\
\hline Congo & 54 & 1.015912 & 0.0649835 & 0.7975834 & 1.203761 \\
\hline Côte d'Ivoire & 54 & 1.007662 & 0.0682727 & 0.7591224 & 1.111583 \\
\hline Democratic R. of Congo & 54 & 0.9995417 & 0.1125425 & 0.7664644 & 1.395575 \\
\hline Ethiopia & 54 & 1.030977 & 0.0784764 & 0.8008052 & 1.221531 \\
\hline Gabon & 54 & 1.027258 & 0.0880181 & 0.8017456 & 1.242083 \\
\hline The Gambia & 54 & 1.004744 & 0.0928998 & 0.7305721 & 1.362432 \\
\hline Ghana & 54 & 1.009596 & 0.0730914 & 0.8256029 & 1.20319 \\
\hline Guinea & 54 & 1.010741 & 0.050105 & 0.8882738 & 1.174274 \\
\hline Kenya & 54 & 1.008767 & 0.0539459 & 0.8916304 & 1.133386 \\
\hline Lesotho & 54 & 1.030701 & 0.0581526 & 0.9286685 & 1.236249 \\
\hline Madagascar & 54 & 0.9877796 & 0.0366009 & 0.8889465 & 1.074602 \\
\hline Malawi & 54 & 1.008736 & 0.072594 & 0.7929404 & 1.246934 \\
\hline Mauritania & 54 & 1.031884 & 0.1566281 & 0.5159126 & 1.654761 \\
\hline Mauritius & 54 & 1.034065 & 0.0827021 & 0.8095848 & 1.343843 \\
\hline Mozambique & 54 & 1.018588 & 0.0566461 & 0.8890447 & 1.291605 \\
\hline Namibia & 54 & 1.019426 & 0.0687746 & 0.8639514 & 1.265776 \\
\hline Niger & 54 & 0.996919 & 0.1005001 & 0.6707417 & 1.434248 \\
\hline Nigeria & 54 & 1.022942 & 0.140603 & 0.7857614 & 1.629491 \\
\hline Rwanda & 54 & 1.011809 & 0.0818174 & 0.6982229 & 1.168109 \\
\hline Senegal & 54 & 0.9985827 & 0.0341297 & 0.8671425 & 1.077301 \\
\hline Sierra Leone & 53 & 1.006857 & 0.0914228 & 0.7336392 & 1.205856 \\
\hline South Africa & 54 & 1.015683 & 0.0225825 & 0.9577858 & 1.063712 \\
\hline Tanzania & 54 & 1.023359 & 0.0573527 & 0.9010585 & 1.300008 \\
\hline Togo & 54 & 1.010119 & 0.0724572 & 0.854517 & 1.220608 \\
\hline Uganda & 54 & 1.011078 & 0.0506233 & 0.8488763 & 1.216916 \\
\hline Zambia & 54 & 1.000783 & 0.0887954 & 0.8090424 & 1.35824 \\
\hline Zimbabwe & 54 & 1.033907 & 0.2064218 & 0.8062489 & 2.338038 \\
\hline
\end{tabular}




\section{Appendix 2.D: Higher Risk-Aversion Level}

Table 2.D.9: Estimates of Welfare Costs in CFA Countries

\begin{tabular}{|c|c|c|c|}
\hline & \multicolumn{2}{|c|}{$\mu(\%)$} & \multirow[t]{2}{*}{$\lambda(\%)$} \\
\hline & s.e. & h.p. & \\
\hline Benin & 2.28 & 0.56 & 0.1081 \\
\hline Burkina Faso & 4.32 & 1.24 & 0.1623 \\
\hline Cameroon & 10.2 & 0.82 & 0.2358 \\
\hline Central A. Republic & 3.9 & 1.58 & $\ldots$ \\
\hline Chad & 15.96 & 4.68 & 1.9577 \\
\hline Congo & 14.74 & 2.04 & 0.3749 \\
\hline Côte d'Ivoire & 12.38 & 2.02 & 0.3246 \\
\hline Gabon & 42.52 & 1.62 & 0.4403 \\
\hline Niger & 8.06 & 3.30 & $\ldots$ \\
\hline Senegal & 3.72 & 0.50 & $\ldots$ \\
\hline Togo & 5.02 & 1.70 & 0.3575 \\
\hline Median & 8.06 & 1.62 & 0.3411 \\
\hline Mean & 11.19 & 1.82 & 0.4951 \\
\hline Standard Deviation & 11.41 & 1.23 & 0.6015 \\
\hline
\end{tabular}

Note: see Table (2.3). 
Table 2.D.10: Estimates of Welfare Costs in Non-CFA Countries

\begin{tabular}{|c|c|c|c|}
\hline & \multicolumn{2}{|c|}{$\mu(\%)$} & \multirow[t]{2}{*}{$\bar{~} \lambda(\%)$} \\
\hline & s.e. & h.p. & \\
\hline Botswana & 9.08 & 2.24 & 0.1853 \\
\hline Burundi & 15.44 & 1.90 & 0.3811 \\
\hline Cabo Verde & 5.28 & 1.66 & 0.1698 \\
\hline Comoros & 5.18 & 1.10 & 0.1518 \\
\hline Democratic R. of Congo & 23.42 & 3.02 & $\ldots$ \\
\hline Ethiopia & 11.22 & 2.20 & 0.2786 \\
\hline The Gambia & 8.52 & 2.90 & 0.9629 \\
\hline Ghana & 11.9 & 1.88 & 0.3727 \\
\hline Guinea & 2.48 & 0.96 & 0.1415 \\
\hline Kenya & 2.94 & 0.98 & 0.1758 \\
\hline Lesotho & 10.24 & 1.88 & 0.2085 \\
\hline Madagascar & 3.20 & 0.5 & $\ldots$ \\
\hline Malawi & 3.18 & 1.74 & 0.2097 \\
\hline Mauritania & 40.00 & 8.5 & 2.6126 \\
\hline Mauritius & 7.78 & 2.62 & 0.3117 \\
\hline Mozambique & 14.66 & 0.92 & 0.1503 \\
\hline Namibia & 8.76 & 1.22 & 0.0039 \\
\hline Nigeria & 20.20 & 4.94 & 1.6151 \\
\hline Rwanda & 12.76 & 2.24 & 0.4990 \\
\hline Sierra Leone & 19.90 & 4.56 & 1.9102 \\
\hline South Africa & 2.68 & 0.22 & 0.1537 \\
\hline Tanzania & 3.36 & 1.10 & 0.1385 \\
\hline Uganda & 23.04 & 0.78 & 0.3119 \\
\hline Zambia & 22.70 & 3.08 & 0.9485 \\
\hline Zimbabwe & 26.62 & 7.20 & 10.5784 \\
\hline Median & 10.24 & 1.88 & 0.2786 \\
\hline Mean & 12.58 & 2.41 & 0.9770 \\
\hline Standard Deviation & 9.44 & 2.00 & 2.1945 \\
\hline
\end{tabular}

Note: see Table (2.3). 


\section{Appendix 2.E: Higher Intertemporal Elasticity of Sub- stitution}

Table 2.E.11: Estimates of Welfare Costs in CFA Countries

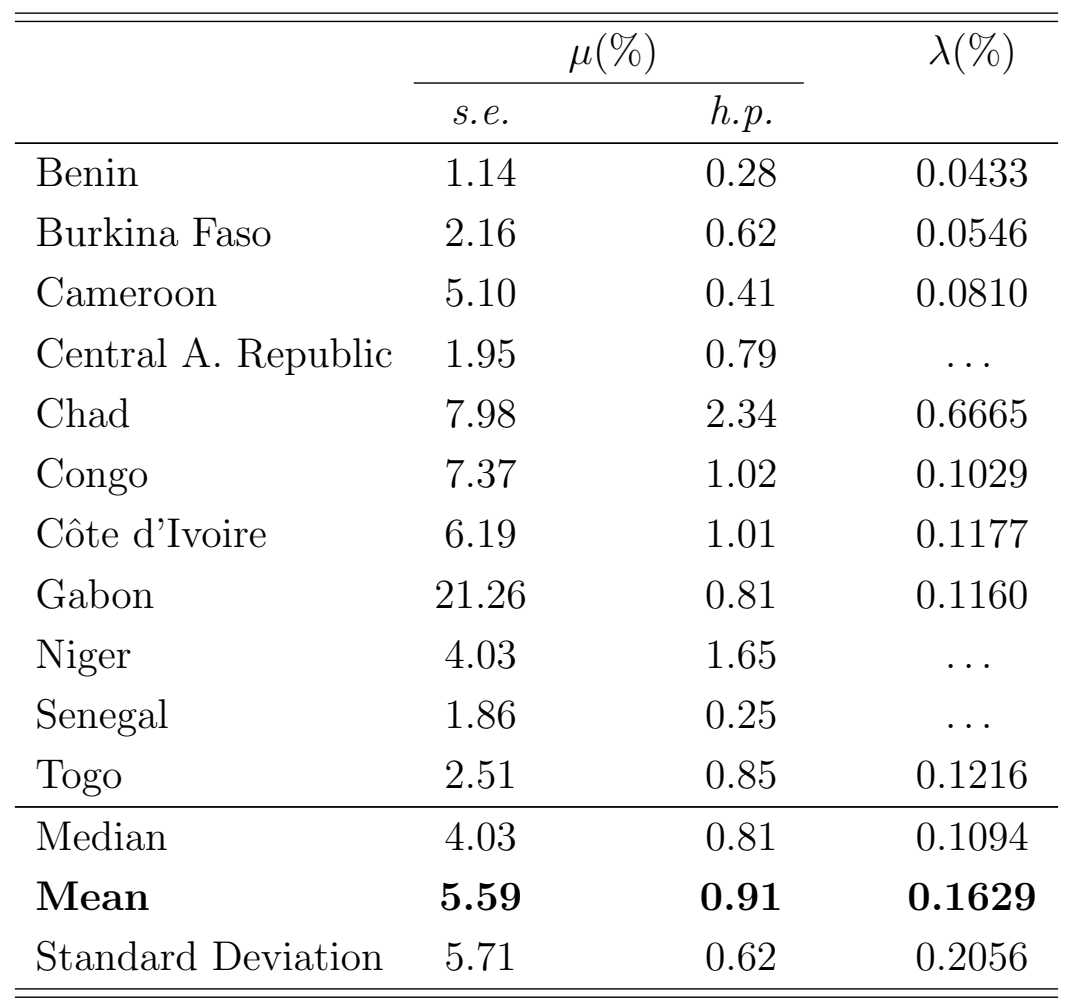

Note: see Table (2.3). 
Table 2.E.12: Estimates of Welfare Costs in Non-CFA Countries

\begin{tabular}{lccc}
\hline \hline & \multicolumn{2}{c}{$\mu(\%)$} & $\lambda(\%)$ \\
\cline { 2 - 3 } & s.e. & $h . p$. & \\
\hline Botswana & 4.54 & 1.12 & 0.0381 \\
Burundi & 7.72 & 0.95 & 0.1131 \\
Cabo Verde & 2.64 & 0.83 & 0.0432 \\
Comoros & 2.59 & 0.55 & 0.0524 \\
Democratic R. of Congo & 11.71 & 1.51 & $\ldots$ \\
Ethiopia & 5.61 & 1.10 & 0.0711 \\
The Gambia & 4.26 & 1.45 & 0.3828 \\
Ghana & 5.95 & 0.94 & 0.1283 \\
Guinea & 1.24 & 0.48 & 0.0475 \\
Kenya & 1.47 & 0.49 & 0.0619 \\
Lesotho & 5.12 & 0.94 & 0.0499 \\
Madagascar & 1.60 & 0.25 & $\ldots$ \\
Malawi & 1.59 & 0.87 & 0.0795 \\
Mauritania & 20.00 & 4.25 & 0.5445 \\
Mauritius & 3.89 & 1.31 & 0.0776 \\
Mozambique & 7.33 & 0.46 & 0.0439 \\
Namibia & 4.38 & 0.61 & 0.0011 \\
Nigeria & 10.10 & 2.47 & 0.4741 \\
Rwanda & 6.38 & 1.12 & 0.1633 \\
Sierra Leone & 9.95 & 2.28 & 0.8237 \\
South Africa & 1.34 & 0.11 & 0.0515 \\
Tanzania & 1.68 & 0.55 & 0.0381 \\
Uganda & 11.52 & 0.39 & 0.0933 \\
Zambia & 11.35 & 1.54 & 0.4524 \\
Zimbabwe & 13.31 & 3.60 & 2.5469 \\
\hline Median & 5.12 & 0.94 & 0.0776 \\
Mean & $\mathbf{6 . 2 1}$ & $\mathbf{0 . 2 7 7}$ \\
\hline \hline & & & 0.5383 \\
\hline
\end{tabular}

Note: see Table (2.3). 


\section{Appendix 2.F: First Sub-Period:1960-1985}

Table 2.F.13: Estimates of Welfare Costs in CFA Countries

\begin{tabular}{lcc}
\hline \hline & \multicolumn{2}{c}{$\mu(\%)$} \\
\cline { 2 - 3 } & s.e. & h.p. \\
\hline Benin & 0.76 & 0.43 \\
Burkina Faso & 1.40 & 0.89 \\
Cameroon & 1.82 & 0.42 \\
Central A. Republic & 0.53 & 0.38 \\
Chad & 6.28 & 4.53 \\
Congo & 2.71 & 0.72 \\
Côte d'Ivoire & 0.71 & 1.19 \\
Gabon & 2.53 & 0.98 \\
Niger & 6.55 & 3.23 \\
Senegal & 1.10 & 0.36 \\
Togo & 2.79 & 0.73 \\
\hline Median & 1.82 & 0.73 \\
Mean & $\mathbf{2 . 4 7}$ & $\mathbf{1 . 2 6}$ \\
Standard Deviation & 2.11 & 1.35 \\
\hline \hline
\end{tabular}

Note: see Table (2.3). 
Table 2.F.14: Estimates of Welfare Costs in Non-CFA Countries

\begin{tabular}{lcc}
\hline \hline & \multicolumn{2}{c}{$\mu(\%)$} \\
\cline { 2 - 3 } & s.e. & $h . p$. \\
\hline Botswana & 2.51 & 0.93 \\
Burundi & 0.99 & 0.67 \\
Cabo Verde & 2.78 & 1.30 \\
Comoros & 0.75 & 0.27 \\
Democratic R. of Congo & 4.12 & 0.89 \\
Ethiopia & 1.51 & 0.97 \\
The Gambia & 2.39 & 1.12 \\
Ghana & 2.36 & 1.22 \\
Guinea & 0.93 & 0.37 \\
Kenya & 1.03 & 0.69 \\
Lesotho & 3.94 & 1.73 \\
Madagascar & 1.37 & 0.34 \\
Malawi & 0.67 & 0.37 \\
Mauritania & 20.54 & 8.56 \\
Mauritius & 3.58 & 2.40 \\
Mozambique & 2.28 & 0.21 \\
Namibia & 1.08 & 0.69 \\
Nigeria & 7.27 & 2.36 \\
Rwanda & 1.43 & 0.96 \\
Sierra Leone & 1.33 & 0.65 \\
South Africa & 0.43 & 0.11 \\
Tanzania & 1.38 & 0.29 \\
Uganda & 3.60 & 0.56 \\
Zambia & 4.98 & 1.32 \\
Zimbabwe & 2.88 & 1.84 \\
\hline Median & & 0.89 \\
Mean & 3.28 \\
\hline \hline
\end{tabular}

Note: see Table (2.3). 


\section{Appendix 2.G: Second Sub-Period:1986-2014}

Table 2.G.15: Estimates of Welfare Costs in CFA Countries

\begin{tabular}{lcc}
\hline \hline & \multicolumn{2}{c}{$\mu(\%)$} \\
\cline { 2 - 3 } & s.e. & h.p. \\
\hline Benin & 0.47 & 0.14 \\
Burkina Faso & 1.42 & 0.39 \\
Cameroon & 3.01 & 0.19 \\
Central A. Republic & 1.82 & 1.16 \\
Chad & 3.21 & 0.33 \\
Congo & 5.71 & 0.68 \\
Côte d'Ivoire & 1.67 & 0.53 \\
Gabon & 3.05 & 0.51 \\
Niger & 0.53 & 0.12 \\
Senegal & 1.11 & 0.15 \\
Togo & 1.09 & 0.98 \\
\hline Median & 1.67 & 0.39 \\
Mean & $\mathbf{2 . 1 0}$ & $\mathbf{0 . 4 7}$ \\
Standard Deviation & 1.54 & 0.35 \\
\hline \hline
\end{tabular}

Note: see Table (2.3). 
Table 2.G.16: Estimates of Welfare Costs in Non-CFA Countries

\begin{tabular}{lcc}
\hline \hline & \multicolumn{2}{c}{$\mu(\%)$} \\
\cline { 2 - 3 } & s.e. & $h . p$. \\
\hline Botswana & 2.62 & 0.85 \\
Burundi & 12.60 & 1.24 \\
Cabo Verde & 1.24 & 0.39 \\
Comoros & 2.35 & 0.79 \\
Democratic R. of Congo & 17.67 & 1.89 \\
Ethiopia & 3.98 & 1.01 \\
The Gambia & 2.53 & 1.71 \\
Ghana & 1.10 & 0.61 \\
Guinea & 1.35 & 0.60 \\
Kenya & 0.46 & 0.19 \\
Lesotho & 0.41 & 0.26 \\
Madagascar & 0.61 & 0.20 \\
Malawi & 1.64 & 1.16 \\
Mauritania & 1.74 & 0.44 \\
Mauritius & 0.32 & 0.16 \\
Mozambique & 2.82 & 0.63 \\
Namibia & 3.23 & 0.56 \\
Nigeria & 2.94 & 2.41 \\
Rwanda & 8.02 & 1.35 \\
Sierra Leone & 12.46 & 3.80 \\
South Africa & 0.90 & 0.12 \\
Tanzania & 1.36 & 0.62 \\
Uganda & 0.52 & 0.29 \\
Zambia & 12.41 & 1.65 \\
Zimbabwe & 19.75 & 5.16 \\
\hline Median & 2.35 & 0.63 \\
Mean & & 1.19 \\
\hline \hline
\end{tabular}

Note: see Table (2.3). 


\title{
Chapter 3
}

\section{Structural Breaks, Growth and the Welfare Cost of Business Cycles}

\begin{abstract}
Macroeconomic fluctuations affect almost all countries across all continents and across all income categories, albeit very differently. Developing countries in general bear the brunt of those aggregate fluctuations, as largely acknowledged by the development macroeconomic literature. This paper combines a robust recursive preference framework and a strong structural break algorithm to infer on both the welfare gains from entirely eliminating consumption fluctuations and the welfare gains from an additional percentage point increase of consumption growth forever. Annual data for 37 Low-Income and Lower-Middle-Income countries - of which 24 are located in sub-Saharan Africa consistently indicate that the gains from boosting consumption growth transcend the gains from consumption stabilisation. This backs up the decades-long growth-enhancing policies in developing countries. Second, and central to our quest, the paper also shows that structural breaks do not matter for the welfare gains from eliminating consumption fluctuations while they consistently do when the welfare gains from an additional percentage point of consumption growth are concerned.
\end{abstract}

Keywords: Business Cycles, Growth, Welfare, Structural Breaks, Mean-Comparison.

JEL Classification: C12, C33, C41, E52, F42.

\footnotetext{
${ }^{0}$ This chapter was submitted for the forthcoming African Integration and Development Review and was successively presented at the First Catalan Economic Society Conference, and at the $5^{\text {th }}$ Congress of African Economists. We gratefully acknowledge the help of Stéphane Pallage from the Université du Québec à Montréal (UQÀM) for providing some of the codes used for the calibration of the recursive model included in this article. All the typos and mistakes herein are those of the author.
} 


\subsection{Introduction}

Preferences modelling has been one of the most buoyant exercise for macroeconomists throughout the last six and plus decades. The wide variety of these preferences reflect the structural difficulty to parameterise human behaviour in general. Of the plethora of possible formulations, the Constant Relative Risk Aversion (CRRA) and the Von NeumannMorgenstern preferences have perhaps been some of the most popular and used utility functions in applied macroeconomics in recent times. Von Neumann and Morgenstern (1953) in particular laid down the foundations for the expected utility theorisation, by showing that, under certain axioms of rational behaviour, a decision-maker (often a consumer) faced with probabilistic outcomes of different choices will behave as if he is maximising the expected value of some function, defined over the potential outcomes at some specified point in the future. These expected utilities have been used in some of the most seminal applied macroeconomic debates in recent years, such as the Real Business Cycle (RBC) theory of Kydland and Prescott (1982), the equity premium puzzle of Mehra and Prescott (1985), or the welfare cost of business cycles debate pioneered by Lucas (1987). ${ }^{1}$

However, on the specific issue of the welfare cost of business cycles, a mounting body of research has challenged Lucas (1987)'s early findings, on several grounds, but particularly on his preferred model of consumers' utility parameterisation. The key message of Lucas (1987) was to conclude that as far as the postwar United States was concerned, consumers would sacrifice at most 0.1 percent of their lifetime consumption, leading him to focus his own research agenda on long-term economic growth rather than short-term aggregate fluctuations. Obstfeld (1994) argues that in a context of intertemporal optimisation, the weights consumers use to cumulate the per-period costs of risks with persistent effects, depend both on the intertemporal substitutability as well as on risk aversion. As such, in dynamic stochastic welfare comparisons, the intertemporal elasticity of substitution (IES) should clearly be distinguished from the risk aversion parameter, if one wants to avoid misleading assessments of the impact of risk aversion on the welfare cost of consumption-risk changes. Additionally, Obstfeld (1994) considers that when shocks are persistent over future periods, the discount rate of their static welfare costs increases with the degree of intertemporal substitutability. As such, a higher IES would imply a larger welfare cost of fluctuations for reasons that are not necessarily inherent to the risk aversion parameter. This is the main reason why the recursive formulation of consumers' preferences à la Epstein and Zin (1989) does a better job in assessing the welfare cost of business cycles than the standard CRRA function, given that the later assumes that the IES is the inverse of the constant risk aversion parameter. This class of utility functions is specifically framed around two key components, as shown by Dolmas (1998): a time aggregator that characterises the preferences in the total absence of uncertainty and a risk

\footnotetext{
${ }^{1}$ The welfare cot of business cycles is defined by Imrohoroglu (1989) as the percentage increase in consumption across all dates and states that would be necessary to make a representative consumer indifferent between a smooth consumption stream and one that is subject to aggregate fluctuations.
} 
aggregator that outlines the certainty equivalent function that characterises preferences over static gambles. The latest major contribution to the literature of welfare cost of business cycles using a recursive Epstein and Zin (1989) preference comes from Ellison and Sargent (2015), who investigate the question using a small noise expansion in a model built to account for fear of misspecification. ${ }^{2}$

Most of the estimates of the welfare cost of business cycles discussed or not mentioned at all in this paper have been for the postwar U.S. economy. Overall, one can reasonably argue over the true welfare cost of macroeconomic fluctuations in the United States to be relatively modest, if not negligible, as initially claimed by Lucas (1987). ${ }^{3}$ The low cost estimates obtained in most of the post-Lucas (1987) literature stems mainly from the fact that the U.S. economy since the 1950s has been relatively stable. What is less debatable however is the sheer magnitude of aggregate fluctuations in developing countries compared to the industrialised world. In particular, the volatility of output in developing countries ranges from two to six times that in the United States (Mendoza, 1995; Carmichael et al., 1999; Agenor et al., 2000). What about the welfare cost of macroeconomic fluctuations in developing countries? Few studies have really explored that question, with the noticeable exception of Pallage and Robe (2003). Using a three-model economy, encompassing a CRRA and an Epstein and Zin (1989) preferences, a stationary auto-regressive and a finite-state Markov chain processes for per capita consumption, Pallage and Robe (2003) showed that the median welfare cost of business cycles in Africa is 10 to 30 times larger than that of the United States. Additionally, they argue that the welfare gain from eliminating aggregate fluctuations in Africa may be so large as to exceed that of receiving an additional 1 percent of growth forever, which suggests the crucial importance of macroeconomic stabilisation policies in developing countries. We follow Pallage and Robe (2003) by focusing on 37 developing countries, of which 24 are located in sub-Saharan Africa and by estimating not only the welfare gains from stabilisation but also those from growth-enhancing.

Why are developing countries more prone to fluctuations? The literature has traditionally attributed the huge volatility of the developing world as seeming to stem from three main sources. First, they face bigger external shocks (capital flows, terms of trade, world interest rate). Second, they seem to experience more domestic shocks, often generated by the intrinsic instability of the development process and self-inflicted policy mistakes. Third, developing countries have weaker "shock stabilisers" in the forms of diversified financial markets and macroeconomic stabilisation policies. The literature suggests three strategies to deal with volatility. First, reducing the level an variability of fiscal expenditures, keeping inflation low and stable, and avoiding price rigidity, mostly

\footnotetext{
${ }^{2}$ Houssa (2013) is another noticeable recent contribution as he departs from the traditional estimation techniques with his use of Bayesian inference.

${ }^{3}$ Congruent with that conclusion, the literature on international risk sharing shows that computational estimates of the welfare gains from better international insurance rely heavily on the underlying economy (Van Wincoop, 1994).
} 
that of the exchange rate (Loayza et al., 2007). Second, strengthening the economy's shock absorbers, and allowing a floating exchange rate regime. Third, managing directly the shocks, following the Ehrlich and Becker (1972) classic "comprehensive insurance" framework.

Compared to the developed world, little attention has been given to the study of macroeconomic fluctuations in developing countries. While industrialised countries' business cycles stylised facts are well-established, the set of empirical studies on the stylised facts of developing countries' business cycles remains very limited. Those stylised facts have been originally surveyed by Agenor et al. (2000), Rand and Tarp (2002), Neumeyer and Perri (2005), Aguar and Gopinath (2007), and more recently by Male (2010), whose extension and generalisation of the early stylised facts encompass three main themes: the volatility, the persistence and the cyclicality. Regarding the first point, output is more volatile by a factor of two or three in developing countries than in developed countries. Consumption is on average $30 \%$ more volatile than output, while investment volatility is about two to four times the one of the output. Government expenditures and revenues are significantly more volatile in the developing countries and they are almost four times more volatile than the aggregate output. Investment volatility in developing countries is nearly two to three times higher than output volatility and of a similar level to that in the developed countries. Trade balance is around three times more volatile than output, with a higher magnitude in developing countries. Imports, exports and the terms of trade follow the similar pattern of trade balance. Regarding the second theme addressed by Male (2010), output and real exchange rates fluctuations are significantly persistent both in developed and developing countries, though the magnitude of that persistence of that persistence is somewhat lower in the latter. Prices and wages are significantly persistent in developing countries and this finding justifies the use of theoretical models with sticky prices and wages for the modeling of developing countries' business cycles (Agenor et al., 2000; Male, 2010). As for the last point, output fluctuations in developing countries are strongly correlated with the economic activities in the developed countries. Real wages are counter-cyclical in developing and developed countries. There is a positive relationship between output and both public and private consumption in developing countries. Investment is strongly pro-cyclical. Government revenues are pro-cyclical while its expenditures are significantly counter-cyclical. Broad money is counter-cyclical in the majority of developing countries. Imports and exports are strongly pro-cyclical in the developed countries, and in the majority of the developing countries. Terms of trade are counter-cyclical for the developed countries while they are pro-cyclical for the majority of developing countries. Finally, it is noticeable that nominal and real effective exchange rates are counter-cyclical in developed countries and both variables exhibit the same cyclical relationship in developing countries.

This paper combines the structural break approach inspired from Andrews (1993), and the recursive preference specifications developed by Epstein and Zin (1989) to ar- 
gue that the welfare gains for developing countries from increasing consumption growth forever consistently and robustly exceed the welfare gains from stabilising consumption fluctuations entirely. This suggests that what appears to be at first glance a developingcountry conundrum between simultaneously controlling adverse fluctuations and improving growth is not exactly as such. To make this case, we use an optimisation model in which consumers are subject to aggregate shocks and ask what happens when consumption series feature trend-changing unknown structural breaks. The framework of the model builds on Obstfeld (1994), Dolmas (1998), Pallage and Robe (2003), and to some extent Bluhm et al. (2016). To get the discrete versions of the national per capita consumption series, we apply the finite state Markov-chain approximations to univariate and multivariate auto-regressions developed by Tauchen (1986). ${ }^{4}$ Most importantly, we find that the null hypothesis of the equality between the sample averages of the welfare cost of business cycles for the general and the restricted models of recursive preference specifications is not rejected. This implies that in the context of an Epstein and Zin (1989) preference specification, unique structural breaks do not matter when it comes to the interpretation of the sample average welfare cost of business cycles, especially when such sample exhibits a high degree of homogeneity. Conversely, the two-tail probability of the test equating the sample averages of the welfare gains from growth between the general and the restricted models is significant and is robustly skewed to the left. The overarching and cardinal implication of this result is that structural breaks do matter for growth, exactly as proposed by Pritchett (2000)'s seminal works with his identification and classification of various growth regimes. And in the specific context of this analysis, the average welfare gain from an additional one percent of yearly consumption becomes higher when structural breaks for each individual country are taken into account.

The most important contribution of this paper is to bring into the fray the concept of structural breaks. While most of the previous literature - from Lucas (1987), to Imrohoroglu (1989) or Barlevy (2004), just to mention the few - have explored the question of the welfare cost of business cycles from a steady perspective, we argue that the consumption series do not evolve according to an ever-lasting uninterrupted trend. This idea is not entirely new. In fact the argument of structural breaks has been vividly put forward and explored recently in macroeconomic time series, especially for the gross domestic product series (Ben-David and Papell, 1995; Jones and Olken, 2008; Papell and Prodan, 2014). The intuition for this observation stems from the fact that growth often consists of qualitatively different episodes, such as crises, recoveries, periods of stagnation, and sudden accelerations. This prompted Pritchett (2000) to provide a classification of the postwar United States growth experiences into "Hills, Plateaus, Mountains, and Plains". Ever since, a growing literature has analysed the features and specifics of different types

\footnotetext{
${ }^{4}$ Tauchen (1986) belongs to a class of econometric time series approximations which also includes Rouwenhorst (1995), who proposes an alternative discretisation methodology for highly persistent processes.
} 
of growth episodes, often using statistical tests of structural stability - successively developed by Bai (1997), Bai and Perron (1998) and Bai (1999) - to define, locate and properly identify the episode of interest.

The remainder of the article is organised as the following: Section (3.2) discusses the theoretical framework underlying the analysis; Section (3.3) presents different estimations and the results of the calibrations; Section (3.4) gives the benchmark mean-comparison tests; Section (3.5) provides the robustness checks; and Section (3.6) concludes.

\subsection{Theoretical Framework}

\subsubsection{Model Economy}

The model used here is a refinement of Obstfeld (1994), Dolmas (1998), and to some extent Pallage and Robe (2003), as well as Houssa (2013). Unlike the original Lucas (1987)'s framework, the building blocks of the model borrow from the recursive preference à la Epstein and Zin (1989) and a stationary auto-regressive process of order one for the consumption growth factor. To these ingredients, the structural breaks from Bai and Perron (1998) are added.

\section{Consumption Process}

The model is set in discrete time, which suggests that all variables mentioned are defined at specific dates (i.e., $t=0,1,2, \ldots, T)$. For a per capita consumption stream $\left\{C_{t}, \forall t=0,1,2, \ldots, T\right\}$, let's denote by $\Psi=\frac{C_{t}}{C_{t-1}}$ the growth factor of $C_{t}$. In addition, let's assume like Pallage and Robe $(2003)$ that $\Psi_{t}$ follows an auto-regressive process of order one of the form:

$$
\Psi_{t}=\underbrace{\left(1-\varphi_{1}\right)(1+g)}_{\varphi_{0}}+\varphi_{1} \Psi_{t-1}+\epsilon_{t}
$$

where $\varphi_{0}$ is the constant term of the auto-regressive process, $\varphi_{1}$ its persistence parameter, and $g=\left\{\frac{\varphi_{0}}{1-\varphi_{1}}-1\right\}$ is the unconditional mean of the process. Finally, $\epsilon_{t}$ is the independently and identically distributed (i.i.d.) Gaussian white noise defined as $\epsilon_{t} \sim \mathcal{N}\left(0, \sigma_{\epsilon}^{2}\right)$. The process (3.1) is similar to the model in Dolmas (1998) and when the persistence parameter $\varphi_{1}$ is not significantly different from zero, it becomes similar to the model developed by Obstfeld (1994). The common feature across all these specifications is to take stock of the random walk hypothesis for the consumption process, which is equivalent of saying that the natural logarithm of per capita consumption $\left\{\ln C_{t}\right\}$ follows a random walk process. ${ }^{5}$

\footnotetext{
${ }^{5}$ The random walk hypothesis for consumption was first hypothesised by Hall (1988), as an answer to the Lucas critique. It later got confirmed by further empirical studies (see, for example, Nelson and Plosser (1982), Ogaki (1992), and Cooley and Ogaki (1996)).
} 


\section{Consumers' Preference}

The original calculations of the welfare cost of business cycles by Lucas (1987) and Imrohoroglu (1989) heavily rely on the role of the consumers' degree of risk aversion embedded in their preferences. ${ }^{6}$ While Lucas (1987)' calculations were based on a Constant Relative Risk Aversion (CRRA) utility function, Obstfeld (1994), and later on Dolmas (1998), Houssa (2013), and Ellison and Sargent (2015) adopted a martingale consumption process and recursive lifetime preferences à la Epstein and Zin (1989). Assuming this new setting, Obstfeld (1994) considers that when shocks are permanent, then a fall in consumption today is expected to persist ad vitam aternam, and he found that the cost of business cycles can be as much as 1.8 percent of lifetime consumption. ${ }^{7}$ Dolmas (1998) shows that the cost of fluctuations can be even larger - over 20 percent of lifetime consumption - when shocks are permanent and when individual preferences exhibit first-order risk aversion. Using Bayesian estimates for welfare effects of consumption fluctuations and economic growth, Houssa (2013) argues that a great deal of caution is needed when drawing conclusions from point estimates of welfare costs of business cycles. More recently, Ellison and Sargent (2015) combine the insights of de Santis (2007) on the double aggregate and idiosyncratic nature of shocks and the intuition of Barillas et al. (2009) about the agents' fear of model misspecification, and conclude that the welfare costs of business cycles are important and larger than previously thought by Lucas (1987). A specific mention has to be given to Alvarez and Jermann (2005) who took a completely different route to evaluate the welfare cost of business cycles. They used a non-parametric approach to evaluate the potential gains from stabilisation policy, relating the marginal cost of business cycle risk to observed market prices without ever committing to a utility function and found much higher estimates than Lucas (1987).

By assuming that the economy is populated by a continuum of infinitely lived, identical individuals of mass one, the perfect example of recursive utility corresponds to the preferences à la Epstein and Zin (1989) of the form:

$$
U_{t}=\left(C_{t}^{1-\theta}+\beta\left[\mathbf{E}\left(U_{t+1}^{1-\gamma}\right)\right]^{\frac{1-\theta}{1-\gamma}}\right)^{\frac{1}{1-\theta}},
$$

which is an increasing, concave, and homogeneous function of degree one in per capita consumption $C_{t}$. The scalar $\beta \in(0,1)$ is a constant discount factor, $\gamma(0<\gamma \neq 1)$ the coefficient of relative risk aversion, and $1 / \theta(0<\theta \neq 1)$ the IES for the deterministic consumption paths. ${ }^{8}$

\footnotetext{
${ }^{6}$ Lucas (1987)'s baseline formula for the welfare cost of business cycles is given by: $\mu=\frac{1}{2} \sigma^{2} \theta$; where $\sigma$ is the standard deviation of the natural logarithm of per capita consumption and $\theta$ is a measure of the degree of risk aversion.

${ }^{7}$ For all positive values of the positive mean adjusted growth rates that result holds. However, when the mean adjusted growth rate is negative, the opposite relationship could be true (Obstfeld, 1994).

${ }^{8}$ When the coefficient of relative risk aversion and the intertemporal elasticity of substitution are identical (i.e., $\gamma \equiv \theta$ ) then the recursive function $U_{t}$ takes the form of a CRRA preference: $U_{t}=$ $\mathbf{E} \sum_{s=0}^{\infty} \beta^{s} \frac{1}{1-\gamma} C_{t+s}^{1-\gamma}$.
} 


\subsubsection{Welfare Effects and Gains from Growth}

$\lambda \equiv \lambda\left(\varphi, \sigma_{\epsilon}^{2}, g\right)$ denotes the welfare effect of consumption fluctuations or the compensatory factor, which depends on the parameters of the auto-regressive process (3.1), the variance of the white noise error term, and the time-invariant long-term growth rate. As in Lucas (1987), $\lambda$ is defined as the percentage increase in consumption, across all states and dates, required to leave the representative consumer indifferent between the risk-free and smooth trend of consumption and the consumption path subject to fluctuations. It could also be defined as the representative consumer's willingness to pay in order to eliminate all volatility in consumption or as the welfare gain that would be obtained if consumption were to be completely stabilised. Equivalently, let $\zeta \equiv \zeta\left(\varphi, \sigma_{\epsilon}^{2}, g\right)$ denote the welfare gains from an additional one percent of yearly consumption growth. Just like $\lambda$, it measures the additional consumption, across all dates and states, that the representative agent would obtain if the trend growth $g$ is increased by one percent.

The calculation of $\lambda$ and $\zeta$ follows from the value function iteration method employed in Dolmas (1998). The recursive utility function could be rewritten as:

$$
v\left(\Psi_{t}\right)=\left(1+\beta\left[\mathbf{E}\left(\Psi_{t+1} v\left(\Psi_{t+1}\right) \mid \Psi_{t}\right)^{1-\gamma}\right]^{\frac{1-\theta}{1-\gamma}}\right)^{\frac{1}{1-\theta}},
$$

where $\Psi_{t}=\frac{C_{t}}{C t-1}$, and $v\left(\Psi_{t}\right)$ is a normalised value function defined as $C_{t} v\left(\Psi_{t}\right)=V\left(C_{t}, \Psi_{t}\right)$ with $V\left(C_{t}, \Psi_{t}\right) \equiv U_{t}$. The stochastic consumption process in equation (3.1) is approximated by a finite state Markov chain process with the methodology proposed by Tauchen (1986). As such, the normalised value functions can be expressed in terms of discrete values of consumption growth $\left\{\tilde{\Psi}^{1}, \tilde{\Psi}^{2}, \ldots, \tilde{\Psi}^{n}\right\}$ across $n$ states. Subsequently, the discrete normalised value functions are solved in an iterative way until successive values differ by no more than $10^{-8}$.

After solving the normalised value functions, the welfare cost of consumption fluctuations gives: ${ }^{10}$

$$
\lambda=\frac{v_{d e t}}{v_{\text {sto }}}-1
$$

where $v_{\text {det }}=\left[\frac{1}{1-\beta(1+g)^{1-\theta}}\right]^{\frac{1}{1-\theta}}$ is the normalised value function for the deterministic consumption path obtained by plugging the deterministic consumption growth factor $\Psi$ in $v\left(\Psi_{t}\right)$, and $v_{s t o}$ is the corresponding value function for the stochastic consumption process. In particular, $v_{\text {sto }}$ is estimated as the weighted average of the normalised value functions across the $n$ states, where the weights are the invariant probabilities $\pi_{j}$ (for $j=1, \ldots, n$ ). Formally:

$$
v_{s t o}=\sum_{j=1}^{n} \pi_{j} v\left(\tilde{\Psi}^{j}\right)
$$

\footnotetext{
${ }^{9}$ In dynamic programming, and under Blackwell (1965)' sufficient conditions, it could be shown that the value function iteration method ultimately leads to a unique solution, as argued by Stokey et al. (1989) and Ljungqvist and Sargent (2000) among others.

${ }^{10}$ The value of $\lambda$ is obtained by assuming the homogeneity of the utility consumption.
} 
The computation of the welfare benefit of an additional one percent of yearly consumption growth is carried out in a similar fashion. The new process for consumption growth identical to the one proposed in Pallage and Robe (2003) - can be written as:

$$
\Psi_{t}=\left(1-\varphi_{1}\right)(1+g+0.01)+\varphi_{1} \Psi_{t-1}+\epsilon_{t}
$$

After approximating this extended auto-regressive process by a finite-state Markov state, and solving for the corresponding value function $v^{g}\left(\Psi_{t+1}\right)$ together with the new unconditional probability distribution $\pi_{j}^{g}$, the welfare gain of the additional percentage point of growth, $\zeta$, is then:

$$
\zeta=\frac{\sum_{j=1}^{n} \pi_{j}^{g} v^{g}\left(\tilde{\Psi}^{j}\right)}{\sum_{j=1}^{n} \pi_{j} v\left(\tilde{\Psi}^{j}\right)}-1,
$$

To define the finite state Markov chain, which stands as an approximation of the stochastic consumption process, two problems need first to be solved: finding the appropriate length $p$ of the auto-regressive process and determining the right number of discrete states $n$. With respect to the lag length, we choose an $A R(1)$, and calibrate the model for each country, to match moments of the real per capita consumption growth series. The mean growth rate of $g$, the persistence parameter $\varphi_{1}$, and the residual variance $\sigma_{\epsilon}^{2}$ are all obtained from a standard $A R(1)$ fit. When the persistence parameter $\varphi_{1}$, is not statistically significant, the other parameters are re-estimated by regressing the consumption growth rate on a constant. All countries with a negative mean growth rate $(g<0)$ are not considered for the estimations, given that their consumption streams converge to zero. Table (3.1) summarises the regression results for the remaining 37 countries. This approach borrows from Pallage and Robe (2003). The discretisation of the auto-regressive process in equation (3.1) is done following the methodology proposed by Tauchen (1986). He shows that a continuous auto-regressive process can be approximated by a finite-state Markov chain. The approximation becomes arbitrarily close to the original process, the finer the grid of state variables is defined. ${ }^{11}$ This therefore requires identifying a certain space of state variables together with a transition probability matrix congruent with the features of the auto-regressive process. As for the number of discrete states, $n$ is chosen such that the new discretised variables mimic as much as possible the behaviour of the original process. ${ }^{12}$

\subsubsection{Structural Breaks}

In macroeconomic time series such as the per capita consumption data used in this paper, the possibility of unexpected shifts in the mean or the variance in the series exists and

\footnotetext{
${ }^{11}$ For highly persistent processes (i.e. $\varphi_{1}>0.9$ ), Rouwenhorst (1995) proposes a different discretisation method, which will not be used in this analysis. Appendix 3.B provides the details for a univariate approximation of an $A R(1)$ process, as exactly developed by Tauchen (1986).

${ }^{12}$ As shown by Otrok et al. (2002), in general, a good approximation is found when the number of discrete states is set to be $n=19$ for the $A R(1)$ processes and $n=5^{p}$ for the $V A R(1)$ processes. We choose $n=50$, just like Pallage and Robe (2003).
} 
should be considered seriously. These unexpected shifts are referred to as structural breaks and could eventually lead to major forecasting errors and a likely unreliability of the model considered. In case the model is linear with a unique known break in the mean, the Chow test (Chow, 1960) has for decades been the classic test, while the Hartley test (Hartley, 1950) was the equivalent test in the situations where the single break in mean is not exactly known.

The method followed in this paper to identify the shifts, constructs a test statistic for a structural break without imposing a known break date by combining the test statistics computed for each break date in the sample. It uses the maximum Wald test at the possible break dates. The limiting distribution of this supremum Wald test is known but non-standard, and depends on an unknown break date, which is not identified under the null hypothesis of no structural break. ${ }^{13}$ The main intuition behind the class of tests such as the supremum Wald statistic is to compare the maximum sample test with what could be expected under the null hypothesis (Quandt, 1960; Kim and Siegmund, 1989; Andrews, 1993).

Almost all the structural break tests proposed by the literature are to some degree a function of the sample statistics computed over a finite range of possible break dates. However, not all sample observations can be tested and registered as break dates given that there are often insufficient observations to estimate the parameters for dates too close to the start or to the end of the sample. This recurrent identification problem is taken care of by trimming, which discards the observations too near the beginning or the end of the sample from the set of possible break dates. Among others, Andrews (1993) recommends a symmetric trimming of $15 \%$ when there is no available information on good and reliable trimming values. ${ }^{14}$

The baseline structural change model of the per capita consumption series is the following:

$$
C_{t}=\psi_{0}+\kappa_{0} \mathbb{1}\left(t \leq T_{1}\right)+\kappa_{1} \mathbb{1}\left(t>T_{1}\right)+\psi_{1} C_{t-1}+\nu_{t}
$$

where $C_{t}$ is the per capita consumption at year $t, T_{1}$ is the potential unique structural break of consumption, $\mathbb{1}(\cdot)$ is the classic indicator function, while $p$ is the lag order as determined by the optimal $A R(p)$ model, and $\nu_{T}$ is the error term. The iteration approach is used to determine the optimal lag, and when none of the candidate models is significant at the 10 percent level, per capita consumption is directly regressed on the constant. Alternatively, the Akaike Information criterion (AIC) or the Bayesian Information Criterion (BIC) could have informed about the optimal lag. The structural break being unique, there is no need to add an additional requirement regarding the distance between different break points.

The partial structural change model of equation (3.8) formalises the idea that the

\footnotetext{
${ }^{13}$ Davies (1987) provides a seminal treatment for this discussion.

${ }^{14}$ Perron (2006) provides an excellent survey on the literature about the inherent properties of the implemented structural break tests.
} 
evolution of per capita consumption is potentially a function of time split into two subperiods: the pre-structural break $\left(t \in\left[t_{0}, T_{1}\right]\right)$ and the post-structural break $\left.\left.(t \in] T_{1}, T\right]\right)$, where $t_{0}$ and $T$ represent the initial and final dates of the series. The exact location of the breakpoint $T_{1}$ is not known at first but estimated within the model. $T_{1}$ is not assumed to specifically precede a slump or a spurt in consumption. Therefore, all the parameters of the model are unrestricted and allowed to be either positive, negative, or not significantly different from zero.

The sequential break search algorithm adopted here to estimate $T_{1}$ draws indirectly from Andrews (1993) and to some extent from Bluhm et al. (2016), with the sole difference that the series are not identical and that the supremum Wald ( $\sup -W$ ) statistic here is not bootstrapped. First, the structural change model specified in equation (3.8) is estimated according to the iterative process previously described. The trimming algorithm ensures that $5 \%$ of the observations at the start and at the end of the sample are excluded, in order to avoid estimating spurious breaks. Second, the supremum Wald test statistic is computed, to test the null hypothesis of no structural change in the per capita consumption series $\left(\mathbb{H}_{0}: \kappa_{0}=\kappa_{1}=0\right)$. If the sup- $W$ test rejects the null hypothesis at the $10 \%$ significance level, the estimated break date $\hat{T}_{1}$ is recorded and the sample is split into a series running until the break, and a series starting right after the break. Appendix 3.A provides the formal description of the break search algorithm inspired from Bluhm et al. (2016).

One thing that this paper will not do is to try define and characterise the structure and evolution of consumption before and after the break. This therefore allows for a higher degree of flexibility and assumes that the series could adopt all forms of growth regimes, as identified by Pritchett (2000). The main assumption underlying the framework here is the random walk hypothesis, which is equivalent of assuming that the natural logarithm of per capita consumption $\left\{\ln C_{t}\right\}$ follows a random walk process. ${ }^{15}$ Thus the consumption series are allowed to be the residuals of any type of growth model: neoclassical steady-state model, endogenous model, or any other empirically relevant standard growth model.

When confronted to the real data, the sequential algorithm for structural break estimation explained here identifies 25 statistically robust break dates for the sample of 37 developing countries covered. Although there is no special pattern regarding the location and distribution of the breaks, the earliest ones occur in 1976 (Bangladesh, Zambia), while the latest breaks happen in 2007 (Nigeria, Zimbabwe). The algorithm also identifies some historical shifts in national consumption series. Two of these historical breaks concern Bolivia, and Burkina Faso. Figure (3.1) below illustrates those breaks for Burkina Faso (Panel (a)) and Bolivia (Panel (b)). The figure displays the natural logarithm of per capita consumption from 1960 to 2014. The algorithm credibly identifies 1995 and 1984

\footnotetext{
${ }^{15}$ The random walk hypothesis for consumption was first hypothesised by Hall (1988), as an answer to the Lucas critique. It later got confirmed by further empirical studies (see, for example, Nelson and Plosser (1982), Ogaki (1992), and Cooley and Ogaki (1996)).
} 
as break dates for Burkina Faso and Bolivia respectively.

Burkina Faso, like 13 other Western and Central sub-Saharan African countries, belongs to the CFA Franc Zone, a seven and plus decades old currency union dating back to the colonial era of the continent. ${ }^{16}$ The CFA Franc (CFAF) is convertible with the French Franc/Euro at a fixed rate and is currently pegged against the Euro. Since its creation, the union has provided a remarkable macroeconomic stability to its member states, especially when it comes to moderate inflation rates (Elbadawi and Majd, 1996; Bleaney and Fielding, 2002). The only exception perhaps to this stability occurred in 1994 when the French authorities unexpectedly decided a 50 percent devaluation of the CFA Franc, in a move to boost the sluggish growth and export competitiveness of the union. The side effect of this unprecedented policy change was a one-time surge in prices, which immediately led to a higher inflation across the union. ${ }^{17}$ One of the countries that ended up bearing the heaviest toll of the devaluation was Burkina Faso. The effects of the devaluation for the country got amplified by a simultaneous sharp drop in the price of cotton, the first exported commodity of Burkina Faso, resulting in a severe deterioration of the terms of trade for the country. This qualifies 1995 as a credible breakpoint for the consumption series of Burkina Faso.

Panel (b) of Figure (3.1) indicates 1984 as the robust break date of Bolivia's per capita consumption series. This coincide precisely with the start of the 1984-1985 hyperinflation of Bolivia, standing out as the most dramatic inflation phenomenon of the time both in Latin America and in the world history. During the 12-month period between August 1984 and August 1985, the average price level increased by more than 20,000 percent, and from May 1985 to August 1985 alone, this figure jumped to an annualised rate of 60,000 percent. This eventually resulted in a change of government in early August 1985, voted in primarily for its comprehensive stabilisation programme. Ultimately, as in similar hyperinflation episodes, the end came abruptly, thanks in part to the proactive policies of the new government. Sachs (1987) provides a detailed analysis of the underlying causes of the Bolivian 1984-1985 hyperinflation as well as some tentative factors that resolved it. It is almost an evidence that a dramatic surge in inflation always leads to a drop in consumption, as shown by Panel (b) of Figure (3.1) below.

\footnotetext{
${ }^{16}$ The other 13 Member states of the CFA Franc Zone as it currently stands are: Benin, Cameroon, Central African Republic, Côte d'Ivoire, Chad, Equatorial Guinea, Gabon, Guinea-Bissau, Mali, Niger, Republic of Congo, and Togo.

${ }^{17}$ Azam and Wane (2001) provide an in-depth analysis of the effects of the 1994 CFAF devaluation on growth and poverty in the Western African Monetary Union (WAEMU).
} 
Figure 3.1: Structural Breaks in per Capita Consumption Series

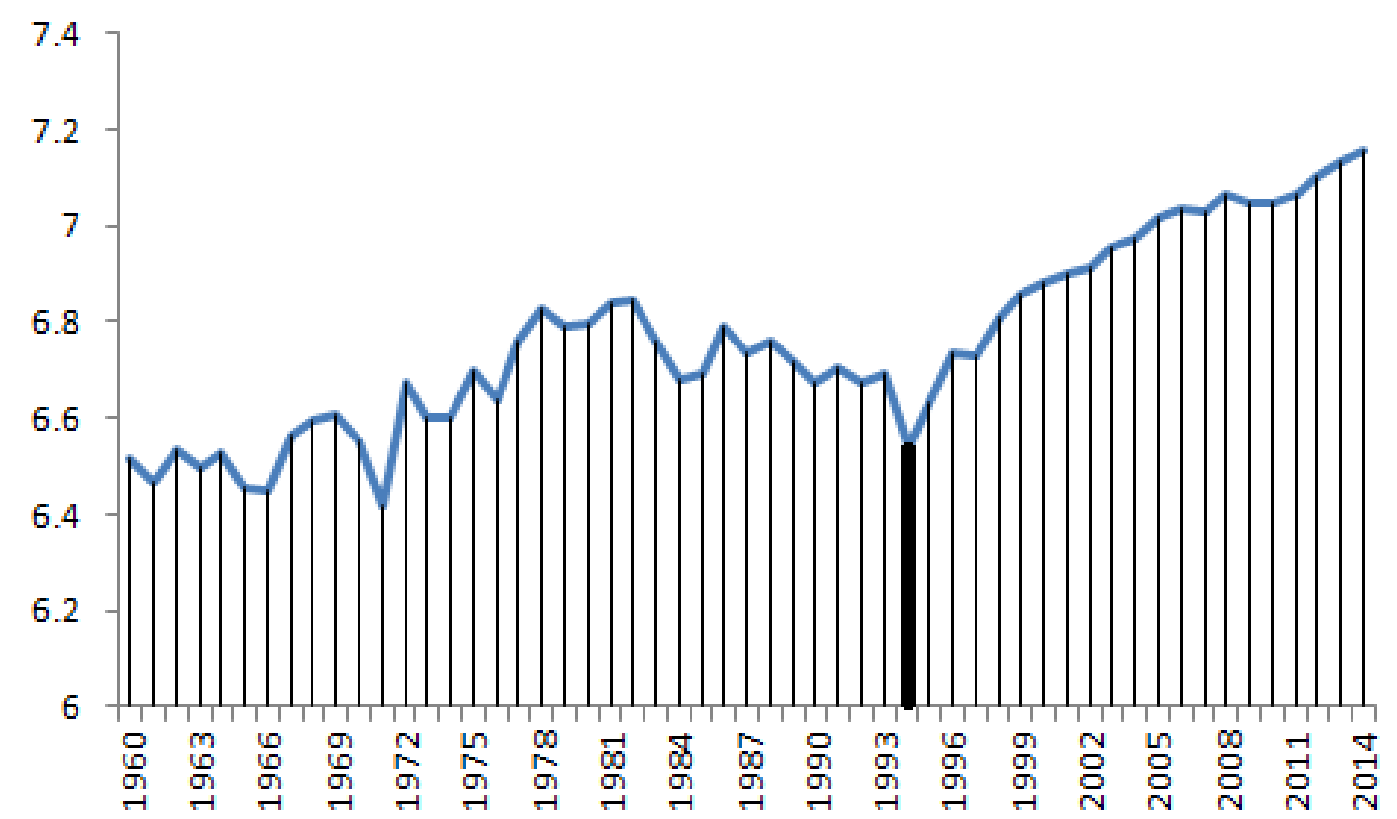

(a) Burkina Faso

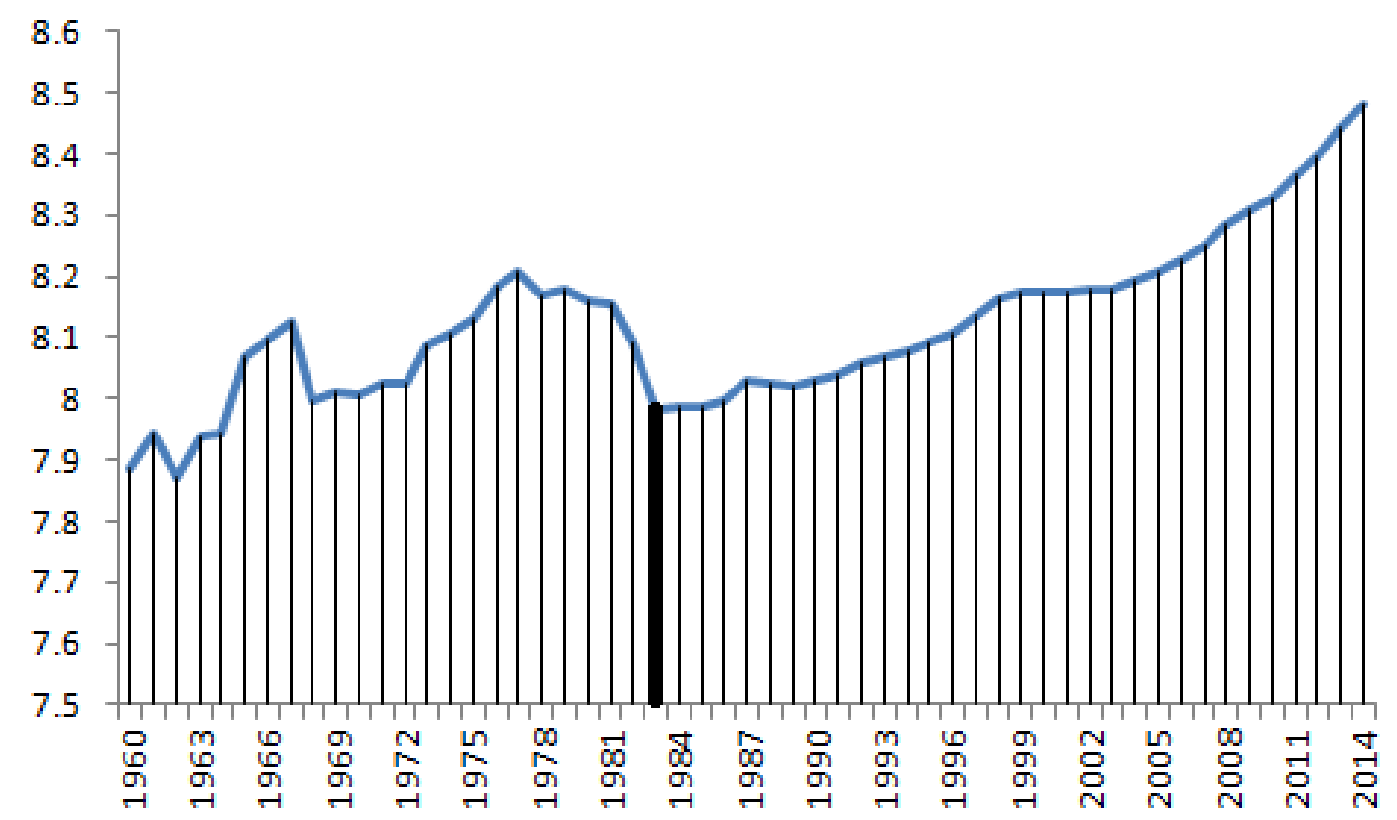

(b) Bolivia

Note: The ordinates on these two graphs display the natural logarithm of per capita consumption in Burkina Faso (Panel a) and in Bolivia (Panel b) respectively, from 1960 to 2014. The bold vertical lines coincide with the breakpoints: 1995 for Burkina Faso and 1984 for Bolivia. 


\subsection{Empirical Analysis}

\subsubsection{Data and Calibration}

In order to quantify the welfare losses brought about by macroeconomic fluctuations and the welfare gains from growth-enhancing in our sample of developing countries, we parameterise each of the recursive models, solve it numerically, calibrate it, and carry out few robustness checks. The data used for that purpose is the natural logarithm of the real per capita consumption at constant 2011 national prices. The aggregate consumption and the population data are all taken from the Penn World Table, version 9.0 (PWT 9.0), which also informs on the levels of relative income, output, inputs, and productivity for 182 countries between 1950 and 2014. ${ }^{18}$ This paper focuses on Low-Income and Lower-MiddleIncome countries, as classified by the World Bank. These countries are unsurprisingly located in sub-Saharan Africa in their vast majority, but also in North-Africa, Latin America, and Asia. These countries are more vulnerable to external shocks - compared to the developed economies - and have to some extent been exposed to abrupt consumption fluctuations in their recent pasts. Another reason to focus on this group of countries comes from the simple fact that they belong to the poorest group of countries in the world, hence the World Bank classification. Unsurprisingly therefore, concerns that volatility may be truly enormous should be most relevant to these economies (Agenor et al., 2000).

For all the 37 countries initially covered in the analysis, the data run from 1960 to 2014. Such long and uniform time-span helps the comparison between the cross-country estimates. A country is excluded from the sample if fewer than 22 consecutive years of data are available for that country. This criterion excludes many Low-Income and Lower-Middle-Income economies from the general Penn World Table. The initial sample is reduced to 25 countries, after the structural break search algorithm is applied to the consumption series. As a shorthand, the model when the whole time-span is covered is referred to as the general model and as the reduced model when the structural break is found. Tables (3.1) and (3.2) summarise the results from estimating the auto-regressive process from equation (3.1) and the welfare gains $\lambda$ and $\zeta$ for the general model. Similarly, Tables (3.3) and (3.4) summarise the results from estimating the auto-regressive process from equation (3.1) and the welfare gains $\lambda$ and $\zeta$ for the reduced or restricted model. Table (3.C.6) in the Appendix provides the summary statistics of the growth factors for each of the 37 countries included in the sample.

\subsubsection{Main Results}

To calibrate the preference parameters of the model, we rely on previous estimates. For yearly data and for developed and developing countries, the discount $\beta$ is often set to vary between 0.95 and 0.97 . Therefore we chose the average 0.96 of the two as base

\footnotetext{
${ }^{18}$ The Penn World Table comes from Feenstra et al. (2015).
} 
value for all the computations. ${ }^{19}$ Regarding the relative risk aversion parameter $(\gamma)$ and the Intertemporal Elasticity of Substitution $(1 / \theta)$, the results presented in this section are based on $\gamma=5.0$ and $\theta=2.5$, which equally correspond to the values commonly used in empirical macroeconomics. However, there is no general consensus about the "true" value of $\gamma$ in the finance literature. To account for this uncertainty, Section (3.5) presents the results of the analysis for higher values of $\gamma$ and $\theta$. This whole exercise stems from the fact that neither the coefficient of relative risk aversion $\gamma$ nor the coefficient of intertemporal elasticity of substitution $\frac{1}{\theta}$ has an undisputed standard value. $\gamma$ is often in the range of $\{1.5,2,2.5,5,10\}$, which coincides with the recognised range by Mehra and Prescott (1985). Equivalently and in congruence with Obstfeld (1994), Dolmas (1998) and to some extent Ostry and Reinhart (1992) argue that $\theta$ is understood to belong to the set $\{1.5,2,2.5,5\}$. Technically, an increase in $\theta$ within the previous range (i.e., a decrease in the intertemporal elasticity of substitution) leads to a smaller cost of macroeconomic fluctuations. Intuitively, the agents with a high elasticity (henceforth a low $\theta$ ) would love to adjust to shocks by substituting intertemporally. However, in the specific context of this model, they cannot do so given that consumption is in effect exogenous. Contrarily, low-elasticity individuals would not substitute much across time, suggesting that they should be less affected. In general, the higher is the representative consumer's elasticity of intertemporal substitution, the costlier should be for him to depart from an optimal consumption stream that is induced by increased volatility.

Tables (3.1) and (3.2) present the estimates of the standard $A R(1)$ fit from equation (3.1), for the general model without any structural break and for the restricted model with one structural break respectively, over the 1960-2014 period. Table (3.1) specifically provides the estimates for 37 countries, while Table (3.2) deals with 21. This difference comes from the fact that all the countries for which the structural break test fails to find a breakpoint have been dropped. For the rest, the estimation of the $A R(1)$ process is made providing that there are enough years covered (at least 22 years) before and/or after the breakpoint. The estimations are done twice for Bolivia and the Philippines, both countries having more than 22 observations before and after their structural breaks. Table (3.A.7) in Appendix 3.A provides the estimates of the break dates, their supremum Wald test statistics as well as the corresponding p-values. In the two tables, $\varphi_{0}$ is the constant term of the auto-regressive process, $\varphi_{1}$ its persistence parameter, $g$ the mean growth rate of per capita consumption, and $\sigma_{\epsilon}$ is the standard deviation of the residuals of the regressions. As stated previously, the regressions for which $\varphi_{1}$ is not significant (at least at a 10 percent level) are then re-estimated directly on the constant term of the random process. The costs of fluctuations and the gains from growth are subsequently estimated for the countries with a strictly positive mean growth rate. This criterion

\footnotetext{
${ }^{19}$ Ostry and Reinhart (1992) argue that the range of the discount rate may be somewhat broader in developing countries, with a lower bound of 0.945 in Africa. Marginally changing the value of the discount factor outside the initial interval does not alter the quality of the results.
} 
excludes some countries from the original sample. Tables (3.1) and (3.2) indicate that developing countries in general display larger shocks (materialised by a large $\sigma_{\epsilon}$ ). This is even more true for countries like Mauritania, Nigeria and Zimbabwe. This result is congruent with previous findings in the literature (Agenor et al., 2000; Mendoza, 1995). In general, ceteris paribus, a higher persistence of shocks automatically leads to larger effects of consumption volatility, as explicitly implied by the Lucas (1987)'s formula. This is largely implied by the fact that the more persistent the shocks are, the longer their effects last and the larger their induced welfare losses become.

Tacking stock of the estimates obtained previously, Tables (3.3) and (3.4) display the point estimates of the cross-country welfare gains from eliminating consumption fluctuations $(\lambda)$, the cross-country welfare gains from increasing consumption growth perpetually by one percent $(\zeta)$, as well as their difference $(\lambda-\zeta)$. The difference is meant to provide an indication on the policy priority for the government of the country concerned. Positive values of $(\lambda-\zeta)$ indicate that stabilisation policies should have the priority while negative differences suggest that long-term growth-enhancing should top the national agendas. ${ }^{20}$

The results for both the general and the restricted models show a remarkable consistency, in the sens that the difference between the gains from stabilisation and the gains from growth-enhancing $(\lambda-\zeta)$ remains negative for all the countries included in the analysis. This is the case when the time-span is the same for all countries (1960-2014), as summarised by Table (3.3). This holds even for countries with a higher cost of fluctuations compared to the rest of the sample. Zimbabwe has for example $5.06 \%$ of lifetime consumption as the welfare loss induced by consumption volatility and $10.71 \%$ as the gain from an additional 1\% increase of lifetime consumption. Despite the sheer magnitude of the former number, it remains nearly half of the latter. Table (3.4) gives an alternative time-span for each country in the sample, providing that the structural break exists. Few countries, ranging from Benin, Chad, Congo, Guatemala, Guinea-Bissau, Lesotho, Malawi, Mauritania, Nepal, Rwanda, Syria, to Tanzania, are dropped from the original estimations. That is because their supremum Wald statistics are not significant at the $10 \%$ level. Further details about the breakpoints are provided by Table (3.D.7) of the Appendix. Again, the results show that the welfare gains from increasing growth exceed the gains from stabilisation. The results are at odds with the findings of Pallage and Robe (2003), who argue that for a large section of sub-Saharan African countries, the impetus should be directed towards eliminating the fluctuations at the expense of growth policies. ${ }^{21}$ This means that, just like the majority of developed countries, the developing economies would also highly gain from growth than from stabilisation. This however does

\footnotetext{
${ }^{20}$ One should note however that this comparison does not incorporate the cost of implementing macroeconomic policies. Moreover, in the real world, it might not be feasible to entirely remove all consumption fluctuations or to indefinitely achieve an increase in long-term growth by one percent in a country, even in the most sophisticated environment.

${ }^{21}$ In a slightly different context, Houssa (2013) points to a higher policy inconclusiveness when developing countries are concerned.
} 
not suggest that macroeconomic stabilisation policies should be discarded altogether. The question should rather be about the exact composition of the growth-stabilisation mix, a question which goes beyond the scope of this paper. ${ }^{22}$

\footnotetext{
${ }^{22}$ Congruent to that discussion, Martin and Ann Rogers (2000) discuss the pros and cons for long-term growth policies and the short-term shocks stabilisers while Aghion and Marinescu (2008) provide some empirical evidences on cyclical budgetary and economic growth policies in the OECD context. See the recent IMF (2015) report for further in-depth discussion.
} 
Table 3.1: Parameter Estimates for the $A R(1)$ Process of the General Model

\begin{tabular}{|c|c|c|c|c|c|c|c|}
\hline \multirow{2}{*}{$\begin{array}{l}\text { Country } \\
\text { Bangladesh }\end{array}$} & \multicolumn{2}{|c|}{$\varphi_{0}$} & \multicolumn{2}{|c|}{$\varphi_{1}$} & \multirow{2}{*}{$\frac{g}{0.005216}$} & \multirow{2}{*}{$\begin{array}{c}\sigma_{\epsilon} \\
0.0460672\end{array}$} & \multirow{2}{*}{$\frac{F \text {-stat }}{\ldots}$} \\
\hline & $1.005216^{* * *}$ & $(0.0062689)$ & 0 & $\ldots$ & & & \\
\hline Benin & $1.00463^{* * *}$ & $(0.0054408)$ & 0 & $\ldots$ & 0.00463 & 0.0399813 & $\ldots$ \\
\hline Bolivia & $1.011858^{* * *}$ & $(0.0053143)$ & 0 & $\ldots$ & 0.011858 & 0.0390519 & $\ldots$ \\
\hline Burkina Faso & $1.299984^{* * *}$ & $(0.1356263)$ & $-0.2805973^{* *}$ & $(0.1334356)$ & 0.0151387 & 0.066718 & 4.42 \\
\hline Burundi & $1.017323^{* * *}$ & $(0.0107213)$ & 0 & $\ldots$ & 0.017323 & 0.0787851 & $\ldots$ \\
\hline Cameroon & $0.7724663^{* * *}$ & $(0.1376411)$ & $0.2332085^{*}$ & $(0.1366002)$ & 0.0074007 & 0.044121 & 2.91 \\
\hline Chad & $1.009766^{* * *}$ & $(0.0159895)$ & 0 & $\ldots$ & 0.009766 & 0.1174985 & $\ldots$ \\
\hline Congo & $0.7210207^{* * *}$ & $(0.1347997)$ & $0.2914929^{* *}$ & $(0.1323876)$ & 0.0176619 & 0.0620041 & 4.85 \\
\hline Côte d'Ivoire & $1.007662^{* * *}$ & $(0.0092907)$ & 0 & $\ldots$ & 0.007662 & 0.0682727 & $\ldots$ \\
\hline Ethiopia & $1.030977^{* * *}$ & $(0.0106793)$ & 0 & $\ldots$ & 0.030977 & 0.0784764 & $\ldots$ \\
\hline The Gambia & $1.004744^{* * *}$ & $(0.0126421)$ & 0 & $\ldots$ & 0.004744 & 0.0928998 & $\ldots$ \\
\hline Ghana & $1.009596^{* * *}$ & $(0.0099465)$ & 0 & $\ldots$ & 0.009596 & 0.0730914 & $\ldots$ \\
\hline Guatemala & $0.3898643^{* * *}$ & $(0.1120214)$ & $0.6154658^{* * *}$ & $(0.1105122)$ & 0.01386118 & 0.0150477 & 31.02 \\
\hline Guinea & $1.010741^{* * *}$ & $(0.0068184)$ & 0 & $\ldots$ & 0.010741 & 0.050105 & $\ldots$ \\
\hline Guinea Bissau & $1.016483^{* * *}$ & $(0.0112259)$ & 0 & $\ldots$ & 0.016483 & 0.0824929 & $\ldots$ \\
\hline Haiti & $1.007287^{* * *}$ & $(0.0081285)$ & 0 & $\ldots$ & 0.007287 & 0.0597321 & $\ldots$ \\
\hline Honduras & $1.01257^{* * *}$ & $(0.004522)$ & 0 & $\ldots$ & 0.01257 & 0.0332295 & $\ldots$ \\
\hline India & $1.029227^{* * *}$ & $(0.0042146)$ & 0 & $\ldots$ & 0.029227 & 0.0309705 & $\ldots$ \\
\hline Indonesia & $0.6251599^{* * *}$ & $(0.13332)$ & $0.3971639^{* * *}$ & $(0.1284767)$ & 0.0370313 & 0.0379693 & 9.56 \\
\hline Kenya & $1.008767^{* * *}$ & $(0.0073411)$ & 0 & $\ldots$ & 0.008767 & 0.0539459 & $\ldots$ \\
\hline Lesotho & $0.7727522^{* * *}$ & $(0.138479)$ & $0.2491918^{*}$ & $(0.1341498)$ & 0.0292272 & 0.0562424 & 3.45 \\
\hline
\end{tabular}


Table 1 - continued

\begin{tabular}{|c|c|c|c|c|c|c|c|}
\hline Country & & & & & $g$ & $\sigma_{\epsilon}$ & $F$-stat \\
\hline Malawi & $1.31322^{* * *}$ & $(0.1346211)$ & $-0.3010352^{* *}$ & $(0.1332295)$ & 0.00936546 & 0.0694526 & 5.11 \\
\hline Mauritania & $0.75733256^{* * *}$ & $(0.12380807)$ & $0.2753032^{* *}$ & $(0.1185394)$ & 0.04503367 & 0.1337729 & 5.39 \\
\hline Morocco & $1.02913^{* * *}$ & $(0.0059189)$ & 0 & $\ldots$ & 0.02913 & 0.043495 & $\ldots$ \\
\hline Mozambique & $1.018588^{* * *}$ & $(0.0077086)$ & 0 & $\cdots$ & 0.018588 & 0.0566461 & $\ldots$ \\
\hline Nepal & $1.280896^{* * *}$ & $(0.1378738)$ & $-0.258054^{*}$ & $(0.1353266)$ & 0.0181566 & 0.0378176 & 3.64 \\
\hline Nicaragua & $1.006948^{* * *}$ & $(0.0088033)$ & 0 & $\ldots$ & 0.006948 & 0.0646911 & $\ldots$ \\
\hline Nigeria & $1.302343^{* * *}$ & $(0.1387341)$ & $-0.2714186^{* *}$ & $(0.1342966)$ & 0.02432275 & 0.1360931 & 4.08 \\
\hline Pakistan & $1.022912^{* * *}$ & $(0.0039915)$ & 0 & $\ldots$ & 0.022912 & 0.0293317 & $\ldots$ \\
\hline Philippines & $0.3405808^{* * *}$ & $(0.1077645)$ & $0.6652003^{* * *}$ & $(0.1059942)$ & 0.017267 & 0.0132033 & 39.39 \\
\hline Rwanda & $1.011809^{* * *}$ & $(0.0111339)$ & 0 & $\ldots$ & 0.011809 & 0.0818174 & $\ldots$ \\
\hline Syria & $1.022631^{* * *}$ & $(0.0158823)$ & 0 & $\ldots$ & 0.022631 & 0.1167106 & $\ldots$ \\
\hline Tanzania & $1.023359^{* * *}$ & $(0.0078047)$ & 0 & & 0.023359 & 0.0573527 & $\ldots$ \\
\hline Togo & $1.010119^{* * *}$ & $(0.0098602)$ & 0 & $\ldots$ & 0.010119 & 0.0724572 & $\ldots$ \\
\hline Uganda & $0.6870145^{* * *}$ & $(0.1351479)$ & $0.3211845^{* *}$ & $(0.1336203)$ & 0.0120784 & 0.0483587 & 5.78 \\
\hline Zambia & $1.000783^{* * *}$ & $(0.0120835)$ & 0 & & 0.000783 & 0.0887954 & 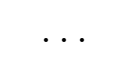 \\
\hline Zimbabwe & $1.033907^{* * *}$ & $(0.0280905)$ & 0 & $\ldots$ & 0.033907 & 0.2064218 & $\ldots$ \\
\hline
\end{tabular}

Note: The standard errors of the regression are in parentheses. ${ }^{* * *},{ }^{* *}$, and ${ }^{*}$ denote the significance at 1,5 and 10 percent levels, respectively. 
Table 3.2: Parameter Estimates for the $A R(1)$ Process of the Restricted Model

\begin{tabular}{lccccccc} 
Country & \multicolumn{2}{c}{$\varphi_{0}$} & & $\varphi_{1}$ & & $\sigma_{\epsilon}$ & $F$-stat \\
\hline Bangladesh & $1.307454^{* * *}$ & $(0.0062689)$ & $-0.2871842^{*}$ & $(0.1558646)$ & 0.0157474 & 0.0336627 & 3.39 \\
Bolivia & $1.005632^{* * *}$ & $(0.0115372)$ & 0 & $\ldots$ & 0.005632 & 0.0565203 & $\ldots$ \\
& $0.4112991^{* *}$ & $(0.16517)$ & $0.5964864^{* * *}$ & $(0.1625512)$ & 0.0192943 & 0.0114028 & 3.39 \\
Burkina Faso & $1.369095^{* * *}$ & $(0.1682504)$ & $-0.359581^{* *}$ & $(0.1670314)$ & 0.0069977 & 0.0779709 & 4.63 \\
Burundi & $1.005535^{* * *}$ & $(0.0111702)$ & 0 & $\ldots$ & 0.005535 & 0.0757599 & $\ldots$ \\
Ethiopia & $1.025078^{* * *}$ & $(0.0120703)$ & 0 & $\ldots$ & 0.025078 & 0.0809699 & $\ldots$ \\
The Gambia & $1.001289^{* * *}$ & $(0.0148553)$ & 0 & $\ldots$ & 0.001289 & 0.0974129 & $\ldots$ \\
Ghana & $1.003176^{* * *}$ & $(0.0118197)$ & 0 & $\ldots$ & 0.003176 & 0.0766006 & $\ldots$ \\
Guinea & $1.003025^{* * *}$ & $(0.0055995)$ & 0 & $\ldots$ & 0.003025 & 0.0379779 & $\ldots$ \\
Haiti & $1.002321^{* * *}$ & $(0.0103879)$ & 0 & $\ldots$ & 0.002321 & 0.0614559 & $\ldots$ \\
Honduras & $1.008327^{* * *}$ & $(0.0057436)$ & 0 & $\ldots$ & 0.008327 & 0.0363255 & $\ldots$ \\
India & $1.022893^{* * *}$ & $(0.0044162)$ & 0 & $\ldots$ & 0.022893 & 0.0296245 & $\ldots$ \\
Indonesia & $0.5872137^{* * *}$ & $(0.1767188)$ & $0.4334813^{* *}$ & $(0.1694817)$ & 0.0365301 & 0.0452204 & 6.54 \\
Kenya & $1.005532^{* * *}$ & $(0.0110075)$ & 0 & $\ldots$ & 0.005532 & 0.065121 & $\ldots$ \\
Morocco & $1.027971^{* * *}$ & $(0.0073713)$ & 0 & $\ldots$ & 0.027971 & 0.0483365 & $\ldots$ \\
Mozambique & $1.013691^{* * *}$ & $(0.0097531)$ & 0 & $\ldots$ & 0.013691 & 0.0632076 & $\ldots$ \\
Nigeria & $1.025819^{* * *}$ & $(0.0206208)$ & 0 & $\ldots$ & 0.025819 & 0.1413693 & $\ldots$ \\
Pakistan & $1.022587^{* * *}$ & $(0.0044519)$ & 0 & $\ldots$ & 0.022587 & 0.0295308 & $\ldots$ \\
Philippines & $0.3160825^{* *}$ & $(0.1529129)$ & $0.6867266^{* * *}$ & $(0.1511999)$ & 0.0089669 & 0.0140301 & 20.63 \\
Togo & $0.4736856^{* *}$ & $(0.1729092)$ & $0.5364939^{* * *}$ & $(0.1691086)$ & 0.0219619 & 0.0117531 & 10.06 \\
\hline & $1.00276^{* * *}$ & $(0.0131069)$ & 0 & $\ldots$ & 0.00276 & 0.0775414 & $\ldots$ \\
\hline
\end{tabular}


Table 2 - continued

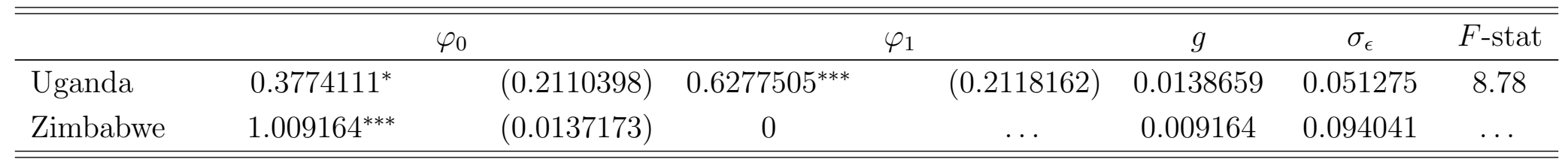

Note: See Table (3.1). 
Table 3.3: Welfare Cost of Fluctuations versus Benefit of Extra 1\% Growth

\begin{tabular}{lccc}
\hline \hline Country & $\lambda(\%)$ & $\zeta(\%)$ & $\lambda(\%)-\zeta(\%)$ \\
\hline Bangladesh & 0.0705 & 18.8781 & -18.8076 \\
Benin & 0.0540 & 19.2232 & -19.1692 \\
Bolivia & 0.0412 & 15.6192 & -15.5780 \\
Burkina Faso & 0.0872 & 14.3926 & -14.3054 \\
Burundi & 0.1901 & 13.6915 & -13.5014 \\
Cameroon & 0.1119 & 17.6875 & -17.5756 \\
Chad & 0.9655 & 16.7701 & -15.8046 \\
Congo & 0.1782 & 13.5841 & -13.4059 \\
Côte d'Ivoire & 0.1620 & 17.5664 & -17.4044 \\
Ethiopia & 0.1391 & 10.3590 & -10.2199 \\
The Gambia & 0.4783 & 19.2842 & -18.8059 \\
Ghana & 0.1859 & 16.6368 & -16.4509 \\
Guatemala & 0.0194 & 14.8381 & -14.8187 \\
Guinea & 0.0707 & 16.0959 & -16.0252 \\
Guinea Bissau & 0.2255 & 13.9706 & -13.7451 \\
Haiti & 0.1161 & 17.7465 & -17.6304 \\
Honduras & 0.0292 & 15.3307 & -15.3015 \\
India & 0.0172 & 10.6733 & -10.6561 \\
Indonesia & 0.0789 & 9.3247 & -9.2458 \\
Kenya & 0.0878 & 16.999 & -16.9112 \\
Lesotho & 0.0997 & 10.6896 & -10.5899 \\
Malawi & 0.1133 & 16.7230 & -16.6097 \\
Mauritania & 1.2264 & 8.4115 & -7.1851 \\
Morocco & 0.0341 & 10.6958 & -10.6617 \\
Mozambique & 0.0751 & 13.2761 & -13.201 \\
Nepal & 0.0185 & 13.3935 & -13.3750 \\
Nicaragua & 0.1433 & 17.9326 & -17.7893 \\
Nigeria & 0.8508 & 11.9027 & -11.0519 \\
Pakistan & 0.0176 & 12.0804 & -12.0628 \\
Philippines & 0.0143 & 13.6705 & -13.6562 \\
Rwanda & 0.2487 & 15.6927 & -15.4440 \\
Syria & 0.6747 & 12.2885 & -11.6138 \\
Tanzania & 0.0692 & 11.9801 & -11.9109 \\
Togo & 0.1784 & 16.3978 & -16.2194 \\
Uganda & 0.1465 & 15.5591 & -15.4126 \\
Zambia & 0.4713 & 22.0174 & -21.5461 \\
Zimbabwe & 5.0637 & 10.7116 & -5.6476 \\
\hline \hline & & & \\
\hline
\end{tabular}

Note: $\lambda$ represents the welfare cost of aggregate fluctuations, as a percentage of lifetime consumption, while $\zeta$ is the percentage gain of consumption from a $1 \%$ increase of its unconditional mean growth rate. 
Table 3.4: Welfare Cost of Fluctuations versus Benefit of Extra 1\% Growth

\begin{tabular}{lccc}
\hline \hline Country & $\lambda(\%)$ & $\zeta(\%)$ & $\lambda(\%)-\zeta(\%)$ \\
\hline Bangladesh & 0.0137 & 14.1661 & -14.1524 \\
Bolivia & 0.1076 & 18.6480 & -18.5404 \\
& 0.0085 & 13.0543 & -13.0458 \\
Burkina Faso & 0.1692 & 17.9130 & -17.7438 \\
Burundi & 0.2355 & 18.7421 & -18.5066 \\
Ethiopia & 0.1736 & 11.5914 & -11.4178 \\
The Gambia & 0.6419 & 21.6847 & -21.0428 \\
Ghana & 0.2644 & 20.2158 & -19.9514 \\
Guinea & 0.0515 & 20.2486 & -20.1971 \\
Haiti & 0.1473 & 20.7643 & -20.6170 \\
Honduras & 0.0395 & 17.1991 & -17.1596 \\
India & 0.0180 & 12.0852 & -12.0672 \\
Indonesia & 0.1104 & 9.4082 & -9.2978 \\
Kenya & 0.1527 & 18.7190 & -18.5663 \\
Morocco & 0.0433 & 10.9329 & -10.8896 \\
Mozambique & 0.1108 & 14.9212 & -14.8104 \\
Nigeria & 1.3066 & 11.6478 & -10.3412 \\
Pakistan & 0.0180 & 12.6230 & -12.6050 \\
Philippines & 0.0251 & 16.8903 & -16.8652 \\
Togo & 0.0074 & 12.3214 & -12.3140 \\
Uganda & 0.2789 & 20.5020 & -20.2231 \\
Zimbabwe & 0.5731 & 15.0101 & -14.4370 \\
\hline \hline & 0.4335 & 16.9054 & -16.4719 \\
\hline
\end{tabular}

Note: $\lambda$ represents the welfare cost of aggregate fluctuations, as a percentage of lifetime consumption, while $\zeta$ is the percentage gain of consumption from a $1 \%$ increase of its unconditional mean growth rate. 


\subsection{Mean-Comparison Tests}

How significantly different are the general and restricted models' estimates from each other? There are many available methods to answer that question, most of which fall under the analysis of variance - ANOVA - umbrella. In its simplest form, ANOVA provides a statistical test of whether the average means of various groups are equal, and hence is a generalisation of the $t$-test to more than two groups. In addition of comparing means, ANOVA is also useful for testing three or more groups or variables for statistical significance. However, the rank-based non-parametric tests, including sign, Mann-Whitney and Kruskal-Wallis, take a rather different route to comparing distributions across samples. These tests make weaker assumptions about the measurement, the distribution, the shape and spread of the objects to be compared. Consequently, they remain completely valid under a wider range of conditions than ANOVA and its inherent parametric relatives. However, both parametric and non-parametric tests are sometimes used together, mostly to see whether the two point toward similar conclusions. We apply the two-sample $t$-test to our results - to both the estimates of the welfare costs of business cycles $\lambda \equiv \lambda\left(\varphi, \sigma_{\epsilon}^{2}, g\right)$ and to those of the welfare gains from an additional one percent of yearly consumption growth $\zeta \equiv \zeta\left(\varphi, \sigma_{\epsilon}^{2}, g\right)$ - to check whether they are robust or not to mean-comparisons between samples. ${ }^{23}$ The null hypotheses of the tests $\mathbb{H}_{0}$ equate two by two the estimates of the welfare cost of business cycles and the estimates of of the welfare gains from an additional one percent of yearly consumption growth.

Table (3.5) below provides the details about the two-sample $t$-tests. The tests are applied to the group of countries that have a robust structural break. This reduces the sample to 21 and corresponds textually to all countries reported in Table (3.4). Such procedure allows for comparing exactly the same group of countries without and with the structural break. The table, in addition to the samples' size, their means, standard errors, standard deviations, and 95\% confidence intervals, also provides the Student statistics, degrees of freedom, as well as the left, right and two-tail probabilities of the two-sample $t$-tests. Across the board, the null hypothesis of the equality between the sample averages of the welfare cost of business cycles for the general and the restricted models is not rejected. ${ }^{24}$ This implies that in the context of an Epstein and Zin (1989) preference specification, unique structural breaks do not matter when it comes to the interpretation of the sample average welfare cost of business cycles, especially when such sample exhibits a high degree of homogeneity. Conversely, the two-tail probability of the test equating the

\footnotetext{
${ }^{23}$ When applied to two samples $X$ and $Y$, the two-sample Student statistic for $\mu_{x}=\mu_{y}-$ with $\sigma_{x}=\sigma_{y}$ - is given by:$$
t=\frac{\bar{x}-\bar{y}}{\left\{\frac{\left(n_{x}-1\right) s_{x}^{2}+\left(n_{y}-1\right) s_{y}^{2}}{n_{x}+n_{y}-2}\right\}^{1 / 2}\left(\frac{1}{n_{x}}+\frac{1}{n_{y}}\right)^{1 / 2}}
$$

${ }^{24}$ Adjusting the $t$-tests for unequal variances between the two samples and alternative distributions do not alter our conclusions.
} 
sample averages of the welfare gains from growth between the general and the restricted models is significant and robustly skewed to the left. The left-tail probability equals 0.0015 and the two-tail probability 0.0031. The immediate overarching and cardinal implication of this result is that structural breaks do matter for growth, precisely as shown by Pritchett (2000)'s seminal works with his identification and classification of various growth regimes. ${ }^{25}$ And in the specific context of this analysis, the average welfare gain from an additional one percent of yearly consumption becomes higher when structural breaks for each individual country are taken into account.

\footnotetext{
${ }^{25}$ The perhaps difference between us and Pritchett (2000) is that our algorithm of structural breaks identification is applied to per capita consumption series rather than income.
} 
Table 3.5: Two-Sample $t$-test for the General and Restricted Models of Welfare $(\lambda)$ and Growth $(\zeta)$

\begin{tabular}{|c|c|c|c|c|c|c|}
\hline Variable & Obs & Mean & Std. Err. & Std. Dev. & \multicolumn{2}{|c|}{ [95\% Conf. Interval] } \\
\hline \multicolumn{7}{|c|}{ Welfare Cost $(\lambda)$} \\
\hline General & 21 & 0.3796524 & 0.2378741 & 1.090076 & -0.1165443 & 0.8758491 \\
\hline Restricted & 21 & 0.2312476 & 0.0664504 & 0.304514 & 0.0926345 & 0.3698607 \\
\hline \multirow[t]{2}{*}{ Diff } & 21 & 0.1484048 & 0.2258872 & 1.035145 & -0.3227878 & 0.6195973 \\
\hline & $t=0.6570$ & d.f. $=20$ & & $\operatorname{Pr}(T<t)=0.7407$ & $\operatorname{Pr}(|T|<|t|)=0.5187$ & $\operatorname{Pr}(T>t)=0.2593$ \\
\hline \multicolumn{7}{|l|}{ Growth $(\zeta)$} \\
\hline General & 21 & 14.2536 & 0.6440121 & 2.951234 & 12.91021 & 15.59698 \\
\hline Restricted & 21 & 15.98747 & 0.8071689 & 3.698913 & 14.30375 & 17.6712 \\
\hline \multirow[t]{2}{*}{ Diff } & 21 & -1.733876 & 0.5150676 & 2.360336 & -2.808288 & -0.6594639 \\
\hline & $t=-3.3663$ & d.f. $=20$ & & $\operatorname{Pr}(T<t)=0.0015$ & $\operatorname{Pr}(|T|<|t|)=0.0031$ & $\operatorname{Pr}(T>t)=0.9985$ \\
\hline
\end{tabular}

Note: Student statistic: $t$; degrees of freedom: d.f.; left-tail probability $\operatorname{Pr}(T<t)$; two-tail probability: $\operatorname{Pr}(|T|<|t|)$, and right-tail probability: $\operatorname{Pr}(T>t)$. 


\subsection{Robustness Checks}

\subsubsection{Alternative Values for the Parameters}

As previously mentioned, there is not a real agreement regarding the exact magnitude of the relative risk aversion $(\gamma)$ and that of the intertemporal elasticity of substitution $(1 / \theta)$. The changes in the values of these parameters affect the estimates of the welfare costs of business cycles and the welfare gains from growth-enhancing. For example, for a given value of $\theta$, the cost of fluctuations increases with the relative risk aversion parameter. This is a reflection of the risk-averse consumers' preference for a smooth consumption stream. Consequently, the more risk-averse a consumer is, the more welfare compensation he would request to offset the effects of volatility in consumption. Alternatively, when the degree of risk aversion $\gamma$ is held constant, the cost of fluctuations decreases with $\theta$. This captures the positive effect of the IES on the welfare cost of fluctuations when the shocks are persistent. In the presence of persistence shocks, the discount factor of static welfare costs of consumption fluctuations over time increases with the IES. ${ }^{26}$

Because of the lack of general agreement regarding the true empirical values of $\gamma$ and $\theta$, we will double the values of these parameters separately (from 5 to 10 for $\gamma$ and from 2.5 to 5 for $\theta$ ). ${ }^{27}$ The results obtained from doubling the value of $\gamma$ (as shown by Tables 3.E.8 and 3.E.9 in the Appendix) ceteris paribus, or those computed from doubling the value of $\theta$ (as displayed by Tables 3.F.10 and 3.F.11 in the Appendix), while keeping $\gamma$ constant, show that the conclusions reached from the benchmark analysis remain robust to parameters shifting.

\subsubsection{Additional Structural Break Tests}

The supremum Wald ( $\sup -W$ ) statistic, chosen here as the benchmark test for validating the potential break dates, belongs to a wider class of statistical tests. Prominent among them are the average Wald test, the average likelihood ratio (LR) test, the supremum LR test as well as the exponential versions of these tests. This diversity stems from the fact that the test at each possible break date is not predetermined and therefore could either be a Wald or a LR. While the supremum Wald test uses the maximum of the sample Wald tests, the supremum LR test uses the maximum of the sample LR tests. It is assumed that the supremum tests have much less power than average and exponential tests, in some specific circumstances (Andrews, 1993). The average test is more suited when the alternative hypothesis is a small change in parameter values at the potential structural break. Andrews and Ploberger (1994) provide further details regarding the properties of

\footnotetext{
${ }^{26}$ The result holds true providing that the mean adjusted growth rate of consumption $\left(g-\frac{1}{2} \gamma \sigma^{2}\right)$ is positive. Otherwise, the opposite relationship is true (see (Obstfeld, 1994) for further discussions).

${ }^{27}$ These are reasonable values, and Ogaki et al. (1996) find for example estimated values of $\theta$ ranging from 2.26 to 2.96 for developing countries, from 1.35 to 2.51 for lower-middle-income countries, from 1.26 to 2.38 for upper-middle-income countries, and from 1.21 to 2.29 for high-income countries.
} 
average and exponential tests.

The average Wald and likelihood ratio tests were conducted in addition to the benchmark supremum Wald test for the 25 identified structural break dates, and although the test statistics sometimes fail to reject the null hypothesis of no structural break in the consumption series $\left(\mathbb{H}_{0}: \kappa_{0}=\kappa_{1}=0\right)$, most of these new statistics remain significant at the $10 \%$ level.

\subsubsection{Analysis of Variance-ANOVA}

As a benchmark mean-comparison method, we chose the two sample $t$-test. The results indicated that the null hypothesis of equal means between the general and the restricted models cannot be rejected for the welfare cost of business cycles while $\mathbb{H}_{0}$ cannot be rejected for the welfare gains from an additional one percent of yearly consumption growth. Although robust, the two-sample $t$-test can sometimes be prone to errors, even when the sample size remains small, as in our case. Because of that we complement the analysis with a more general analysis of variance - ANOVA. Both the $t$-test and the ANOVA are parametric and rely on the same set of assumptions: normal distribution of the sample population, homogeneity of variance, independence of observations, measurement of the dependent variable on the ratio or interval level, etc. The analysis of variance offers a more general mean-comparison approach than the two-sample $t$-test. When applied to our estimates of $\lambda \equiv \lambda\left(\varphi, \sigma_{\epsilon}^{2}, g\right)$ and $\zeta \equiv \zeta\left(\varphi, \sigma_{\epsilon}^{2}, g\right)$ of the general and restricted models, the two-sample ANOVA confirms our main results, namely that structural breaks do not matter for the welfare cost of business cycles while they do for the welfare gains from an additional one percent of yearly consumption growth.

\subsection{Concluding Remarks}

This paper combines a robust recursive preference framework and a strong structural break algorithm to infer on the welfare costs of consumption fluctuations and the gains from consumption growth. It departs from the previous literature specifically on the ground of structural change, which is likely to arise in any aggregate time series, as acknowledged by the recent macroeconomic literature. All the 37 countries covered in this analysis belong to the Low-Income and the Lower-Middle-Income categories of the World Bank's classification, and cover Africa, Asia, Latin America, and South-East Asia to some extent. In addition to the large basket of developing countries covered, the time-span considered runs from 1960 to 2014.

At first, the results show that for all the countries concerned by the analysis and for a relatively long period of time - as the one considered here -, the welfare gains from a perpetual one percent increase of lifetime consumption growth transcends the welfare costs of aggregate consumption fluctuations. These results hold firmly when the analysis 
is repeated before and after structural breaks, given that the number of years covered exceeds 22 years. Second, and central to this analysis, we find that the null hypothesis of the equality between the sample averages of the welfare cost of business cycles for the general and the restricted models is not rejected. The implication for this result is that in the context of an Epstein and Zin (1989) preference specification, unique structural breaks do not matter when it comes to the interpretation of the sample average welfare cost of business cycles, especially when such sample exhibits a high degree of homogeneity. Conversely, the two-tail probability of the test equating the sample averages of the welfare gains from growth between the general and the restricted models is significant. The paramount implication of this result is that structural breaks do matter for growth. In the specific context of this analysis, the average welfare gain from an additional one percent of yearly consumption becomes higher when structural breaks for each individual country are taken into account. To check for the robustness of the previous results, the coefficient of relative risk aversion and the intertemporal elasticity of substitution parameters are doubled separately. Additionally, alternative structural break tests are provided. Finally, we use an analysis of variance - ANOVA - to check the robustness of our benchmark mean-comparison test. Overall, the findings remain unchanged and the majority of the candidate breakpoints of the consumption series stand unaltered. Although the welfare gains from consumption stabilisation and the welfare gains from consumption growthenhancing are computed using point estimates, they show that growth-enhancing policies should still top the agendas of developing countries' governments, as long advocated by the World Bank and other international organisations.

This paper, despite its contributions, leaves however many unanswered questions in the developing countries' macroeconomic fluctuations' debate. Is the amplitude of aggregate fluctuations mostly related to economic diversification-or lack thereof? And if so to which extent. Are domestic macroeconomic stabilisation policies key to reducing aggregate consumption volatility? Can a developing country's integration in the international capital markets help significantly contain consumption volatility? All these questions deserve serious considerations and promise fruitful venues for further research. 


\section{Appendix 3.A: Estimation of Structural Breaks}

This section underlines the sequential procedure for testing and dating the structural breaks in the consumption series. The procedure builds on Bluhm et al. (2016), whose approach itself is a continuation of Bai (1997)'s sequential likelihood ratio tests for structural change. ${ }^{28}$ It assumes that the series under consideration are regime-wise trend-stationary. Although this paper uses consumption rather than output series, we will adopt the same assumption. Therefore, the task of verifying this assumption will not be the focus of the paper, as testing for unit roots in the presence of structural breaks. The procedure displayed here is different from the Bluhm et al. (2016)'s approach on two grounds: the structural break is unique and the supremum Wald statistic (which tests the significance of of the break estimate) is not bootstrapped after the estimation. The four-steps sequential procedure is therefore:

1. Determine the optimal lag length of the auto-regressive process $(A R(p))$ from equation (3.8). The iteration approach is used to determine the optimal lag, and when none of the candidate models is significant at the 10 percent level, per capita consumption is directly regressed on the constant. Alternatively, the Akaike Information Criterion (AIC) or the Bayesian Information Criterion (BIC) could have informed about the optimal lag. Using the iterative approach, we find that $p_{\max }=3$.

2. Specify the structural change model applied to per capita consumption series of the form:

$$
C_{t}=\psi_{0}+\kappa_{0} \mathbb{1}\left(t \leq T_{1}\right)+\kappa_{1} \mathbb{1}\left(t>T_{1}\right)+\psi_{1} C_{t-1}+\nu_{t}
$$

where $C_{t}$ is the per capita consumption at year $t, T_{1}$ is the potential unique structural break of consumption, $\mathbb{1}(\cdot)$ is the classic indicator function, while $p$ is the lag order as determined by the optimal $A R(p)$ model. The structural break being unique, there is no need to add an additional requirement regarding the distance between different break points.

3. Define the trimming parameter $\tau$, where typically $\tau \in[0.05,0.25]$ of the data. Andrews (1993) recommends a symmetric trimming of $15 \%$ when there is no available information on good and reliable trimming values, while by default, $\tau=0.05$.

4. Compute the sup- $W$ test statistic of the null of no break versus a break $\left(\mathbb{H}_{0}: \kappa_{0}=\right.$ $\left.\kappa_{1}=0\right)$. The supremum is chosen according to the following:

$$
\sup _{t_{0} \leq T_{1} \leq T} \quad W\left(T_{1}\right)=\sup _{t_{0} \leq T_{1} \leq T} \quad\left(\frac{T-K}{3}\right) \frac{S S R^{r}-S S R^{u}}{S S R^{u}}
$$

where $K$ the total number of parameters, $S S R^{r}$ and $S S R^{u}$ the sum of squared residuals and the sum of squared residuals from the regression imposing and without imposing $\mathbb{H}_{0}$ respectively.

\footnotetext{
${ }^{28}$ The extensions of these sequential likelihood ratio tests exist in Bai and Perron (1998) and in Bai (1999).
} 


\section{Appendix 3.B: Markov-Chain Approximation}

The methodology for a finite state Markov-chain approximation to univariate and vector auto-regressions was first developed by Tauchen (1986), and is presented here. His procedure for finding a discrete-valued Markov chain whose sample paths approximate well those of a vector auto-regression draws from an additively separable intertemporal utility function equation for the asset price $p$ of the form:

$$
u^{\prime}(h) p(h)=\beta \int u^{\prime}\left(h^{\prime}\right)\left[p\left(h^{\prime}\right)+h^{\prime}\right] F\left(d h^{\prime} \mid h\right),
$$

where $u^{\prime}(h)$ is the marginal utility of consumption, $h$ is the dividend, $\beta$ is the subjective rate of discount, and $F\left(d h^{\prime} \mid h\right)$ is the conditional distribution of the dividend. Defining the logarithm of the dividend as the state variable $(y=\log (h))$, the law of motion is $y^{\prime}=\lambda y+\epsilon$, where $\epsilon$ is a white noise. Tauchen (1986) assumes that the recursive utility function admits a unique solution for the asset price as a function $p(y)$ of the logarithm of the dividend. ${ }^{29}$

Tauchen (1986)'s method proposes an algorithm for choosing the state variables and the transition probabilities, so that the resulting finite state Markov chain mimics closely an underlying continuous-valued auto-regression. For a state variable $y_{t}$ generated by the auto-regressive scheme,

$$
y_{t}=\lambda y_{t-1}+\epsilon_{t},
$$

where $\epsilon_{t}$ is a white noise process with a variance of $\sigma_{\epsilon}^{2}$. The distribution function of $\epsilon_{t}$ is assumed to be $\operatorname{Pr}[\epsilon \leq u]=F\left(u / \sigma_{\epsilon}\right)$, where $F$ is a cumulative distribution function (cdf) with unit variance. $\tilde{y}_{t}$ denotes the discrete-valued process that approximates the continuous-valued of the $A R(1)$ process, and $\bar{y}^{1}<\bar{y}^{2}, \ldots,<\bar{y}^{N}$ represent the values that $\tilde{y}_{t}$ may take. Tauchen (1986)'s method for selecting the values $\bar{y}^{j}$ is to let $\bar{y}^{N}$ be a multiple $m$ of the unconditional standard deviation $\sigma_{y}=\left(\sigma_{\epsilon}^{2} /\left(1-\lambda^{2}\right)\right)^{1 / 2}$. It is assumed that $\bar{y}^{1}=-\bar{y}^{N}$, while the remaining discrete values are equispaced over the interval $\left[\bar{y}^{1}, \bar{y}^{N}\right]$.

The method for calculating the transition matrix $p_{j k}=\operatorname{Pr}\left[\tilde{y}_{t}=\bar{y}^{k} \mid \tilde{y}_{t-1}=\bar{y}^{j}\right]$ follows. Putting $w=\bar{y}^{k}-\bar{y}^{k-1}$, and for each $j$, if $k$ is between 2 and $N-1$, setting

$$
\begin{aligned}
p_{j k}=\operatorname{Pr}\left[\bar{y}^{k}-w / 2 \leq \lambda \bar{y}^{j}+\epsilon_{t} \leq \bar{y}^{k}+w / 2\right]= & F\left(\frac{\bar{y}^{k}-\lambda \bar{y}^{j}-w / 2}{\sigma_{\epsilon}}\right) \\
& -F\left(\frac{\bar{y}^{k}-\lambda \bar{y}^{j}-w / 2}{\sigma_{\epsilon}}\right)
\end{aligned}
$$

otherwise,

$$
p_{j 1}=F\left(\frac{\bar{y}^{1}-\lambda \bar{y}^{j}+w / 2}{\sigma_{\epsilon}}\right)
$$

and

$$
p_{j N}=1-F\left(\frac{\bar{y}^{N}-\lambda \bar{y}^{j}-w / 2}{\sigma_{\epsilon}}\right)
$$

\footnotetext{
${ }^{29}$ Such pricing functions date back to Lucas (1978), Brock (1982), and others.
} 
This assignment of the transition probabilities is equivalent of making the distribution of $\tilde{y}_{t}$ conditional on $\tilde{y}_{t-1}=\bar{y}^{j}$ as a discrete approximation of the distribution of a certain random variable contingent on $\bar{y}^{j}$ and $\epsilon \cdot{ }^{30}$ To assess the adequacy of the approximation of the transition probabilities, note that the discrete process $\tilde{y}_{t}$ admits representation of the form, $\tilde{y}_{t}-\bar{\lambda} \tilde{y}_{t-1}=\tilde{\epsilon}_{t}$, with $\operatorname{cov}\left(\tilde{\epsilon}_{t}, \tilde{y}_{t-1}\right)=0$, where $\bar{\lambda}=\operatorname{cov}\left(\tilde{y}_{t}, \tilde{y}_{t-1}\right) / \operatorname{var} \tilde{y}_{t}$, and $\sigma_{\tilde{\epsilon}}^{2}=\left(1-\bar{\lambda}^{2}\right) \operatorname{var}\left(\tilde{y}_{t}\right)$. The parameters $\bar{\lambda}$ and $\sigma_{\tilde{\epsilon}}^{2}$ are functions of the second moments of the $\tilde{y}_{t}$ process, and these moments can be computed from the transition matrix and the set $\left\{\bar{y}^{j}\right\}$.

\footnotetext{
${ }^{30}$ This random variable is of the form: $v=\lambda \bar{y}^{j}+\epsilon$ where $\lambda \bar{y}^{j}$ is fixed and $\epsilon$ is distributed at the white noise $\epsilon_{t}$.
} 


\section{Appendix 3.C: Descriptive Statistics}

Table 3.C.6: Descriptive Statistics of Consumption Growth Factors (1960-2014)

\begin{tabular}{|c|c|c|c|c|c|}
\hline Country & Obs. & Mean & Std. Dev. & Min & Max \\
\hline Bangladesh & 54 & 1.005216 & 0.0460672 & 0.8464927 & 1.086463 \\
\hline Benin & 54 & 1.00463 & 0.0399813 & 0.8393903 & 1.085028 \\
\hline Bolivia & 54 & 1.011858 & 0.0390519 & 0.8786815 & 1.136234 \\
\hline Burkina Faso & 54 & 1.014325 & 0.0693802 & 0.8589628 & 1.287234 \\
\hline Burundi & 54 & 1.017323 & 0.0787851 & 0.8422803 & 1.278561 \\
\hline Cameroon & 54 & 1.007109 & 0.0449415 & 0.874505 & 1.106108 \\
\hline Chad & 54 & 1.009766 & 0.1174986 & 0.777664 & 1.689235 \\
\hline Congo & 54 & 1.015912 & 0.0649835 & 0.7975834 & 1.203761 \\
\hline Côte d'Ivoire & 54 & 1.007662 & 0.0682727 & 0.7591224 & 1.111583 \\
\hline Ethiopia & 54 & 1.030977 & 0.0784764 & 0.8008052 & 1.221531 \\
\hline The Gambia & 54 & 1.004744 & 0.0928998 & 0.7305721 & 1.362432 \\
\hline Ghana & 54 & 1.009596 & 0.0730914 & 0.8256029 & 1.20319 \\
\hline Guatemala & 54 & 1.013591 & 0.0189034 & 0.9461869 & 1.050522 \\
\hline Guinea & 54 & 1.010741 & 0.050105 & 0.8882738 & 1.174274 \\
\hline Guinea Bissau & 54 & 1.016483 & 0.0824929 & 0.7541997 & 1.260783 \\
\hline Haiti & 54 & 1.007287 & 0.0597321 & 0.86766 & 1.163125 \\
\hline Honduras & 54 & 1.01257 & 0.0332295 & 0.9505893 & 1.123654 \\
\hline India & 54 & 1.029227 & 0.0309705 & 0.940853 & 1.082704 \\
\hline Indonesia & 54 & 1.036852 & 0.0409917 & 0.9209041 & 1.13411 \\
\hline Kenya & 54 & 1.008767 & 0.0539459 & 0.8916304 & 1.133386 \\
\hline Lesotho & 54 & 1.030701 & 0.0581526 & 0.9286685 & 1.236249 \\
\hline Malawi & 54 & 1.008736 & 0.072594 & 0.7929404 & 1.246934 \\
\hline Mauritania & 54 & 1.031884 & 0.1566281 & 0.5159126 & 1.654761 \\
\hline Morocco & 54 & 1.02913 & 0.043495 & 0.934367 & 1.152151 \\
\hline Mozambique & 54 & 1.018588 & 0.0566461 & 0.8890447 & 1.291605 \\
\hline Nepal & 54 & 1.018217 & 0.0387728 & 0.9292915 & 1.145406 \\
\hline Nicaragua & 54 & 1.006948 & 0.0646911 & 0.7463497 & 1.169188 \\
\hline Nigeria & 54 & 1.022942 & 0.140603 & 0.7857614 & 1.629491 \\
\hline Pakistan & 54 & 1.022912 & 0.0293318 & 0.9602338 & 1.095673 \\
\hline Philippines & 54 & 1.016854 & 0.0174161 & 0.962156 & 1.059689 \\
\hline Rwanda & 54 & 1.011809 & 0.0818174 & 0.6982229 & 1.168109 \\
\hline Syria & 54 & 1.022631 & 0.1167106 & 0.7924271 & 1.480501 \\
\hline Tanzania & 54 & 1.023359 & 0.0573527 & 0.9010585 & 1.300008 \\
\hline Togo & 54 & 1.010119 & 0.0724572 & 0.854517 & 1.220608 \\
\hline Uganda & 54 & 1.011078 & 0.0506233 & 0.8488763 & 1.216916 \\
\hline Zambia & 54 & 1.000783 & 0.0887954 & 0.8090424 & 1.35824 \\
\hline Zimbabwe & 54 & 1.033907 & 0.2064218 & 0.8062489 & 2.338038 \\
\hline
\end{tabular}




\section{Appendix 3.D: Structural Breaks Estimates}

Table 3.D.7: Estimated Structural Breaks: 37 Interruptions

\begin{tabular}{|c|c|c|c|c|c|c|}
\hline Country & Lag-length & $t_{0}$ & $T_{1}$ & $T$ & Sup- $W$ & $\mathrm{p}$-value \\
\hline Bangladesh & 2 & 1960 & 1976 & 2014 & 18.0713 & 0.0086 \\
\hline Benin & 1 & 1960 & 1989 & 2014 & 7.8929 & 0.2134 \\
\hline Bolivia & 1 & 1960 & 1984 & 2014 & 13.7829 & 0.0194 \\
\hline Burkina Faso & 1 & 1960 & 1995 & 2014 & 11.4547 & 0.0522 \\
\hline Burundi & 1 & 1960 & 2006 & 2014 & 17.3521 & 0.0040 \\
\hline Cameroon & 2 & 1960 & 1978 & 2014 & 29.3124 & 0.0000 \\
\hline Chad & 1 & 1960 & 2005 & 2014 & 7.1942 & 0.2748 \\
\hline Congo & 2 & 1960 & 1985 & 2014 & 4.7196 & 0.8366 \\
\hline Côte d'Ivoire & 1 & 1960 & 1980 & 2014 & 44.2737 & 0.0000 \\
\hline Ethiopia & 1 & 1960 & 2005 & 2014 & 18.3622 & 0.0025 \\
\hline The Gambia & 1 & 1960 & 2003 & 2014 & 10.4158 & 0.0801 \\
\hline Ghana & 1 & 1960 & 2002 & 2014 & 11.2312 & 0.0573 \\
\hline Guatemala & 2 & 1960 & 1987 & 2014 & 11.6343 & 0.1188 \\
\hline Guinea & 1 & 1960 & 2006 & 2014 & 10.5098 & 0.0771 \\
\hline Guinea Bissau & 1 & 1960 & 1998 & 2014 & 7.2526 & 0.2691 \\
\hline Haiti & 1 & 1960 & 1995 & 2014 & 14.6280 & 0.0134 \\
\hline Honduras & 1 & 1960 & 2000 & 2014 & 12.2277 & 0.0378 \\
\hline India & 1 & 1960 & 2005 & 2014 & 18.2749 & 0.0026 \\
\hline Indonesia & 1 & 1960 & 1998 & 2014 & 13.6875 & 0.0540 \\
\hline Kenya & 1 & 1960 & 1995 & 2014 & 19.1033 & 0.0018 \\
\hline Lesotho & 1 & 1960 & 1979 & 2014 & 9.0464 & 0.1379 \\
\hline Malawi & 2 & 1960 & 2002 & 2014 & 11.2902 & 0.1347 \\
\hline Mauritania & 1 & 1960 & 1980 & 2014 & 3.5040 & 0.8103 \\
\hline Morocco & 2 & 1960 & 2003 & 2014 & 13.9874 & 0.0479 \\
\hline Mozambique & 1 & 1960 & 2002 & 2014 & 21.7556 & 0.0005 \\
\hline Nepal & 2 & 1960 & 1984 & 2014 & 6.9797 & 0.5263 \\
\hline Nicaragua & 1 & 1960 & 1978 & 2014 & 12.8617 & 0.0288 \\
\hline Nigeria & 2 & 1960 & 2007 & 2014 & 49.0393 & 0.0000 \\
\hline Pakistan & 1 & 1960 & 2004 & 2014 & 15.8126 & 0.0079 \\
\hline Philippines & 2 & 1960 & 1986 & 2014 & 12.9854 & 0.0712 \\
\hline Rwanda & 1 & 1960 & 2005 & 2014 & 7.7204 & 0.2274 \\
\hline Syria & 1 & 1960 & 1974 & 2014 & 7.7523 & 0.2247 \\
\hline Tanzania & 1 & 1960 & 1997 & 2014 & 6.6095 & 0.3366 \\
\hline Togo & 1 & 1960 & 1980 & 2014 & 11.5051 & 0.0512 \\
\hline Uganda & 2 & 1960 & 1994 & 2014 & 16.5071 & 0.0169 \\
\hline Zambia & 2 & 1960 & 1976 & 2014 & 15.1518 & 0.0298 \\
\hline Zimbabwe & 2 & 1960 & 2007 & 2014 & 27.7080 & 0.0001 \\
\hline
\end{tabular}

Note: The sequential algorithm identifies 37 breakpoints, of which only 25 are significant according to the supremum Wald test. 


\section{Appendix 3.E: Higher Risk-Aversion Level}

Table 3.E.8: Welfare Cost of Fluctuations versus Benefit of Extra 1\% Growth

\begin{tabular}{lccc}
\hline \hline Country & $\lambda(\%)$ & $\zeta(\%)$ & $\lambda(\%)-\zeta(\%)$ \\
\hline Bangladesh & 0.1411 & 18.8995 & -18.7584 \\
Benin & 0.1081 & 19.2398 & -19.1317 \\
Bolivia & 0.0825 & 15.6298 & -15.5473 \\
Burkina Faso & 0.1623 & 14.4102 & -14.2479 \\
Burundi & 0.3811 & 13.7355 & -13.3544 \\
Cameroon & 0.2358 & 17.7246 & -17.4888 \\
Chad & 1.9577 & 17.0396 & -15.0819 \\
Congo & 0.3749 & 13.6313 & -13.2564 \\
Côte d'Ivoire & 0.3246 & 17.6126 & -17.2880 \\
Ethiopia & 0.2786 & 10.3845 & -10.1059 \\
The Gambia & 0.9629 & 19.4331 & -18.4702 \\
Ghana & 0.3727 & 16.6875 & -16.3148 \\
Guatemala & 0.0196 & 14.8382 & -14.8186 \\
Guinea & 0.1415 & 16.1145 & -15.9730 \\
Guinea Bissau & 0.4524 & 14.0238 & -13.5714 \\
Haiti & 0.2325 & 17.7799 & -17.5474 \\
Honduras & 0.0585 & 15.3381 & -15.2796 \\
India & 0.0344 & 10.6766 & -10.6422 \\
Indonesia & 0.1700 & 9.3433 & -9.1733 \\
Kenya & 0.1758 & 17.0233 & -16.8475 \\
Lesotho & 0.2085 & 10.7112 & -10.5027 \\
Malawi & 0.2097 & 16.7488 & -16.5391 \\
Mauritania & 2.6126 & 8.6371 & -6.0245 \\
Morocco & 0.0682 & 10.7022 & -10.6340 \\
Mozambique & 0.1503 & 13.2930 & -13.1427 \\
Nepal & 0.0329 & 13.3966 & -13.3637 \\
Nicaragua & 0.2871 & 17.9743 & -17.6872 \\
Nigeria & 1.6151 & 12.0546 & -10.4395 \\
Pakistan & 0.0353 & 12.0840 & -12.0487 \\
Philippines & 0.0143 & 13.6705 & -13.6562 \\
Rwanda & 0.4990 & 15.7573 & -15.2583 \\
Syria & 1.3629 & 12.4329 & -11.0700 \\
Tanzania & 0.1385 & 11.9943 & -11.8558 \\
Togo & 0.3575 & 16.4458 & -16.0883 \\
Uganda & 0.3119 & 15.6044 & -15.2925 \\
Zambia & 0.9485 & 22.1818 & -21.2333 \\
Zimbabwe & 10.9784 & 11.7873 & -0.8089 \\
\hline \hline & & & \\
\hline
\end{tabular}

Note: See Table (3.3). 
Table 3.E.9: Welfare Cost of Fluctuations versus Benefit of Extra 1\% Growth

\begin{tabular}{lccc}
\hline \hline Country & $\lambda(\%)$ & $\zeta(\%)$ & $\lambda(\%)-\zeta(\%)$ \\
\hline Bangladesh & 0.0233 & 14.1683 & -14.1450 \\
Bolivia & 0.2155 & 18.6803 & -18.4648 \\
& 0.0085 & 13.0543 & -13.0458 \\
Burkina Faso & 0.3083 & 17.9522 & -17.6439 \\
Burundi & 0.4725 & 18.8133 & -18.3408 \\
Ethiopia & 0.3480 & 11.6264 & -11.2784 \\
The Gambia & 1.2951 & 21.9065 & -20.6114 \\
Ghana & 0.5305 & 20.3011 & -19.7706 \\
Guinea & 0.1031 & 20.2652 & -20.1621 \\
Haiti & 0.2951 & 20.8128 & -20.5177 \\
Honduras & 0.0791 & 17.2101 & -17.1310 \\
India & 0.0360 & 12.0889 & -12.0529 \\
Indonesia & 0.2374 & 9.4339 & -9.1965 \\
Kenya & 0.3059 & 18.7650 & -18.4591 \\
Morocco & 0.0866 & 10.9412 & -10.8546 \\
Mozambique & 0.2219 & 14.9487 & -14.7268 \\
Nigeria & 2.6647 & 11.9191 & -9.2544 \\
Pakistan & 0.0360 & 12.1661 & -12.1301 \\
Philippines & 0.0251 & 16.8903 & -16.8652 \\
Togo & 0.0074 & 12.3214 & -12.3140 \\
Uganda & 0.5597 & 20.5931 & -20.0334 \\
Zimbabwe & 1.2454 & 15.2250 & -13.9796 \\
\hline \hline & 0.8723 & 17.0259 & -16.1536 \\
\hline
\end{tabular}

Note: See Table (3.3). 


\section{Appendix 3.F: Higher Intertemporal Elasticity of Sub- stitution}

Table 3.F.10: Welfare Cost of Fluctuations versus Benefit of Extra 1\% Growth

\begin{tabular}{|c|c|c|c|}
\hline Country & $\lambda(\%)$ & $\zeta(\%)$ & $\lambda(\%)-\zeta(\%)$ \\
\hline Bangladesh & 0.0553 & 12.6815 & -12.6262 \\
\hline Benin & 0.0433 & 13.1133 & -13.0700 \\
\hline Bolivia & 0.0270 & 9.1616 & -9.1346 \\
\hline Burkina Faso & 0.0546 & 8.0495 & -7.9949 \\
\hline Burundi & 0.1131 & 7.4560 & -7.3429 \\
\hline Cameroon & 0.0810 & 11.2864 & -11.2054 \\
\hline Chad & 0.6665 & 10.2976 & -9.6311 \\
\hline Congo & 0.1029 & 7.3673 & -7.2644 \\
\hline Côte d'Ivoire & 0.1177 & 11.1519 & -11.0342 \\
\hline Ethiopia & 0.0711 & 4.9874 & -4.9163 \\
\hline The Gambia & 0.3828 & 13.1885 & -12.8057 \\
\hline Ghana & 0.1283 & 10.1637 & -10.0354 \\
\hline Guatemala & 0.0410 & 8.4576 & -8.4166 \\
\hline Guinea & 0.0475 & 9.6215 & -9.5740 \\
\hline Guinea Bissau & 0.1360 & 7.6886 & -7.5526 \\
\hline Haiti & 0.0852 & 11.3524 & -11.2672 \\
\hline Honduras & 0.0189 & 8.8911 & -8.8722 \\
\hline India & 0.0089 & 5.1987 & -5.1898 \\
\hline Indonesia & 0.0335 & 4.3201 & -4.2866 \\
\hline Kenya & 0.0619 & 10.5405 & -10.4786 \\
\hline Lesotho & 0.0499 & 5.2094 & -5.1595 \\
\hline Malawi & 0.0795 & 10.2527 & -10.1732 \\
\hline Mauritania & 0.5445 & 3.7617 & -3.2172 \\
\hline Morocco & 0.0177 & 5.2139 & -5.1962 \\
\hline Mozambique & 0.0439 & 7.1182 & -7.0743 \\
\hline Nepal & 0.0112 & 7.2129 & -7.2017 \\
\hline Nicaragua & 0.1063 & 11.5622 & -11.4559 \\
\hline Nigeria & 0.4741 & 6.0638 & -5.5897 \\
\hline Pakistan & 0.0098 & 6.1961 & -6.1863 \\
\hline Philippines & 0.0270 & 7.4482 & -7.4212 \\
\hline Rwanda & 0.1633 & 9.2307 & -9.0674 \\
\hline Syria & 0.3749 & 6.3499 & -5.9750 \\
\hline Tanzania & 0.0381 & 6.1219 & -6.0838 \\
\hline Togo & 0.1216 & 9.9212 & -9.7996 \\
\hline Uganda & 0.0933 & 9.1039 & -9.0106 \\
\hline Zambia & 0.4524 & 17.1668 & -16.7144 \\
\hline Zimbabwe & 2.5469 & 5.2144 & -2.6675 \\
\hline
\end{tabular}

Note: See Table (3.3). 
Table 3.F.11: Welfare Cost of Fluctuations versus Benefit of Extra 1\% Growth

\begin{tabular}{lccc}
\hline \hline Country & $\lambda(\%)$ & $\zeta(\%)$ & $\lambda(\%)-\zeta(\%)$ \\
\hline Bangladesh & 0.0086 & 7.8549 & -7.8463 \\
Bolivia & 0.0832 & 12.4006 & -12.3174 \\
& 0.0152 & 6.9465 & -6.9313 \\
Burkina Faso & 0.1266 & 11.5398 & -11.4132 \\
Burundi & 0.1829 & 12.5141 & -12.3312 \\
Ethiopia & 0.0938 & 5.8390 & -5.7452 \\
The Gambia & 0.6003 & 16.6220 & -16.0217 \\
Ghana & 0.2249 & 14.4308 & -14.2059 \\
Guinea & 0.0440 & 14.4781 & -14.4341 \\
Haiti & 0.1301 & 15.2146 & -15.0845 \\
Honduras & 0.0282 & 10.7533 & -10.7251 \\
India & 0.0100 & 6.1997 & -6.1897 \\
Indonesia & 0.0477 & 4.3722 & -4.3245 \\
Kenya & 0.1185 & 12.4864 & -12.3679 \\
Morocco & 0.0227 & 5.3760 & -5.3533 \\
Mozambique & 0.0701 & 8.5165 & -8.4464 \\
Nigeria & 0.7021 & 5.8770 & -5.1749 \\
Pakistan & 0.0100 & 6.2570 & -6.2470 \\
Philippines & 0.0657 & 10.4564 & -10.3907 \\
Togo & 0.0123 & 6.3798 & -6.3675 \\
Uganda & 0.2416 & 14.8341 & -14.5925 \\
Zimbabwe & 0.3320 & 8.5822 & -8.2502 \\
\hline \hline & 0.3029 & 10.4407 & -10.1378 \\
\hline
\end{tabular}

Note: See Table (3.3). 


\section{Part II}

\section{Volatility from the Output Perspective}




\title{
Chapter 4
}

\section{Structural Change and Macroeconomic Volatility: A Linear and Threshold Panel Analysis}

\begin{abstract}
This paper analyses the relationships between structural characteristics and economic volatility, using both a linear panel model and a threshold panel approach. The analysis is based on a novel macro-panel dataset of sectoral shares in the GDP and the volatility of growth rates for 108 countries from 1960 to 2010. Our dependent variable - the growth volatility - is measured as the standard deviations of consecutive five-year per capita GDP growth rates. Structural characteristics include the degree of sectoral specialisation, the share of manufacturing and the share of modern sector in GDP. We find that higher shares of manufacturing, high and increasing shares of the modern sector and a more diversified structure of production all contribute to a reduced volatility of the growth patterns. In addition while using the threshold model to investigate potential non-linearities, we found that the impact of economic structure on growth volatility depends on a certain specific threshold of the production structure of the economy, the initial per capita income level in 1960, the countries' population in 1960 and to a lesser extent on a threshold of exports share in GDP.
\end{abstract}

Keywords: Volatility, Growth, Specialisation, Structural Change, Thresholds.

JEL Classification: C33, O4, O14, O47, L16.

\footnotetext{
${ }^{0}$ This chapter is based on joint paper with Neil Foster-McGregor of UNU-MERIT, which itself extends Foster-McGregor et al. (2015), a background paper for the 2016 United Nations Industrial Development Organization (UNIDO)'s Industrial Development Report.
} 


\subsection{Introduction}

Macroeconomic stability is an important factor for the long-run growth and the overall economic performance, and developing countries exhibit an economic volatility far above the world average (Ramey and Ramey, 1995; Azeinman and Pinto, 2005; Imbs, 2007), as shown by Figure (4.1) below. The numerous global economic crises of the last decade alone have made macroeconomic volatility a key issue in analysing the determinants of economic growth. The multiplicity of ways in which it affects the long-term growth potential of economies, its diverse causes and the array of methods by which it is measured, make economic volatility a multiplex and multidimensional phenomenon (Cariolle, 2012). Countries' vulnerability to macroeconomic volatility is often driven by a number of handicaps, which are either structural or depend on the level of economic development: the exposition to bigger external shocks (capital flows, terms of trade, world interest rate), the frequency of domestic shocks, often generated by intrinsic self-inflicted policy mistakes, and finally the absence of strong "shock stabilisers" in the forms of diversified financial markets and macroeconomic stabilisation policies (Loayza et al., 2007). According to estimates produced by Hnatkovska and Loayza (2005), based on a sample of 79 countries, increasing the average value of volatility by the value of its standard deviation would have resulted in an average loss of 1.3 points for growth in GDP over the period 1960-2000, and a 2.2 points for the decade 1990-2000.

This paper investigates the relationships between structural change and the ability of economies to sustain a stable economic growth over longer periods of time, using both a linear panel model and a threshold panel analysis. It borrows heavily and extend on Foster-McGregor et al. (2015), which was initially written as a background paper for the United Nations Industrial Development Organisation (UNIDO)'s 2016 Industrial Development Report (IDR) on Sustainable and Inclusive Industrial Development. The central question addressed in the 2016 IDR was under what conditions technological change can trigger virtuous processes of structural change in developing countries and emerging economies resulting in sustainable and inclusive patterns of economic growth. The report distinguishes three dimensions of sustainability: (a) The ability of countries to sustain uninterrupted economic growth over longer periods of time; (b) The inclusiveness of the process of economic development and the extent to which broad segments of the population participate in and benefit from the fruits of economic development; and (c) The environmental sustainability of economic development. This paper - just like its original longer version - focuses on the first dimension of sustainability and specifically asks what types of economic structure and what patterns of structural change contribute to developing countries' and to emerging economies' ability to sustain stable economic growth over longer periods of time.

To answer this question we consider one specific dimension of economic performance. In particular, we consider the relationship between economic structure and the volatility of per capita GDP growth. Our main argument put forward in this paper is that Low and 
Middle-Income countries, diversification of the structure of economic activities is important for the ability to sustain stable growth over longer periods of time and thus achieve sustained growth and catch up. To capture this relationship, we relate the volatility of economic growth to a wide range of variables measuring different structural characteristics of modern economies. These include measures of the share of manufacturing - and other modern sectors - in the GDP and indicators of the degree of specialisation and diversification. We consider both the levels (structure) and changes over time (structural change) in these variables. The empirical analysis is primarily based on a newly created database of sectoral shares in value added for the 1960-2010 period, which includes data for 108 developing and advanced economies. This macro-panel dataset is used to construct the indicators of economic structure and specialisation, which are combined with data on economic growth from the Maddison Project database to address our questions of interest.

The theoretical rationale for considering indicators of specialisation relates to portfolio arguments. A country with a more diversified production structure is expected to be less vulnerable to external shocks, fluctuations and growth interruptions. Equally, a more diversified structure may create more opportunities for linkage and spillover effects, such that productivity and technological change in one sector may have positive effects on developments in other sectors. Thus, one can hypothesise that a country with a very strong concentration of activities in a single actor (e.g., agriculture, mining or tourism) will be less able to sustain stable growth over longer periods of time than a country with a broader portfolio of activities. The counter-argument to this is that specialisation according to comparative advantages might provide more growth benefits. For countries at lower levels of per capita income, the findings of this paper show that a more diversified economic structure makes it easier to sustain a stable economic growth. Dynamically, diversification also contributes to the stability of growth. In addition we use a threshold model to investigate these non-linearities and found that the impact of economic structure on growth volatility depends on a certain specific threshold of the production structure of the economy, the initial per capita income level in 1960, the countries' population in 1960 and to a lesser extent on a threshold of exports share in GDP.

In the context of structural change, special attention is paid to industrialisation and the role of the manufacturing sector. Does stability of growth depend on a large and/or increasing share of manufacturing in the GDP (i.e., industrialisation)? One of the wellknown methods to approach this issue empirically is to include the share of manufacturing in GDP in the regressions (Szirmai and Verspagen, 2015). We also examine the effects of newer measures such as the share of the so-called 'modern-sector' in total employment (Lavopa and Szirmai, 2014, 2015). The modern sector includes the sectors with the greatest potential for productivity increases. Besides manufacturing, these include mining, utilities, construction, transport, storage and communication and finance, insurance and business services. Finally, we also examine the impact of the share of manufacturing in 
value added within the modern sector.

The paper provides indications that, other things equal, a larger share of manufacturing in the economy - i.e., greater industrialisation - contributes to a lower volatility of economic growth. In contrast, the share of the modern sector taken as a whole does not have significant effects on volatility, though the share of manufacturing within the modern sector has a substantial and significant impact on the ability to sustain stable growth. These latter effects are even more marked than those of manufacturing shares in the total economy.

Figure 4.1: Macroeconomic Volatility and Economic Growth

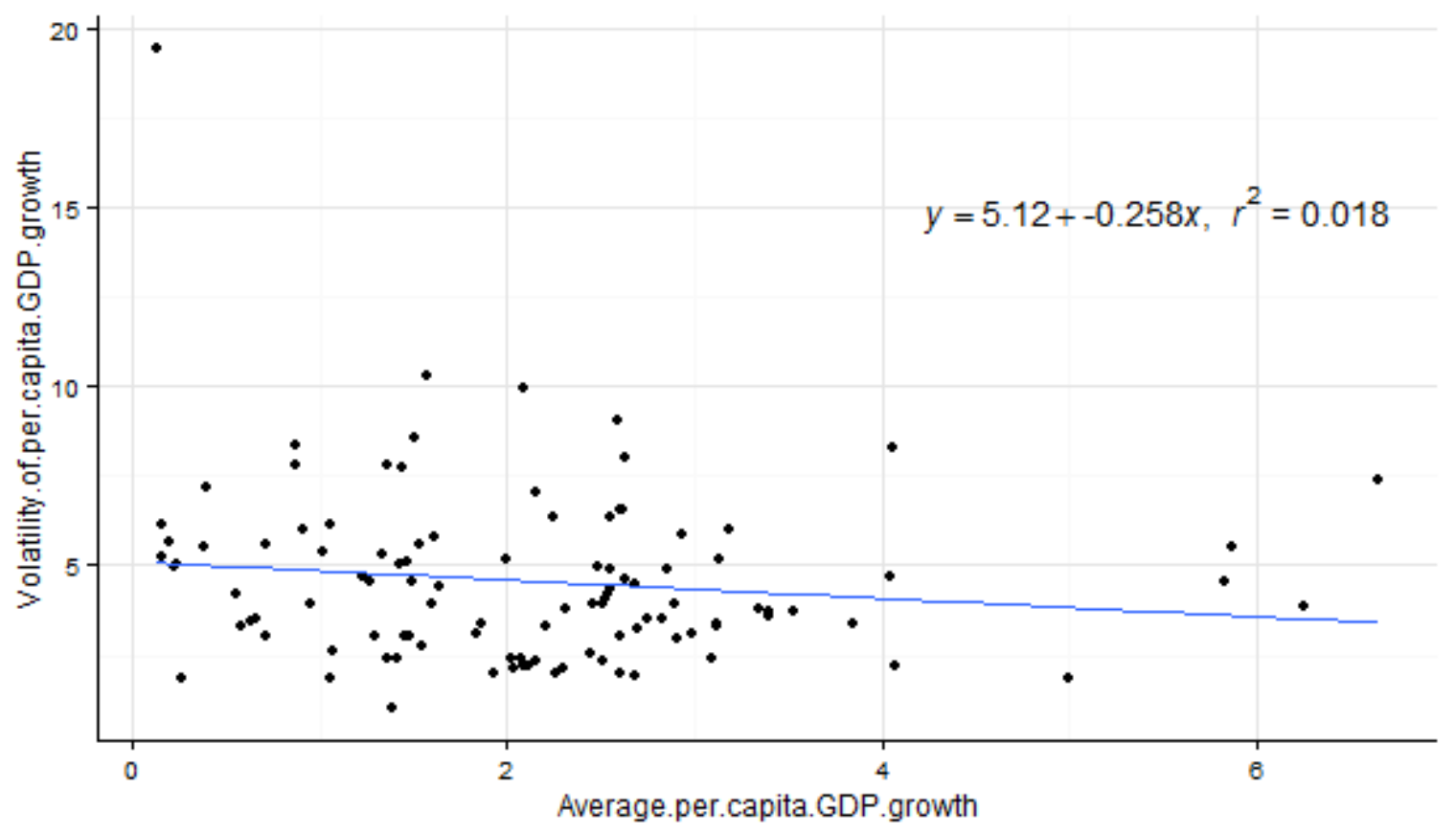

Note: The volatility of economic growth is measured as the standard deviation of the annual growth rate of per capita GDP within each five-year period, from 1960 to 2010. The average GDP growth on the $\mathrm{x}$-axis is also measured over the same time-span for our sample of 108 countries.

In our analysis we account for the possibility of non-linear effects related to a country's level of economic development. At lower levels of per capita GDP, growth generally tends to be more erratic and more vulnerable to sudden interruptions, especially if the production structure is highly undiversified and the manufacturing sector is underdeveloped. Some countries achieve structural transformations, which go hand in hand with longer and more stable growth experiences. Advanced economies tend to have fewer interruptions in their growth process and longer lasting growth episodes (Pritchett, 2000). But at high levels of per capita income, further diversification may no longer be so important. We therefore account for the potentially differing impacts of specialisation and structure on performance at different levels of economic development in our analysis.

The remainder of the paper is structured as follows: Section (4.2) discusses the rele- 
vant literature; Section (4.3) describes the details of the linear panel model; Section (4.4) describes the data used and reports initial summary statistics; Section (4.5) presents the results of the linear panel model; section (4.6) presents both the framework of the single-threshold panel model and its results; Section (4.7) describes alternative specialisation/diversification indicators; while Section (4.8) concludes.

\subsection{Related Literature}

\subsubsection{Structural Diversification and Growth}

Two aspects of structural change will be singled out for attention in this paper, namely specialisation/diversification and industrialisation/deindustrialisation.

A recent UNIDO report, entitled Diversification vs. Specialization as Alternative Strategies for Economic Development, summarises the theoretical debates concerning specialisation and diversification (Kaulich, 2012). On the one hand, trade theories of comparative advantage argue that successful economic development is associated with specialisation in a narrow range of activities. On the other hand, many theories argue that successful economic development involves a process of diversification of sectors, activities and exports. Too much specialisation results in vulnerability to shocks (Osakwe, 2007) and changes in the terms of trade. One needs a broad portfolio of activities.

In a seminal contribution, Imbs and Wacziarg (2003) take an intermediate position. They propose a non-linear U-shaped relationship between GDP per capita and sectoral specialisation. For low-income countries there is a positive relationship between diversification and levels of GDP per capita. The underlying assumption is that developing countries that succeed in diversifying the structure of their production or the structure of their export package will grow more rapidly, because diversification makes them more resilient to external shocks. However, beyond some threshold level of GDP per capita, the opposite relationship comes to dominate. As GDP per capita continues to increase, this is associated with increasing concentration and specialisation, both in the total economy and within manufacturing. The turning point at which specialisation sets in is quite high (16.500 PPP dollars of 2000).

From the perspective of the Low and Lower-Middle-Income economies, this implies that diversification away from agriculture and diversification within the manufacturing sector is associated with increases in GDP per capita. The implication for Low-Income countries, in particular, is that they can overcome their economic marginalisation through the acquisition of skills and knowledge necessary to diversify their economic portfolio rather than by focusing on "what they do best", while High-Income countries seem to only benefit from specialisation (Kaulich, 2012). According to Subramanian (2007), diversification is intrinsic to development. Diversification is also linked to sophistication. It is the ability to competitively produce a wider range of increasingly sophisticated goods, 
which drives the process of diversification. Low-Income economies are typically specialised in a limited range of products. As their per capita income increases, the economy becomes more diversified and the range of products broadens. At higher levels of income, specialisation again comes to predominate.

In a careful empirical analysis of both export and sector structure data, the author of the UNIDO report examines the inverted U-curve relationship and finds support for the notion that at lower levels of GDP per capita, there is a positive relationship between the degree of diversification and the level of per capita income. With regard to specialisation at higher levels, the findings are mixed, but that is of less relevance to the present report which focuses on Low and Middle-Income countries. However, the report warns that evidence is not conclusive. In particular, the findings are still driven by large timeinvariant differences in degrees of specialisation in cross-country datasets.

In this paper we will examine the effects of specialisation/diversification on growth performance at different levels of economic development. As our database on economic structure refers to value added, we focus on specialisation/diversification of the structure of the economy rather than the structure of exports. Note however, that the inverted Ushaped relationship discussed above is about relationships between level variables: How are levels of development related to degrees of specialisation? Our analysis will focus on: (1) the relationship between degrees of specialisation and growth; and (2) the relationship between changes in specialisation and growth.

\subsubsection{Which Sectors Act as the Engines of Growth?}

What all structuralist theories have in common is that the structure of the economy is important for economic growth, because some sectors have more growth potential than others. This means that when an economy succeeds in increasing the share of sectors with high growth potential in a given period, this will enhance the growth of the economy, while if the share of sectors with low growth potential increases, this will reduce the growth of the economy. This opens the search for the structural shifts which are growth enhancing or reducing (McMillan and Rodrik, 2011; Timmer and Szirmai, 2000). In this context, there are debates on the respective roles of agriculture and industry, or the respective roles of industry and the service sector. Also, there is a search for specific sectors that can act as engines of growth such as ICT hardware, ICT software services, the automobile industry, capital goods sectors or high-tech sectors. Since 1950, one of the classic hypothesis in development economics is that the manufacturing sector has a key role to play as an engine of growth in low-income economies.

One should realise that the role of sectors may change over time and that different sectors may play key roles in different types of economies. One of the important stylised facts of economic development is that the share of manufacturing in value added and employment tends to increase when developing countries start growing at low levels of development. It peaks at intermediate levels of per capita income and subsequently de- 
clines as the service sector becomes more important at high levels of per capita income (Szirmai, 2012; Tregenna, 2013, 2015). The interpretation of the increase in the manufacturing share is that manufacturing plays a special role as engine of growth and catch up at lower levels of economic development. Even when its share starts to decline at higher levels, it remains important as a driver of growth, though perhaps less exclusively so.

The role of manufacturing as an engine of growth is due to the special characteristics of this sector (Kaldor, 1966, 1967; McMillan and Rodrik, 2011; Rowthorn, 1994; Szirmai, 2012; Szirmai and Verspagen, 2011, 2015). First, productivity levels in manufacturing are higher than those in other sectors and productivity growth is more rapid. Therefore structural changes involving a shift of resources to manufacturing provide both the static and dynamic productivity bonuses. The assumption is that the service sector as a whole has fewer productivity bonuses, due to Baumol's law operating, in many sub-sectors of services, especially personal services. Second, manufacturing provides special opportunities for accumulation of capital, spatial concentration, agglomeration economies and economies of scale. Also, manufacturing goods are easily tradable so the sector can profit not only from domestic demand but also from global demand. Finally, the manufacturing sector plays a special role as a driver of technological advance, the factor which is perhaps the most important in modern economic growth (Kaldor, 1966; Cornwall, 1977). Actually, this argument involves a number of strands. Firstly, manufacturing and certain sectors within manufacturing are presumed to be more R\&D intensive than other sectors (Jacob and Sasso, 2015). Secondly, it is assumed that more innovation takes place in manufacturing than in other sectors. This is particularly the case for some sub-sectors of manufacturing. Thirdly, manufacturing provides special opportunities for technologically lagging countries to profit from global technology and knowledge flows. Finally, it is assumed that the spillovers and linkages for manufacturing are stronger than for other sectors. The argument that the manufacturing sector plays a key role in technological advance for the total economy is perhaps the most important argument in favour of industrial policies favouring this sector.

A substantial part of the literature, as summarised in Szirmai (2012), Szirmai and Verspagen (2015), Lavopa (2015), and Tregenna (2015), provides a measure of support for the engine of growth hypothesis. But the hypothesis is also fiercely contested. Critics argue that several modern service sectors such as ICT services, financial services, or transport and logistics can and do play the role of engine of growth in a manner very similar to that of manufacturing in the past (Dasgupta and Singh, 2006; Eichengreen, 2009; Van Ark et al., 2003). The example of India is often mentioned as a case of serviceled growth since the 1990s. In this paper we will empirically examine the relationship between (changes in the) the share of manufacturing and the volatility of growth to contribute to the debate of sectoral sources of economic growth.

One of the arguments of critics of the engine of growth hypothesis is that some modern service sectors such as software, financial services or logistics have many of the 
same characteristics of dynamic manufacturing sectors and can also act as engines of growth. Rather than focusing only on the distinction between manufacturing and services in the discussion of structural change, Lavopa (2015) and Lavopa and Szirmai (2014) have examined the role of the so-called modern sector. The modern sector includes the industrial sector (mining, manufacturing, utilities and construction) and dynamic services (transport, storage and communication and finance, insurance and business services). While Lavopa and Szirmai (2014) develop a new index of modernisation, based on the product of the share of the sector in employment and its relative productivity compared with the global frontier, the present paper only includes a variable measuring the share of the modern sector in GDP (as with the share of manufacturing).

\subsubsection{What is the Role of Thresholds?}

A very common and recurrent problem of panel data is the heterogeneity of individuals. This entails that each individual in the analysis is specific, and that structural relationships may markedly vary across individuals. This heterogeneity, often palpable in intercepts, is reflected by the fixed effect or the random effect. Hsiao (2003) considers many varying slope models for this problem. Among this cluster of models, Hansen (1999)'s fixed-effect panel threshold provides a simple specification but clear implications for economic policy. Although threshold models have long been used in time-series analyses, their use with panel data has somehow been limited.

The relationship between the variables of regression is not always monotonic. The threshold model is aimed at describing the jumping character of structural breaks in the relationships between these variables. One very popular non-linear time-series threshold model for example is the threshold auto-regressive (TAR) model (Tong, 1983). The potential applications of the model are numerous. For example, using five-year interval averages of standard measures of growth, financial development and inflation for a sample of 84 countries and over the 1960-95 period, Rousseau and Wachtel (2009) showed that there is an inflation threshold for the growth and finance relationship that varies between 13 and $25 \%$. When inflation exceeds the threshold, finance ceases to increase economic growth. High levels of inflation could be quite detrimental to growth, while moderate levels of inflation, given the right conditions, could benefit it. Another application of the threshold auto-regressive model concerns the technical spillover of foreign direct investments (FDIs), a widely studied phenomenon. Girma (2005) for instance found that the productivity benefit from FDIs increases with the absorptive capacity until some threshold level, at which point it becomes less pronounced. Equally, there is also a minimum absorptive capacity threshold level below which productivity spillovers tend to be negligible or even negative.

This brief review of the theoretical literature and our early findings suggest that, for any individual country, improvements in the production structure can come through a variety of channels, whose relative importance will depend on certain characteristics of the 
country concerned. One implication is that the impact of a larger share of manufacturing or that of the modern sector on the volatility of growth will also depend on the country characteristics. This is largely confirmed by the empirical literature, where the evidence of a simple linear relationship between economic structure and growth volatility is often mixed, and the evidence for a non-linear relationship, particularly involving thresholds relating to the level of economic development, rather stronger.

\subsection{Linear Panel Analysis}

To examine the relationship between economic structure and aggregate volatility we estimate the following equation, using data on five-year periods with the 1960-2010 period:

$$
\begin{aligned}
\sigma_{i t}= & \alpha_{i}+\beta_{1} \Delta \operatorname{lnPOP} P_{i t}+\beta_{2} R E L U S_{i t}+\beta_{3} E X P G D P_{i t}+\beta_{4} G C F_{i t} \\
& +\beta_{5} K G A T E M P_{i}+\delta \mathbf{Z}_{i t}+\theta X_{i t}+\varphi_{t}+\varepsilon_{i t}
\end{aligned}
$$

where $\sigma$ captures the volatility of economic growth and is measured as the standard deviation of the annual growth rate of per capita GDP within each five-year period, $\triangle \ln P O P$ is the average annual growth rate of population within each five-year period, i.e. $R E L U S_{i t}=\ln \left(G D P P C_{i t} / G D P P C_{U S, t}\right), E X P G D P$ is the average ratio of exports to GDP within each five-year period, $G C F$ is the average ratio of gross capital formation to GDP in each five-year period, $K G A T E M P$ is a dummy variable taking the value one if the country lies in a temperate climate zone, $X$ regroups other controls, and $\mathbf{Z}$ represents our main variable of interest (i.e., a measure of structure or specialisation). Finally included in the baseline model are country and time fixed effects.

Given the panel nature of our dataset, we are able to account for unobserved countryspecific effects through the use of either a random or fixed effects regression. As the Hausman specification test rejects random effects specification, we report results from fixed effects regression models. ${ }^{1}$ One drawback of the fixed effects model is that it eliminates the between (i.e., cross-country) effects completely, with the within-groups estimator expressing the data in deviations from country means. Given that many of our variables, most notably the indicators of economic structure and specialisation, evolve slowly over time, we may expect that the between effects are relatively strong (Szirmai and Verspagen, 2015). For this reason we would like to account for these effects. To do this we further report results using the Hausman-Taylor estimator (Hausman and Taylor, 1981). This is essentially a random effects method that takes the dependency between the country effect and some of the dependent variables into account using instrumental variables for the affected explanatory variables (i.e. the 'endogenous' variables). The method requires that at least one of the instruments is time-variant. In our analysis we have the variable on climate zone (KGATEMP) that is time-invariant. When estimating the Hausman-

\footnotetext{
${ }^{1}$ We also estimated the model using pooled regression, with results from a Chow test indicating that there are significant differences in the country specific fixed effect, thus supporting the fixed effects model.
} 
Taylor model however, we further include other variables capturing initial conditions, and in particular the 1960 values of logged population, of logged GDP per capita, and of years of schooling.

The Hausman-Taylor estimations also require us to determine which of the explanatory variables are endogenous, i.e., correlated with the country effect. To do this, we follow a procedure inspired by Baltagi et al. (2003) and also applied in Jacob and Osang (2007). In this procedure, we run a regression with our dependent variable, i.e. volatility, and, one at a time, a single explanatory variable. Both a random effects and a fixed effects model is estimated, and a Hausman test is carried out to test whether the random effects estimation is appropriate. If it is, the variable is considered as exogenous (i.e., not correlated with the country effect). If the Hausman test indicates that the random effects estimation is not appropriate, we consider the variable as endogenous in the HausmanTaylor estimations. In the baseline regression, only the variable $R E L U S$ is found to be endogenous according to the Hausman test. KGATEMP and the initial values of population, per capita GDP and years of schooling are taken as the time-invariant exogenous variables.

When including the measures of economic structure/specialisation we test a number of possibilities. We begin by including the initial value of the structure/specialisation within each five-year period or at the start of each episode. We then examine whether it is the change, rather than the level, of economic structure/specialisation that is more relevant by including the change in structure/specialisation within each five-year period. For completeness, we include both the level and the change together, along with their interaction. Finally, we allow for the possibility that the effect of structure/specialisation may depend upon the income level of the country (relative to the US). We therefore include an interaction between RELUS and structure/specialisation to capture this, as well as splitting the sample into quartiles based upon RELUS and estimating separate coefficients on structure/specialisation for each of the income quartiles.

\subsection{Data, Variables and Descriptive Statistics}

In order to proceed with the analysis, we use a rich data set from a variety of sources. As for the indicators of economic structure and specialisation, we build on our own database. This database includes data on 108 countries, covering the 1950-2012 period. The dataset contains information about sectoral shares in value added at current prices. The sectoral breakdown is done along nine major economic sectors. ${ }^{2}$ In our analysis we use data within the 1960-2010 period. For the 1950s there were too many missing values, which made it impossible to include this earlier data.

\footnotetext{
${ }^{2}$ Those sectors are: 1. Agriculture; 2. Mining; 3. Manufacturing; 4. Utilities; 5. Construction; 6. Trade, Restaurants and Hotels; 7. Transport, Storage and Communication; 8. Finance, Insurance, Real Estate and Business Services; 9. Government Services, Community, Social and Personal Services.
} 
For quite many countries there were no data for the earlier years because of boundary changes or because the country did not exist yet (e.g. Eritrea, Bangladesh, United Germany, former Soviet Republics, United Vietnam, the Czech and Slovak Republics, the former Yugoslav Republics). The total number of observations for sector structure in the final unbalanced dataset was 1034.

The dataset was compiled from a variety of sources, namely: (1) the Groningen Growth and Development Centre, Ten-sector database (hhtp://www.rug.nl/research/ ggdc/data/10-sector-database). This database includes 42 countries, ten sectors, 1950-2010; (2) The Groningen Growth and Development Centre, World Input-Output Database (http://www.wiod.org/new_site/home.htm). This database includes 40 countries, 35 sectors for the period since 1995; and (3) the UN national accounts website, Table 2.1 Value added by industries at current prices (ISIC Rev. 3), http: //www.data . un.org/Data.aspx?d=SNA\&f=group_code\%3a201, downloaded in February 2015. This source contains country data, with different degrees of breakdown going back to 1950. D. Hard copies of UN National Accounts Statistics: UN Yearbook of National Accounts, 1967 has data for 1953, 1955, 1957-66; UN, Yearbook of National Accounts, 1975 which has data for 1967-74. This source usually provides a breakdown for 11 sectors. The published yearbooks provide data for more countries before 1975, than source (3).

Data on per capita GDP levels and growth rates are obtained from the Maddison database (http://www.ggdc.net/maddison/maddison-project/home.htm). Data on most of the control variables are from the World Bank's World Development Indicators database. Variables constructed from this database include population and population growth, the ratio of gross capital formation to GDP $(G F C)$, and the ratio of exports to GDP $(E X P G D P)$. The variable capturing a country's climate zone (KGATEMP), which is the dummy for whether a country lies in the temperate climate zone, is taken from the dataset of Gallup et al. (1999). Data on years of schooling (SCH) is taken from the Barro and Lee dataset (www. barrolee.com).

In terms of the dependent variables in our analysis, volatility is measured through the standard deviation of the per capita GDP growth rates over each five-year period for the growth modeling, starting with the 1960-64 period and ending with the period 2005-2009.

In the empirical analysis of the relationships between economic structure and economic volatility, there is a wide range of measures of structural characteristics. The first important distinction that can be made is between measures focusing on the degree of specialisation or diversification of the economic structure as a whole and measures capturing the share of selected sectors - e.g. manufacturing - in GDP. The second important distinction is between measures focusing on sector shares in GDP (at either constant or current prices) and sectoral shares in employment. Unless indicated otherwise, we have opted for current price sectoral shares in GDP. The third distinction is between measures 
characterising the structure of the domestic economy and measures characterising the structure of exports. In this paper we use only indicators for the structure of the domestic economy. ${ }^{3}$ The fourth distinction is between static measures of structure at given points in time and changes in structural characteristics over time. Combining these four distinctions results in a wide range of measures that could be constructed, with the main constraint being the availability of consistent long run measures of economic structure for long periods of time and large numbers of countries. The measures used in our analysis are discussed below.

In our empirical analysis we focus on three measures of industrial structure that capture different dimensions of economic structure and a single measure of specialisation. The structure variables are the share of manufacturing in current value added ( $M A N S H)$, the share of the modern sector in current value added $(M O D S H)$, defined as mining, manufacturing, utilities, construction, transport, storage and communication and finance, insurance and business services, and the share of manufacturing value added within the modern sector (MANMODSH). This variable derives from Lavopa (2015).

As measure of specialisation, we use the normalised Theil index $(T H E I L) .{ }^{4}$ The normalised Theil index is defined as follows:

$$
\text { Theil }_{i j t}=\left[\frac{1}{N} \sum_{j=1}^{N}\left(\frac{S_{i j t}}{\bar{S}_{i t}}\right) \ln \left(\frac{S_{i j t}}{\bar{S}_{i t}}\right)\right] / \ln N
$$

where $i, j$ and $t$ index country, sector and time respectively; $N$ refers to the number of sectors, $S_{i j t}$ is the share of industry $j$ in country $i$ in time $t$, and $\bar{S}_{i t}$ is the average share of value added across all sectors for country $i$ in time $t$, i.e. $\bar{S}_{i t}=\frac{1}{n} \sum_{j=1}^{n} S_{i j t}$. Dividing by $\ln N$ ensures that the Theil index lies between zero and one, with a larger value indicating more sophistication or a more unequal distribution. In our analysis the Theil index is constructed using data on value added shares of nine sectors.

Table (4.1) below reports the descriptive statistics for the data used in the five-year panel regressions with volatility as the dependent variable. The table reports that the average value of the volatility across countries and five-year time periods was 0.034. The average manufacturing share is just 18\%, though the maximum value is as high as $58 \%$. The modern sector however is much larger on average at $51 \%$, with a maximum of $90 \%$. Other notable features from this table are the relatively low average value of the Theil index computed on the basis of structural shares in value added, suggesting a relatively low degree of sophistication. Also noteworthy are the relatively low values - just $0.28-$ of income relative to the United States (RELUS). This is an indication of large income gaps with respect to the US. Note that the values of RELUS in excess of 1 are for Qatar, which has a level of GDP above the US.

\footnotetext{
${ }^{3}$ For the use of export shares see Lavopa and Szirmai (2015).

${ }^{4}$ Results are also available using alternative indicators of specialisation in the robustness section, i.e., the Gini, Herfindahl and Hirschman indices.
} 
The descriptive statistics in this table hide differences across income levels. Table (4.2) therefore reports the mean and the standard deviation of the variables for each quartile. Note that the quartiles are constructed on a period-by-period basis rather than by considering quartiles for the full set of data as whole. This table shows substantial differences in the average values of our variables across the different quantiles. Average growth volatility is highest in the lowest quartile and lowest in the highest quartile. The share of manufacturing in the modern sector is also found, on average, to be largest in the highest quartile and smallest in the lowest quartile. As expected the change in the manufacturing and modern sector shares are negative in the highest quartiles, suggesting a process of deindustrialisation in the richest countries. Specialisation tends to be largest in the lowest income quartile, though the change in specialisation is negative - suggesting increased diversification - and relatively large for this group. As expected, the higher income countries tend to have higher investment rates, lower population growth and be more open to trade. 
Table 4.1: Summary Statistics for the Volatility Panel Dataset

\begin{tabular}{|c|c|c|c|c|c|}
\hline Variable & Obs & Mean & Std. Dev. & Min & Max \\
\hline$\triangle \ln G D P P C$ & 1034 & 0.0198 & 0.0347 & -0.3080 & 0.2516 \\
\hline$\sigma$ & 1034 & 0.0335 & 0.0294 & 0.0003 & 0.2658 \\
\hline ManSh & 952 & 0.1827 & 0.0873 & 0.0019 & 0.5839 \\
\hline ModSh & 964 & 0.5085 & 0.1370 & 0.0935 & 0.8970 \\
\hline ModManSh & 952 & 0.3644 & 0.1422 & 0.0023 & 0.8259 \\
\hline Theil & 964 & 0.1618 & 0.0840 & 0.0399 & 0.6355 \\
\hline$\Delta$ ManSh & 915 & -0.0011 & 0.0296 & -0.1936 & 0.1969 \\
\hline$\Delta M o d S h$ & 929 & 0.0018 & 0.0445 & -0.2594 & 0.2408 \\
\hline$\Delta$ ModManSh & 915 & -0.0031 & 0.0569 & -0.3880 & 0.2451 \\
\hline$\Delta$ Theil & 929 & -0.0057 & 0.0354 & -0.2571 & 0.3822 \\
\hline$R E L U S$ & 1034 & 0.2809 & 0.2835 & 0.0165 & 2.8964 \\
\hline$\triangle \ln P O P$ & 1090 & 0.0181 & 0.0138 & -0.0464 & 0.1551 \\
\hline$E X P G D P$ & 904 & 0.3229 & 0.0731 & 0.0441 & 0.6537 \\
\hline$G C F$ & 889 & 0.2262 & 0.0731 & 0.0441 & 0.6537 \\
\hline $\ln P O P_{1960}$ & 1090 & 15.6585 & 1.5640 & 10.7646 & 20.3184 \\
\hline $\ln G D P P C_{1960}$ & 990 & 7.5913 & 0.9354 & 5.9713 & 10.3985 \\
\hline$S C H_{1960}$ & 1010 & 3.2821 & 2.3952 & 0.0133 & 8.8984 \\
\hline$K G A T E M P$ & 1060 & 0.3397 & 0.4211 & 0.0000 & 1.0000 \\
\hline
\end{tabular}

Note: ManSh, ModSh, ModManSh, and Theil refer to the values of the structure and specialisation variables in the initial year of each five-year period, with $\Delta$ ManSh, $\Delta$ ModSh, $\Delta$ ModManSh and $\Delta$ Theil being the change in the variables within each five-year period. $R E L U S$ refers to relative income, $S C H$ to years of education of the population of 15 years and above, $G F C$ to Gross Fixed Capital Formation and KGATEMP to the dummy for temperate climate zone and EXPGDP to the share of exports in GDP. 
Table 4.2: Summary Statistics for the Volatility Panel Dataset by Income Quartile

\begin{tabular}{|c|c|c|c|c|c|c|c|c|}
\hline & Lowest Quartile & & Second Quartile & & Third Quartile & & Highest Quartile & \\
\hline Variable & Mean & Std. Dev. & Mean & Std. Dev. & Mean & Std. Dev. & Mean & Std. Dev. \\
\hline$\triangle \ln G D P P C$ & 0.0128 & 0.0324 & 0.0219 & 0.0323 & 0.0214 & 0.0428 & 0.0226 & 0.0290 \\
\hline$\sigma$ & 0.0377 & 0.0335 & 0.0320 & 0.0263 & 0.0398 & 0.0332 & 0.0248 & 0.0209 \\
\hline ManSh & 0.1128 & 0.0587 & 0.1740 & 0.0676 & 0.2066 & 0.0927 & 0.2261 & 0.0801 \\
\hline ModSh & 0.3527 & 0.1195 & 0.4856 & 0.1051 & 0.5729 & 0.917 & 0.5956 & 0.0849 \\
\hline ModManSh & 0.3249 & 0.1297 & 0.3695 & 0.1316 & 0.3672 & 0.1516 & 0.3897 & 0.1461 \\
\hline Theil & 0.2242 & 0.1101 & 0.1366 & 0.0544 & 0.1406 & 0.0769 & 0.1530 & 0.0580 \\
\hline$\Delta$ ManSh & 0.0025 & 0.0263 & 0.0035 & 0.0315 & -0.0012 & 0.0321 & -0.0076 & 0.0267 \\
\hline$\Delta M o d S h$ & 0.0113 & 0.0468 & 0.0088 & 0.0482 & -0.0005 & 0.0436 & -0.0091 & 0.0373 \\
\hline$\Delta$ ModManSh & -0.0020 & 0.0614 & -0.0004 & 0.0641 & -0.0016 & 0.0531 & -0.0078 & 0.0497 \\
\hline$\Delta$ Theil & -0.0121 & 0.0404 & -0.0081 & 0.0266 & -0.0052 & 0.0334 & 0.0012 & 0.0387 \\
\hline RELUS & 0.0436 & 0.0142 & 0.1184 & 0.0310 & 0.2666 & 0.0593 & 0.6853 & 0.2615 \\
\hline$\triangle \ln P O P$ & 0.0247 & 0.0095 & 0.0215 & 0.0104 & 0.0168 & 0.0165 & 0.0112 & 0.0135 \\
\hline$E X P G D P$ & 0.2201 & 0.1387 & 0.3184 & 0.1614 & 0.3665 & 0.2641 & 0.3778 & 0.3365 \\
\hline$G C F$ & 0.1912 & 0.0894 & 0.2250 & 0.0739 & 0.2361 & 0.0636 & 0.2513 & 0.0458 \\
\hline $\ln P O P_{1960}$ & 15.6329 & 1.5785 & 15.5544 & 1.4879 & 15.5715 & 1.6297 & 15.8302 & 1.5519 \\
\hline $\ln G D P P C_{1960}$ & 6.5325 & 0.3496 & 7.2144 & 0.4148 & 7.9413 & 0.5364 & 8.6814 & 0.5374 \\
\hline $\ln S C H_{1960}$ & 1.0150 & 0.6547 & 1.8931 & 1.1913 & 3.4930 & 1.8434 & 5.7435 & 1.8756 \\
\hline$K G A T E M P$ & 0.0545 & 0.2034 & 0.0997 & 0.2121 & 0.3966 & 0.4217 & 0.7251 & 0.3639 \\
\hline
\end{tabular}

Note: ManSh, ModSh, ModManSh, and Theil refer to the values of the structure and specialisation variables in the initial year of each five-year period, with $\triangle$ ManSh, $\triangle$ ModSh, $\triangle$ ModManSh and $\triangle$ Theil being the change in the variables within each five-year period. $R E L U S$ refers to relative income, $S C H$ to years of education of the population of 15 years and above, GFC to Gross Fixed Capital Formation and $K G A T E M P$ to the dummy for temperate climate zone and EXPGDP to the share of exports in GDP. 


\subsection{Empirical Results}

Before providing the results of the baseline regression, it is noteworthy to highlight some specific features of our measure of volatility, which is low is an important characteristic of the ability to sustain growth. In other words, the lower the degree of volatility, the more sustainable the growth pattern is. Besides the standard deviation, the growth volatility can be approximated by a variety of measures, including the coefficient of variation. It is typically the case that the volatility of growth is higher in Low and Middle-Income countries than in advanced countries. In Table (4.3) we focus on the coefficient of variation of growth for 97 countries between 1960 and 2010. We distinguish the ten groups of countries, based on their quintile ranking by GDP per capita in 1960 and 2010.

Table 4.3: Volatility and Income Category, 1960-2010

\begin{tabular}{llcc}
\hline \hline & & Volatility & $\mathrm{N}$ \\
\hline 1 & Bottom quintile in 1960 and 2010 & 3.7 & 13 \\
2 & Relative improvement: bottom quintile in 1960, second or third quintile in 2010 & 1.5 & 7 \\
3 & Second quintile in 1960 and 2010 & 10.6 & 12 \\
4 & Relative improvement: second quintile in 1960, third quintile or higher in 2010 & 1.3 & 7 \\
5 & Third quintile in 1960 and 2010 & 2.9 & 17 \\
6 & Relative improvement: third quintile in 1960, fourth or fifth quintile in 2010 & 1.1 & 2 \\
7 & Fourth quintile in 1960 and 2010 & 1.8 & 16 \\
8 & Relative improvement: fourth quintile in 1960, fifth quintile in 2010 & 0.8 & 3 \\
9 & Falling behind: fifth quintile in 1960, fourth quintile in 2010 & 3.9 & 6 \\
10 & Fifth quintile in 1960 and 2010 & 0.9 & 14 \\
\hline \hline
\end{tabular}

Note:97 countries, ranked in quintiles by GDP per capita in 1960 to 2010. Countries that were formerly part of the Soviet Union haven been excluded, primarily because the data scarcity for all the period prior to 1989 .

Some powerful messages emerge from this table. Volatility is very much higher in Low-Income countries when compared with High-Income countries, with a coefficient of variation of 3.7 for countries stuck in the bottom quintile. In the second quintile the coefficient of variation is no less than 10.6. In contrast, the top quintiles in both 1960 and 2010 have a coefficient of variation of just 0.9. Next, it is also clear that for each given quintile in 1960, the volatility of growth is much lower in countries that have improved their relative income rankings, than in countries trapped in the same quintile. In the longrun, reduced volatility of growth is a key ingredient of successful economic development.

Table (4.4) reports the results from panel regressions between the volatility of per capita GDP growth rates and the manufacturing share using both the within-groups and the Hausman-Taylor estimators. Of the control variables, only the ratio of investment to GDP is consistently significant, with the coefficient being negative, while of the initial values of population, GDP per capita and schooling in the Hausman-Taylor model, only the schooling variable is significant (and negative), with the coefficient of KGATEMP also being significant. Coefficients on the manufacturing share however tend to be significant, 
with the coefficient being negative, suggesting that a higher manufacturing share reduces growth volatility. The exceptions of this being when included alone in the within-groups model and when interacted with RELUS, in which case the interaction is also found to be insignificant. Coefficients on the change in the manufacturing share are often negative, but usually insignificant, as is the coefficient on the interaction between the initial value and the change in the manufacturing share. Finally, when estimating separate coefficients on the manufacturing share by income quartile we find coefficients that are generally negative, and that tend to be significant for the lowest and highest income quartile. Coefficients tend to be largest - in absolute value - for the lowest income quartile followed by the high income quartile, with coefficients in the middle two quartiles tending to be smaller and insignificant. This non-monotonic pattern to the coefficients when split by income quartile may help explain the insignificant coefficients on the interaction of the manufacturing share with RELUS. Overall, the results in the Table (4.4) over the full sample period suggest that the manufacturing share may be associated with lower growth volatility, particularly for the poorest and richest countries in the sample.

Table (4.5) discusses a similar set of results, but concentrate on the relationship between the volatility of economic growth and the share of modern share in the GDP. The results on the control variables when considering the relationship between the modern sector share and volatility are largely similar to those reported in Table (4.4). The coefficient on the initial share of the modern sector is found to be insignificant in the case of the within-groups estimator - though usually positive -, while in the Hausman-Taylor case the coefficients are usually positive and often significant, suggesting that a larger modern sector increases volatility. Coefficients on the change in the modern sector however tend to be negative and tend to be significant (the exception being when the change in the modern sector is included alongside the share of the modern sector and their interaction, in which case the coefficients on the interaction are negative - and significant in the Hausman-Taylor case - while those on the change in the modern sector share are positive but not significant). Interesting results are observed when we consider non-linearities related to RELUS. When including the interaction with RELUS we find a coefficient on the interaction term that is positive and significant (with that on the modern sector share being negative but insignificant). Such a result suggests that it is for relatively richer countries that a larger modern sector increases volatility. This is confirmed when estimating a separate effect of the modern sector share for the different income quartiles. Here we find positive and significant coefficients on the modern sector share in the two highest income quartiles, with coefficients in the two lower quartiles tending to be smaller, sometimes negative, and usually insignificant.

Table (4.6) reports the results from the panel regressions when including the share of manufacturing in the modern sector. When considering the relationship between the share of manufacturing in the modern sector and volatility, we find that a higher share of manufacturing in the modern sector is associated with lower growth volatility, a result 
congruent with those previously reported in Table (4.4). The reduction in volatility is found to be largest in the highest income quartile, followed by those in the lowest quartile. We find no evidence of a change in the share of manufacturing in the modern sector impacting upon growth volatility. In sum, a higher share of manufacturing in the modern sector is associated with less volatility.

Finally, Table (4.7) reports the relationship between our indicator of specialisation, i.e., the Theil index, and the volatility of economic growth. When considering the relationship between both the initial value and the change in specialisation and volatility, we find no evidence of any significant relationship. ${ }^{5}$

\footnotetext{
${ }^{5}$ Results are also available using alternative indicators of specialisation in the robustness section, i.e. the Gini, Herfindahl and Hirschman indices.
} 
Table 4.4: Manufacturing Shares and Volatility-Panel Regression Results

\begin{tabular}{|c|c|c|c|c|c|c|c|c|c|c|c|c|}
\hline \multirow[t]{2}{*}{ Variables } & \multicolumn{6}{|c|}{ "Within-Groups Model } & \multicolumn{6}{|c|}{ "Hausman-Taylor Model } \\
\hline & (1) & $(2)$ & (3) & (4) & $(5)$ & (6) & (7) & (8) & (9) & $(10)$ & (11) & $(12)$ \\
\hline ManSh & $\begin{array}{c}-0.0483 \\
(0.0302)\end{array}$ & & $\begin{array}{l}-0.0600^{* *} \\
(0.0273)\end{array}$ & $\begin{array}{l}-0.0611^{* *} \\
(0.0272)\end{array}$ & $\begin{array}{c}-0.0532 \\
(0.0525)\end{array}$ & & $\begin{array}{l}-0.0431^{* *} \\
(0.0176)\end{array}$ & & $\begin{array}{c}-0.0445^{* *} \\
(0.0192)\end{array}$ & $-\underset{(0.0192)}{-0.0466^{* *}}$ & $\begin{array}{c}-0.0298 \\
(0.0269)\end{array}$ & \\
\hline$\Delta M a n S h$ & & $\begin{array}{l}-0.0306 \\
(0.0430)\end{array}$ & $\begin{array}{c}-0.0717^{*} \\
(0.0427)\end{array}$ & $\begin{array}{c}0.00378 \\
(0.116)\end{array}$ & & & & $\underset{(0.0338)}{-0.0244}$ & $\underset{(0.0358)}{-0.0534}$ & $\begin{array}{l}0.0751 \\
(0.0882)\end{array}$ & & \\
\hline ManSh $\times \Delta$ ManSh & & & & $\begin{array}{c}-0.400 \\
(0.490)\end{array}$ & & & & & & $\begin{array}{l}-0.678 \\
(0.425)\end{array}$ & & \\
\hline$M a n S h \times R E L U S$ & & & & & $\underset{(0.0812)}{0.0142}$ & & & & & & $\begin{array}{c}-0.0434 \\
(0.0648)\end{array}$ & \\
\hline $\operatorname{ManSh}(Q 1)$ & & & & & & $\begin{array}{c}-0.100^{* * *} \\
(0.0369)\end{array}$ & & & & & & $\begin{array}{c}-0.0794^{* * *} \\
(0.0304)\end{array}$ \\
\hline $\operatorname{ManSh}(Q 2)$ & & & & & & $\begin{array}{c}-0.0497 \\
(0.0427)\end{array}$ & & & & & & $-{ }_{(0.0213)}^{0.0460^{* *}}$ \\
\hline $\operatorname{ManSh}(Q 3)$ & & & & & & $\begin{array}{c}-0.0187 \\
(0.0352)\end{array}$ & & & & & & $\begin{array}{c}-0.0127 \\
(0.0200)\end{array}$ \\
\hline $\operatorname{ManSh}(Q 4)$ & & & & & & $-{ }_{(0.0252)}^{0.0508^{* *}}$ & & & & & & $-{ }_{(0.0235)}^{0.0564^{* *}}$ \\
\hline RELUS & $\begin{array}{l}0.00307 \\
(0.0249)\end{array}$ & $\begin{array}{l}0.00629 \\
(0.0234)\end{array}$ & $\begin{array}{l}0.00461 \\
(0.0245)\end{array}$ & $\begin{array}{l}0.00428 \\
(0.0244)\end{array}$ & $\underset{(0.0292)}{0.000783}$ & $\underset{(0.0234)}{0.00451}$ & $\begin{array}{l}-0.0111 \\
(0.0138)\end{array}$ & $\begin{array}{l}0.00198 \\
(0.0145)\end{array}$ & $-\underset{(0.0142)}{0.00211}$ & $-\underset{(0.0141)}{-0.00697}$ & $\underset{(0.0186)}{-0.00569}$ & $\underset{(0.0157)}{0.000293}$ \\
\hline$\triangle \ln P O P$ & $\begin{array}{c}-0.0997 \\
(0.222)\end{array}$ & $\begin{array}{c}-0.0505 \\
(0.223)\end{array}$ & $\begin{array}{l}-0.104 \\
(0.235)\end{array}$ & $\begin{array}{c}-0.107 \\
(0.236)\end{array}$ & $\begin{array}{c}-0.0977 \\
(0.223)\end{array}$ & $-\underset{(0.227)}{-0.0905}$ & $\begin{array}{c}-0.0412 \\
(0.104)\end{array}$ & $\begin{array}{c}-0.0180 \\
(0.106)\end{array}$ & $\begin{array}{c}-0.0618 \\
(0.107)\end{array}$ & $\begin{array}{c}-0.0617 \\
(0.107)\end{array}$ & $-\underset{(0.105)}{-0.0480}$ & $-\underset{(0.104)}{-0.0351}$ \\
\hline$E X P G D P$ & $\begin{array}{l}0.0192 \\
(0.0167)\end{array}$ & $\begin{array}{l}0.0142 \\
(0.0180)\end{array}$ & $\begin{array}{l}0.0203 \\
(0.0178)\end{array}$ & $\begin{array}{l}0.0205 \\
(0.0177)\end{array}$ & $\begin{array}{l}0.0193 \\
(0.0169)\end{array}$ & $\begin{array}{l}0.0124 \\
(0.0160)\end{array}$ & $\begin{array}{l}0.00812 \\
(0.00884)\end{array}$ & $\frac{0.000150}{(0.00900)}$ & $\begin{array}{l}0.00502 \\
(0.00923)\end{array}$ & $\begin{array}{l}0.00607 \\
(0.00918)\end{array}$ & $\begin{array}{l}0.00746 \\
(0.00896)\end{array}$ & $\begin{array}{l}0.00801 \\
(0.00898)\end{array}$ \\
\hline$G C F$ & $\begin{array}{c}-0.0650^{* * *} \\
(0.0191)\end{array}$ & $\begin{array}{c}-0.0781^{* * * *} \\
(0.0191)\end{array}$ & $\begin{array}{c}-0.0675^{* * *} \\
(0.0190)\end{array}$ & $\begin{array}{c}-0.0665^{* * *} \\
(0.0192)\end{array}$ & $\begin{array}{c}-0.0654^{* * *} \\
(0.0187)\end{array}$ & $\begin{array}{c}-0.0645^{* * *} \\
(0.0189)\end{array}$ & $\begin{array}{c}-0.0478^{* * *} \\
(0.0152)\end{array}$ & $\begin{array}{c}-0.0599^{* * *} \\
(0.0154)\end{array}$ & $\begin{array}{c}-0.0527^{* * *} \\
(0.0157)\end{array}$ & $\begin{array}{c}-0.0504^{* * *} \\
(0.0157)\end{array}$ & $\begin{array}{c}-0.0470^{* * * *} \\
(0.0152)\end{array}$ & $\begin{array}{c}0.0485^{* * *} \\
(0.0151)\end{array}$ \\
\hline $\ln P O P_{1960}$ & & & & & & & $\begin{array}{c}-0.00103 \\
(0.00124)\end{array}$ & $\begin{array}{c}-0.00291^{* *} \\
(0.00124)\end{array}$ & $\begin{array}{c}-0.00191 \\
(0.00132)\end{array}$ & $\underset{(0.00131)}{-0.00158}$ & $\begin{array}{c}-0.00116 \\
(0.00126)\end{array}$ & $\begin{array}{c}-0.00187 \\
(0.00123)\end{array}$ \\
\hline $\ln G D P P C_{1960}$ & & & & & & & $\begin{array}{l}0.00464 \\
(0.00325)\end{array}$ & $\underset{(0.00343)}{0.000512}$ & $\begin{array}{c}0.00185 \\
(0.00345)\end{array}$ & $\begin{array}{l}0.00280 \\
(0.00341)\end{array}$ & $\begin{array}{l}0.00461 \\
(0.00325)\end{array}$ & $\begin{array}{c}0.000467 \\
(0.00340)\end{array}$ \\
\hline $\ln S C H_{1960}$ & & & & & & & $\begin{array}{c}-0.00264^{* *} \\
(0.00119)\end{array}$ & $\begin{array}{c}-0.00259^{* *} \\
(0.00124)\end{array}$ & $\begin{array}{c}-0.00256^{* *} \\
(0.00124)\end{array}$ & $\begin{array}{c}-0.00245^{* *} \\
(0.00123)\end{array}$ & $\begin{array}{c}-0.00249^{* *} \\
(0.00115)\end{array}$ & $\begin{array}{c}-0.00230^{* *} \\
(0.00113)\end{array}$ \\
\hline KGATEMP & & & & & & & $\begin{array}{l}0.00514 \\
(0.00525)\end{array}$ & $\begin{array}{l}0.00228 \\
(0.00548)\end{array}$ & $\begin{array}{l}0.00390 \\
(0.00554)\end{array}$ & $\begin{array}{l}0.00424 \\
(0.00550)\end{array}$ & $\begin{array}{l}0.00602 \\
(0.00518)\end{array}$ & $\begin{array}{l}0.00542 \\
(0.00508)\end{array}$ \\
\hline Obs & 731 & 709 & 709 & 709 & 731 & 731 & 731 & 709 & 709 & 709 & 731 & 731 \\
\hline $\mathrm{R}^{2}$ & 0.105 & 0.102 & 0.112 & 0.113 & 0.105 & 0.116 & & & & & & \\
\hline F-Stat & $5.797^{* * *}$ & $5.769^{* * *}$ & $5.289^{* * *}$ & $5.052^{* * *}$ & $5.454^{* * *}$ & $5.699^{* * *}$ & $5.182^{* * *}$ & $4.802^{* * *}$ & $4.865^{* * *}$ & $4.740^{* * *}$ & $4.989^{* * *}$ & $5.093^{* * *}$ \\
\hline
\end{tabular}

Note: All regressions in the table include unreported time dummy variables; Standard errors are clustered at the country level; ${ }^{* * *},{ }^{* *}$ and ${ }^{*}$ denote significance at 1, 5 and 10 percent levels, respectively; $\operatorname{ManSh}(Q 1), \operatorname{ManSh}(Q 2), \operatorname{ManSh}(Q 3)$, and ManSh(Q4) report the coefficients on the manufacturing share for the four income quartiles, with 1 being the lowest and 4 the highest income quartile. 
Table 4.5: The Share of the Modern Sector and Volatility-Panel Regression Results

\begin{tabular}{|c|c|c|c|c|c|c|c|c|c|c|c|c|}
\hline \multirow[t]{2}{*}{ Variable } & \multicolumn{6}{|c|}{ "Within-Groups Model } & \multicolumn{6}{|c|}{ "Hausman-Taylor Model } \\
\hline & $(1)$ & (2) & (3) & (4) & (5) & (6) & $(7)$ & $(8)$ & $(9)$ & (10) & (11) & $(12)$ \\
\hline ModSh & $\begin{array}{l}0.0212 \\
(0.0189)\end{array}$ & & $\begin{array}{c}0.00388 \\
(0.0304)\end{array}$ & $\begin{array}{c}0.00736 \\
(0.0309)\end{array}$ & $\begin{array}{l}-0.0167 \\
(0.0230)\end{array}$ & & $\begin{array}{l}0.0308^{* *} \\
(0.0125)\end{array}$ & & $\begin{array}{c}-0.0254^{*} \\
(0.0150)\end{array}$ & $\begin{array}{l}0.0278^{* *} \\
(0.0149)\end{array}$ & $-\underset{(0.0164)}{-0.00456}$ & \\
\hline$\Delta$ ModSh & & $\begin{array}{c}-0.0755^{* * *} \\
(0.0249)\end{array}$ & $\begin{array}{l}-0.0732^{* *} \\
(0.0276)\end{array}$ & $\begin{array}{l}0.0319 \\
(0.0733)\end{array}$ & & & & $\begin{array}{c}-0.0712^{* * *} \\
(0.0206)\end{array}$ & $\begin{array}{c}-0.0553^{* *} \\
(0.0226)\end{array}$ & $\begin{array}{l}0.0760 \\
(0.0683)\end{array}$ & & \\
\hline ModSh $\times \Delta$ ModSh & & & & $\begin{array}{l}-0.202 \\
(0.139)\end{array}$ & & & & & & $\begin{array}{l}-0.254^{* *} \\
(0.125)\end{array}$ & & \\
\hline$M o d S h \times R E L U S$ & & & & & $\begin{array}{c}0.195^{* * *} \\
(0.0618)\end{array}$ & & & & & & $\begin{array}{l}185^{* * *} \\
(0.0564)\end{array}$ & \\
\hline $\operatorname{ModSh}(Q 1)$ & & & & & & $-\underset{(0.0209)}{0.00424}$ & & & & & & $\begin{array}{c}0.00997 \\
(0.0153)\end{array}$ \\
\hline $\operatorname{ModSh}(Q 2)$ & & & & & & $\begin{array}{l}0.0203 \\
(0.0197)\end{array}$ & & & & & & $\begin{array}{l}0.0220^{*} \\
(0.0130)\end{array}$ \\
\hline $\operatorname{ModSh}(Q 3)$ & & & & & & ${ }_{(0.0186)}^{0.0364^{*}}$ & & & & & & $\frac{0.0415^{* * *}}{(0.0130)}$ \\
\hline $\operatorname{ModSh}(Q 4)$ & & & & & & $\begin{array}{c}0.0348^{*} \\
(0.0200)\end{array}$ & & & & & & $\begin{array}{c}0.0349^{* *} \\
(0.0159)\end{array}$ \\
\hline$R E L U S$ & $-\underset{(0.0227)}{-0.000627}$ & $\begin{array}{c}0.00200 \\
(0.0209)\end{array}$ & $\begin{array}{l}0.00127 \\
(0.0212)\end{array}$ & $-\underset{(0.0201)}{0.00130}$ & $\begin{array}{l}-0.129^{* * *} \\
(0.0408)\end{array}$ & $\begin{array}{c}-0.0147 \\
(0.0196)\end{array}$ & $\begin{array}{l}-0.0129 \\
(0.0137)\end{array}$ & $\begin{array}{l}-0.0104 \\
(0.0141)\end{array}$ & $\begin{array}{l}-0.0148 \\
(0.0139)\end{array}$ & $\begin{array}{l}-0.0129 \\
(0.0138)\end{array}$ & $\begin{array}{c}-0.1311^{* * *} \\
(0.0388)\end{array}$ & $\begin{array}{c}-0.0118 \\
(0.0188)\end{array}$ \\
\hline$\triangle \ln P O P$ & $\begin{array}{c}-0.0572 \\
(0.213)\end{array}$ & $-\underset{(0.211)}{-0.0431}$ & $\begin{array}{c}-0.0437 \\
(0.210)\end{array}$ & $\begin{array}{c}-0.0803 \\
(0.218)\end{array}$ & $\begin{array}{l}-0.147 \\
(0.225)\end{array}$ & $\begin{array}{c}-0.0584 \\
(0.213)\end{array}$ & $\underset{(0.103)}{0.00159}$ & $\begin{array}{c}-0.00851 \\
(0.105)\end{array}$ & $\begin{array}{c}-0.00632 \\
(0.105)\end{array}$ & $\begin{array}{c}-0.0498 \\
(0.106)\end{array}$ & $\begin{array}{c}-0.0830 \\
(0.105)\end{array}$ & $\underset{(0.102)}{0.000611}$ \\
\hline$E X P G D P$ & $\underset{(0.0169)}{0.0110}$ & $\underset{(0.0181)}{0.0120}$ & $\begin{array}{l}0.0113 \\
(0.0204)\end{array}$ & $\begin{array}{l}0.0119 \\
(0.0202)\end{array}$ & $\begin{array}{l}0.0107 \\
(0.0174)\end{array}$ & $\begin{array}{l}0.00187 \\
(0.0174)\end{array}$ & $\begin{array}{c}-0.00291 \\
(0.00893)\end{array}$ & $\begin{array}{c}-0.000148 \\
(0.00898)\end{array}$ & $\begin{array}{c}-0.00436 \\
(0.00944)\end{array}$ & $\begin{array}{c}-0.00520 \\
(0.00938)\end{array}$ & $\begin{array}{c}-0.00164 \\
(0.00882)\end{array}$ & $\begin{array}{c}-0.00851 \\
(0.00921)\end{array}$ \\
\hline$G C F$ & $\begin{array}{c}-0.0814^{* * *} \\
(0.0209)\end{array}$ & $\begin{array}{l}-0.0763^{* * *} \\
(0.0192)\end{array}$ & $\begin{array}{c}-0.0776^{* * *} \\
(0.0212)\end{array}$ & $\begin{array}{c}-0.0739^{* * *} \\
(0.0208)\end{array}$ & $\begin{array}{c}-0.0679^{* * *} \\
(0.0216)\end{array}$ & $\begin{array}{c}-0.0750^{* * *} \\
(0.0210)\end{array}$ & $\begin{array}{c}-0.0694^{* * *} \\
(0.0160)\end{array}$ & $\begin{array}{c}-0.0580^{* * *} \\
(0.0154)\end{array}$ & $\begin{array}{c}-0.0687^{* * *} \\
(0.0167)\end{array}$ & $\begin{array}{l}-0.0653^{* * *} \\
(0.0168)\end{array}$ & $\begin{array}{l}-0.0567^{* * *} \\
(0.0163)\end{array}$ & $\begin{array}{c}0.0666^{* * *} \\
(0.0160)\end{array}$ \\
\hline $\ln P O P_{1960}$ & & & & & & & $-\underset{(0.00114)}{-0.00248^{* *}}$ & $-\frac{0.00290^{* *}}{(0.00124)}$ & $\begin{array}{l}-0.00294^{* *} \\
(0.00123)\end{array}$ & $\underset{(0.00121)}{-0.00309^{* *}}$ & $-\underset{(0.00112)}{-0.00219^{*}}$ & $\begin{array}{c}-0.00306^{* * *} \\
(0.00117)\end{array}$ \\
\hline $\ln G D P P C_{1960}$ & & & & & & & $\begin{array}{l}0.00118 \\
(0.00326)\end{array}$ & $\begin{array}{l}0.00119 \\
(0.00339)\end{array}$ & $\frac{0.000413}{(0.00347)}$ & $-\underset{(0.00342)}{-1.70 e-05}$ & $\begin{array}{l}0.00435 \\
(0.00327)\end{array}$ & $\begin{array}{c}-0.00338 \\
(0.00362)\end{array}$ \\
\hline $\ln S C H_{1960}$ & & & & & & & $\begin{array}{c}-0.00243^{* *} \\
(0.00115)\end{array}$ & $\begin{array}{c}-0.00193 \\
(0.00124)\end{array}$ & $\begin{array}{c}-0.00196 \\
(0.00123)\end{array}$ & $\begin{array}{c}-0.00199 \\
(0.00122)\end{array}$ & $-{ }_{(0.00109)}^{0.00256^{* *}}$ & $\begin{array}{c}-0.00223^{* *} \\
(0.00112)\end{array}$ \\
\hline KGATEMP & & & & & & & $\begin{array}{l}0.00606 \\
(0.00513)\end{array}$ & $\begin{array}{l}0.00417 \\
(0.00548)\end{array}$ & $\begin{array}{l}0.00564 \\
(0.00548)\end{array}$ & $\begin{array}{l}0.00452 \\
(0.00542)\end{array}$ & $\underset{(0.00503)}{0.00902^{*}}$ & $\begin{array}{l}0.00538 \\
(0.00504)\end{array}$ \\
\hline Obs & 732 & 710 & 710 & 710 & 732 & 732 & 732 & 710 & 710 & 710 & 732 & 732 \\
\hline $\mathrm{R}^{2}$ & 0.101 & 0.121 & 0.121 & 0.125 & 0.117 & 0.115 & & & & & & \\
\hline F-Stat & $5.906^{* * *}$ & $6.022^{* * *}$ & $5.784^{* * *}$ & $5.493^{* * *}$ & $6.993^{* * *}$ & $5.849^{* * *}$ & $5.272^{* * *}$ & $5.555^{* * *}$ & $5.399^{* * *}$ & $5.384^{* * *}$ & $5.661^{* * *}$ & $5.103^{* * *}$ \\
\hline
\end{tabular}

Note: All regressions in the table include unreported time dummy variables; Standard errors are clustered at the country level; ${ }^{* * *}{ }^{* *}$ and * denote significance at 1, 5 and 10 percent levels, respectively; $\operatorname{Mod} \operatorname{Sh}(Q 1), \operatorname{Mod} S h(Q 2), \operatorname{Mod} \operatorname{Sh}(Q 3)$, and $\operatorname{Mod} \operatorname{Sh}(Q 4)$ report the coefficients on the modern sector share for the four income quartiles, with 1 being the lowest and 4 the highest income quartile. 
Table 4.6: The Share of Manufacturing in the Modern Sector and Volatility-Panel Regression Results

\begin{tabular}{|c|c|c|c|c|c|c|c|c|c|c|c|c|}
\hline \multirow[t]{2}{*}{ Variable } & \multirow[b]{2}{*}{ (1) } & \multirow[b]{2}{*}{ (2) } & \multicolumn{4}{|c|}{ "Within-Groups Model } & \multicolumn{6}{|c|}{ Hausman-Taylor Model } \\
\hline & & & (3) & (4) & (5) & (6) & (7) & (8) & (9) & (10) & (11) & (12) \\
\hline ManModSh & $\begin{array}{c}-0.0397^{* *} \\
(0.0158)\end{array}$ & & $\begin{array}{c}-0.0375^{*} \\
(0.0221)\end{array}$ & $\begin{array}{l}-0.0372^{*} \\
(0.0224)\end{array}$ & $\begin{array}{l}-0.0316 \\
(0.0222)\end{array}$ & & $\begin{array}{l}-0.0368^{* * *} \\
(0.00942)\end{array}$ & & $\begin{array}{c}-0.0331^{* * *} \\
(0.0106)\end{array}$ & $\begin{array}{c}-0.0336^{* * *} \\
(0.0106)\end{array}$ & $\underset{(0.0133)}{-0.0252^{*}}$ & \\
\hline$\Delta$ ManModSh & & $\begin{array}{l}0.0212 \\
(0.0260)\end{array}$ & $\begin{array}{c}-0.00149 \\
(0.0337)\end{array}$ & $\begin{array}{l}-0.0549 \\
(0.0636)\end{array}$ & & & & $\begin{array}{l}0.0237 \\
(0.0162)\end{array}$ & $\underset{(0.0173)}{0.00398}$ & $\underset{(0.0479)}{-0.0291}$ & & \\
\hline ManModSh $\times \Delta$ ManModSh & & & & $\begin{array}{l}0.147 \\
(0.195)\end{array}$ & & & & & & $0_{(0.122)}^{0.0907}$ & & \\
\hline ManModSh $\times$ RELUS & & & & & $\begin{array}{l}-0.0263 \\
(0.0326)\end{array}$ & & & & & & $\begin{array}{l}-0.0430 \\
(0.0330)\end{array}$ & \\
\hline $\operatorname{ManModSh}(Q 1)$ & & & & & & $\begin{array}{c}-0.0436^{* * *} \\
(0.0162)\end{array}$ & & & & & & $\begin{array}{c}-0.0342^{* * *} \\
(0.0126)\end{array}$ \\
\hline $\operatorname{ManModSh}(Q 2)$ & & & & & & $\begin{array}{c}-0.0331 \\
(0.0207)\end{array}$ & & & & & & $\begin{array}{c}-0.0332^{* * *} \\
(0.0110)\end{array}$ \\
\hline $\operatorname{ManModSh}(Q 3)$ & & & & & & $\begin{array}{l}-0.0264 \\
(0.0214)\end{array}$ & & & & & & $-{ }_{(0.0112)}^{0.0221^{*}}$ \\
\hline $\operatorname{ManModSh}(Q 4)$ & & & & & & $-\underset{(0.0155)}{-0.0473^{* *}}$ & & & & & & $-0.0499^{* * *}$ \\
\hline RELUS & $\underset{(0.0241)}{-0.00301}$ & $\begin{array}{l}0.00518 \\
(0.0239)\end{array}$ & $-\underset{(0.0245)}{0.000976}$ & $-\underset{(0.0243)}{-0.00138}$ & $\begin{array}{l}0.00415 \\
(0.0285)\end{array}$ & $\begin{array}{l}0.00456 \\
(0.0240)\end{array}$ & $\begin{array}{l}-0.0170 \\
(0.0139)\end{array}$ & $\underset{(0.0145)}{0.000835}$ & $-\underset{(0.0144)}{-0.00601}$ & $\begin{array}{l}-0.0111 \\
(0.0143)\end{array}$ & $-\underset{(0.0170)}{-0.00631}$ & $\underset{(0.0153)}{-0.000373}$ \\
\hline$\triangle \ln P O P$ & $\begin{array}{c}-0.106 \\
(0.221)\end{array}$ & $\begin{array}{l}-0.0460 \\
(0.215)\end{array}$ & $\begin{array}{l}-0.108 \\
(0.220)\end{array}$ & $\begin{array}{c}-0.0923 \\
(0.205)\end{array}$ & $\begin{array}{l}-0.120 \\
(0.226)\end{array}$ & $\begin{array}{l}-0.110 \\
(0.227)\end{array}$ & $\begin{array}{l}-0.0524 \\
(0.103)\end{array}$ & $\underset{(0.106)}{-0.0168}$ & $\begin{array}{c}-0.0735 \\
(0.106)\end{array}$ & $\begin{array}{l}-0.0625 \\
(0.107)\end{array}$ & -0.0740 & $\underset{(0.103)}{-0.0641}$ \\
\hline$E X P G D P$ & $\begin{array}{l}0.0183 \\
(0.0158)\end{array}$ & $\begin{array}{l}0.0140 \\
(0.0179)\end{array}$ & $\begin{array}{l}0.0174 \\
(0.0173)\end{array}$ & $\begin{array}{l}0.0173 \\
(0.0173)\end{array}$ & $\begin{array}{l}0.0181 \\
(0.0161)\end{array}$ & $\begin{array}{l}0.0142 \\
(0.0157)\end{array}$ & $\begin{array}{l}0.00674 \\
(0.00857)\end{array}$ & $\underset{(0.00897)}{-0.000251}$ & $\underset{0.00891)}{0.00261}$ & $\begin{array}{l}0.00391 \\
(0.00892)\end{array}$ & $\begin{array}{l}0.00593 \\
(0.00855)\end{array}$ & $\underset{(0.00875)}{0.00114}$ \\
\hline$G C F$ & $-{ }_{(0.0177)}^{0.0694^{* * *}}$ & $-{ }_{(0.0194)}^{0.0769^{* * *}}$ & $-{ }^{0.0734^{* * *}}$ & $-0.0753^{* * * *}$ & $-{ }_{(0.0182)}^{0.0665^{* * *}}$ & $-0.0684^{* * * *}$ & $-{ }^{-0.0535^{* * *}}$ & $-0.0586^{* * *}$ & $-{ }^{0.0578^{* * *}}$ & $-0.0582^{* * *}$ & $-0.0493^{* * * *}$ & $\underset{(0.0151)}{0.0523^{* * *}}$ \\
\hline $\ln P O P_{1960}$ & & & & & & & $-\underset{(0.00118)}{-0.000712}$ & $-\mathrm{C}_{(0.00124)}^{0.00284^{* *}}$ & $\begin{array}{c}-0.00167 \\
(0.00127)\end{array}$ & $\begin{array}{c}-0.00136 \\
(0.00127)\end{array}$ & $-\underset{(0.00118)}{0.000879}$ & $\begin{array}{c}-0.00163 \\
(0.00119)\end{array}$ \\
\hline $\ln G D P P C_{1960}$ & & & & & & & $\begin{array}{l}0.00446 \\
(0.00315)\end{array}$ & $\underset{(0.00341)}{0.000793}$ & $\begin{array}{l}0.00169 \\
(0.00336)\end{array}$ & $\begin{array}{l}0.00270 \\
(0.00335)\end{array}$ & $\begin{array}{l}0.00475 \\
(0.00304)\end{array}$ & $\underset{(0.00336)}{0.00137}$ \\
\hline $\ln S C H_{1960}$ & & & & & & & $-0.0 .00251^{* *}$ & $-{ }^{-0.00248^{* *}}$ & $-{ }^{-0.00248^{* *}}$ & $-{ }_{(0.00121)}^{0.00241^{* *}}$ & $-0.0 .00240^{* *}$ & $-{ }^{-0.00230^{* *}}$ \\
\hline KGATEMP & & & & & & & $\underset{(0.00666)}{0.00516}$ & $\underset{0.00235}{0.00545)}$ & $\begin{array}{l}0.00489 \\
(0.00541)\end{array}$ & $\begin{array}{l}0.00584 \\
(0.00545)\end{array}$ & ${ }_{(0.00504)}^{0.00832^{*}}$ & $\begin{array}{l}0.00748 \\
(0.00505)\end{array}$ \\
\hline Obs & 731 & 709 & 709 & 709 & 731 & 731 & 731 & 709 & 709 & 709 & 731 & 731 \\
\hline $\mathrm{R}^{2}$ & 0.113 & 0.103 & 0.114 & 0.116 & 0.114 & 0.119 & & & & & & \\
\hline F-Stat & $9.189^{* * *}$ & $5.911^{* * *}$ & $5.643^{* * *}$ & $5.290^{* * *}$ & $5.685^{* * *}$ & $5.521^{* * *}$ & $5.786^{* * *}$ & $4.896^{* * *}$ & $5.224^{* * *}$ & $4.957^{* * *}$ & $5.732^{* * *}$ & $5.431^{* * *}$ \\
\hline
\end{tabular}

Note: All regressions in the table include unreported time dummy variables; Standard errors are clustered at the country level; ${ }^{* * *}$, ${ }^{* *}$ and * denote significance at 1, 5 and 10 percent levels, respectively; ManModSh(Q1), ManModSh(Q2), ManModSh(Q3), and ManModSh(Q4) report the coefficients on the manufacturing share in the modern sector for the four income quartiles, with 1 being the lowest and 4 the highest income quartile. 
Table 4.7: The Theil Index and Volatility-Panel Regression Results

\begin{tabular}{|c|c|c|c|c|c|c|c|c|c|c|c|c|}
\hline \multirow{2}{*}{ Variable } & \multicolumn{6}{|c|}{ Within-Groups Model } & \multicolumn{6}{|c|}{ "Hausman-Taylor Model } \\
\hline & $(1)$ & $(2)$ & (3) & $(4)$ & $(5)$ & $(6)$ & $(7)$ & $(8)$ & (9) & $(10)$ & $(11)$ & $(12)$ \\
\hline Theil & $\begin{array}{c}0.00956 \\
(0.0256)\end{array}$ & & $\begin{array}{l}0.0259 \\
(0.0336)\end{array}$ & $\begin{array}{l}0.0337 \\
(0.0348)\end{array}$ & $\begin{array}{c}-0.00447 \\
(0.0339)\end{array}$ & & $\begin{array}{l}0.0211 \\
(0.0168)\end{array}$ & & $\begin{array}{l}0.0284 \\
(0.0200)\end{array}$ & $\begin{array}{l}0.0321 \\
(0.0211)\end{array}$ & $\begin{array}{l}0.0162 \\
(0.0220)\end{array}$ & \\
\hline$\Delta$ Theil & & $-\underset{(0.0343)}{0.000541}$ & $\begin{array}{l}0.0155 \\
(0.0463)\end{array}$ & $\begin{array}{c}-0.0317 \\
(0.0711)\end{array}$ & & & & $\begin{array}{c}-0.00598 \\
(0.0249)\end{array}$ & $\begin{array}{l}0.0121 \\
(0.0280)\end{array}$ & $\begin{array}{c}-0.0105 \\
(0.0542)\end{array}$ & & \\
\hline Theil $\times \Delta$ Theil & & & & $\begin{array}{l}0.217 \\
(0.255)\end{array}$ & & & & & & $\begin{array}{l}0.105 \\
(0.210)\end{array}$ & & \\
\hline Theil $\times$ RELUS & & & & & $\begin{array}{l}0.0760 \\
(0.0801)\end{array}$ & & & & & & $\begin{array}{l}0.0313 \\
(0.0810)\end{array}$ & \\
\hline Theil $(Q 1)$ & & & & & & $\begin{array}{l}0.00753 \\
(0.0281)\end{array}$ & & & & & & $\begin{array}{l}0.0223 \\
(0.0188)\end{array}$ \\
\hline Theil $(Q 2)$ & & & & & & $\begin{array}{c}0.00739 \\
(0.0398)\end{array}$ & & & & & & $0_{(0.0244)}^{0.00962}$ \\
\hline Theil(Q3) & & & & & & $\begin{array}{c}0.00945 \\
(0.0433)\end{array}$ & & & & & & $\begin{array}{l}0.0491 \\
(0.0300)\end{array}$ \\
\hline Theil $(Q 4)$ & & & & & & $\begin{array}{l}0.0188 \\
(0.0402)\end{array}$ & & & & & & $\begin{array}{l}0.0114 \\
(0.0352)\end{array}$ \\
\hline$R E L U S$ & $\begin{array}{c}0.00326 \\
(0.0239)\end{array}$ & $\begin{array}{l}0.00562 \\
(0.0239)\end{array}$ & $\begin{array}{c}0.00358 \\
(0.0241)\end{array}$ & $\begin{array}{l}0.00429 \\
(0.0245)\end{array}$ & $-\underset{(0.0283)}{-0.00937}$ & $\frac{0.00311}{(0.0259)}$ & $-\underset{(0.0139)}{0.00936}$ & $\begin{array}{c}-0.00464 \\
(0.0142)\end{array}$ & $-\underset{(0.0142)}{-0.00943}$ & $\begin{array}{c}-0.0107 \\
(0.0142)\end{array}$ & $\begin{array}{c}-0.0201 \\
(0.0190)\end{array}$ & $\underset{(0.0169)}{-0.00614}$ \\
\hline$\triangle \ln P O P$ & $\frac{-0.0602}{(0.217)}$ & $\underset{(0.224)}{-0.0519}$ & $\begin{array}{l}-0.0555 \\
(0.220)\end{array}$ & $-\underset{(0.224)}{-0.0422}$ & $\underset{(0.223)}{-0.0765}$ & $\underset{(0.224)}{-0.0627}$ & $\underset{(0.104)}{-0.0131}$ & $-\underset{(0.107)}{-0.0183}$ & $\underset{(0.107)}{-0.0297}$ & $\begin{array}{c}-0.0228 \\
(0.108)\end{array}$ & $-\underset{(0.106)}{-0.0222}$ & $\underset{(0.105)}{-0.0203}$ \\
\hline$E X P G D P$ & $\underset{(0.0163)}{0.0142}$ & $\underset{(0.0182)}{0.0144}$ & $\begin{array}{l}0.0133 \\
(0.0182)\end{array}$ & $\begin{array}{l}0.0131 \\
(0.0183)\end{array}$ & $\begin{array}{l}0.0144 \\
(0.0165)\end{array}$ & $\begin{array}{l}0.0146 \\
(0.0169)\end{array}$ & $\begin{array}{l}0.00334 \\
(0.00867)\end{array}$ & $\underset{(0.00900)}{0.000964}$ & $\begin{array}{c}0.000956 \\
(0.00895)\end{array}$ & $\begin{array}{l}0.00143 \\
(0.00898)\end{array}$ & $\begin{array}{l}0.00337 \\
(0.00874)\end{array}$ & $\begin{array}{l}0.00269 \\
(0.00904)\end{array}$ \\
\hline$G C F$ & $-0.0 .0700^{* * *}$ & $\begin{array}{c}-0.0786^{* * *} \\
(0.0192)\end{array}$ & $\begin{array}{c}-0.0700^{* * *} \\
(0.0247)\end{array}$ & $\begin{array}{c}-0.0702^{* * *} \\
(0.0250)\end{array}$ & $-0.0727^{* * *}$ & $-0.0707^{* * *}$ & $-0.0475^{* * *}$ & $\begin{array}{c}-0.0594^{* * *} \\
(0.0155)\end{array}$ & $\begin{array}{c}-0.0496^{* * *} \\
(0.0169)\end{array}$ & $\begin{array}{c}-0.0495^{* * *} \\
(0.0169)\end{array}$ & $\begin{array}{c}-0.0477^{* * *} \\
(0.0165)\end{array}$ & $\frac{0.0485^{* * *}}{(0.0166)}$ \\
\hline $\ln P O P_{1960}$ & & & & & & & $-\underset{(0.00115)}{-0.00207^{*}}$ & $-{ }_{(0.00123)}^{0.00268^{* *}}$ & $-\frac{0.00250^{* *}}{(0.00122)}$ & $-{ }^{-0.00245^{* *}}$ & $\begin{array}{c}-0.00210^{*} \\
(0.00117)\end{array}$ & $-{ }_{(0.00118)}^{0.00213^{*}}$ \\
\hline $\ln G D P P C_{1960}$ & & & & & & & $\begin{array}{l}0.00367 \\
(0.00330)\end{array}$ & $\begin{array}{l}0.00164 \\
(0.00337)\end{array}$ & $\begin{array}{c}0.00289 \\
(0.00343)\end{array}$ & $\begin{array}{l}0.00306 \\
(0.00345)\end{array}$ & $\begin{array}{l}0.00422 \\
(0.00328)\end{array}$ & $\underset{(0.00383)}{0.00220}$ \\
\hline $\ln S C H_{1960}$ & & & & & & & $\begin{array}{l}-0.00250^{* *} \\
(0.00117)\end{array}$ & $\begin{array}{c}-0.00238^{*} \\
(0.00124)\end{array}$ & $-{ }^{-0.00220^{*}}$ & $-{ }_{(0.00124)}^{0.00213^{*}}$ & $\begin{array}{c}-0.00219^{*} \\
(0.00116)\end{array}$ & $-\frac{0.00220^{*}}{(0.00116)}$ \\
\hline KGATEMP & & & & & & & $\begin{array}{l}0.00326 \\
(0.00519)\end{array}$ & $\begin{array}{c}0.00354 \\
(0.00545)\end{array}$ & $\begin{array}{l}0.00278 \\
(0.00542)\end{array}$ & $\begin{array}{c}0.00309 \\
(0.00546)\end{array}$ & $\begin{array}{l}0.00389 \\
(0.00519)\end{array}$ & $\begin{array}{c}0.00325 \\
(0.00520)\end{array}$ \\
\hline Obs & 732 & 710 & 710 & 710 & 732 & 732 & 732 & 710 & 710 & 710 & 732 & 732 \\
\hline F-Stat & $6.080^{* * *}$ & $5.895^{* * *}$ & $5.984^{* * *}$ & $5.500^{* * *}$ & $5.642^{* * *}$ & $5.322^{* * *}$ & $4.964^{* * *}$ & $4.793^{* * *}$ & $4.669^{* * *}$ & $4.434^{* * *}$ & $4.767^{* * *}$ & $4.429^{* * *}$ \\
\hline
\end{tabular}

Note: All regressions in the table include unreported time dummy variables; Standard errors are clustered at the country level; ${ }^{* * *},{ }^{* *}$ and ${ }^{*}$ denote significance at 1, 5 and 10 percent levels, respectively; Theil $(Q 1)$, Theil(Q2), Theil(Q3), and Theil(Q4) report the coefficients on the Theil index for the four income quartiles, with 1 being the lowest and 4 the highest income quartile. 


\subsection{Threshold Panel Analysis}

Our review of the theory and evidence indicated that threshold effects are possible. Fortunately, a general method of testing for thresholds is available. Hansen (1996, 1999, 2000) provides an econometric technique that allows the sample data to determine the number and location of the potential thresholds. The method, described in the Appendix, is based on a threshold regression model where observations fall into regimes that depend on an unknown value of an observed variable.

We start by applying this technique directly to our measure of economic structure itself: the share of manufacturing in total value added, the share of the modern sector in GDP and the share of manufacturing in the modern sector. The only exception is the measure of specialisation - the Theil index -, which did not provide significant results in our previous estimations. Our results so far suggest a negative relationship between most measures of economic structure and the volatility of growth. But, does this reflect a relationship where such protection must exceed some minimum cutoff for growth-stability benefits to be obtained? Are the growth-stability benefits to be obtained? Are the growthstability benefits of larger share of manufacturing for example still present if current levels of industrialisation are relatively high? To investigate these we allow the parameter associated with economic structure to change discretely depending upon the level of the economic structure.

Our analysis uses almost the same model as in equation (4.1) to investigate these non-linearities further, focusing in thresholds in particular. The starting point of our new estimations is the following single-threshold model, which could also be seen as a transformation of our baseline model:

$$
\sigma_{i t}=\mathbf{Z}_{i t}\left(T H R E S_{i t}<\gamma\right) \delta_{1}+\mathbf{Z}_{i t}\left(T H R E S_{i t} \geq \gamma\right) \delta_{2}+\beta X_{i t}+\theta_{i}+\vartheta_{t}+\varepsilon_{i t}
$$

where $\sigma$ is still our dependent variable, i.e., the volatility of economic growth as measured by the standard deviation of the annual growth rate of per capita GDP within each five-year period, THRES is the threshold variable, and $\gamma$ the threshold parameter that divides the equation into two regimes with coefficients $\delta_{1}$ and $\delta_{2}$. X regroups all the regime-independent variables, such as the level of inflation as measured by the Consumer Price Index (CPI) or the average ratio of gross capital formation to GDP in each five-year period. Parameters $\theta_{i}$ and $\vartheta_{t}$ are the country and time-specific fixed-effect, respectively, while $\epsilon_{i t}$ is the disturbance. The threshold equation could also be written as the following:

$$
\sigma_{i t}=\vartheta+\mathbf{Z}_{i t}(\text { THRES } i t, \gamma) \delta+\beta X_{i t}+\theta_{i}+\varepsilon_{i t}
$$

where

$$
\mathbf{Z}_{i t}\left(\text { THRES }_{i t}, \gamma\right)=\left\{\begin{array}{l}
\mathbf{Z}_{i t} I(\text { THRES } \\
\text { it }<\gamma) \\
\mathbf{Z}_{i t} I\left(\text { THRES } S_{i t} \geq \gamma\right)
\end{array}\right.
$$


To estimate equation (4.2), we first need to jointly estimate the breakpoint - threshold value $-\gamma$ and the slope parameters. Chan (1993) and Hansen (2000) recommend obtaining the least squares estimate of $\gamma$ as the value that minimises the concentrated sum of squared errors. We estimate our model for all values of the threshold variable THRES between the 10th and 90th quantile and use as the threshold the value of the threshold variable that minimises the sum of squared errors. After obtaining a value of $\gamma$, we can hence estimate the parameters of our threshold model.

Having found a threshold, we need to identify whether it is statistically significant. This involves testing the null hypothesis that $\delta_{1}=\delta_{2}$, where rejecting the null allows us to conclude that a threshold exists. One complication is that the threshold $\gamma$ is not identified under the null hypothesis, implying that the classical tests do not have the standard distributions and critical values cannot be read off standard distribution tables. We follow Hansen (1996) and bootstrap to obtain the $p$-value for the test of a significant threshold. Once a threshold is confirmed, it is important to be able to form some kind of confidence interval around it so that countries can be allocated to the two regimes. Once again standard methods are not ideal when estimating an unknown threshold. Hansen (2000) derives the correct distribution function and provides the appropriate critical values for the likelihood ratio statistic. The confidence interval of the threshold estimate of $\gamma$ consists of those values of the threshold variable for which the likelihood ratio statistic is less than the critical value. According to Hansen (2000) the 90\% critical value is 5.94, which is the value we adopt.

Table (4.8) reports the results from our estimation of a single-threshold based on various specifications of equation (4.2). ${ }^{6}$ We grouped the results according to the choice of the regime-dependent variable, which takes successively each one of our three measures of economic structure: the share of manufacturing in value added (ManSh), the share of the modern sector in value added (ModSh), and the share of manufacturing in the modern sector (ManModSh). For each regime-dependent variable we successively apply four different threshold variables (THRES): the measure of economic structure itself, the export share in GDP (EXPGD), the per capita GDP at the start of the time-span $\left(G D P P C_{1960}\right)$ and finally the natural logarithm of population in $1960\left(\ln P O P_{1960}\right)$. This exercise results in twelve different specifications of equation (4.2). Not all specifications are significant however, as testified by the bootstrapped $p$-value in the table.

When the regime-dependent variable is the share of manufacturing in value added, three specifications out of four are statistically significant - at least when the bootstrapped $p$-value is concerned. First, when the threshold variable is ManSh, we find a threshold of $28.2 \%$ of manufacturing share in GDP that minimises the sum of squared residuals. The test of whether the threshold was significant resulted in a $p$-value of 0.004 , allowing us to accept the non-linearity of the 'growth volatility'-'economic structure' at the $10 \%$

\footnotetext{
${ }^{6}$ Following this exercise, we also estimated a double-threshold estimation of (4.2), and found no new significant results, confirming the single-threshold model as the best specification.
} 
level. The estimated coefficients $\left(\delta_{1}\right.$ and $\left.\delta_{2}\right)$ show that growth volatility is negatively and significantly affected by an increase in manufacturing share in GDP mostly for values below $28.2 \%$ and not for those above. This result is mostly congruent with those in Table (4.4). Second, when the threshold variable is the share of exports in GDP, we find no significant threshold below or beyond which economic structure has a stronger negative impact on economic volatility. Third, when the threshold variable is the initial per capita GDP in 1960, we find a significant threshold of $G D P P C_{1960}$, as shown by a $p$-value of 0.007. A larger share of manufacturing strongly reduces growth volatility for countries with the 1960 income per capita below 5818.38 dollars. Again, this reinforces the proven fact that the volatility-reducing effect of manufacturing is higher for the countries at the lowest quartiles. Finally, when the threshold variable is the natural logarithm of population in 1960, we find a significant threshold of 14.74 . This corresponds to a population of 2.5 million. Hence, smaller countries - with a population below 2.5 million - benefit the most from reduced growth volatility as their manufacturing sector increases.

When the regime-dependent variable is the share of the modern sector in value added (ModSh), only one specification out of four shows enough statistical significance. That is the case when the threshold variable is the same as the regime-dependent variable, i.e., ModSh. We find a very significant threshold of $32.1 \%$, corresponding to a $p$-value of 0.000 . This result suggests that for all countries with ModSh below $32.1 \%$ of value added, they benefit from a significant reduction of their growth volatility as the size of their modern sector increases. Such cannot be said about the other potential thresholds in this context.

Finally, when the share of manufacturing in the modern sector (ManModSh) is the chosen regime-dependent variable, $50 \%$ of the specifications display statistically significant thresholds. Columns 12 and 13 of the table show those significant results. Choosing ManModSh and EXPGDP as threshold variables do not entail any meaningful implication for the analysis: the first because the estimated coefficient is not significant and the second because the bootstrapped $p$-value cannot reject the null hypothesis of the equality between the two regimes. However, when the threshold variables are $G D P P C_{1960}$ and $\ln P O P_{1960}$ we find 908.35 and 15.48 as threshold candidates, with 0.006 and 0.017 as $p$-values respectively. The first threshold implies that a larger share of manufacturing in the modern sector contributes in significantly reducing the volatility of economic growth for countries with the 1960 income per capita above 908.35 dollars. This income threshold is significantly different the one found with the share of manufacturing in value added, 5818.38 dollars. Finally, the value of 15.48 for the threshold variable $\ln P O P_{1960}$ corresponds to a population of 7.4 million, suggesting that only countries with a population below that level benefit from a more significant reduction in their growth volatility as their manufacturing share in the modern sector continues to increase. This population threshold is many times larger than the 2.5 million we found earlier when the share of manufacturing in value added was the preferred regime-dependent variable. 
Table 4.8: Single-Threshold Volatility-Panel Regression Results

\begin{tabular}{|c|c|c|c|c|c|c|c|c|c|c|c|c|}
\hline \multirow[t]{2}{*}{ Variables } & \multirow[b]{2}{*}{ ManSh } & \multicolumn{3}{|c|}{ Manufacturing Share } & \multicolumn{4}{|c|}{ Modern Sector Share } & \multirow[b]{2}{*}{ ManModSh } & \multicolumn{3}{|c|}{ Manufacturing Share in Modern Sector } \\
\hline & & $E X P G D P$ & $G D P P C_{1960}$ & $\ln P O P_{1960}$ & ModSh & $E X P G D P$ & $G D P P C_{1960}$ & $\ln P O P_{1960}$ & & $E X P G D P$ & $G D P P C_{1960}$ & $\ln P O P_{1960}$ \\
\hline$R E L U S_{1960}$ & $\begin{array}{c}0.0549^{* * *} \\
(0.0177)\end{array}$ & $\begin{array}{c}0.0580^{* * *} \\
(0.0188)\end{array}$ & $\begin{array}{c}0.0447^{* *} \\
(0.0182)\end{array}$ & $\begin{array}{c}0.0510^{* *} \\
(0.0196)\end{array}$ & $\begin{array}{l}0.0483^{* *} \\
(0.0195)\end{array}$ & $\begin{array}{l}0.0515^{* *} \\
(0.0210)\end{array}$ & $\begin{array}{c}0.0340^{*} \\
(0.0191)\end{array}$ & $\begin{array}{c}0.0539^{* * *} \\
(0.0203)\end{array}$ & $\begin{array}{l}0.0568^{* * *} \\
(0.0186)\end{array}$ & $\begin{array}{c}0.0542^{* * *} \\
(0.0188)\end{array}$ & $\begin{array}{c}0.0513^{* * *} \\
(0.0187)\end{array}$ & $\begin{array}{c}0.0543^{* * *} \\
(0.0187)\end{array}$ \\
\hline$\triangle \ln P O P$ & $\underset{(0.207)}{-0.0162}$ & $\begin{array}{l}-0.0222 \\
(0.205)\end{array}$ & $\underset{(0.209)}{0.00495}$ & $-\underset{(0.205)}{-0.0173}$ & $\underset{(0.186)}{0.00737}$ & $\frac{0.0400}{(0.219)}$ & $\begin{array}{l}0.0206 \\
(0.198)\end{array}$ & $\frac{0.0377}{(0.206)}$ & $-\underset{(0.207)}{0.00882}$ & $\begin{array}{l}-0.0269 \\
(0.203)\end{array}$ & $\underset{(0.185)}{0.00159}$ & $\underset{(0.194)}{-0.0213}$ \\
\hline$E X P G D P$ & $\begin{array}{l}0.00977 \\
(0.0138)\end{array}$ & $\begin{array}{l}0.00602 \\
(0.0150)\end{array}$ & $\begin{array}{l}0.00819 \\
(0.0129)\end{array}$ & $\underset{(0.0131)}{0.00928}$ & $\begin{array}{l}0.00296 \\
(0.0131)\end{array}$ & $\begin{array}{l}0.0120 \\
(0.0163)\end{array}$ & $\begin{array}{l}0.00211 \\
(0.0130)\end{array}$ & $\begin{array}{l}0.00750 \\
(0.0134)\end{array}$ & $\begin{array}{l}0.0104 \\
(0.0131)\end{array}$ & $\begin{array}{l}0.00490 \\
(0.0137)\end{array}$ & $\begin{array}{l}0.00825 \\
(0.0135)\end{array}$ & $\begin{array}{l}0.0126 \\
(0.0125)\end{array}$ \\
\hline$G C F$ & $-\underset{(0.0226)}{0.0605^{* * *}}$ & $-{ }^{-0.0581^{* *}}$ & $\begin{array}{c}-0.0643^{* * *} \\
(0.0214)\end{array}$ & $-{ }_{(0.0218)}^{0.0619^{* * *}}$ & $-{ }_{(0.0221)}^{0.0649^{* * *}}$ & $\begin{array}{c}-0.0747^{* * *} \\
(0.0234)\end{array}$ & $-0.0729^{* * * *}$ & $-{ }_{(0.0219)}^{0.0714^{* * *}}$ & $-\underset{(0.0214)}{-0.0625^{* * *}}$ & $\begin{array}{c}-0.0633^{* * *} \\
(0.0212)\end{array}$ & $-{ }^{-0.0541^{* *}}$ & $-0.0697^{* * *}$ \\
\hline INFLATION & $\underset{(0.00131)}{0.00324^{* *}}$ & $\underset{(0.00141)}{0.00334^{* *}}$ & $\underset{(0.00131)}{0.00323^{* *}}$ & $\underset{(0.00139)}{0.00329^{* *}}$ & $\underset{(0.00131)}{0.00319^{* *}}$ & $\underset{(0.00131)}{0.00318^{* *}}$ & $\underset{(0.00125)}{0.00309^{* *}}$ & $\underset{(0.00134)}{0.00323^{* *}}$ & $\underset{(0.00132)}{0.00340^{* *}}$ & $\underset{(0.00134)}{0.00336^{* *}}$ & $\underset{(0.00135)}{0.00337^{* *}}$ & $\begin{array}{c}0.00327^{* *} \\
(0.00138)\end{array}$ \\
\hline$\underset{(\mathbf{Z} \leq \gamma)}{\mathbf{Z}}$ & $-{ }_{(0.0397)}^{0.0841^{* *}}$ & & & & $\begin{array}{c}-0.102^{* * *} \\
(0.0369)\end{array}$ & & & & $\underset{(0.0285)}{-0.00628}$ & & & \\
\hline$\underset{(\mathbf{Z}>\gamma)}{\mathbf{Z}}$ & $\begin{array}{c}-0.0407 \\
(0.0337)\end{array}$ & & & & $\begin{array}{l}0.0390 \\
(0.0255)\end{array}$ & & & & $\underset{(0.0213)}{-0.0234}$ & & & \\
\hline$\underset{(E X P G D P \leq \gamma)}{\mathbf{Z}}$ & & $\begin{array}{l}-0.0476 \\
(0.0307)\end{array}$ & & & & $\begin{array}{l}0.0228 \\
(0.0254)\end{array}$ & & & & $\frac{-0.0438^{* *}}{(0.0178)}$ & & \\
\hline$\underset{(E X P G D P>\gamma)}{\mathbf{Z}}$ & & $\begin{array}{c}-0.0260 \\
(0.0383)\end{array}$ & & & & $\begin{array}{l}0.0132 \\
(0.0262)\end{array}$ & & & & $\begin{array}{c}-0.0299 \\
(0.0214)\end{array}$ & & \\
\hline$\frac{\mathbf{Z}}{\left(G D P P C_{1960} \leq \gamma\right)}$ & & & $\begin{array}{c}-0.0647^{*} \\
(0.0346)\end{array}$ & & & & $\begin{array}{l}0.0126 \\
(0.0254)\end{array}$ & & & & $\underset{(0.0216)}{0.00281}$ & \\
\hline$\underset{\left(G^{\prime} P P C_{1960}>\gamma\right)}{\mathbf{Z}}$ & & & $\begin{array}{c}-0.0164 \\
(0.0289)\end{array}$ & & & & $\begin{array}{l}0.0352 \\
(0.0245)\end{array}$ & & & & $\begin{array}{l}-0.0400^{* *} \\
(0.0183)\end{array}$ & \\
\hline$\underset{\left(\ln P O P_{1960} \leq \gamma\right)}{\mathbf{Z}}$ & & & & $\underset{(0.0401)}{-0.105^{* * *}}$ & & & & $\begin{array}{c}0.00830 \\
(0.0249)\end{array}$ & & & & $\begin{array}{c}-0.0571^{* * *} \\
(0.0205)\end{array}$ \\
\hline$\underset{\left(\ln P O P_{1960}>\gamma\right)}{\mathbf{Z}}$ & & & & $\begin{array}{c}-0.0256 \\
(0.0285)\end{array}$ & & & & $\begin{array}{l}0.0380 \\
(0.0253)\end{array}$ & & & & $\begin{array}{c}-0.0275 \\
(0.0196)\end{array}$ \\
\hline Obs & 719 & 719 & 719 & 719 & 720 & 720 & 720 & 720 & 719 & 719 & 719 & 719 \\
\hline Threshold & 0.282 & 0.469 & 5818.383 & 14.739 & 0.321 & 0.503 & 5818.383 & 17.245 & 0.362 & 0.463 & 908.356 & 15.482 \\
\hline Percentile & 86 & 73 & 39 & 20 & 10 & 79 & 39 & 74 & 50 & 72 & 11 & 36 \\
\hline$p$-value & 0.004 & 0.266 & 0.007 & 0.013 & 0.000 & 0.209 & 0.003 & 0.018 & 0.054 & 0.210 & 0.006 & 0.017 \\
\hline F-Stat & 5.702 & 5.566 & 5.276 & 5.634 & 6.983 & 6.350 & 6.360 & 6.453 & 5.997 & 5.676 & 6.342 & 5.537 \\
\hline $\mathrm{R}^{2}$ & 0.191 & 0.180 & 0.189 & 0.189 & 0.197 & 0.180 & 0.191 & 0.187 & 0.192 & 0.189 & 0.197 & 0.197 \\
\hline
\end{tabular}

Note: All regressions in the table include unreported country and time dummy variables; Standard errors are clustered at the country level; $t$-statistics are in brackets; All models estimated using White Heteroscedasticity-Consistent standard errors; ${ }^{* * *},{ }^{* *}$ and ${ }^{*}$ denote significance at 1,5 and 10 percent levels, respectively. 


\subsection{Alternative Specialisation Indicators}

The Theil entropy index was our preferred indicator for economic specialisation. We showed that when considering the relationship between this indicator and growth volatility, there was no evidence of any significant relationship. But the Theil index is only one indicator in many to measure the degree of economic specialisation. Alternative indicators include the Gini coefficient, the Herfindahl and the Hirschman indices, as sufficiently described below. The results for all these additional indicators - available upon request - confirm our initial findings with the Theil index, that economic specialisation in the context of this analysis does not reduce the volatility of economic growth. Figure (4.2) below displays in four fitted scatter-plots the relationship between growth volatility and the Theil, Gini, Herfindahl and Hirschman indices of specialisation respectively. Although downward sloping, the relationships do not appear significantly evident.

\subsubsection{The Gini Coefficient}

The Gini coefficient is another very common specialisation indicator used in the literature. Originally, it was designed as a statistical dispersion measure which primary objective was to provide a clear and concise representation of the income distribution of the residents of a given nation. It is technically defined from the Lorenz curve, which in itself is the graphical representation of the cumulative distribution function of the empirical probability distribution of wealth or income. The Gini coefficient varies within a closed interval $[0,1]$. A Gini coefficient of 0 means a perfect income equality among the members of the society, while a value of 1 reflects an absolute income inequality.

The Gini coefficient - although its original function was to determine the level of wealth and income inequality within a given society - has been massively used in other fields as well, such as sociology, ecology, health science, as well as engineering and agriculture. In economics, the Gini coefficient has also been used to quantify the degree of specialisation of an economy. Although its absolute value remains bounded in the $[0,1]$ interval, the interpretation of the Gini coefficient now differs. The cumulative distribution of income is replaced by that of the total value added of the economy - which could be either from the production or from the exports - while the cumulative population is replaced by the sectors (or product lines) that compose the economy. A Gini value of 1 means one sector or product line accounts for the total value of production or exports and inversely a value of 0 refers to a perfect equality among those sectors or product lines in explaining the total value added. Omitting country and time subscripts, a mathematical expression of the Gini coefficient - referred to as the Brown formula - designed as an absolute measure of specialisation is the following:

$$
G=\left|1-\sum_{k=1}^{K}\left(S_{k}-S_{k-1}\right)(2 k-1) / K\right|
$$


where $K$ is the total number of sectors or product lines, $S_{k}$ the cumulative value added (or exports) shares, which can be written as:

$$
S_{k}=\sum_{i=1}^{k} s_{i} / \sum_{i=1}^{K} s_{i}
$$

$s_{k}$ being the value added (or export value) of the product line or sector $k$. For each country and time period, the products are sorted in increasing order of their value added $s$ in such a way that $s_{k} \leq s_{k+1}$ for each product line or sector $k$.

\subsubsection{The Normalised Herfindahl Index}

An alternative measure of specialisation is the Herfindahl index. It is a statistical variable originally designed to measure the size of firms in relation to the industry and an indicator of the overall amount of competition among those firms. Technically, it is defined as the sum of the squares of the market shares of the 50 largest firms (or summed over all the firms if there are fewer than 50) within a given industry, where all the market shares are expressed as fractions. The subsequent result is made proportional to the average market share, weighted by the market share of the incumbent firm. Consequently, the value of the Herfindahl index ranges in the interval $[0,1]$, where the value of 0 reflects a huge number of often very small firms, while 1 is a symbol of a single monopolistic producer. Any increase in the value of the Herfindahl index generally shows a decrease in competition and therefore an increase of market power, whereas decreasing indicate the opposite.

Shifted to the analysis of specialisation, the market shares in the original formulation become the shares of different product lines or sectors in the total value added or exports of a given country. A value of 0 for the Herfindahl index in this context will mean that the value added of the economy is equally shared between all the sectors or product lines, while a value of 1 is equivalent to saying that only one sector accounts for all the value added. These two extreme values - as in the case of the Gini index - are hardly met in practice, but they serve as convenient boundaries to make the case clearer. Omitting country and time subscripts, the mathematical expression of the normalised Herfindahl index is:

$$
H=\frac{\sum_{k=1}^{K} s_{k}^{2}-\frac{1}{K}}{1-\frac{1}{K}}
$$

where $K$ is the total number of sectors or product lines and $s_{k}=x_{k} / \sum_{i=1}^{K} x_{i}$ the share of product line $k$ in total value added.

\subsubsection{The Hirschman Index}

The Hirschman index is another measure of specialisation. It has a clear correlation with the Herfindahl index, since both measures heavily rely on the shares of different product 
lines or sectors in the total value added or exports. The mathematical formulation of this indicator for a given country at a given time period is:

$$
H I=\sqrt{\sum_{k=1}^{K} s_{k}^{2}}
$$

To see that there is a clear equivalence between the Herfindahl and the Hirschman indices, we can decompose the Herfindahl index as follow: $H=\frac{\sum_{k=1}^{K} s_{k}^{2}-\frac{1}{K}}{1-\frac{1}{K}} \Rightarrow$ $\sum_{k=1}^{K} s_{k}^{2}-\frac{1}{K}=H\left(1-\frac{1}{K}\right) \quad \Rightarrow \quad \sum_{k=1}^{K} s_{k}^{2}=\frac{1}{K}+H\left(1-\frac{1}{K}\right)=H+(1-H) \frac{1}{K}$.

Taking the square root of both sides of the previous equation leads to the Hirschman index:

$$
\sqrt{\sum_{k=1}^{K} s_{k}^{2}}=\sqrt{\left(1-\frac{1}{K}\right) H+\frac{1}{K}}=H I
$$

Figure 4.2: Growth Volatility and Indicators of Structural Diversification

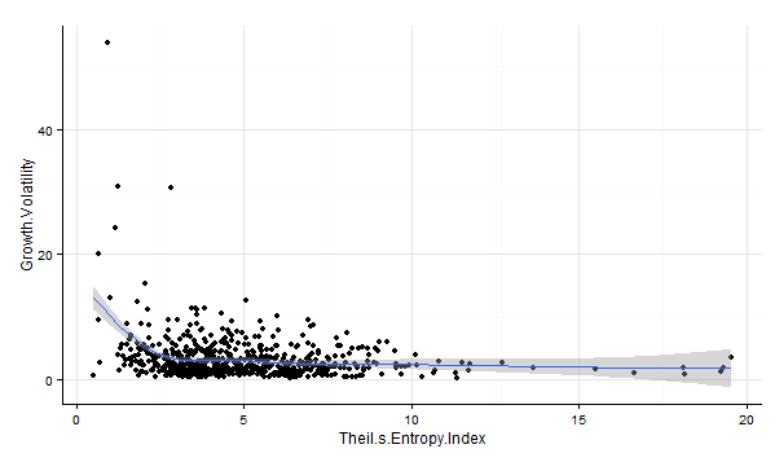

(a) Theil Index

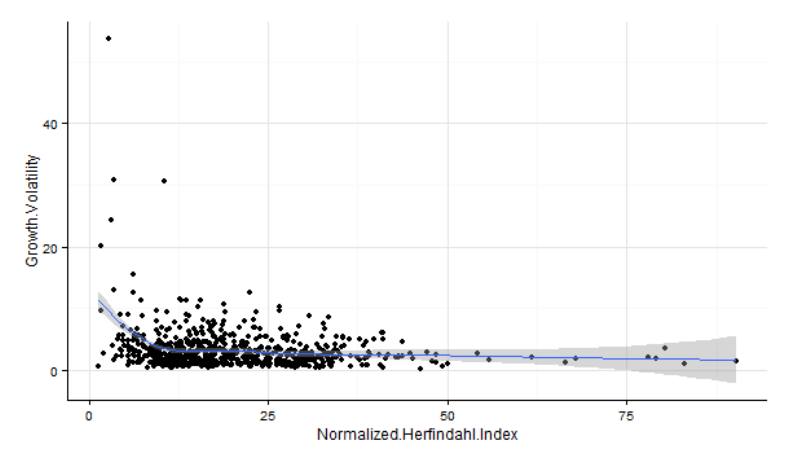

(c) Herfindahl Index

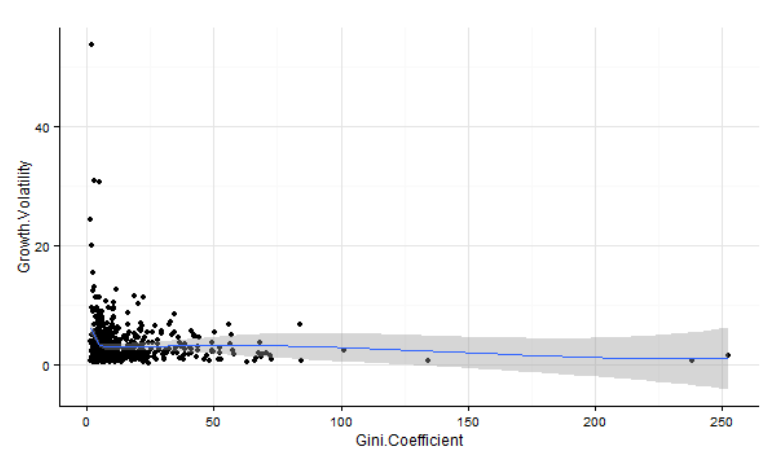

(b) Gini Coefficient

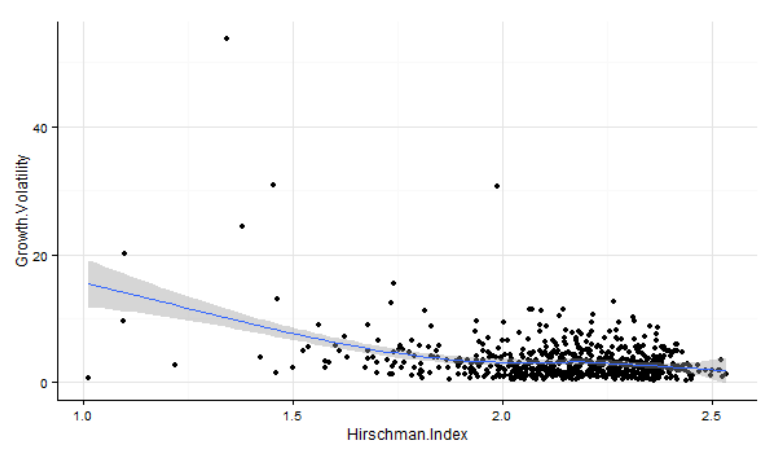

(d) Hirschman Index

Note: The volatility of economic growth on the y-axis is measured as the standard deviation of the annual growth rate of per capita GDP within each five-year period, from 1960 to 2010. The Theil index, Gini coefficient, Herfindahl and Hirschman indices on the x-axes is also measured over the same time-span for our sample of 108 countries. 


\subsection{Concluding Remarks}

In this paper, we have examined the relationship between economic structure and the ability of countries to sustain stable economic growth, using both a linear panel and a threshold panel models. The structural variables included the degree of specialisation in the structure of value added as measured by the Theil index, the share of manufacturing in value added, the share of the modern sector in value added and the share of manufacturing within the modern sector. These variables were measured both in terms of initial levels at the beginning of period, or in terms of their changes over that period. The key dependent variable was the volatility of growth rates in five-year periods. The analysis resulted in a large set of specialisations which have been discussed systematically in the previous sections. Though this research does not draw from definitive specifications and lead to absolutely firm conclusions, some interesting patterns are beginning to emerge nevertheless. ${ }^{7}$

In the linear model we found that, first, a higher manufacturing share may help reduce the volatility of economic growth. In other words, manufacturing seems to be related to the ability to sustain growth. Second, if we look at the share of manufacturing value added within the modern sector of the economy rather than its share in the GDP, a very similar picture emerges. The modern sector share is significantly associated with a lower growth volatility. Third, the impact of the modern sector share on the ability to sustain growth is more ambiguous than that of manufacturing. It seems to be dependent on the change in that share. The impact of the modern sector share on growth volatility is therefore difficult to interpret, with the direct effects being negative. A larger modern sector is associated with higher volatility. Finally, the results for specialisation unexpectedly show no significant effect on volatility. From the portfolio perspective discussed earlier, one would expect that a more diversified economy is less subject to volatility. On the basis of our current - imperfect - measures of specialisation and volatility this turns out not to be exactly the case.

In the threshold model, we used twelve different specifications grouped in three main categories, mainly according to the choice of our regime-dependent variable. Estimating thresholds based directly on the level of economic structure does not always yield a significant result. For instance, the share of manufacturing in modern sector does not add any meaningful layer to the analysis when this indicator is chosen both as regime-dependent and threshold variable. When the share of manufacturing in value added is chosen as both the regime-dependent and threshold variable, we find a significant threshold of $28.2 \%$, allowing us to accept the non-linearity of the 'growth volatility'-'economic structure' at the $10 \%$ level. Partially in line with the results of the linear model, this suggests that growth volatility is negatively and significantly affected by an increase in manufacturing share in

\footnotetext{
${ }^{7}$ The conclusions are primarily based on the Hausman-Taylor specifications, which capture both within country and between country variations. The within group specifications are usually less informative, but are almost always congruent with the Hausman-Taylor specifications.
} 
GDP mostly for values below $28.2 \%$ and not necessarily for those above. Similarly, when the share of the modern sector in value added is chosen as both the regime-dependent and the threshold variable, we find $32.1 \%$ as the threshold below which the volatility-reduction benefits are higher as the share of the modern sector increases.

Finally, we alternate various regime-independent variables - the share of exports in GDP, the per capita GDP in 1960 and the natural logarithm of population in 1960 - as alternative threshold variables. The share of exports in GDP does not act as a significant threshold in none of our specifications. The original income level of 1960 however matters in two cases, first when the share of manufacturing in value added is concerned and when the share of manufacturing in the modern sector is the regime-dependent variable. A larger share of manufacturing in GDP strongly reduces volatility for countries with the 1960 per capita income below 5818.38 dollars. However, a larger share of manufacturing in the modern sector only contributes in reducing growth volatility for countries with the 1960 income per capita above the threshold of 908.35 dollars. We also found that population somehow matters when it comes to the volatility-reducing effects of economic structure. Countries with a population below 2.5 and 7.4 million benefit the most from reduced growth volatility as their share of manufacturing in GDP and the share of manufacturing in the modern sector increase, respectively. ${ }^{8}$

\footnotetext{
${ }^{8}$ All these results were based on a single-threshold model. The results of the quintile linear models suggest however that there is a room for at least a double-threshold analysis. Following this observation, we hence conducted a double-threshold analysis of the model but could not find significantly conclusive results. This reinforces the fact that the single-threshold model is the best non-linear specification adapted to the question, in the second part of this paper.
} 


\section{Appendix 4.A: Single-Threshold Regression Model}

In a series of papers Hansen $(1996,1999,2000)$ identifies three issues that need to be addressed when employing threshold regression techniques, namely the joint estimation of the regression coefficients and the threshold value, testing for the significance of the estimated threshold. In this Appendix we briefly discuss each. ${ }^{9}$

\section{A.1 Estimation}

Let's consider the following single-threshold model, similar to the one in equation (4.2):

$$
y_{i t}=\vartheta_{t}+\mathbf{X}_{i t}\left(q_{i t}<\gamma\right) \delta_{1}+\mathbf{X}_{i t}\left(q_{i t} \geq \gamma\right) \delta_{2}+\theta_{i}+\varepsilon_{i t}
$$

where $q_{i t}$ is the threshold variable, and $\gamma$ the threshold parameter that divides the equation into two regimes with coefficients $\delta_{1}$ and $\delta_{2}$. Parameters $\theta_{i}$ and $\vartheta_{t}$ are the individual and time-specific fixed-effects, respectively, while $\epsilon_{i t}$ is the disturbance. The threshold equation is equivalent to the following:

$$
y_{i t}=\vartheta_{t}+\mathbf{X}_{i t}\left(q_{i t}, \gamma\right) \delta+\theta_{i}+\varepsilon_{i t}
$$

where

$$
\mathbf{X}_{i t}\left(q_{i t}, \gamma\right)=\left\{\begin{array}{l}
\mathbf{X}_{i t} I\left(q_{i t}<\gamma\right) \\
\mathbf{X}_{i t} I\left(q_{i t} \geq \gamma\right)
\end{array}\right.
$$

The two regimes are distinguished by the two different regression slopes $\delta_{1}$ and $\delta_{2}$. Chan (1993) and Hansen (1999) recommend estimation of $\gamma$ by least squares, which involves finding the value of $\gamma$ that minimises the concentrated sum of squared errors. In practice this involves searching over distinct values of $q_{i t}$ for the value of $\gamma$ at which the sum of squared errors is smallest. This value of $\gamma$ is our estimate of the threshold of $\hat{\gamma}$. To avoid the possibility of too few observations being in any particular regime we restrict the search for $\gamma$ such that at least $10 \%$ of observations are in each regime. Once we have a value for $\hat{\gamma}$ it becomes straightforward to estimate the coefficients of the regression model. Given $\gamma$, the ordinary least-squares estimator of $\delta$ is:

$$
\hat{\delta}=\left\{\mathbf{X}^{*}(\gamma)^{\prime} \mathbf{X}^{*}(\gamma)\right\}^{-1}\left\{\mathbf{X}^{*}(\gamma)^{\prime} \mathbf{y}^{*}\right\}
$$

where $\mathbf{y}^{*}$ and $\mathbf{X}^{*}$ are within-group deviations. The residual sum of squares (RSS) is equal to $\hat{e}^{\prime} \hat{e}^{*}$. To estimate $\gamma$, one can search over a subset of the threshold variable $q_{i t}$. Instead of searching over the whole sample, we restrict the range within the interval $(\underline{\gamma}, \bar{\gamma})$, which are quantiles of $q_{i t}$. The estimator of $\gamma$ is the value that minimises the RSS, that is:

$$
\hat{\gamma}=\underset{\gamma}{\arg \min } S_{1}(\gamma)
$$

\footnotetext{
${ }^{9}$ See Wang (2015) for an in-depth discussion of the single and multiple-thresholds models, as well as a description of the Stata codes to carry out the estimations.
} 
If $\gamma$ is known, the model is no different from the ordinary linear model. But if $\gamma$ is unknown, as in our case, there is a nuisance parameter problem, which makes the $\gamma$ estimator's distribution non-standard. Hansen (1999) proved that $\hat{\gamma}$ is a consistent estimator for $\gamma$, and he argued that the best way to test $\gamma=\gamma_{0}$ to form the confidence interval using the "no-rejection region" method with a likelihood-ratio (LR) statistic, as follows:

$$
\begin{gathered}
\operatorname{LR}_{1}(\gamma)=\frac{\left\{\mathrm{LR}_{1}(\gamma)-\mathrm{LR}_{1}(\hat{\gamma})\right\}}{\hat{\sigma}^{2}} \rightarrow \xi \\
\operatorname{Pr}(x<\xi)=\left(1-e^{\frac{-x}{2}}\right)^{2}
\end{gathered}
$$

Given a significance level $\alpha$, the lower limit corresponds to the maximum value in the LR series, which is less than the $\alpha$ quantile, and the upper limit corresponds to the maximum value in the LR series, which is less than the $\alpha$ quantile. The $\alpha$ quantile can be computed from the following inverse function in equation (4.11):

$$
c(\alpha)=-2 \log (1-\sqrt{1-\alpha})
$$

For example, for $\alpha=0.1,0.05$ and 0.01 , the quantiles are $6.53,7.35$, and 10.59 , respectively. If $\operatorname{LR}_{1}\left(\gamma_{0}\right)$, then we reject $\gamma=\gamma_{0}$.

\section{A.2 Testing for a Threshold}

Having found a threshold, it is important to determine whether it is statistically significant or not, i.e., to test whether the coefficients $\delta_{1}$ and $\delta_{2}$ are the same in each regime. The null hypothesis and the alternative hypothesis (the liner versus the single-threshold model) are:

$$
\mathbb{H}_{0}: \delta_{1}=\delta_{2} \quad \mathbb{H}_{a}: \delta_{1} \neq \delta_{2}
$$

Given that the threshold $\gamma$ is not identified under the null hypothesis, this test has a non-standard distribution and critical values cannot be read off standard distribution tables. Hansen (1996) suggests bootstrapping to simulate the asymptotic distribution of the likelihood ratio test allowing us to obtain a $p$-value for this test. First, one estimates the model under the null (linearity) and alternative (threshold occurring at $\gamma$ ). This gives the actual value of the likelihood ratio test: ${ }^{10}$

$$
F_{1}=\frac{S_{0}-S_{1}(\hat{\gamma})}{\hat{\sigma}^{2}}
$$

Given that under $\mathbb{H}_{0}$, the threshold value $\gamma$ is not identified, and $F_{1}$ has nonstandard distribution, the bootstrap on the critical values of the $F$ statistic to test the significance of the threshold effect is used. $S_{0}$ is the RSS of the linear model. Hansen (1996) suggested the following bootstrap design:

\footnotetext{
${ }^{10}$ Where: $\hat{\sigma}^{2}=\frac{S_{1}(\hat{\gamma})}{n(t-1)}$
} 
1. Fit the model under $\mathbb{H}_{a}$ an obtain the residual $\hat{e}_{i l}^{*}$.

2. Make a cluster resampling $\hat{e}_{i t}^{*}$ with replacement, and obtain the new residual $v_{i t}^{*}$.

3. Generate a new series under the $\mathbb{H}_{a}$ data-generating process (DGP), $y_{i t}^{*}=\mathbf{X}^{*} \delta+v_{i t}^{*}$, where $\delta$ can take arbitrary values.

4. Fit the model under $\mathbb{H}_{0}$ and $\mathbb{H}_{a}$, and compute the $F$ statistic using (4.20).

5. Repeat steps $1-4 B$ times, and the probability of $F$ is $\operatorname{Pr}=I\left(F>F_{1}\right)$, namely, the proportion of $F>F_{1}$ in bootstrap number $B$. In our case $B$ is fixed at large value: 1000 .

To obtain the $p$-value the bootstrap procedure is followed with the dependent variable $y_{i t}$ being generated under the null hypothesis of a single threshold. This bootstrap estimate of the $p$-value for $F_{1}$ under the null is given by the percentage of draws for which the simulated statistic $F_{1}$ exceeds the actual one.

\section{A.3 Confidence Intervals}

Finally, once we have found the threshold that is significant we would like to classify observations in each regime with some degree of certainty. Normally the confidence interval for a parameter is found by inverting the Wald or $t$-statistics, but in case where the parameter is unidentified in a certain region Wald statistics have poorly behaved sampling statistics (Dufour, 1997). Hansen (2000) however derives the correct distribution function and provides the appropriate critical values, $c(\alpha)$, for the likelihood ratio statistic given by $\mathrm{LR}_{1}$, as previously shown. From Hansen (2000), the 90, 95, and $99 \%$ critical values are given by $5.94,7.35$, and 10.59 , respectively.

The previous procedure could 'easily' be generalised to a multiple-thresholds setting - that is, multiple regimes. A double-threshold model similar to the previous example would look like this:

$$
y_{i t}=\vartheta_{t}+\mathbf{X}_{i t}\left(q_{i t}<\gamma_{1}\right) \delta_{1}+\mathbf{X}_{i t}\left(\gamma_{1} \leq q_{i t}<\gamma_{2}\right) \delta_{2}+\mathbf{X}_{i t}\left(q_{i t} \geq \gamma_{2}\right) \delta_{3}+\theta_{i}+\varepsilon_{i t}
$$

Here, $\gamma_{1}$ and $\gamma_{2}$ are the thresholds that divide the equation into three regimes with coefficients $\delta_{1}, \delta_{2}$, and $\delta_{3}$. We need to compute this $(N \times T)^{2}$ times using the grid search method, which is not feasible in practice. According to Bai (1997) and Bai and Perron (1998), the sequential estimator is consistent, just like in the case of structural breaks. In the multiple-thresholds case, the construction of the $F$ statistic and the bootstrap design are similar to the single-threshold model. Chan (1993) and Hansen (1999) show that the dependence of the estimation and inference of $\delta$ on the threshold estimate is not of first-order asymptotic importance, so the inference of $\delta$ can proceed because the threshold value $\gamma$ is given. 


\title{
Chapter 5
}

\section{A Stochastic Model of Rare Disasters and Economic Growth}

\begin{abstract}
This chapter proposes a new model of rare disasters and investigates their overarching implications for both the steady-state economic growth and the balanced growth path's speed of convergence. It follows a growing trend in the macroeconomics and finance literature of analysing low probability events with sometimes massive negative impacts on relevant economic aggregates, such as consumption or the price of equities. Taking stock of Barro (2006), Gourio (2012), Fernández-Villaverde and Levintal (2017) and others, we show in an exclusively theoretical setting that a rare disaster affects the steady-state economic growth - derived from a standard Euler equation - through the expected value of the equilibrium interest rate. We also show that a rare disaster disrupts the speed of convergence through the elasticity of output with respect to the stead-state intensive-form physical capital, and that the direction and amplitude of this disruption depend on how the new value of this elasticity compares to the share of physical capital in total output in the absence of shocks.
\end{abstract}

Keywords: Rare Disasters, Economic Growth, Speed of Convergence.

JEL Classification: C61, O40, O47.

\footnotetext{
${ }^{0}$ This chapter was 'recently' presented at the Second Edition of the UNU-MERIT Internal Conference. We are extremely grateful to Serdar Turkeli for his insightful comments and suggestions. All the typos and mistakes herein are those of the author.
} 


\subsection{Introduction}

Models with rare disasters have recently become a new popular field of research in macroeconomics and finance, as convincingly shown by Fernández-Villaverde and Levintal (2017). One of the many reasons of this upswing in research is the potential for rare disasters to explain an array of growth disruptions and asset-pricing puzzles (Barro and Ursúa, 2012). It is also a reflection of a rebalance of interests since the global macroeconomic, financial and sovereign-debt crises of the last decade. Moreover, time-varying probabilities could be an important ingredient of closed and open-economy models of business cycles (Barro, 2006).

The notion that rare disasters - defined as a collection of low-probability events with a massive negative effect on economic variables, mostly consumption - can account for many asset pricing puzzles, such as the Mehra and Prescott (1985)'s equity premium puzzle, was successively and in various degrees popularised by Rietz (1988), Barro (2006) and Gabaix (2012) among others. Barro (2006), in particular, argues that a rare disaster model calibrated to match data from 35 countries can fairly reproduce the high equity premium, the low risk-free rate, and the stock market volatility. Barro (2006) also assumed disaster probabilities of 1.7 percent a year and declines in output/consumption in a range of 15 to 64 percent. Furthermore, Barro (2009) can also match the responses of the price/dividend ratio to increases in uncertainty.

Barro (2006) and Barro (2009) have been path-breaking works and many have followed that lead in formulating, calibrating, estimating, and solving sometimes very complicated models with disaster probabilities and declines in consumption and other macroeconomic variables in ways congruent in spirit with the original formulations of the problem. Barro and Ursúa (2012) rely on long-term data covering 28 countries for consumption and 40 for GDP and found that their calibrated baseline model replicates well the observed peak-to-trough disasters of the individual series. Barro and Jin (2011) use the framework of macroeconomic disasters to provide robust estimates of the coefficient of relative risk aversion, a key parameter for most analyses of agents' behaviour towards risk. Nakamura et al. (2013) estimate an empirical model of consumption disasters using new data on consumption for 24 countries over more than 100 years, and then study its implications for asset prices. Their model allows for partial recoveries after disasters that unfold over multiple years. They found that roughly half of the drop in consumption due to disasters is subsequently reversed. ${ }^{1}$ Wachter (2015) uses the framework to show that time-varying risk of rare disasters can explain parts of the aggregate markets volatility. In her model, aggregate consumption follows a Gaussian distribution with low volatility most of the

\footnotetext{
${ }^{1}$ The model of Nakamura et al. (2013) also generates a sizable equity premium from disaster risk, but one that is substantially smaller than previous simpler models, and hence implies that a large value of the intertemporal elasticity of substitution is necessary to explain stock-market crashes at the onset of disasters.
} 
time, but with some probability of a consumption realisation far out in the tail. ${ }^{2}$

In addition to Barro and Ursúa (2012), Barro and Jin (2011), Nakamura et al. (2013), and Wachter (2015), the rare disasters approach has also been used and often extended to investigate business cycles (Gourio, 2012), credit risk (Gourio, 2013), and foreign exchange markets (Farhi and Gabaix, 2016), among others. These various calibrations and estimations share a commonality: they include large non-linearities in the solution of the model. Dealing with such non-linearities is not much of a challenge when the economies are characterised by endowments, and an appropriate parameterisation could help derive either closed-form solutions or formulae that may be easily evaluated. This in mind, Fernández-Villaverde and Levintal (2017) propose different solution methods for computing the equilibrium of dynamic stochastic general equilibrium (DSGE) models with rare disasters in the same vein as those proposed by Rietz (1988), Barro (2006), Gabaix (2012), and Gourio (2012). After solving a standard New Keynesian model with Epstein and Zin (1989) preferences and time-varying disaster risk with perturbation, Taylor projection, and Smolyak collocation, they found that the Taylor projection delivers the best accuracy and speed trade-off among the tested solutions. They also found that third-order perturbations may generate solutions that suffer mostly from accuracy problems and that Smolyak collocation can be computationally costly in terms of run time and memory requirements.

An alternative way of analysing rare disasters is to look at their specific nature, notably political shocks (Aisen and Veiga, 2013). Political instability, defined by Alesina et al. (1996) as the propensity of government collapse, has been shown to substantially reduce economic growth. Using data on 113 countries from 1950 to 1982, Alesina et al. (1996) have shown that GDP growth is significantly lower in countries and time periods with a high propensity of government collapse. Chen and Feng (1996) show that regime instability, political polarisation and government repression all have a negative impact on economic growth. Brunetti (1997) comprehensively surveys and summarises the main political variables hindering economic growth. He argues that policy variables and subjective perception of politics are most successful in cross-country growth regressions, unlike democracy. Using a dynamic panel system Generalised Method of Moments, Jong-A-Pin (2009) has shown that the four dimensions of political instability - politically motivated violence, mass civil protest, instability within the political regime, and instability of the political regime - have different effects on economic growth. He also found that only the instability of the political regime has a robust and significant negative effect on economic growth. ${ }^{3}$ Regarding private investment, Alesina and Perotti (1996) show that

\footnotetext{
${ }^{2}$ The eventuality for this poor outcome, as shown by Wachter (2015) substantially increases the equity premium, while time-variation in the probability of this outcome drives high stock market volatility and excess return predictability.

${ }^{3} \mathrm{~A}$ dissenting view comes from Campos and Nugent (2002), who find no evidence of a causal and negative long-run relation between political instability and economic growth. They only find evidence of a short-run effect.
} 
socio-political instability generates an uncertain politico-economic environment, raising risks and reducing investment. Political instability leads to higher shares of government spending in GDP (Devereux and Wen, 1998) and political uncertainty in OECD countries tends to reduce public investment (Darby et al., 2004). Political instability also leads to a greater reliance on seigniorage revenues and to higher inflation as shown by Aisen and Veiga (1996). Quite interestingly, the mechanics at work to explain inflation in their articles resemble those affecting economic growth; namely that political instability shortens the horizons of governments, hence disrupting long-term economic policies' effectiveness.

In this paper we investigate theoretically the relationship between the steady-state economic growth and rare disasters on the one hand and the implications for the speed of convergence of rare disasters on the other, taking stock from Barro (2006), Gourio (2012), and Fernández-Villaverde and Levintal (2017) among others. The steady-state economic growth is derived from a standard Euler equation, which itself results from the joint optimisations of a social planner with an infinitely-lived household and a rational representative firm. In our model, a rare disaster affects economic growth through its adverse effects on the three proximate factors of production: physical capital, labour and total factor productivity. It affects the speed of convergence through the elasticity of output with respect to the balanced growth path's intensive-form physical capital, which incidentally happens to be also the share of physical capital in total output.

In Section (2) of this paper we set up the fundamentals of the model, its underlying assumptions, we present the optimisation problems of the representative firm and household. Using all these information, we strip down the full model, using the Euler equation and some results from probability theory. The representative firm of the benchmark economy uses a Harrod-neutral Cobb-Douglas technology and is subject to constant returns to scale. The market of goods is competitive, i.e., factors are paid at their marginal products. The households in our model are dynastic families whose size grows at an exponential and exogenous rate. This household maximises its lifetime utility subject to a specific budget constraint, taking into account the overall wealth of the household at each point in time. To ensure that our economy converges to a balanced growth path, we choose a standard CRRA as our preferred instantaneous utility function.

In Section (3) we extend the model by using alternative production specifications, in the spirit of Rebelo (1991) and Arrow (1962). When the production function espouses an $A K$ form or when the TFP follows a learning-by-doing shape, we show that the features of the expected growth is not that much different from that in the baseline model.

In Section (4) we investigate the implications of a rare and violent shock on the speed at which an economy converges toward its steady-state. We derive the speed of convergence following the same iteration as Romer (2011). We find that a rare disaster affects convergence through the expected elasticity of output with respect to the intensiveform physical capital. We also show through a back-of-the-envelop calibration that the direction of this effect depends on how this expected elasticity compares to the share of 
capital in output when there is no shock.

\subsection{The Model}

\subsubsection{Modelling Rare Disasters}

We model rare disasters by their deleterious effects on the factors of production: physical capital $\left(K_{t}\right)$, labour $\left(L_{t}\right)$, and total factor productivity $\left(\zeta_{t}\right)$. The latter input is also known as knowledge or the effectiveness of labour. At any time, the economy has some amounts of capital, labour, and knowledge, that are combined to produce output $Y_{t}$, which form and properties will be discussed later. Throughout the model, we are concerned with a discrete-time, infinite horizon economy, where time is denoted by $t=0,1,2,3 \ldots$ Rare disasters are considered as random and violent shocks that could potentially destroy the stock of production inputs or alter their accumulation. The triplet of inputs $\left\{\zeta_{t}, K_{t}, L_{t}\right\}$ therefore define the stochastic process on the probability space $(\Omega, \mathcal{F}, P)$.

The set of events $\mathcal{F}$ in this model is a singleton where the only certainty is the advent of a random shock. And for each random input variable $\zeta_{t}, K_{t}$, and $L_{t}$ correspond three possible ex-post outcomes: the input $X_{t}$ could either be totally destroyed as a result of a rare disaster with a probability $p_{X, 1}$, partially destroyed with probability $p_{X, 2}$, or left intact with probability $p_{X, 3}$. Thus the probability measure $P$ is a function:

$$
P: \mathcal{F} \rightarrow[0,1]
$$

In real life, there is almost no precedent in human history where the entire stock of capital, technology and/or labour force is destroyed by a conflict or a natural disaster. Even in the prominent cases of Nazi Germany or Imperial Japan, the sustained and forensic bombardments of the Allies never resulted in the total annihilation of the aforementioned countries' productive capacities. In the case of global warming, no other group of nations is more vulnerable to its devastating effects than the Small Island Developing States (SIDS). With one-third of their population living on land - that is less than five meters below sea level -, the threat of sea level rise, storm surges, and coastal destruction pose existential risks to SIDS (UNDP, 2017). But even in that extreme case, the eventuality of a full annihilation of all livelihoods, entire economies and nation states appears remote at most and speculative at best. Therefore, for all the aforementioned reasons and many more, it is reasonable to make the following assumption:

Assumption 1 Given the triplet of inputs $\left\{\zeta_{t}, K_{t}, L_{t}\right\}$ and a probability space $(\Omega, \mathcal{F}, P)$, the likelihood of a rare disaster resulting in a complete destruction of the inputs taken individually or collectively is equal to zero. That is to say $P\left(X_{t}=0 \mid \mathcal{F}\right)=0$ with $X_{t}=$ $\left\{\zeta_{t}, K_{t}, L_{t}\right\}$.

The sample space $\Omega_{X}$ for each input $X_{t}$ contains three different outcomes $\left\{x_{1}, x_{2}, x_{3}\right\}$ respectively corresponding to the situations: totally destroyed, partially destroyed, and 
not destroyed. Therefore, the expected value of input $X_{t}$ in the aftermath of the political shock is equivalent to:

$$
\mathbf{E}\left(X_{t}\right)=\sum_{s=1}^{3} P\left(X_{t}=x_{s} \mid \mathcal{F}\right) x_{s}
$$

In case the input is partially destroyed, let's denote by $\lambda_{X}\left(0<\lambda_{X}<1\right)$ the fraction of $X_{t}$ that is left after the shock, i.e. $x_{2}=\lambda_{X} X_{t}$. Putting all these information together changes $\mathbf{E}\left(X_{t}\right)$ into:

$$
\begin{aligned}
\mathbf{E}\left(X_{t}\right) & =p_{X, 1} 0+p_{X, 2} \lambda_{X} X_{t}+p_{X, 3} X_{t} \\
& =\left(p_{X, 2} \lambda_{X}+p_{X, 3}\right) X_{t}
\end{aligned}
$$

Drawing from the fact that the sum of the probabilities of the outcomes in the sample space $\Omega$ is equal to $1\left(\sum_{X \in \Omega} p_{X, s}=1\right)$, we could deduce that $p_{X, 3}=1-p_{X, 2}$ and therefore:

$$
\begin{aligned}
\mathbf{E}\left(X_{t}\right) & =\left(1-p_{X, 2}+p_{X, 2} \lambda_{X}\right) X_{t} \\
& =\left(1-p_{X}+p_{X} \lambda_{X}\right) X_{t}
\end{aligned}
$$

It is important to notice from equation (5.3) that the impact of the rare disaster on the production factor $X_{t}$ is entirely captured by the expression $\left(1-p_{X}+p_{X} \lambda_{X}\right){ }^{4}$ This expression is an overall index of the uncertainty (or instability) induced by the rare disaster. The assumptions concerning the size of $p_{X, 2}$ and $\lambda_{X}$ imply that the expression is non-negative and never greater than one. Furthermore, it collapses to one (no impact at all of the rare disaster) for $p_{X, 2}=0$; that is the negative state of the world is never realised, or when $\lambda_{X}=1$; that is, when the economy appropriates the whole of the factor of production even in the advent of the negative state of the world.

To account for aggregate outcomes and facilitate the aggregation across different inputs, we will need to keep track of the cross-sectional distribution of idiosyncratic conditions. We know that $p_{X}$ denotes the probability of $X_{t}$ being partially destroyed and $\lambda_{X}$ the fraction of the input remaining after the political shock. Notice that these two objects are not exactly the same thing. But with an economy characterised by a finite number of economic agents, we could adopt the following assumption:

Assumption 2 In an economy characterised by a rare disaster, the Law of Large Numbers implies that when the number of economic agents increases, the fraction of a given

\footnotetext{
${ }^{4}$ In case Assumption 1 does not hold, this expression becomes $\left[1-p_{X, 1}-\left(1-\lambda_{X}\right) p_{X, 2}\right]$ and equation (5.3) becomes:

$$
\begin{gathered}
\mathbf{E}\left(X_{t}\right)=\left(p_{X, 2} \lambda_{X}+1-p_{X, 1}-p_{X, 2}\right) X_{t} \\
=\left[1-p_{X, 1}-\left(1-\lambda_{X}\right) p_{X, 2}\right] X_{t}
\end{gathered}
$$
}

This is because $P\left(X_{t}=0 \mid \mathcal{F}\right) \neq 0$ in this instance. 
production input destroyed by the shock converges almost surely to the probability of that input being destroyed, i.e.. ${ }^{5}$

$$
\operatorname{Pr}\left(\lim _{n \rightarrow \infty} \lambda_{X}=p_{X}\right)=1
$$

This assumption therefore implies that the expected value of the production input $X_{t}$ gets down to:

$$
\begin{aligned}
\mathbf{E}\left(X_{t}\right) & =\left(1-\lambda_{X}+\lambda_{X}^{2}\right) X_{t} \\
& =h\left(\lambda_{X}\right) X_{t}
\end{aligned}
$$

where $h\left(\lambda_{X}\right)$ is a polynomial function of a unique variable $\lambda_{X}$. Therefore the expected values of the triplet $\left\{\zeta_{t}, K_{t}, L_{t}\right\}$ are fully defined by the system of polynomials:

$$
S(\lambda)=\left\{\begin{array}{l}
h\left(\lambda_{\zeta}\right)=1-\lambda_{\zeta}+\lambda_{\zeta}^{2} \\
h\left(\lambda_{K}\right)=1-\lambda_{K}+\lambda_{K}^{2} \\
h\left(\lambda_{L}\right)=1-\lambda_{L}+\lambda_{L}^{2}
\end{array}\right.
$$

This conceptualisation of rare disasters borrows from and extend on Carmignani (2003)'s modelisation of political instability. The latter is consistent with the analytical framework developed in a number of contributions in the political economy literature. Barro and Sala-i-Martin (1995) discuss a general case of uncertainty about maintaining ownership in one's output. Svensson (1998) investigates the link between political instability, security of property rights and the incentive for agents to invest. Stevens (2000) presents a formal model of investment under uncertainty, where uncertainty is due to the risk of expropriation and shutdowns, focusing in particular on foreign direct investment. Aron (2000) proposes an intuitive formulation of the relationships between political instability, quality of institutions and economic growth in developing countries.

\subsubsection{The Firms}

The production function of the representative firm for the benchmark economy is a Harrod-neutral Cobb-Douglas function with the already mentioned three proximate inputs $\left\{\zeta_{t}, K_{t}, L_{t}\right\}$. A Harrod-neutral or labour-augmenting technological progress simply suggests that $\zeta_{t}$ and $L_{t}$ enter the production function multiplicatively. ${ }^{6}$ At any time the economy has some amounts of capital $K_{t}$, labour $L_{t}$, and knowledge $\zeta_{t}$ and these are combined to produce the output. The production function takes the following form:

$$
F\left(K_{t}, \zeta_{t} L_{t}\right)=K_{t}^{\alpha}\left(\zeta_{t} L_{t}\right)^{1-\alpha}
$$

\footnotetext{
${ }^{5}$ This assumption helps avoid some technical complications and is a route commonly adopted in the literature.

${ }^{6}$ If technological progress enters the production function multiplicatively with the stock of physical capital, it is called capital-augmenting or Solow-neutral. Finally, when it enters the production function independently, it is Hicks-neutral.
} 
with $0<\alpha<1$. This production function's main assumption is that it has constant returns to scale in its two arguments, physical capital and effective labour. That is, multiplying both arguments by any non-negative parameter $\eta$ causes output to change by exactly the same factor. ${ }^{7}$ The assumption of constant returns can be thought of as a combination of different assumptions: first, that the economy is big enough that the gains from specialisation have been exhausted; second, that inputs other than capital, labour, and knowledge, such as land an natural resources, are relatively unimportant. It is only in very small economies that there are probably enough possibilities for further specialisation and often in practice, the availability of natural resources does not always appear to be a major constraint on economic growth (Romer, 2011). It is hence reasonable to assume constant returns to scale for the Cobb-Douglas production function.

Each input follows its own dynamic in the model and is defined at each point in time, given the dynamic nature of the model. The initial levels of capital, labour, and knowledge are taken as given. Labour and knowledge grow at constant rates in normal times:

$$
\begin{gathered}
\dot{L}_{t}=n L_{t} \\
\dot{\zeta}_{t}=g \zeta_{t}
\end{gathered}
$$

where $n$ and $g$ are exogenous growth rates. In addition, $Y_{t}$ is divided between consumption and investment. The fraction of output devoted to investment, is the difference between aggregate output $Y_{t}$ and aggregate consumption $C_{t} L_{t}$. One unit of output devoted to investment yields one unit of new capital. In addition, existing capital depreciates at rate $\delta$. Thus:

$$
\dot{K}_{t}=Y_{t}-C_{t} L_{t}-\delta K_{t}
$$

The behaviour of firms is relatively simple. At each point in time, they employ the stocks of labour and capital, and pay them their marginal products, and sell the resulting output. Therefore, knowing that capital gets depreciated at rate $\delta$, the real interest rate and the real wage at time $t$ are:

$$
\begin{gathered}
W_{t}=\frac{\partial F\left(K_{t}, \zeta_{t} L_{t}\right)}{\partial L_{t}}=F_{L}\left(K_{t}, \zeta_{t} L_{t}\right) \\
r_{t}=\frac{\partial F\left(K_{t}, \zeta_{t} L_{t}\right)}{\partial K_{t}}-\delta=F_{K}\left(K_{t}, \zeta_{t} L_{t}\right)-\delta
\end{gathered}
$$

These two results derive from the fact that a competitive equilibrium requires that all firms - and thus the representative firm - maximise profits and factor markets clear. Specifically, the demands for labour and capital must be equal to the supplies of these

\footnotetext{
${ }^{7}$ Simply put: $F\left(\eta K_{t}, \eta \zeta_{t} L_{t}\right)=\eta K_{t}^{\alpha}\left(\zeta_{t} L_{t}\right)^{1-\alpha}$ for all $\eta \geq 0$.
} 
factors at all times (unless the prices of these factors are equal to zero, which we rule out). This observation implies that the representative firm should make zero profits, since otherwise it would wish to hire arbitrarily large amounts of capital and labour exceeding the supplies, which hare fixed. It also implies that total demand for labour, $L$, must be equal to the available supply of labour, $L_{t}$. Similarly, the total amount for capital, $K$, should equal the total supply, $K_{t}$. If this were not the case and $L<L_{t}$, then there would be an excess supply of labour and the wage would be equal to zero. But this is not consistent with firm maximisation, otherwise the representative firm would then wish to hire an arbitrarily large amount of labour, exceeding the supply. This argument, combined with the fact that the production function is differentiable, implies that given the supplies of capital and labour at time $t, K_{t}$ and $L_{t}$, factor prices must satisfy the familiar conditions equating factor prices to marginal products. ${ }^{8}$

\subsubsection{The Households}

In the model there are a large number of identical households, each one of whom is modeled as a dynastic family whose size grows exponentially at the same exogenous growth rate as the total population $n>0$. At every point in time, each member of the representative household supplies one unit of labour. Additionally, the household rents whatever capital it owns to firms and chooses an intertemporal path of consumption so as to maximise its utility subject a budget constraint. The household has initial capital holdings of $K_{0} / H$, where $K_{0}$ is the initial amount of capital in the economy and $H$ the total number of households. The household's utility takes the form:

$$
U=\int_{t=0}^{\infty} e^{-\rho t} u\left(C_{t}\right) \frac{L_{t}}{H} d t
$$

where $C_{t}$ is the individual consumption at time $t, L_{t}$ the total population of the economy, $H$ the number of households, $\rho$ the discount rate, and $u(\bullet)$ the instantaneous utility function. $L_{t} / H$ is hence the number of members in the household. Thus $u\left(C_{t}\right) L_{t} / H$ is the household's total instantaneous utility at time $t$. The instantaneous utility function takes the form:

$$
u\left(C_{t}\right)=\frac{C_{t}^{1-\theta}}{1-\theta}
$$

with $\theta>0$ and $\rho-n-(1-\theta) g>0$. This instantaneous utility function is the standard constant-relative-risk-aversion (or CRRA) utility. This specification ensures that the economy converges to a balanced growth path. The name $C R R A$ derives from the fact

\footnotetext{
${ }^{8}$ An alternative way to derive these results is to consider the cost minimisation problem of the representative firm, which takes the form of minimising $r_{t} K_{t}+W_{t} L_{t}$ with respect to $K_{t}$ and $L_{t}$, subject to the constraint that $F\left(K_{t}, \zeta_{t} L_{t}\right)=Y_{t}$ for some level of output $Y_{t}$. This problem has a unique solution for any given level of $Y_{t}$. Then imposing market clearing, that is, $Y_{t}=F\left(K_{t}, \zeta_{t} L_{t}\right)$ with $K_{t}$ and $L_{t}$ corresponding to the supplies of capital and labour, yields to equations (5.9) and (5.10).
} 
that the coefficient of relative risk aversion - defined as $-C u^{\prime \prime}(C) / u^{\prime}(C)$ - for this utility function is $\theta$, and thus is independent of $C$. Few features of the instantaneous utility are worth mentioning. First, $C^{1-\theta}$ is increasing in $C$ if $\theta<1$ but decreasing if $\theta>1$; dividing $C^{1-\theta}$ by $1-\theta$ thus ensures that the marginal utility of consumption is positive, regardless of the value of $\theta$. Second, in the special case of $\theta \longrightarrow 1$, the instantaneous utility function simplifies to $\ln C$; this is often a useful case to consider. ${ }^{9}$ And third, the assumption that $\rho-n-(1-\theta) g>0$ ensures that lifetime utility does not diverge: if this condition does not hold, the household can attain infinite lifetime utility, and its maximisation problem does not have a well-defined solution. ${ }^{10}$

Since the household has $L_{t} / H$ members, its labour income at $t$ is $W_{t} L_{t} / H$, and its consumption expenditures are $C_{t} L_{t} / H$. Its initial wealth is $1 / H$ of total wealth at time 0 , or $K_{0} / H$. The budget constraint of the household is therefore the following:

$$
\int_{t=0}^{\infty} e^{-R_{t}} C_{t} \frac{L_{t}}{H} d t \leq \frac{K_{0}}{H}+\int_{t=0}^{\infty} e^{-R_{t}} W_{t} \frac{L_{t}}{H} d t
$$

where $R_{t}=\int_{\tau=0}^{t} r_{\tau} d \tau$ and $W_{t}$ represent the cumulative interest rate and the real wage of the model. In many instances, it is difficult to find the integrals in this expression. Fortunately, we can express the budget constraint in terms of the limiting behaviour of the household's capital holdings; and even when it is not possible to compute the integrals in (5.13), it is often possible to describe the limiting behaviour of the economy.

An alternative reformulation of the the household's budget constraint (5.13) could be made. The household asset accumulates according to the following function:

$$
\dot{A}_{t}=r_{t} A_{t}+W_{t} L_{t}-C_{t} L_{t}
$$

where $A_{t}$ is the household asset at time $t$. Written in per capita terms, this budget constraint becomes: ${ }^{11}$

$$
\dot{a}_{t}=\left(r_{t}-n\right) a_{t}+W_{t}-C_{t}
$$

After solving for the household maximisation problem, the solution of the model goes down to the following well-known Euler-equation: ${ }^{12}$

$$
\frac{\dot{C}_{t}}{C_{t}}=\frac{r_{t}-\rho}{\theta}
$$

\footnotetext{
${ }^{9}$ To see this, first subtract $1 /(1-\theta)$ from the utility function; since this changes utility by a constant, it does not affect behaviour. Then take the limit as $\theta$ approaches 1; this requires using l'Hôpital's rule. The result is $\ln C$.

${ }^{10}$ Phelps (1966) discusses how growth models can be analysed when households can obtain infinite utility.

${ }^{11}$ Appendix 5.B provides the details for this transformation.

${ }^{12}$ The details of this utility maximisation problem are available in the Appendices 5.A and 5.B. Appendix 5.A solves the problem using the standard Lagrangian while Appendix 5.B does so using the Hamiltonian.
} 
In a stationary economy, this corresponds to the growth rate of the individual consumption but also to that of the economy as a whole. It has the advantage of combining both the demand and supply sides of the economy. But an exogenous shock in the form of a rare disaster has the capacity to distort the smooth growth path and could turn the variables in the Euler equation into random objects. That is to say that the new growth rate of the economy should be:

$$
\mathbf{E}\left(\frac{\dot{C}_{t}}{C_{t}}\right)=\mathbf{E}\left(\frac{r_{t}-\rho_{t}}{\theta}\right)
$$

This Euler equation is key to the model and will be the benchmark point from which most of the extensions and discussions will be derived from. Equation (5.17) epitomises a stochastic growth rate of the economy, where the uncertainty stems from three variables: $r_{t}$ the real interest rate and $\rho_{t}$ the subjective discount rate of the consumption path, and $\theta$ the constant-relative-risk-aversion coefficient. What a random and violent shock does is to change the marginal productivity of each input of production and affect the households' consumption/saving trade-offs and eventually their risk-aversion. Therefore, finding a convincing proxy for the set $\left(\mathbf{E}\left(r_{t}\right), \mathbf{E}\left(\rho_{t}\right), \mathbf{E}(\theta)\right)$ is crucial in order to determine the new path of the economy. However, regarding the inverse of the inter-temporal elasticity of substitution, we need to make the following assumption:

Assumption 3 A rare disaster does not affect the representative household's risk behaviour $\theta$ in the short and medium-run, as well as the way it discounts future consumption relative to current consumption, i.e.:

$$
\mathbf{E}(\theta)=\theta \quad \text { and } \quad \mathbf{E}(\rho)=\rho
$$

Therefore the stochastic growth rate of the economy becomes:

$$
\begin{aligned}
\mathbf{E}\left(\frac{\dot{C}_{t}}{C_{t}}\right) & =\frac{\mathbf{E}\left(r_{t}\right)-\mathbf{E}\left(\rho_{t}\right)}{\mathbf{E}(\theta)} \\
& =\frac{\mathbf{E}\left(r_{t}\right)-\rho}{\theta}
\end{aligned}
$$

To find $\mathbf{E}\left(r_{t}\right)$ we need to use the supply side of the economy, introduced earlier. Looking for $\mathbf{E}\left(r_{t}\right)$ is equivalent of finding the expected marginal product of physical capital $\mathbf{E}\left(F_{K}\left(K_{t}, \zeta_{t} L_{t}\right)-\delta\right)$, which could be rewritten as $\mathbf{E}\left(F_{K}\left(K_{t}, \zeta_{t} L_{t}\right)\right)-\delta$ given that the depreciation rate $\delta$ is certain.

\subsubsection{Stripping Down the Full Model}

To examine the computational properties of the model, we take stock of all the information from the setup and the results from both the representative firm and the representative household's optimisations. Prior to stripping down the result, we need to make the following assumption: 
Assumption 4 We assume that the triplet of production inputs $\left\{\zeta_{t}, K_{t}, L_{t}\right\}$ are independent from one another. That is, considered as a triplet of random variables, their joint expectation is equal to the product of their individual expectations, i.e.:

$$
\mathbf{E}\left(\zeta_{t} K_{t} L_{t}\right)=\mathbf{E}\left(\zeta_{t}\right) \mathbf{E}\left(K_{t}\right) \mathbf{E}\left(L_{t}\right)
$$

Proof 1 The inputs $\zeta_{t}, K_{t}$ and $L_{t}$ are all positive, and let consider their joint product $Z$ in the form $z=\zeta k l$, for $\zeta \in \zeta(\Omega), K \in K(\Omega)$ and $L \in L(\Omega)$. For $z \in Z(\Omega)$, we consider the following set:

$$
A_{z}=\{(\zeta, k, l) \in \zeta(\Omega) \times K(\Omega) \times L(\Omega) ; \zeta k l=z\}
$$

It is evident that all the $A_{z}$ form a partition of $\zeta(\Omega) \times K(\Omega) \times L(\Omega)$ and that:

$$
[Z=z]=U_{(\zeta, k, l) \in A_{z}}[\zeta=\zeta] \cap[K=k] \cap[L=l]
$$

And:

$$
\begin{aligned}
\sum_{z \in Z(\Omega)} z \mathbf{P}(Z=z) & =\sum_{z \in Z(\Omega)}\left(z \sum_{(\zeta, k, l) \in A_{z}} \mathbf{P}([\zeta=\zeta] \cap[K=k] \cap[L=l])\right) \\
& =\sum_{z \in Z(\Omega)}\left(z \sum_{(\zeta, k, l) \in A_{z}} \mathbf{P}(\zeta=\zeta) \mathbf{P}(K=k) \mathbf{P}(L=l)\right) \\
& =\sum_{z \in Z(\Omega)}\left(\sum_{(\zeta, k, l) \in A_{z}} \zeta k l \mathbf{P}(\zeta=\zeta) \mathbf{P}(K=k) \mathbf{P}(L=l)\right) \\
& =\sum_{(\zeta, k, l) \in \zeta(\Omega) \times K(\Omega) \times L(\Omega)} \zeta k l \mathbf{P}(\zeta=\zeta) \mathbf{P}(K=k) \mathbf{P}(L=l) \\
& =\sum_{\zeta \in \zeta(\Omega)} \zeta \mathbf{P}(\zeta=\zeta) \sum_{k \in K(\Omega)} \zeta \mathbf{P}(K=k) \sum_{l \in L(\Omega)} l \mathbf{P}(L=l)<+\infty
\end{aligned}
$$

The second equation in the chain derives from the fact that the three variables are independent while the fourth from the observation that a series with positive terms could be summed up by groups.

Proposition 1 A rare disaster affects the steady-state economic growth according to the following dynamic:

$$
\mathbf{E}\left(\frac{\dot{C}_{t}}{C_{t}}\right)=\frac{\alpha\left\{\prod_{X} h\left(\lambda_{X}\right)\right\} K_{t}^{\alpha-1}\left(\zeta_{t} L_{t}\right)^{1-\alpha}-\delta-\rho}{\theta}
$$

Proof 2 The proposition derives from various iterations of the Euler equation, using 
Assumption 4 among others:

$$
\begin{aligned}
\frac{\mathbf{E}\left(r_{t}\right)-\rho}{\theta} & =\frac{\mathbf{E}\left(F_{K}\left(K_{t}, \zeta_{t} L_{t}\right)-\delta\right)-\rho}{\theta} \\
& =\frac{\mathbf{E}\left(\alpha K_{t}^{\alpha-1}\left(\zeta_{t} L_{t}\right)^{1-\alpha}\right)-\delta-\rho}{\theta} \\
& =\frac{\alpha \mathbf{E}\left(K_{t}^{\alpha-1}\left(\zeta_{t} L_{t}\right)^{1-\alpha}\right)-\delta-\rho}{\theta} \\
& =\frac{\alpha \mathbf{E}\left(K_{t}^{\alpha-1}\right) \mathbf{E}\left(\zeta_{t} L_{t}\right)^{1-\alpha}-\delta-\rho}{\theta} \\
& =\frac{\alpha \mathbf{E}\left(K_{t}^{\alpha-1}\right) \mathbf{E}\left(\zeta_{t}^{1-\alpha}\right) \mathbf{E}\left(L_{t}^{1-\alpha}\right)-\delta-\rho}{\theta} \\
& =\frac{\alpha h\left(\lambda_{\zeta}\right) h\left(\lambda_{K}\right) h\left(\lambda_{L}\right) K_{t}^{\alpha-1}\left(\zeta_{t} L_{t}\right)^{1-\alpha}-\delta-\rho}{\theta} \\
& =\frac{\alpha\left\{\prod_{X} h\left(\lambda_{X}\right)\right\} K_{t}^{\alpha-1}\left(\zeta_{t} L_{t}\right)^{1-\alpha}-\delta-\rho}{\theta}
\end{aligned}
$$

with $\prod_{X} h\left(\lambda_{X}\right) \equiv h\left(\lambda_{\zeta}\right) h\left(\lambda_{K}\right) h\left(\lambda_{L}\right)$ and $X \in\left\{\zeta_{t}, K_{t}, L_{t}\right\}$.

Equation (5.20) gives the steady-state growth rate of all per capita variables - consumption, physical capital, and output. The impact of the rare disaster on growth is encapsulated by the expression $\prod_{X} h\left(\lambda_{X}\right)$ with $X \in\left\{\zeta_{t}, K_{t}, L_{t}\right\}$. This effect operates through the uncertainty induced over output maintenance by the advent of the event. That is, a rare disaster distorts the path of factors accumulation and hence consumption and output growth. This proposition is the central tenet of the paper.

\subsection{Possible Extensions}

\subsubsection{The AK Model}

To build models with positive steady-state growth of per capita variables, growth theorists have sometimes made use of the $\zeta_{t} K_{t}$ specification for the production function (Rebelo, 1991). In this instance output is specified as $Y_{t}=\zeta_{t} K_{t}$, where $\zeta_{t}$ is still a positive constant that reflects the level of technology and $K$ represents capital, now broadly defined to include both human and physical capitals. With such formulation, the marginal product of capital is equal to the constant $\zeta$ and in equilibrium profit maximising firms will set $r_{t}=\zeta-\delta$. The growth rate of the economy in presence of uncertainty induced by a rare violent event about the degree of appropriation of output is then given by:

$$
\mathbf{E}\left(\frac{\dot{C}_{t}}{C_{t}}\right)=\frac{h\left(\lambda_{\zeta}\right) \zeta-\delta-\rho}{\theta}
$$

with $h\left(\lambda_{\zeta}\right)=1-\lambda_{\zeta}+\lambda_{\zeta}^{2}$. The resemblance between equation (5.21) and equation (5.20) or equation (5.18) is immediately clear and the general result that rare disasters reduce economic growth in steady-state holds true. 


\subsubsection{Learning-by-Doing Technology}

From a purely exogenous accumulation of knowledge in the benchmark model, we will introduce the learning-by-doing process into the model. The final determinant of knowledge accumulation is somewhat different in character (Romer, 2011). The central idea is that, as individuals produce goods, they inevitably think of ways of improving the the production process. In this model, as suggested by Arrow (1962) among others, the accumulation of knowledge occurs in part not as a result of deliberate efforts, but as a side effect of conventional economic activity. This type of knowledge accumulation is known as learning-by-doing. As such, it is a semi-endogenous model of economic growth.

When learning-by-doing is the source of technological progress, the rate of knowledge accumulation depends not on the fraction of the economy's resources engaged in R\&D, but on how much new knowledge is generated by conventional economic activity. Analysing learning-by-doing therefore requires some changes to our benchmark model. All inputs being engaged in goods production, the production function remains the same as in the basic model. The simplest case of learning-by-doing is when learning occurs as a side effect of the production of new capital. With this formulation, since the increase in knowledge is a function of the increase in capital, the stock of knowledge is a function of the stock of capital. Thus there is only one stock variable whose behaviour is endogenous. 13 The new total factor productivity of the model becomes:

$$
\zeta_{t}=B K_{t}^{\phi}
$$

where $B>0$ and $\phi>0$ are a shift parameter and a scalar governing the path of the economy (if $\phi>1$ the long-run growth rate of the economy is explosive). Using this expression of the TFP, the constant-return-to-scale Cobb-Douglas production function of the economy becomes:

$$
\begin{aligned}
Y_{t} & =K_{t}^{\alpha} B^{1-\alpha} K_{t}^{\phi(1-\alpha)} L_{t}^{1-\alpha} \\
& =B^{1-\alpha} K_{t}^{\alpha+\phi(1-\alpha)} L_{t}^{1-\alpha}
\end{aligned}
$$

And since $\dot{K}_{t}=Y_{t}-C_{t} L_{t}-\delta K_{t}$, the law of motion of physical capital is given by:

$$
\dot{K}_{t}=B^{1-\alpha} K_{t}^{\alpha+\phi(1-\alpha)} L_{t}^{1-\alpha}-C_{t} L_{t}-\delta K_{t}
$$

The expected value of the stochastic real interest rate $\mathbf{E}\left(r_{t}\right)$ will now be determined in the context of this framework, where knowledge accumulation is considered as a spillover effect of physical capital accumulation and occurs as a side effect of conventional economic

\footnotetext{
${ }^{13}$ It is also possible to model knowledge accumulation as a side effect of goods production rather than of capital accumulation.
} 
activity. Applying the same iteration to equation (5.23) yields:

$$
\mathbf{E}\left(\frac{\dot{C}_{t}}{C_{t}}\right)=\frac{B^{1-\alpha}\left\{\prod_{X} h\left(\lambda_{X}\right)\right\} K_{t}^{\alpha+\phi(1-\alpha)} L_{t}^{1-\alpha}-\delta-\rho}{\theta}
$$

with $\prod_{X} h\left(\lambda_{X}\right) \equiv h\left(\lambda_{K}\right) h\left(\lambda_{L}\right)$ and $X \in\left\{K_{t}, L_{t}\right\}$. Equation (5.25) follows the same pattern as the steady-state growth rate in the benchmark model.

\subsection{Implications for Convergence}

Before investigating the implications of the advent of a rare disaster for convergence, we first need to further manipulate the benchmark Cobb-Douglas production. ${ }^{14}$ The assumption of constant returns to scale of the production function allows us to work with this function in intensive-form. Setting $\eta=1 / \zeta L$ in equation (5.5) yields:

$$
F\left(\frac{K_{t}}{\zeta_{t} L_{t}}\right)=\frac{1}{\zeta_{t} L_{t}} F\left(K_{t}, \zeta_{t} L_{t}\right)
$$

Where $K_{t} / \zeta_{t} L_{t}$ is the amount of capital per unit of effective labour, and $F\left(K_{t}, \zeta_{t} L_{t}\right) / \zeta_{t} L_{t}$ is $Y_{t} / \zeta_{t} L_{t}$, output per effective labour. Defining $k_{t}=K_{t} / \zeta_{t} L_{t}, y_{t}=Y_{t} / \zeta_{t} L_{t}$, and $f\left(k_{t}\right)=$ $F\left(k_{t}, 1\right)$. Then we can rewrite $(5.26)$ as:

$$
y=f(k)
$$

This intensive-form production function is assumed to satisfy $f(0)=0, f^{\prime}(k)>$ $0, f^{\prime \prime}(k)<0$. Since $F(K, \zeta L)$ equals $\zeta L f(K / \zeta L)$, it follows that the marginal product of capital, $\partial F(K, \zeta L) / \partial K$, equals $\zeta L f^{\prime}(K / \zeta L)(1 / \zeta L)$, which is just $f^{\prime}(k)$. Thus the assumption that $f^{\prime}(k)$ is positive and $f^{\prime \prime}(k)$ is negative imply that the marginal product of capital is positive, but that it declines as capital (per unit of effective labour) rises. In addition, $f(\bullet)$ is assumed to satisfy the so-called Inada Conditions (Inada, 1964): $\lim _{k \longrightarrow 0} f^{\prime}(k)=\infty, \lim _{k \longrightarrow \infty} f^{\prime}(k)=0$. These conditions (which are stronger than needed for the model's central results) state that the marginal product of capital is very large when the capital stock is sufficiently small and that it becomes very small as the capital stock becomes large; their role is to ensure that the path of the economy does not diverge. A production satisfying $f^{\prime}(\bullet)>0, f^{\prime \prime}(\bullet)<0$, and the Inada conditions, is concave by nature. Applied to the Cobb-Douglas function, the intensive form of the production

\footnotetext{
${ }^{14}$ We follow Romer (2011) in the derivation of both the intensive-form output but also the speed of convergence.
} 
function yields:

$$
\begin{aligned}
f\left(k_{t}\right) & \equiv F\left(\frac{K_{t}}{\zeta_{t} L_{t}}, 1\right) \\
& =\left(\frac{K_{t}}{\zeta_{t} L_{t}}\right)^{\alpha} \\
& =k_{t}^{\alpha}
\end{aligned}
$$

This equation implies that $f^{\prime}(k)=\alpha k^{\alpha-1}$. It is straightforward to check that this expression is positive, that it approaches infinity as $k$ approaches zero, and that it approaches zero as $k$ approaches infinity. Finally, $f^{\prime \prime}(k)=-(1-\alpha) \alpha k^{\alpha-2}$, which is negative. ${ }^{15}$ Equally, the intensive form of the capital motion in equation (5.8) is the following:

$$
\dot{k}_{t}=s f\left(k_{t}\right)-(n+g+\delta) k_{t}
$$

Equation (5.29) is the key ingredient of the Solow (1956) model. It states that the rate of change of the capital stock per unit of effective labour is the difference between two terms. The first, $s f(k)$, is the actual investment per unit of effective labour: output per unit of effective labour is $f(k)$, and the fraction of that output that is invested is $s$. The second term, $(n+g+\delta) k$, is break-even investment, the amount of investment that must be done just to keep $k$ at its existing level. There are two reasons that some investment is needed to prevent $k$ from falling. First, existing capital is depreciating; this capital must be replaced to keep the capital stock from falling. This is the $\delta k$ term in (5.29). Second, the quantity of effective labour is growing. Thus doing enough investment to keep the capital stock $(K)$ constant is not enough to the keep the capital stock per unit of effective labour $(k)$ constant. Instead, since the quantity of effective labour is growing at rate $n+g$, the capital stock must grow at rate $n+g$ to hold $k$ steady. ${ }^{16}$ This is the $(n+g) k$ term in (5.29). When actual investment per unit of effective labour exceeds the investment needed to break even, $k$ is rising. When actual investment falls short of break-even investment, $k$ is falling. And when the two are equal, $k$ is constant.

Imagining the two terms of the expression for $\dot{k}$ as functions of $k$, break-even investment, $(n+g+\delta) k$, becomes proportional to $k$, while actual investment, $s f(k)$, equals a constant times output per unit of effective labour. Since $f(0)=0$, actual investment and break-even investment are equal at $k=0$. The Inada conditions imply that at $k=0$, $f^{\prime}(k)$ is large, and thus that the $s f(k)$ line is steeper in a fictive two-dimension space than the $(n+g+\delta) k$ line. Thus for small values of $k$, actual investment is larger than break-even investment. The Inada conditions also imply that $f^{\prime}(k)$ falls toward zero as $k$ becomes large. At some point, the slope of the actual investment line falls below the

\footnotetext{
${ }^{15}$ Note that with the Cobb-Douglas production function, labour-augmenting, capital-augmenting, and Hicks-neutral technological progress are all essentially the same.

${ }^{16}$ The fact that the growth rate of the quantity of effective labour, $\zeta_{t} L_{t}$, equals $n+g$ is an instance of the fact that the growth rate of the product of two variables equals the sum of their growth rates.
} 
slope of the break-even investment line in the imaginary Euclidean space. With the $s f(k)$ line flatter than the $(n+g+\delta) k$ line, the two must eventually cross. Finally, the fact that $f^{\prime \prime}(k)<0$ implies that the two lines intersect only once for $k>0$. We let $k^{*}$ denote the value of $k$ where actual investment and break-even investment are equal. If $k$ is initially less than $k^{*}$, actual investment exceeds break-even investment, and so $\dot{k}$ is positive - that is, $k$ is rising. If $k$ exceeds $k^{*}, k$ is negative. Finally, if $k$ equals $k^{*}$, then $k$ is zero. Thus, regardless of where $k$ starts, it converges to $k^{*} \cdot{ }^{17}$

Since $k$ converges to $k^{*}$, it is natural to ask how the variables of the model behave when $k$ equals $k^{*}$. By assumption, labour and knowledge are growing at rates $n$ and $g$, respectively. The capital stock, $K_{t}$, equals $\zeta_{t} L_{t} k_{t}$; since $k$ is constant at $k^{*}, K_{t}$ is growing at rate $n+g$ (that is, $\dot{K}_{t} / K_{t}$ equals $n+g$ ). With both capital and effective labour growing at rate $n+g$, the assumption of constant returns implies that output, $Y_{t}$, is also growing at that rate. Finally, capital per worker, $K_{t} / L_{t}$, and output per worker, $Y_{t} / L_{t}$, are growing at rate $g$.

Definition 1 The Solow (1956) model implies that, regardless of its starting point, the economy converges to a balanced growth path, a situation where each variable of the model is growing at a constant rate. On the balanced growth path, the growth rate of output per worker is determined solely by the rate of technological progress. ${ }^{18}$

In practice, we are concerned not only in the eventual effects of some change (such as a change in the saving rate), but also in how rapidly those effects occur. Again, we can use approximations around the long-run equilibrium to address this issue. For simplicity, we focus on the behaviour of $k$ rather than $y$. Our goal is thus to determine how rapidly $k$ approaches $k^{*}$. We know that $\dot{k}$ is determined by $k$ : recall that the key equation of the model is $\dot{k}=s f(k)-(n+g+\delta) k$. Thus we can write $\dot{k}=\dot{k}(k)$. When $k$ equals $k^{*}, \dot{k}$ is zero. A first-order Taylor-series approximation of $\dot{k}(k)$ around $k=k^{*}$ therefore yields:

$$
\dot{k} \simeq\left[\left.\frac{\partial \dot{k}(k)}{\partial k}\right|_{k=k^{*}}\right]\left(k-k^{*}\right)
$$

That is, $\dot{k}$ is approximately equal to the product of the difference between $k$ and $k^{*}$ and the derivative of $\dot{k}$ with respect to $k$ at $k=k^{*}$.

Let $\lambda$ denote $-\partial \dot{k}(k) /\left.\partial k\right|_{k=k^{*}}$. With this definition, (5.30) becomes:

$$
\dot{k}_{t} \simeq-\lambda\left[k_{t}-k^{*}\right]
$$

Since $\dot{k}$ is positive when $k$ is slightly below $k^{*}$ and negative when it is slightly above, $\partial \dot{k}(k) /\left.\partial k\right|_{k=k^{*}}$. Equivalently, $\lambda$ is positive.

\footnotetext{
${ }^{17}$ If $k$ is initially zero, it remains there. We ignore this possibility in the evaluation of the speed of convergence.

${ }^{18}$ The broad behaviour of the U.S. economy and many other major industrialised economies over the past century or more is reasonably well described by the balanced growth path of the Solow (1956) model.
} 
Equation (5.31) implies that the in the vicinity of the balanced growth path, $k$ moves toward $k^{*}$ at a speed approximately proportional to its distance from $k^{*}$. That is, the growth rate of $k_{t}-k^{*}$ is approximately constant and equal to $-\lambda$. This implies that:

$$
k_{t} \simeq k^{*}+e^{-\lambda t}\left[k_{0}-k^{*}\right]
$$

where $k_{0}$ is the initial value of $k$. Note that (5.32) follows just from the facts that the system is stable (that is, that $k$ converges to $k^{*}$ ) and that we are linearising the equation for $\dot{k}$ around $k=k^{*}$.

It remains to find $\lambda$; this is where the specifics of the model enter the analysis. Differentiating expression (5.29) for $\dot{k}$ with respect to $k$ and evaluating the resulting expression at $k=k^{*}$ yields:

$$
\begin{aligned}
\lambda \equiv-\left.\frac{\partial \dot{k}(k)}{\partial k}\right|_{k=k^{*}} & =-\left[s f^{\prime}\left(k^{*}\right)-(n+g+\delta)\right] \\
& =(n+g+\delta)-s f^{\prime}\left(k^{*}\right) \\
& =(n+g+\delta)-\frac{(n+g+\delta) k^{*} f^{\prime}\left(k^{*}\right)}{f\left(k^{*}\right)} \\
& =\left[1-\alpha_{K}\left(k^{*}\right)\right](n+g+\delta)
\end{aligned}
$$

where the third line again uses the fact that $s f\left(k^{*}\right)=(n+g+\delta) k^{*}$ to substitute for $s$, and where the last line uses the definition of $\alpha_{K}$. Thus, $k$ converges to its balanced-growthpath value at rate $\left[1-\alpha_{K}\left(k^{*}\right)\right](n+g+\delta)$. In addition, one can show that $y$ approaches $y^{*}$ at the same rate that $k$ approaches $k^{*}$. That is, $y_{t}-y^{*} \simeq e^{-\lambda t}\left[y_{0}-y^{*}\right]{ }^{19}$

Proposition 2 A rare disaster affects the speed of convergence through the elasticity of output with respect to capital at $k=k^{*}:^{20}$

$$
\mathbf{E}(\lambda)=\left[1-\mathbf{E}\left(\alpha_{K}\left(k^{*}\right)\right)\right](n+g+\delta)
$$

and the amplitude of this effect depends on how $\mathbf{E}\left(\alpha_{K}\left(k^{*}\right)\right)$ compares to the elasticity of output when there is no shock $\alpha_{K}\left(k^{*}\right)$.

1. If $\mathbf{E}\left(\alpha_{K}\left(k^{*}\right)\right)>\alpha_{K}\left(k^{*}\right)$, the economy converges slower to its balanced growth path,

2. If $\mathbf{E}\left(\alpha_{K}\left(k^{*}\right)\right)<\alpha_{K}\left(k^{*}\right)$, the economy converges faster to its balanced growth path.

\footnotetext{
${ }^{19}$ The time it takes for a variable (in this case, $y-y^{*}$ ) with a constant negative growth to fall in half is approximately equal to 70 divided by its growth rate in percent. Similarly, the doubling time of a variable with positive growth is 70 divided by the growth rate. Thus in this case the half-life is roughly $70 /(4 \% /$ year $)$, or about 17 years. More exactly, the half-life, $t^{*}$, is the solution to $e^{-\lambda t}=0.5$, where $\lambda$ is the rate of decrease. Taking logs of both sides, $t^{*}=-\ln (0.5) / \lambda \simeq 0.69 / \lambda$.

${ }^{20}$ The details about the derivation of this elasticity are available in Appendix 5.C.
} 
To see the implications of this proposition and how quickly an economy is likely to approach it balanced growth path with and without the disaster, we could calibrate $\lambda$ and $\mathbf{E}(\lambda)$. Typically, in all situations $n+g+\delta$ is about $6 \% \cdot{ }^{21}$ In case there is no adverse shock, the traditional value of capital share in output $\lambda$ is roughly one-third, $\left(1-\alpha_{K}\right)(n+g+\delta)$ is thus roughly 4 percent. Therefore $k$ and $y$ move 4 percent of the remaining distance toward $k^{*}$ and $y^{*}$ each year, and take approximately 17 years to get halfway to their balanced-growth-path values. In case there is a rare disaster, with $\mathbf{E}\left(\alpha_{K}\left(k^{*}\right)\right)>\alpha_{K}\left(k^{*}\right)$, with an expected capital share of one-half for example, we find that $\left(1-\mathbf{E}\left(\alpha_{K}\left(k^{*}\right)\right)\right)(n+g+\delta)$ equals roughly 3 percent. In this case, $k$ and $y$ move 3 percent of the remaining distance toward $k^{*}$ and $y^{*}$ each year, and take approximately 23 years to get halfway to their balanced-growth-path values. Finally, in case of a rare disaster, with $\mathbf{E}\left(\alpha_{K}\left(k^{*}\right)\right)<\alpha_{K}\left(k^{*}\right)$, with an expected capital share of one-fifth for example, we find that the expected speed of convergence $\left(1-\mathbf{E}\left(\alpha_{K}\left(k^{*}\right)\right)\right)(n+g+\delta)$ equals roughly 4.8 percent. Hence $k$ and $y$ move 4.8 percent of the remaining distance toward $k *$ and $y^{*}$ yearly, and take approximately 14 and half years to get halfway to their balanced-growth-path values.

\subsection{Concluding Remarks}

A broad understanding of rare disasters includes low probability events with potentially large impacts on economic activity, such as social unrest, violent coups d'Etats, vicious wars and unexpected environmental disasters. All these features of rare disasters are likely to affect both the behaviour of the economy but also the levels of the proximate factors of growth: physical capital, labour and total factor productivity. This paper has considered the effects of a probabilistic rare disaster on the steady-state economic growth as well as its overarching implications for the speed of convergence. Attention has mostly been given to purely theoretical considerations ahead of empirical investigations. For what is a mostly theoretical argumentation, we posit after various assumptions that a rare disaster affects economic growth through its adverse impact on the equilibrium real interest rate, which is the price of physical capital when markets are clear and when there is no externality. This result is extended to alternative production function specifications, notably to the $A K$ model and to a learning-by-doing technology. Furthermore, we show that a rare disaster affects the balanced growth path's speed of convergence through the elasticity of output with respect to the intensive-form physical capital. The direction and amplitude of this impact fundamentally depends on how the new value of this elasticity compares to the share of physical capital in total output when there is no shock.

\footnotetext{
${ }^{21}$ This would arise, for example, with 1 to 2 percent population growth, 1 to 2 percent growth in output per worker, and 3 to 4 percent depreciation.
} 


\section{Appendix 5.A: Household Maximisation Problem}

The representative household wants to maximise its lifetime utility subject to its budget constraint. As in the Solow (1956) model, it is easier to work with variables normalised by the quantity of effective labour. To do this, we need to express both the objective function and the budget constraint in terms of consumption and labour income per unit of effective labour.

We start with the objective function. Define $c_{t}$ to be consumption per unit of effective labour. Thus $C_{t}$, consumption per worker, equals $\zeta_{t} c_{t}$. The household's instantaneous utility, (5.12), is therefore:

$$
\begin{aligned}
\frac{C_{t}^{1-\theta}}{1-\theta} & =\frac{\left[\zeta_{t} c_{t}\right]^{1-\theta}}{1-\theta} \\
& =\frac{\left[\zeta_{0} e^{g t}\right]^{1-\theta}}{1-\theta} \\
& =\zeta_{0}^{1-\theta} e^{(1-\theta) g t} \frac{c_{t}^{1-\theta}}{1-\theta}
\end{aligned}
$$

Substituting (5.35) and the fact that $L_{t}=L_{0} e^{n t}$ into the household's objective function,(5.11)-(5.12),yields:

$$
\begin{aligned}
U & =\int_{t=0}^{\infty} e^{-\rho t} \frac{C_{t}^{1-\theta}}{1-\theta} \frac{L_{t}}{H} d t \\
& =\int_{t=0}^{\infty} e^{-\rho t}\left[\zeta_{0}^{1-\theta} e^{(1-\theta) g t} \frac{c_{t}^{1-\theta}}{1-\theta}\right] \frac{L_{0} e^{n t}}{H} d t \\
& =\zeta_{0}^{1-\theta} \frac{L_{0}}{H} \int_{t=0}^{\infty} e^{-\rho t} e^{(1-\theta) g t} e^{n t} \frac{c_{t}^{1-\theta}}{1-\theta} d t \\
& \equiv B \int_{t=0}^{\infty} e^{-\beta t} \frac{c_{t}^{1-\theta}}{1-\theta} d t
\end{aligned}
$$

where $B \equiv \zeta_{0}^{1-\theta} L_{0} / H$ and $\beta \equiv \rho-n-(1-\theta) g$.

Now consider the budget constraint, (5.13). The household's total consumption at time $t, C_{t} L_{t} / H$, equals consumption per unit of effective labour, $c_{t}$, times the household's quantity of effective labour, $\zeta_{t} L_{t} / H$. Similarly, its total labour income at $t$ equals the wage per unit of effective labour, $w_{t}$, times $\zeta_{t} L_{t} / H$. And its initial capital holdings are capital per unit of effective labour at time $0, k_{0}$, times $\zeta_{0} L_{0} / H$. Thus we can rewrite (5.13) as:

$$
\int_{t=0}^{\infty} e^{-R_{t}} c_{t} \frac{\zeta_{t} L_{t}}{H} d t \leq k_{0} \frac{\zeta_{0} L_{0}}{H}+\int_{t=0}^{\infty} e^{-R_{t}} w_{t} \frac{\zeta_{t} L_{t}}{H} d t
$$

$\zeta_{t} L_{t}$ equals $\zeta_{0} L_{0} e^{(n+g) t}$. Substituting this fact into (5.37) and dividing both sides by $\zeta_{0} L_{0} / H$ yields:

$$
\int_{t=0}^{\infty} e^{-R_{t}} c_{t} e^{(n+g) t} d t \leq k_{0}+\int_{t=0}^{\infty} e^{-R_{t}} w_{t} e^{(n+g) t} d t
$$


The household's problem is to choose the path of $c_{t}$ to maximise lifetime utility, (5.36), subject to the budget constraint, (5.38). Although this involves choosing $c$ at each instant of time - rather than choosing a finite set of variables, as in standard maximisation problems -, conventional maximisation techniques can be used. Since the marginal utility of consumption is always positive, the household satisfies its budget constraint with equality. We can therefore use the objective function, (5.36), and the budget constraint, (5.38), to set up the Lagrangian:

$$
\begin{aligned}
\mathcal{L} & =B \int_{t=0}^{\infty} e^{-\beta t} \frac{c_{t}^{1-\theta}}{1-\theta} d t \\
& +\pi\left[k_{0}+\int_{t=0}^{\infty} e^{-R_{t}} c_{t} e^{(n+g) t} w_{t} d t-\int_{t=0}^{\infty} e^{-R_{t}} c_{t} e^{(n+g) t} c_{t} d t\right]
\end{aligned}
$$

The household chooses $c$ at each point in time; that is, it chooses infinitely many $c_{t}$ 's. The first-order condition for an individual $c_{t}$ is:

$$
B e^{-\beta t} c_{t}^{-\theta}=\pi e^{-R_{t}} c_{t} e^{(n+g) t}
$$

The household's behaviour is characterised by (5.40) and the budget constraint, (5.38). To see what (5.40) implies for the behaviour of consumption, first we take the natural logarithms of both sides:

$$
\begin{aligned}
\ln B-\beta t-\theta \ln c_{t} & =\ln \pi-R_{t}+(n+g) t \\
& =\ln \pi-\int_{\tau=0}^{t} r(\tau) d \tau+(n+g) t
\end{aligned}
$$

where the second line uses the definition of $R_{t}$ as $\int_{\tau=0}^{t} r_{\tau} d \tau$. Now note that since the two sides of (5.41) are equal for every $t$, the derivatives of the two sides with respect to $t$ must be the same. Thus condition is:

$$
\beta-\theta \frac{\dot{c}_{t}}{c_{t}}=-r_{t}+(n+g)
$$

where we have once again used the fact that the time derivative of the logarithm of a variable equals its growth rate. Solving (5.42) for $\dot{c}_{t} / c_{t}$ yields:

$$
\begin{aligned}
\frac{\dot{c}_{t}}{c_{t}} & =\frac{r_{t}-n-g-\beta}{\theta} \\
& =\frac{r_{t}-\rho-\theta g}{\theta}
\end{aligned}
$$

where the second line uses the definition of $\beta$ as $\rho-n-(1-\theta) g$. 
To interpret (5.43), note that since $C_{t}$ - consumption per worker, rather than consumption per unit of effective labour - equals $c_{t} \zeta_{t}$, the growth rate of $C$ is given by:

$$
\begin{aligned}
\frac{\dot{C}_{t}}{C_{t}} & =\frac{\dot{\zeta}_{t}}{\zeta_{t}}+\frac{\dot{c}_{t}}{c_{t}} \\
& =g+\frac{r_{t}-\rho-\theta g}{\theta} \\
& =\frac{r_{t}-\rho}{\theta}
\end{aligned}
$$

where the second line uses (5.43). This condition states that consumption per worker is rising of the real return exceeds the rate at which the household discounts future consumption, and is falling if the reverse holds. The smaller is $\theta$ - the less marginal utility changes as consumption changes - the larger are the changes in consumption in response to differences between the real interest rate and the discount rate. Equation (5.43) is known as the Euler equation for this maximisation problem. An alternative way of deriving (5.43) is to use the Hamiltonian rather than the Lagrangian. We will apply the Hamiltonian to derive the same result in the next section of the Appendix.

\section{Appendix 5.B: Alternative Maximisation Problem}

Given the household's asset accumulation function:

$$
\dot{A}_{t}=r_{t} A_{t}+W_{t} L_{t}-C_{t} L_{t}
$$

we obtain the following per capita budget constraint by dividing the equation (5.45) by $L_{t}$ :

$$
\frac{\dot{A}_{t}}{L_{t}}=r_{t} a_{t}+W_{t}-C_{t}
$$

where $C_{t}$ is once again the per capita consumption. Differentiating the per capita asset $a_{t}=\frac{A_{t}}{L_{t}}$ with respect to time $t$ gives:

$$
\dot{a}_{t}=\frac{\dot{A}_{t} L_{t}-A_{t} \dot{L}_{t}}{L_{t}^{2}}=\frac{\dot{A}_{t}}{L_{t}}-n a_{t}
$$

We can obtain the per capita budget constraint by plugging equation (5.47) in equation (5.46):

$$
\dot{a}_{t}=\left(r_{t}-n\right) a_{t}+W_{t}-C_{t}
$$

Hence the household's optimisation problem is now given by:

$$
\begin{gathered}
\max \quad U=\int_{t=0}^{\infty} e^{-(\rho-n) t} \frac{C_{t}^{1-\theta}}{1-\theta} d t \\
\text { subject to: } \quad \dot{a}_{t}=\left(r_{t}-n\right) a_{t}+W_{t}-C_{t}
\end{gathered}
$$


Based on the previous information, the present value Hamiltonian is then given by:

$$
\mathcal{H}=e^{-(\rho-n) t} \frac{C_{t}^{1-\theta}}{1-\theta}+\mu_{t}\left[\left(r_{t}-n\right) a_{t}+W_{t}-C_{t}\right]
$$

where $\mu$ is simply the co-state variable associated with the budget constraint (5.46). The per capita consumption $C_{t}$ and the per capita asset $a_{t}$ are the control variable and the state variable, respectively. The necessary optimal conditions follow:

$$
\begin{gathered}
\frac{\partial \mathcal{H}}{\partial C_{t}}=e^{-(\rho-n) t} C_{t}^{-\theta}-\mu_{t} \\
\frac{\partial \mathcal{H}}{\partial a_{t}}=\mu_{t}\left(r_{t}-n\right)=-\dot{\mu}_{t}
\end{gathered}
$$

Together with the transversality condition $\lim _{t \rightarrow \infty} e^{-(\rho-n) t} \mu_{t} a_{t}$, log-differentiating equation (5.51) will yield:

$$
\frac{\dot{\mu}_{t}}{\mu_{t}}=n-\rho-\theta \frac{\dot{C}_{t}}{C_{t}}
$$

And from equation (5.52), it follows that:

$$
\frac{\dot{\mu}_{t}}{\mu_{t}}=n-\rho-r_{t}
$$

Equating equations (5.53) and (5.54) leads to the Euler equation once again.

\section{Appendix 5.C: Finding the Elasticity of Output}

The long-term effect of a rise in saving on output is given by:

$$
\frac{\partial y^{*}}{\partial s}=f^{\prime}\left(k^{*}\right) \frac{\partial K^{*}(s, n, g, \delta)}{\partial s}
$$

where $y^{*}=f\left(k^{*}\right)$ is the level of output per unit of effective labour on the balanced growth path. Thus to find $\partial y^{*} / \partial s$, we need to find $\partial k^{*} / \partial s$. To do this, note that $k^{*}$ is defined by the condition that $\dot{k}=0$. Thus $k^{*}$ satisfies:

$$
s f\left(k^{*}(s, n, g, \delta)\right)=(n+g+\delta) k^{*}(s, n, g, \delta)
$$

Equation (5.56) holds for all values of $s$ (and of $n, g$ and $\delta$ ). Thus the derivation of the two sides with respect to $s$ are equal: ${ }^{22}$

$$
s f^{\prime}\left(k^{*}\right) \frac{\partial k^{*}}{\partial s}+f\left(k^{*}\right)=(n+g+\delta) \frac{\partial k^{*}}{\partial s}
$$

where the arguments of $k^{*}$ are omitted for simplicity. This can be rearranged to obtain:

$$
\frac{\partial k^{*}}{\partial s}=\frac{f\left(k^{*}\right)}{(n+g+\delta)-s f^{\prime}\left(k^{*}\right)}
$$

\footnotetext{
${ }^{22}$ This technique is known as implicit differentiation.
} 
Substituting (5.58) into (5.57) yields:

$$
\frac{\partial y^{*}}{\partial s}=\frac{f^{\prime}\left(k^{*}\right) f\left(k^{*}\right)}{(n+g+\delta)-s f^{\prime}\left(k^{*}\right)}
$$

Two changes help in interpreting this expression. The first is to convert it to an elasticity by multiplying both sides by $s / y^{*}$. The second is to use the fact that $s f\left(k^{*}\right)=(n+g+\delta) k^{*}$ to substitute for $s$. Making these changes gives us:

$$
\begin{aligned}
\frac{s}{y^{*}} \frac{\partial y^{*}}{\partial s} & =\frac{s}{f\left(k^{*}\right)} \frac{f^{\prime}\left(k^{*}\right) f\left(k^{*}\right)}{(n+g+\delta)-s f^{\prime}\left(k^{*}\right)} \\
& =\frac{(n+g+\delta) k^{*} f^{\prime}\left(k^{*}\right)}{f\left(k^{*}\right)\left[(n+g+\delta)-(n+g+\delta) k^{*} f^{\prime}\left(k^{*}\right) / f\left(k^{*}\right)\right]} \\
& =\frac{k^{*} f^{\prime}\left(k^{*}\right) / f\left(k^{*}\right)}{1-\left[k^{*} f^{\prime}\left(k^{*}\right) / f\left(k^{*}\right)\right]}
\end{aligned}
$$

$k^{*} f^{\prime}\left(k^{*}\right) / f\left(k^{*}\right)$ is the elasticity of output with respect to capital at $k=k^{*}$. Hence we note:

$$
\alpha_{K}\left(k^{*}\right)=\frac{k^{*} f^{\prime}\left(k^{*}\right)}{f\left(k^{*}\right)}
$$

$\alpha_{K}\left(k^{*}\right)$ is also the share of total income that goes to capital on the balanced growth path. Hence the relationship between this elasticity of output and the long-run effect of saving on output is:

$$
\frac{s}{y^{*}} \frac{\partial y^{*}}{\partial s}=\frac{\alpha_{K}\left(k^{*}\right)}{1-\alpha_{K}\left(k^{*}\right)}
$$

If markets are competitive and there are no externalities, capital earns its marginal product, in which case the total amount earned by capital per unit of effective labour on the balanced growth path is $k^{*} f^{\prime}\left(k^{*}\right)$. The share of total income that goes to capital on the balanced growth path is then $k^{*} f^{\prime}\left(k^{*}\right) / f\left(k^{*}\right)$, or simply $\alpha_{K}\left(k^{*}\right)$. In most countries, the share of income paid to capital is about one-third. 


\section{Chapter 6}

\section{Synthesis}

Motivated by a renewed interest in development macroeconomic fluctuations, this dissertation asked four overarching questions, each treated in a separate chapter:

- How does the welfare cost of business cycles in a developing-country currency union - such as the sub-Saharan African CFA Franc Zone - compare to that of other developing countries outside the union?

- How do consumption series' structural breaks contribute in amplifying or lowering both the welfare gains from entirely eliminating consumption fluctuations and the welfare gains from an additional percentage point increase of consumption growth forever?

- What types of economic structure and what patterns of structural change contribute to developing countries' and to emerging economies' ability to sustain stable economic growth over longer periods of time?

- How does a stochastic violent shock - rare disaster - affect the steady-state economic growth and what does it imply for the balanced growth path's speed of convergence?

In Chapter 2 of the dissertation, we computed the welfare cost of macroeconomic fluctuations in 36 sub-Saharan African countries, of which eleven are members of the CFA Franc Zone, a seven and plus decades currency union. This was carried out using various techniques that have been proposed in the macroeconomic literature. Depending on the calibration model used, we found that the sample mean cost of business cycles for the group of non-CFA member states is between 11 and 48 percent higher than that of the members of the union. However, a parametric two-sample $t$-test showed that these results were not sufficiently robust to means difference comparisons.

Because of the high variance of some estimates - which is a direct consequence of the different estimation techniques used -, it is important not to adopt these numbers as the absolute costs of macroeconomic fluctuations in each individual country. However, the results serve well the purpose of cross-country comparison and hold consistent through a 
wide range of robustness checks. Two important constants of this analysis are: first, that the welfare cost of economic fluctuations for all the countries in the sample is higher than that of the United States, taken as the benchmark; second, that despite the change in methodology, in the preferred values of key parameters and despite the structural breaks, the CFA Franc Zone countries seemingly absorb better the adverse macroeconomic shocks than the rest of their African counterparts, albeit not significantly. This lack of significance might be a result of the fixed exchange rate regime in the CFA Franc Zone, a policy that has been remarkably consistent for more than seven decades. The immediate implication of such monetary arrangement is the inability to use monetary policy to effectively deal with real and financial crises affecting the union members as well as with external shocks that have the power to change the exchange rates between global currencies (Aizenman, 2016). This goes against the backdrop of a growing ideological and political calls from some member states to leave the union altogether. Potential ways forward could be moving towards a semi-flexible exchange rate regime and the anchoring of the CFA Franc on a basket of international currencies instead of the Euro alone.

Chapter 3 combined a robust recursive preference framework and a strong structural break algorithm to infer on the welfare costs of consumption fluctuations and the gains from consumption growth. It departed from the previous literature specifically on the ground of structural change, which is likely to arise in any aggregate time series, as acknowledged by the recent macroeconomic literature. All the 37 countries covered in the analysis belong to the Low-Income and the Lower-Middle-Income categories of the World Bank's classification, and covered Africa, Asia, Latin America, and South-East Asia to some extent. In addition to the large basket of developing countries covered, the time-span considered runs from 1960 to 2014.

At first, the results showed that for all the countries concerned by the analysis and for a relatively long period of time - as the one considered here -, the welfare gains from a perpetual one percent increase of lifetime consumption growth transcend the welfare costs of aggregate consumption fluctuations. These results hold firmly when the analysis is repeated before and after structural breaks, given that the number of years covered exceeds 22 years. Second, and central to the analysis, we found that the null hypothesis of the equality between the sample averages of the welfare costs of business cycles for the general and the restricted models is not rejected. The implication for this result is that in the context of an Epstein and Zin (1989) preference specification, unique structural breaks do not matter when it comes to the interpretation of the sample average welfare cost of business cycles, especially when such sample exhibits a high degree of homogeneity. Conversely, the two-tail probability of the test equating the sample averages of the welfare gains from growth between the general and the restricted models was significant. The paramount implication of this result is that structural breaks do matter for growth. In the specific context of this chapter, the average welfare gain from an additional one percent of yearly consumption becomes higher when structural breaks 
for each individual country are taken into account. To check for the robustness of the previous results, the coefficient of relative risk aversion and the intertemporal elasticity of substitution parameter were doubled separately. Additionally, alternative structural break tests were provided. Finally, we used an analysis of variance - ANOVA - to check the robustness of our benchmark mean-comparison test. Overall, the findings remained unchanged and the majority of the candidate breakpoints of the consumption series stood unaltered. Although the welfare gains from consumption stabilisation and the welfare gains from consumption growth-enhancing were computed using point estimates, they show that growth-enhancing policies should still top the agendas of developing countries' governments, as long advocated by the World Bank and other international organisations.

In Chapter 4, we have examined the relationship between economic structure and the ability of countries to sustain stable economic growth, using both a linear panel and a threshold panel models. The structural variables included the degree of specialisation in the structure of value added as measured by the Theil index, the share of manufacturing in value added, the share of the modern sector in value added and the share of manufacturing within the modern sector. These variables were measured both in terms of initial levels at the beginning of the estimation period, or in terms of their changes over that period. The key dependent variable was the volatility of growth rates in five-year periods. The analysis resulted in a large set of specialisations which have been discussed systematically in the corresponding sections of the chapter. Though this research does not draw from definitive specifications and leads to absolutely firm conclusions, some interesting patterns did emerge nevertheless.

In the linear model we found that, first, a higher manufacturing share may help reduce the volatility of economic growth. In other words, manufacturing seems to be related to the ability to sustain growth. Second, if we look at the share of manufacturing value added within the modern sector of the economy rather than its share in the GDP, a very similar picture emerges. The modern sector share was significantly associated with a lower growth volatility. Third, the impact of the modern sector share on the ability to sustain growth was more ambiguous than that of manufacturing. It seemed to be dependent on the change in that share. The impact of the modern sector share on growth volatility was therefore difficult to interpret, with the direct effects being negative. A larger modern sector was often associated with higher volatility. Finally, the results for specialisation unexpectedly showed no significant effect on volatility. From the portfolio perspective discussed in the chapter, one would have expected that a more diversified economy would be less subject to volatility. On the basis of our current - imperfect measures of specialisation and volatility this turned out not to be exactly the case.

In the threshold model, we used twelve different specifications grouped in three main categories, mainly according to the choice of our regime-dependent variable. Estimating thresholds based directly on the level of economic structure did not always yield a significant result. For instance, the share of manufacturing in modern sector did not 
add any meaningful layer to the analysis when this indicator was chosen both as regimedependent and threshold variable. When the share of manufacturing in value added was chosen as both the regime-dependent and threshold variable, we found a significant threshold of $28.2 \%$, allowing us to accept the non-linearity of the 'growth volatility'-'economic structure' at the $10 \%$ level. Partially in line with the results of the linear model, this suggested that growth volatility is negatively and significantly affected by an increase in manufacturing share in GDP mostly for values below $28.2 \%$ and not necessarily for those above. Similarly, when the share of the modern sector in value added was chosen as both the regime-dependent and the threshold variable, we found $32.1 \%$ as the threshold below which the volatility-reduction benefits are higher as the share of the modern sector increases.

Finally, we alternated various regime-independent variables - the share of exports in GDP, the per capita GDP in 1960 and the natural logarithm of population in 1960 - as alternative threshold variables. The share of exports in GDP did not act as a significant threshold in none of our specifications. The original income level of 1960 however mattered in two cases: first when the share of manufacturing in value added was concerned and when the share of manufacturing in the modern sector was the regime-dependent variable. A larger share of manufacturing in GDP strongly reduces volatility for countries with the 1960 per capita income below 5818.38 USD. However, a larger share of manufacturing in the modern sector only contributed in reducing growth volatility for countries with the 1960 income per capita above the threshold of 908.35 USD. We also found that population somehow mattered when it comes to the volatility-reducing effects of economic structure. Countries with a population below 2.5 and 7.4 million benefit the most from reduced growth volatility as their share of manufacturing in GDP and the share of manufacturing in the modern sector increase, respectively.

Chapter 5 methodologically departs from the previous three empirical and calibration-based chapters in analysing macroeconomic volatility. For what was a mostly theoretical argumentation, we posited after various assumptions that a random violent shock, also referred to as rare disaster, affects economic growth through its adverse impact on the equilibrium real interest rate, which is the price of physical capital when markets are clear and when there is no externality. This result was extended to alternative production function specifications, notably to the $A K$ model and to a learning-by-doing technology. Furthermore, we showed that a rare disaster affects the balanced growth path's speed of convergence through the elasticity of output with respect to the intensive-form physical capital. The direction and amplitude of this impact fundamentally depend on how the new value of this elasticity compares to the share of physical capital in total output when there is no shock. This chapter could be extended for further detailed calibrations and simulations, based on estimates from either structural models or VAR models. It provides a simple new stochastic model of rare disasters, a collection of small probability damaging events that have recently caught the attention of macroeconomics and finance experts. 


\section{Bibliography}

Agenor, P., J. McDermott, and E. Prasad (2000). Macroeconomic Fluctuations in Developing Countries: Some Stylized Facts. World Bank Economic Review 14(2), 251-285.

Aghion, P. and I. Marinescu (2008). Cyclical Budgetary Policy and Economic Growth: What Do We Learn from OECD Panel Data? NBER Macroeconomic Annual 22.

Aguar and Gopinath (2007). Emerging Market Business Cycles: The Cycle is the Trend. Journal of Political Economy 115, 69-102.

Aisen, A. and J. Veiga (1996). Does Political Instability Lead to Higher Inflation? A Panel Data Analysis. Journal of Money, Credit, and Banking 38, 1379-1389.

Aisen, A. and J. Veiga (2013). How Does Political Instability Affect Economic Growth? European Journal of Political Economy 29, 151-167.

Aizenman, J. (2016). Optimal Currency Area: A 20th Century Idea for the 21st Century. NBER Working Paper No. 22097.

Alesina, A., S. Ozler, N. Roubini, and P. Swagel (1996). Political Instability and Economic Growth. Journal of Economic Growth 1(2), 189-211.

Alesina, A. and R. Perotti (1996). Income Distribution, Political Instability, and Investment. European Economic Review 40(6), 1203-1228.

Alvarez, F. and U. Jermann (2005). Using Asset Prices to Measure the Cost of Business Cycles. Econometrica 73(6), 1977-2016.

Andrews, D. (1993). Tests for Parameter Instability and Structural Change with Unknown Change Point. Econometrica 61, 821-856.

Andrews, D. and W. Ploberger (1994). Optimal Tests When a Nuisance parameter is present Only Under the Alternative. Econometrica 62, 1383-1414.

Aron, J. (2000). Growth and Institutions: A Review of the Evidence. The World Bank Research Observer 15, 99-135.

Arrow, K. (1962). The Economic Implication of Learning by Doing. Review of Economic Studies 29(3), 155-173.

Atkeson, A. and C. Phelan (1994). Reconsidering the Costs of Business Cycles with Incomplete Markets. NBER Macroeconomic Annual. Cambridge, MA:MIT Press.

Azam, J. P. and W. Wane (2001). The 1994 Devaluation and Poverty in the WAEMU. Washington, DC: World Bank, unpublished. 
Azeinman, J. and B. Pinto (2005). Managing economic volatility and crises. Cambridge University Press.

Bai, J. (1997). Estimating Multiple Breaks one at a Time. Econometric Theory 13, $315-352$.

Bai, J. (1999). Likelihood Ratio Tests for Multiple Structural Change. Journal of Econometrics $91(2), 299-323$.

Bai, J. and P. Perron (1998). Estimating and Testing Linear Models with Multiple Structural Changes. Econometrica 66, 47-78.

Baltagi, B., G. Brensson, and A. Pirotte (2003). Fixed Effects Random Effects or Hausman-Taylor? A Pretest Estimator. Economics Letters 79(3), 361-369.

Bamba, L. N. (2004). Analyse du Processus de Convergence dans la Zone UEMOA. WIDER Research Paper 18. Helsinki: UNU-WIDER.

Barillas, B., L. Hansen, and T. Sargent (2009). Doubts or Variability? Journal of Economic Theory 144, 2388-2418.

Barlevy, G. (2004). The Cost of Business Cycles under Endogenous Growth. American Economic Review 94(4), 964-990.

Barlevy, G. (2005). The Cost of Business Cycles and the Benefits of Stabilization. Economic Perspectives 29(1), 32-49.

Barro, R. (2006). Rare Disasters and Asset Markets in the Twentieth Century. Quarterly Journal of Economics 121(3), 823-866.

Barro, R. (2009). Rare Disasters, Asset Markets, and the Welfare Costs. American Economic Review 99(1), 243-264.

Barro, R. and T. Jin (2011). On the Size Distribution of Macroeconomic Disasters. Econometrica 79(5), 1567-1589.

Barro, R. and X. Sala-i-Martin (1995). Economic Growth. New York: McGraw-Hill.

Barro, R. and J. Ursúa (2012). Rare Macroeconomic Disasters. Annual Review of Economics 4(1), 83-109.

Bathia, R. (1986). The West African Monetary Union: An Analyrical Survey. IMF Occasional Paper 35. Washington, DC:IMF.

Beaudry, P. and C. Pages (2001). The Cost of Business Cycles and the Stabilization Value of Unemployment Insurance. European Economic Review 45 (8), 1545-1572. 
Ben-David, D. and D. Papell (1995). The Great Wars, the Great Crash, and Steady State Growth: Some New Evidence about an Old Stylized Fact. Journal of Monetary Economics 36(3), 453-475.

Bénassy-Quéré, A. and M. Coupet (2003). On the Adequacy of Monetary Arrangements in sub-Saharan Africa. THEMA, Working Paper, Université de Paris X Nanterre/Université de Cergy-Pontoise.

Blackwell, D. (1965). Discounted Dynamic Programming. The Annals of Mathematical Statistics 36(1), 226-235.

Blanchard, O. and D. Quah (1989). Dynamic Effects of Aggregate Demand and Supply Disturbances. American Economic Review 79, 655-673.

Bleaney, M. and D. Fielding (2002). Exchange Rate Regimes, Inflation and Output Volatility in Developing Countries. Journal of Development Economics 68, 233-245.

Bleaney, M. and A. Nishiyama (2002). Explaining Growth: A Contest Between Models. Journal of Economic Growth 7(1), 43-56.

Bluhm, R., D. Crombrugghe, and A. Szirmai (2016). Do Weak Institutions Prolong Crises? On the Identification, Characteristics, and Duration of Declines During Economic Slumps. UNU-MERIT Working Paper.

Brock, W. (1982). Asset Prices in a Production Economy. University of Chicago Press.

Brunetti, A. (1997). Political Variables in Cross-Country Growth Analysis. Journal of Economic Surveys 11, 136-190.

Campos, N. and J. Nugent (2002). Who is Afraid of Political Instability? Journal of Development Economics 67, 157-172.

Cariolle, J. (2012). Measuring Macroeconomic Volatility: Applications to Export Revenue Data, 1970-2005. Fondation pour les Etudes et Recherches sur le Developpement International Working Paper Series 114.

Carmichael, B., S. Keita, and L. Samson (1999). Liquidity Constraints and Business Cycles in Developing Economies. Review of Economic Dynamics 2(2), 370-402.

Carmignani, F. (2003). Political Instability, Uncertainty and Economics. Journal of Economic Surveys 17(1), 1-54.

Chan, K. (1993). Consistency and Limiting Distribution of the Least Squares Estimator of a Threshold Autoregressive Model. The Annals of Statistics 21, 520-533.

Chen, B. and Y. Feng (1996). Some Political Determinants of Economic Growth: Theory and Empirical Applications. European Journal of Political Economy 12, 609-627. 
Chow, G. (1960). Test of Equality Between Sets of Coefficients in Two Linear Regressions. Econometrica 28(3), 591-605.

Coleman, S. (2004). An Aggregate View of Macroeconomic Shocks in sub-Saharan Africa: A Comparative Study Using Innovation Accounting. Research Paper 2004/9. Helsinki: UNU-WIDER.

Cooley, T. and M. Ogaki (1996). A Time Series Analysis of Real Wages, Consumption, and Asset Returns. Journal of Applied Econometrics 11(2), 119-134.

Corden, W. (1972). Monetary Integration, Essays in International Finance. Princeton University Press.

Cornwall, J. (1977). Modern Capitalism. Its Growth and Transformation. New York: St. Martin's Press.

Darby, J., J. Li, and A. Muscatelli (2004). Political Uncertainty, Public Expenditure and Growth. European Journal of Political Economy 20, 153-179.

Dasgupta, S. and A. Singh (2006). Manufacturing, Services and Premature Deindustrialization in Developing Countries: A Kaldorian Analysis. Working Papers RP2006/49, World Institute for Development Economic Research (UNU-WIDER).

Davies, R. (1987). Hypothesis Testing When a Nuisance Parameter is Present Only Under the Alternative. Biometrica $74,33-43$.

de Santis, M. (2007). Individual Consumption Risk and the Welfare Cost of Business Cycles. American Economic Review 97(4), 60-66.

Devarajan, S. and J. de Melo (1987). Evaluating Participation in African Monetary Unions. World Development 15, 483-496.

Devereux, M. and J. Wen (1998). Political Instability, Capital Taxation, and Growth. European Journal of Political Economy 42(1), 1635-1651.

Dolmas, J. (1998). Risk Preferences and the Welfare Cost of Business Cycles. Review of Economic Dynamics 1(2), 646-676.

Dufour, J. (1997). Some Impossibility Theorems in Econometrics with Applications to Structual Variables and Dynamic Models. Econometrica 65, 365-384.

Easterly, W., M. Kremer, L. Pritchett, and L. Summers (1993). Good Policy or Good Luck. Journal of Monetary Economics 32(2), 459-483.

Ehrlich and Becker (1972). Market Insurance, Self-Insurance, and Self-Protection. Journal of Political Economy 80(4), 623-648. 
Eichengreen, B. (2009). The Two Waves of Service Sector Growth. NBER Working Paper Series, Working Paper 14968, Cambridge Mass: National Bureau of Economic Research.

Elbadawi, I. and N. Majd (1996). Adjustment and Economic Performance under a Fixed Exchange Rate: A Comparative Analysis of the CFA Zone. World Development 24, 939-951.

Ellison, M. and T. Sargent (2015). Welfare Cost of Business Cycles with Idiosyncratic Consumption Risk and a Preference for Robustness. American Economic Journal 7(2), $40-57$.

Epaulard, A. and A. Pommeret (2003). Recursive Utility, Growth, and the Welfare Cost of Volatility. Review of Economic Dynamics 6(2), 672-684.

Epstein, L. and S. Zin (1989). Substitution, Risk Aversion, and the Temporal Behavior of Consumption and Asset Returns: A Theoretical Framework. Econometrica 57(4), 937-969.

Farhi, E. and X. Gabaix (2016). Rare Disasters and Exchange Rates. Quarterly Journal of Economics 131(1), 1-52.

Feenstra, R., R. Inklaar, and M. Timmer (2015). The Next Generation of the Penn World Table. American Economic Review 105(10), 3150-31-52.

Fernández-Villaverde, J. and O. Levintal (2017). Solutions Methods for Models with Rare Disasters. Quantitative Economics, forthcoming.

Fielding, D. (2004). How Does Monetary Policy Affect the Poor? Evidence from the West African Economic and Monetary Union. UNU-WIDER Research Paper 2004/2. Helsinki.

Fielding, D., K. Lee, and K. Shields (1995). The Characteristics of Macroeconomic Shocks ine the Franc Zone. Journal of African Economies 13(4), 488-517.

Fielding, D. and K. Shields (2001). Modeling Macroeconomic Shocks in the CFA Franc Zone. Journal of Development Economics 66, 199-223.

Foster-McGregor, N., I. S. Kaba, and A. Szirmai (2015). Structural Change and the Ability to Sustain Growth. UNU-MERIT Working Paper Series 2015-048.

François, P. and H. Lloyd-Ellis (2006). Growth, Cycles and Welfare: A Schumpeterian Perspective. Working Paper 1090, Queen's University, Department of Economics.

Gabaix, X. (2012). Variable Rare Disasters: An Exactly Solved Framework for Ten Puzzles in Macro-Finance. Quaterly Journal of Economics 127(3), 645-700. 
Gallup, J., J. Sachs, and A. Mellinger (1999). Geography and Economic Development. International Regional Science Review 22, 179-232.

Girma, S. (2005). Absorptive Capacity and Productivity Spillovers from FDI: A Treshold Analysis Export. Oxford Bulletin of Economics and Statistics 67, 281-306.

Gomez, J., J. Greenwood, and S. Rebelo (2001). Equilibrium Unemployment. Journal of Monetary Economics 48, 109-152.

Gourio, F. (2012). Disaster Risk and Business Cycles. American Economic Review 102(6), $2734-2766$.

Gourio, F. (2013). Credit Risk and Disaster Risk. American Economic Journal: Macroeconomics 5(3), 1-34.

Hall, R. (1988). Intertemporal Substitution in Consumption. Journal of Political Economy $96(2), 339-357$.

Hansen, B. E. (1996). Interference When a Nuisance Parameter is not Identified Under the Null Hypothesis. Econometrica 64, 413-430.

Hansen, B. E. (1999). Threshold Models in Non-Dynamic Panels: Estimating, Testing, and Interference. Journal of Econometrics 93, 345-368.

Hansen, B. E. (2000). Sample Splitting and Threshold Estimation. Econometrica 68, $575-603$.

Hartley, H. (1950). The Use of Range in Analysis of Variance. Biometrika 37, 271-280.

Hausman, J. and W. Taylor (1981). Panel Data and Unobservable Individual Effects. Econometrica 49(6), 1377-1398.

Heaton, J. (1995). An Empirical Investigation of Asset Pricing with Temporal Dependent Preference Specifications. Econometrica 63(3), 681-717.

Hnatkovska, V. and N. Loayza (2005). Volatility and Growth. Cambridge University Press.

Hoffmaister, A., J. Roldós, and P. Wickham (1998). Macroeconomic Fluctuations in sub-Saharan Africa. IMF Staff Papers 45, 132-160.

Houssa, R. (2013). Uncertainty About the Welfare Effects of Business Cycles. European Economic Review 59(3), 35-62.

Hsiao, C. (2003). Analysis of Panel Data. Cambridge University Press.

Imbs, J. (2007). Growth and Volatility. Journal of Monetary Economics 54(17), 18481862. 
Imbs, J. and R. Wacziarg (2003). Stages of Diversification. American Economic Review 93(1), 63-86.

IMF (2015). Now is the Time: Fiscal Policies for Sustainable Growth. Fiscal Monitor, Chapter 2; International Monetary Fund.

Imrohoroglu, A. (1989). Cost of Business Cycles with Indivisibilities and Liquidity Constraints. Journal of Political Economy 97(6), 1364-1383.

Imrohoroglu, A. (2008). Welfare Cost of Business Cycles. In: Durlauf, S.N., Blume, L.E. (Eds.), The Nnew Palgrave Dictionary of Economics. Palgrave Macmilan, Basingstoke.

Inada, K. (1964). Some Structural Characteristics of Turnpike Theorems. Review of Economic Studies 31, 43-58.

Ishiyama, Y. (1975). The Theory of Optimum Currency Areas: A Survey. IMF Staff Papers 22, 344-383.

Jacob, J. and T. Osang (2007). Institutions, Geography and Trade: A Panel Data Study. Southern Methodist University, Department of Economics, Departmental Working Paper 0706 .

Jacob, J. and S. Sasso (2015). Foreign Direct Investment and Technology Spillovers in Low and Middle-Income Countries: A Comparative Cross-Sectional Analysis. Background Paper for the 2016 Industrial Development Report, UNU-MERIT Working Paper Series 2015-035.

Jones, B. and B. Olken (2008). The Anatomy of Start-Stop Growth. Review of Economics and Statistics 90(3), 582-587.

Jong-A-Pin, R. (2009). On the Measurement of Political Instability and its Impact on Economic Growth. European Journal of Political Economy 25(1), 15-29.

Kaldor, N. (1966). Causes of the Slow Rate of Growth of the United Kingdom. Cambridge University Press.

Kaldor, N. (1967). Strategic Factors in Economic Development. New York: Ithaca.

Kaulich, F. (2012). Diversification vs. Specialization as Alternative Strategies for Economic Development: Can We Settle a Debate by Looking at the Empirical Evidence? Veinna, UNIDO, Development Policy, Statistics and Research Branch Working Paper 3.

Kenen, P. (1969). The Theory of Optimum Currency Areas: An Eclectic View. Chicago University Press. 
Kim, H. and D. Siegmund (1989). The Likelihood Ratio Test for a Change-Point in Simple Linear Regression. Biometrica 76, 409-423.

Krebs, T. (2003). Growth and Welfare Effects of Business Cycles in Economies with Idiosyncratic Human Capital Risk. Review of Economic Dynamics 6(4), 846-868.

Krebs, T. (2007). Job Displacement Risk and the Cost of Business Cycles. American Economic Review 97(3), 664-686.

Krugman, P. (2012). Revenge of the Optimum Currency Area. NBER Macroeconomics Annual 27, 439-448.

Krusell, P. and A. Smith (1999). On the Welfare Effects of Eliminating Business Cycles. Review of Economic Dynamics 2(1), 245-272.

Kydland, F. and E. Prescott (1982). Time to Build and Aggregate Fluctuations. Econometrica 50(6), 1345-1370.

Lavopa, A. (2015). Structural Transformation and Economic Development: Can Developments Traps be Avoided? PhD Thesis, Maastricht University.

Lavopa, A. and A. Szirmai (2014). Structural Modernisation and Underdevelopment Traps. An Empirical Approach. UNU-MERIT Working Paper Series 2014-076.

Lavopa, A. and A. Szirmai (2015). Drivers of Structural Modernisation. The Role of Manufacturing. UNU-MERIT Working Paper Series.

Ljungqvist, L. and T. Sargent (2000). Recursive Macroeconomic Theory, 2nd Edition. MIT Press.

Loayza, Ranciere, Serven, and Ventura (2007). Macroeconomic Volatility and Welfare in Developing Countries: An Introduction. The World Bank Economic Review 21(3), $343-357$.

Lucas, R. (1978). Asset Prices in an Exchange Economy. Econometrica 46, 1429-1445.

Lucas, R. E. (1987). Models of Business Cycle. Oxford: Basil Blackwell.

Lucas, R. E. (2003). Macroeconomic Priorities. American Economic Review 93(1), 1-14.

Maddison, A. (1988). Ultimate and Proximate Growth Causality: A Critique of Mancur Olson on the Rise and Decline of Nations. Scandinavian Economic History Review 36(2), 25-29.

Male, R. (2010). Developing Country Business Cycles: Revisiting the Stylized Facts. University of London. 
Martin, P. and C. Ann Rogers (2000). Long-term Growth and Short-term Economic Instability. European Economic Review 44(2), 359-381.

McKinnon, R. (1963). Optimum Currency Area. American Economic Review 53(4), $717-725$.

McMillan, M. and D. Rodrik (2011). Globalization, Structural Change and Productivity Growth. NBER Working Paper Series 17143.

Mehra, R. and E. Prescott (1985). The Equity Premium: A Puzzle. Journal of Monetary Economics 15(2), 145-161.

Mendoza, E. (1995). The Terms of Trade, the Real Exchange Rate, and Economic Fluctuations. International Economic Review 36(1), 101-137.

Mundell, R. (1961). A Theory of Optimum Currency Areas. American Economic Review 51(1), 657-665.

Nakamura, E., J. Steinsson, R. Barro, and J. Ursúa (2013). Cries and Recoveries in an Empirical Model of Consumption Disasters. Amercian Economic Journal: Macroeconomics 5(3), 35-74.

Nelson, C. and C. Plosser (1982). Trends and Random Walks in Macroeconomic Time Series: Some Evidence and Implications. Journal of Political Economy 10(2), 139-162.

Neumeyer and Perri (2005). Business Cycles in Emerging Economies: The Role of Interest Rates. Journal of Monetary Economics 99(6), 1166-1187.

Obstfeld, M. (1994). Evaluating Risky Consumption Paths: The Role of Intertemporal Substituability. European Economic Review 37(5), 1471-1486.

Ogaki, M. (1992). Engel's Law and Cointegration. Journal of Political Economy $100(5)$, 1027-1046.

Ogaki, M., C. Reinhart, and J. Ostry (1996). Saving Behavior in Low and Middle-Income Developing Countries: A Comparison. IMF Staff Papers 43(1), 38-71.

Osakwe, P. (2007). Foreign Aid, Resources and Export Diversification in Africa: A New Test of Existing Theories. United Nations Economic Commission for Africa, African Trade Policy Centre, Work in Progress 61.

Ostry, J. and C. Reinhart (1992). Private Savings and Terms of Trade Shocks: Evidence from Developing Countries. IMF Staff Papers 39(3), 495-517.

Otrok, C. (2001). On Measuring the Welfare Cost of Business Cycles. Journal of Monetary Economics $47(1), 61-92$. 
Otrok, C., B. Ravikumar, and C. Whiteman (2002). Evaluating the Asset-Pricing Models Using the Hansen-Jagannathan Bound: a Monte Carlo Investigation. Journal of Applied Econometrics 17(2), 149-174.

Pallage, S. and M. Robe (2003). On the Welfare Cost of Economic Fluctuations in Developing Countries. International Economic Review 44(2), 677-698.

Papell, D. and R. Prodan (2014). Long-Run Time Series Tests of Constant Steady-State Growth. Economic Modelling 42, 464-474.

Perron, P. (2006). Dealing with Structural Breaks. Handbook of Econometric Theory 1, $278-352$.

Phelps, E. (1966). Golden Rules of Economic Growth. New York: W. W. Norton.

Plane, P. (1988). Performances Comparées en Matière de Croissance Economique. Stratégies de Développement Comparées. Paris: Economica.

Plane, P. (1989). Performances Comparées en Matière de Stabilité des Prix. Stratégies de Développement Comparées. Paris: Economica.

Pomeranz, K. (2009). The Great Divergence: China, Europe, and the Making of the Modern World Economy. Princeton University Press.

Pritchett, L. (1997). Divergence, Big Time. Journal of Economic Perspectives 11(3), $3-17$.

Pritchett, L. (2000). Understanding Patterns of Economic Growth: Searching for Hills among Plateaux, Mountains, and Plains. World Bank Economic Review 14(2), 221250.

Quandt, R. (1960). Tests of the Hypothesis that a Linear Regression System Obeys Two Separate Regimes. Journal of the American Statistical Association 55, 324-330.

Ramey, G. and V. Ramey (1991). Technology Commitment and the Cost of Economic Fluctuations. National Bureau of Economic Research Working Paper 3755.

Ramey, G. and V. Ramey (1995). Cross-Country Evidence on the Link between Volatility and Growth. American Economic Review 85(5), 1138-1151.

Rand and Tarp (2002). Business Cycles in Developing Countries: Are they Different? World Development 30, 2071-2088.

Rebelo, S. (1991). Long-Run Policy Analysis and Long-Run Growth. Journal of Political Economy 99, 500-521. 
Rietz, T. (1988). The Equity Risk Premium: A Solution. Journal of Monetary Economics 22(1), 117-131.

Romer, D. (2011). Advanced Macroeconomic. McGraw-Hill Irwin.

Rousseau, P. and P. Wachtel (2009). What is Happening to the Impact of Financial Deepening on Economic Growth? Vanderbilt University Department of Economics.

Rouwenhorst, K. G. (1995). Asset Pricing Implications of Equilibrium Business Cycle Models. in: T. F. Cooley, ed., Frontiers of Business Cycle Research (Princeton University Press, Princeton, New Jersey).

Rowthorn, R. (1994). Korea at the Cross-Roads. Cambridge: Centre for Business Research, Working Paper 11.

Sachs, J. (1987). The Bolivian Hyperinflation and Stabilization. American Economic Review 17(2), 279-283.

Shortland, A. and D. Stasavage (2003). Monetary Policy in the Franc Zone: Estimating Interest Rate Rules for the BCEAO. UNU-WIDER Working Paper. Helsinki.

Solow, R. M. (1956). A Contribution to the Theory of Economic Growth. Quarterly Journal of Economics 70, 65-94.

Stevens, G. (2000). Politics, Economics and Investment: Explaining Plant and Equipment Spending by US Direct Investors in Argentina, Brazil and Mexico. Journal of International Money and Finance 19, 153-183.

Stokey, N., R. Lucas, and E. Prescott (1989). Recursive Methods in Economic Dynamics. Harvard University Press.

Storesletten, K., C. Telmer, and A. Yaron (2001). The Welfare Cost of Business Cycles Revisited: Finite Lives and Cyclical Variation in Idiosyncratic Risk. European Economic Review 45(7), 1311-1339.

Subramanian, A. (2007). Capital Account Convertibility: A Neglected Consideration. Peterson Institute for International Economics.

Svensson, J. (1998). Investment, Property Rights, Political Instability: Theory and Evidence. European Economic Review 42, 1317-1341.

Szirmai, A. (2012). Industrialisation as an Engine of Growth in Developing Countries, 1950-2005. Structural Change and Economic Dynamics 23(4).

Szirmai, A. and B. Verspagen (2011). Manufacturing and Economic Ggrowth in Developing Countries, 1950-2005. UNU-MERIT Working Paper Series 2011-069. 
Szirmai, A. and B. Verspagen (2015). Manufacturing and Economic Growth in Developing Countries, 1950-2005. Structural Change and Economic Dynamics 34(3), 46-59.

Tallarini, T. D. (2000). Risk-Sensitive Real Business Cycles. Journal of Monetary Economics 45(3), 507-532.

Tauchen, G. (1986). Finite State Markov-Chain Approximation and Vector Autoregressions. Economics Letters 20(2), 177-181.

Timmer, M. and A. Szirmai (2000). Productivity in Asian Manufacturing: The Structural Bonus Hypothesis Examined. Structural Change and Economic Dynamics (11), 371392.

Tong, H. (1983). Threshold Models in Non-Linear Time Series Analysis. Lecture Notes in Statistics.

Tower, E. and T. Willet (1976). The Theory of Optimum Currency Areas and Exchange Rate Flexibility: A More General Framework. Princeton University Press.

Tregenna, F. (2013). Manufacturing, Productivity, Deindustrialisation and Reindustrialisation. in Pathways to Industrialization in the 21st Century: New Challenges and Emerging Paradigms, A. Szirmai, W. Naudé, and L. Alcorta (eds.), Oxford: Oxford University Press.

Tregenna, F. (2015). Deindustrialisation, Structural Change and Sustainable Economic Growth. Background Paper for 2016 Industrial Development Report. UNU-MERIT Working Paper Series 2015-032.

UNDP (2017). Rising Tides, Rising Capacity: Supporting a Sustainable Future for Small Island Developing States.

Van Ark, H., R. Inklaar, and R. McGuckin (2003). ICT and Productivity in Europe and the United States. Where Do the Differences Come From? Ifo Studien 3, 295-318.

Van Wincoop, E. (1994). Welfare Gains from International Risk Sharing. Journal of Monetary Economics 34(2), 175-200.

Vizy, M. (1989). La Zone Franc. Paris: CHEAM.

Von Neumann, J. and O. Morgenstern (1953). Theory of Games and Economic Theory. Princeton University Press.

Wachter, J. (2015). Can Time-Varying Risk of Rare Disasters Explain Aggregate Stock Market Volatility. Journal of Finace 68(3), 987-1035.

Wang, Q. (2015). Fixed-Effect Panel Threshold Model Using Stata. The Stata Journal 15(1), 121-134. 
Wolfers, J. (2003). Is Business Cycle Volatility Costly? Evidence from Surveys of Subjective Well-Being. International Finance 6(1), 1-26. 


\section{Societal Relevance}

In accordance with article 23.5 of the "Regulation governing the attainment of doctoral degrees at Maastricht University" decreed by resolution of the Board of Deans, dated 3 July 2013, an addendum must be added about valorization.

\section{Looking Back}

The aim of this dissertation was to assemble a number of studies concerned with the analysis of developing-country macroeconomic volatility, both from consumption and output perspectives. This addendum on valorization provides an opportunity to reflect on that encompassing exercise and to draw some general lessons from it, as well as to indicate some directions for the future. We begin with briefly summarising the stories once again.

The areas of application were diverse. On the consumption side, Chapter 2 investigated the welfare cost of business cycles in 36 sub-Saharan African countries, of which 11 are members of the CFA Franc Zone, a seven and plus decades currency union. Two parametric and one nonparametric methods were used to compare the welfare cost of aggregate consumption fluctuations between the CFA member states and the countries outside the union. Depending on the calibration model used, we found that the sample mean cost of business cycles for the group of non-CFA member states is between 11 and 48 percent higher than that of the members of the union. However, a parametric twosample $t$-test showed that these results were not sufficiently robust to means difference comparisons.

The next chapter was concerned with the role of structural breaks in aggregate time series, also looking from the consumption side. Specifically, Chapter 3 combines a robust recursive preference framework and a strong structural break algorithm to infer on the welfare costs of consumption fluctuations and the gains from consumption growth. It departs from the previous literature specifically on the ground of structural change, which is likely to arise in any aggregate time series, as acknowledged by the recent macroeconomic literature. The chapter covers 37 Low-Income and the Lower-Middle-Income countries, from sub-Saharan Africa, Asia, Latin America and South-East Asia to some extent, and 
considers the 1960-2014 time-span. At first, the results show that for all countries concerned and for a relatively long period of time, the welfare gains from a perpetual one percent increase of lifetime consumption growth transcend the welfare costs of aggregate consumption fluctuations. These results hold firmly when the analysis is repeated before and after structural breaks, given that the number of years covered exceeds 22. Second, and central to the analysis, Chapter 3 shows that the null hypothesis of the equality between the sample averages of the welfare cost of business cycles for the general and the restricted models is not rejected. The overarching implication for this result is that in the context of a recursive preference specification, unique structural breaks do not matter when it comes to the interpretation of the sample average welfare cost of business cycles, especially when such sample exhibits a high degree of homogeneity. However, the two-tail probability of the test equating the sample averages of the welfare gains from growth between the general and the restricted models was significant, suggesting that structural breaks do matter for growth.

On the output side, Chapter 4 examined the relationship between economic structure and the ability of countries to sustain stable economic growth, using both a linear panel and a threshold panel models. The structural variables included the degree of specialisation in the structure of value added as measured by the Theil index, the share of manufacturing in value added, the share of the modern sector in value added and the share of manufacturing within the modern sector. These variables were all measured both in terms of initial levels at the start of the period, or in terms of their changes over that period, and the main dependent variable was the volatility of growth rates in consecutive five-year periods. In the linear model, the results show that, first, a higher manufacturing share may help reduce the volatility of economic growth. Second, if we look at the share of manufacturing value added within the modern sector of the economy rather than its share in the GDP, a very similar picture emerges. Third, the impact of the modern sector's share on the ability to sustain growth was more ambiguous than that of manufacturing, hence making it more difficult to interpret. Finally, the results for specialisation unexpectedly showed no significant effect on volatility.

In the threshold model of Chapter 4, we used twelve different specifications grouped in three main categories, mainly according to the choice of our regime-dependent variable. Estimating thresholds based directly on the level of economic structure did not always yield a significant result. For instance, the share of manufacturing in modern sector did not add any meaningful layer to the analysis when this indicator was chosen both as regime-dependent and threshold variable. Finally, we alternated various independent variables - the share of exports in GDP, the per capita GDP in 1960 and the natural logarithm of population in 1960 - as alternative threshold variables. The share of exports in GDP did not act as a significant threshold in none of our specifications. The original income level of 1960 however mattered in two cases, when the share of manufacturing in value added and the share of manufacturing in the modern sector were our preferred 
regime-dependent variables, respectively. We also found that the population somehow mattered when it comes to the volatility-reducing effects of economic structure.

A final chapter (Chapter 5) of this second part of the dissertation explored, in what was a mostly theoretical argumentation, about the effects of random violent shocks also referred to as rare disasters - both on economic growth and the steady-state speed of convergence. We showed that rare disasters impact the economic growth through its adverse effects on the equilibrium real interest rate, which is also the price of physical capital when markets are clear and when there is no externality. This result was extended to alternative production function specifications, notably to the $A K$ model and to a learning-by-doing technology. Furthermore, we showed that a rare disaster affects the balanced growth path's speed of convergence through the elasticity of output with respect to the intensive-form physical capital. The direction and amplitude of this impact depend fundamentally on how the new value of this elasticity compares to the share of physical capital in total output when there is no shock.

\section{Looking Ahead}

Just like any other branch of social science, economic research is also made out of little steps, sometimes up and sometimes down, on the irregular road of progress and discoveries. The real world is far too complex for our modest analyses of it to pretend ever to be complete, definitive or exhaustive. Every issue being "resolved" opens the way for more unanswered questions. Hence it is not surprising that the complications which showed down in the preceding chapters also made room and created perspectives for further work. Based on that, the immediate follow-up is to venture in some ideas for future research.

On the Optimum Currency Area (OCA) debate and the role of structural breaks, an interesting guideline for further work is not only to allow for more general heterogeneity between countries and for the possibility of multiple breaks, but also and ultimately to account for more features found in aggregate consumption data, especially when the compensatory factor to fluctuations is concerned. Concretely, what role could economic and exports sophistication play in taming the welfare effects of aggregate fluctuations? Are currency unions with pegged exchange rates such as the CFA Franc potentially vulnerable to the fluctuations of the Euro? How much the development of robust domestic debt markets could contribute to reducing the exposure of developing countries to the interest rates volatility? Are domestic macroeconomic fiscal and monetary stabilisation policies key in reducing aggregate consumption volatility? Can a developing country's integration in the international capital markets help significantly contain consumption volatility? And what could be the implications of allowing for multiple structural breaks in the sequential procedure for testing and dating interruptions in the consumption series, both for the welfare costs of fluctuations as well as the welfare gains of consumption stabilisation? Each one of these questions deserves on its own a detailed and systematic attention. 
On the subject of investigating the role of economic structure on the ability of countries to sustain growth, the main question left unattended was perhaps the integration in the linked estimation framework of recent developments in growth episodes and non-linear patterns. That is because growth is fundamentally uneven in the developing world and could be probably better understood by identifying and analysing sequences of qualitatively different growth episodes, such as accelerations, collapses, stagnation and subsequent recoveries. This could certainly expand our understanding of the many dynamics of growth and the ability of economic structure to sustain it.

On the purely theoretical part of this dissertation - Chapter 5 -, we do need to have a better understanding, beyond a simple back-of-the-envelope calibration, of the exact directions and magnitudes of the effects of rare random shocks on economic growth and the speed of convergence. Perhaps a convenient way to do so could be by using detailed simulations, based on estimates from either structural or VAR models.

\section{Pondering on Policy}

Testament of the societal relevance of this research is the fact that most of its policyoriented findings were presented in the fall of 2017 at Malabo (Equatorial Guinea), during the 5th Congress of African Economists, in front of various policy makers from the African Union, national governments officials and other operatives from the regional blocks of the continent, such as the Economic Organization of West African States (ECOWAS), the Central African Economic and Monetary Union (CAEMC), the West African Monetary Union (WAEMU), and some delegates from the European Union. Also, an earlier and longer version of Chapter 4 was intended as a background paper for the 2016 United Nations Industrial Development Organization (UNIDO)'s Industrial Development Report on The Role of Technology and Innovation in Inclusive and Sustainable Industrial Development.

A core target group of this research consists of policy makers in international agencies (African Union, United Nations, International Monetary Fund, World Bank, European Commission, ECOWAS, African Development Bank, etc.). Other target groups of this dissertation are macroeconomic practitioners, central bankers, national governments and statistical offices. The research also targets the wider academic community as well as the readership of journals and blogs (such as the UNU-MERIT blog). The outputs of all four papers were discussed at various conferences and events, as part of the dissemination efforts.

All research in this dissertation is intended to be published in peer-reviewed and internationally acclaimed journals, whenever possible. As a first step in this direction, Chapter 2 and Chapter 3 are separately forthcoming in the African Integration and Development Review. 


\section{Samenvatting in het Nederlands}

Deze dissertatie gaat over de empirische analyse van macroeconomische fluctuaties en economische groei. Het beantwoordt fragmenten van de grote vragen die impliciet gesteld zijn in de titel. De dissertatie addresseert in twee delen verschillende aspecten van de ontwikkelingspuzzel: het begrijpen hoe macroeconomische volatiliteit ontwikkeling beinvloedt, vanuit zowel het consumptieperspectief als het productieperspectief. Deel 1 bevat twee empirische essays over de conjunctuurcycli die inherent zijn aan consumptiereeksen. Deel 2 bevat twee empirische essays over groeivolatiliteit, en de theoretische aspecten van stochastische schokken in groei en in de convergentiesnelheid.

Hoofdstuk 1 bevat een algemene introductie tot de thesis.

Hoofdstuk 2 maakt de balans op van recente ontwikkelingen in het debat over "Optimum Currency Area" (OCA, oftewel het optimaal valutiegebied) en is gebaseerd op verschillende parametrische en non-parametrische modellen. Het stelt dat de welvaartskosten van conjunctuurcycli - gedefinieerd als de compenserende factor oftewel de procentuele toename in consumptie in alle periodes en toestanden die noodzakelijk is om een representatieve consument onverschillig te laten zijn tussen een vlak en fluctuerend verbruikspad - tussen de 11 en 48 procent hoger zijn voor landen in sub-Sahara Africa buiten de CFA Franc Zone (11 landen in onze steekproef) dan voor landen in de monetaire unie (25 landen in onze steekproef). ${ }^{1}$ Een parametrische $t$-test voor twee steekproeven laat echter zien dat deze resultaten niet voldoende robuust zijn in gemiddeldverschilvergelijkingen, wat een bijkomende consequentie suggereert voor het decennialange vaste-wisselkoersenbeleid van de CFA Franc. Uit de verschillende opties beschikbaar voor de monetaire unie stelt dit hoofdstuk een semi-flexibel-wisselkoersenbeleid voor, en pleit voor het koppelen van de CFA Franc aan een selectie van internationale valuta in plaats van alleen de Euro.

Hoofdstuk 3 combineert een robuust recursief raamwerk à la Epstein and Zin (1989) met een sterk structurelebreukalgoritme dat congruent is met dat van Bai (1997), Bai and Perron (1998), en Bluhm et al. (2016), om zowel de welvaartsstijging van het volledig elimineren van macroeconomische consumptieschommelingen alsmede de welvaartsstijging van

\footnotetext{
${ }^{1}$ De CFA Franc Zone is een meer dan zeventig jaar oude monetaire unie in sub-Sahara Afrika. Momenteel zijn de meeste voormalige Franse kolonies in West en Centraal Africa lid - Benin, Burkina Faso, Kameroen, de Centraal Afrikaanse Republiek, Ivoorkust, Tsjaad, Gabon, Mali, Niger, de Democratische Republiek Congo, en Togo - met als opvallende uitzonderingen Equitoriaal-Guinea en Guinee-Bissau.
} 
één additioneel procentpunt groei in consumptie ad infinito af te leiden. Van 37 lagereen lagere-middeninkomenslanden - van wie er 24 in sub-Sahara Afrika liggen - is jaarlijkse data verzameld. Deze data laat consequent zien dat de baten van het stimuleren van de consumptiegroei de baten van consumptiestabilisatie overtreffen. Dit resultaat rechtvaardigt het decennialange groei-stimulerende beleid van ontwikkelingslanden. Daarbovenop - en dit is centraal in de zoektocht van Hoofdstuk 3 - laten we zien dat structurele breuken niet uitmaken voor de welvaartsstijgingen die voortvloeien uit het elimineren van consumptieschommelingen, terwijl ze dat consequent wél zijn voor de welvaartsstijging van een additioneel procentpunt consumptiegroei.

Hoofdstuk 4 onderzoekt de complexe verhoudingen tussen de structurele karakteristieken van economische ontwikkeling en macroeconomische volatiliteit, daarbij gebruikmakend van zowel een lineair panelmodel als een drempelpaneelbenadering. De analyse is gebaseerd op een nieuwe macro-panel dataset van de bijdragen van de verschillende sectoren aan het BNP en de volatiliteit van groeicijfers voor 108 landen over de periode 1960 tot 2010. De afhankelijke variabele - de groeivolatiliteit - wordt gemeten als de standaardafwijking van opeenvolgende vijf-jaarlijkse per capita BNP groeicijfers. Structurele karakteristieken zijn de mate van sectorspecialisatie, het aandeel van de industriesector en het aandeel van de moderne sector in het BNP. Het hoofdstuk laat zien dat een hoger aandeel van de industrie, een hoog en toenemend aandeel van de moderne sector, alsmede een meer gediversifieerde productiestructuur allemaal bijdragen aan een verminderde volatiliteit van groeipatronen. Tevens ontdekten we - toen we het drempelmodel gebruikten om mogelijke non-lineairiteiten te onderzoeken - dat de impact van de economische structuur op groeivolatiliteit staat of valt met een specifieke drempel van de productiestructuur van de economie, het oorspronkelijke per capita inkomensniveau in 1960, de bevolking in datzelfde jaar, en in mindere mate een drempelniveau van het aandeel van export aan het BNP. ${ }^{2}$

Hoofdstuk 5 introduceert een nieuw stochastisch model van zeldzame rampen gedefinieerd as een verzameling van gebeurtenissen met een lage waarschijnlijkheid maar met een enorm negative effect op economische variabelen (voornamelijk consumptie) - en onderzoekt hun overkoepelende gevolgen voor zowel de steady-state economische groei als de convergentiesnelheid. Het volgt een groeiende trend in de macroeconomie- en financiële literatuur. Rekening houdend met Barro (2006), Gourio (2012), Fernández-Villaverde and Levintal (2017), laat het in een louter theoretische setting zien dat een zeldzame ramp de steady-state economische groei - afgeleid van een standaard Eulervergelijking - beïnvloedt door middel van de verwachte waarde van het rente equilibrium. Het laat ook zien dat een zeldzame ramp de convergentiesnelheid ontregelt door middel van de

\footnotetext{
${ }^{2}$ Dit hoofdstuk is gebaseerd op een gezamenlijk artikel geschreven met Neil Foster-McGregor van UNUMERIT, wat op zijn beurt weer bouwt op het artikel van Foster-McGregor et al. (2015), een achtergrondsartikel voor het Industrial Development Report uit 2016 van de Industriële Ontwikkelingsorganisatie van de VN, UNIDO.
} 
productie-elastictiteit in relatie tot het steady-state 'intensieve vorm' kapitaal, en dat de richting en omvang van deze ontregeling afhangt van hoe de nieuwe waarde van deze elasticiteit zich verhoudt tot het aandeel van kapitaal in de totale productie als er geen schok is. $^{3}$

Hoofdstuk 6 sluit de dissertatie af met enkele beleidsaanbevelingen en voorgestelde richtingen voor toekomstig onderzoek.

${ }^{3}$ De steady-state economische groei is een groeipad waarbij alle per capita variabelen (productie, kapitaal, consumptie, etcetera) met dezelfde snelheid groeien als de totale factor productiviteit. 


\section{About the Author}

Ibrahima Sory Kaba was born three decades ago in Koundara, Republic of Guinea. In 2007, he won a government scholarship to pursue his studies abroad, as an award for ranking third nationally after his scientific Baccalauréat exams.

Subsequently, he holds a dou-

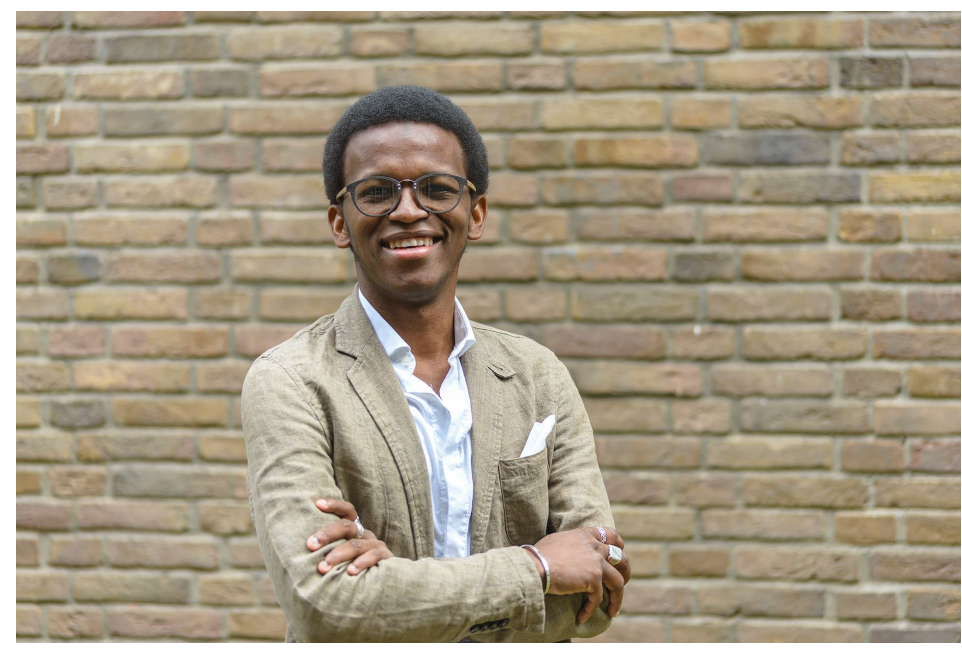
ble BSc in Econometrics, first from the University Hassan 1 of Morocco (FSJES, Settat, 20072010), where he graduated cum laude (highest distinction), and from the Toulouse 1 University Capitole (UT1, Toulouse, 20102011), France. He also holds a double MSc, first in Econometrics and Statistics (E\&S, Toulouse, 2011-2012) and in Economics, with a research-track specialisation in Public Policy and Development (PP\&D, Toulouse, 2012-2013), both from the Toulouse School of Economics (TSE), France. In 2013, Ibrahima joined the PhD programme of UNU-MERIT, under the research theme "Economic Development, Innovation, Governance and Institutions". There, he partook in the making of the 2016 United Nations Industrial Development Organization (UNIDO)'s Industrial Development Report, together with Professor Adam Szirmai, Doctor Neil Foster-McGregor and many others. For four consecutive academic years (2015-2019), he has been responsible for both lecturing and tutoring the first-year Introductory Quantitative Methods and Microeconomics course of the UNU-MERIT PhD programme. His research interests veer around Development and International Economics, Macro and Monetary Economics, Mathematical and Quantitative Methods.

Alongside his knack for Quantitative Economics and his passion for photography, Ibrahima is also a storyteller, a public speaker and a debate moderator at large. In September 2018, he was appointed Teaching Assistant (TA) at the AE2 (Algemene Economie 2) Department of The Maastricht University's School of Business and Eco- 
nomics (SBE), and has been teaching various subjects ever since: Globalisation Debate (EBC2143), Microeconomics (EBC1010-11), Growth and International Economic Relations in Emerging Economies (EBC2155), Reflections on Academic Discourse (EBS1001), An Economist's Point of View (EUS1005), Micro-Macroeconomics (EUS1008), Making a European Market (EUS2004), International Economics (EUS2007), etc. 